\title{
The in vivo Oxyhaemoglobin Dissociation Curve at Sea Level and High Altitude
}

by

Dahlia Balaban

A thesis submitted in conformity with the requirements

for the degree of Master's of Science

Institute of Medical Science

University of Toronto

(C) Copyright by Dahlia Balaban 2009 


\title{
The in vivo Oxyhaemoglobin Dissociation Curve at Sea Level and High Altitude
}

\author{
Dahlia Balaban \\ Master's of Science \\ Institute of Medical Science \\ University of Toronto
}

2009

\section{Abstract}

Some animals have adapted to hypoxia by increasing their haemoglobin affinity for oxygen, but in vitro studies have not shown any change of haemoglobin affinity for oxygen in human high altitude natives or lowlanders acutely acclimatized to high altitude. We conducted the first in vivo study of the oxyhaemoglobin dissociation curve by progressively reducing arterial $\mathrm{PO}_{2}$ while maintaining normocapnia in lowlanders at sea level, lowlanders sojourning at $3600 \mathrm{~m}$ for two weeks and native Andeans at the same altitude. We found that the in vivo $\mathrm{PO}_{2}$ at which haemoglobin is half-saturated $\left(\mathrm{P}_{50}\right)$ is higher in lowlanders at sea level $(32 \mathrm{mmHg})$ than that measured in vitro $(27 \mathrm{mmHg})$ and that lowlanders and highlanders do significantly increase the in vivo affinity of their haemoglobin for oxygen with exposure to high altitude. These results indicate the value of an in vivo approach for studying the oxyhaemoglobin dissociation curve. 


\section{Acknowledgments}

I would like to thank a number of people who have played instrumental roles in the conceptualization, performance and preparation of my thesis studies.

First and foremost I would like to thank my supervisor, Dr. Joe Fisher. He provided me with life-changing opportunities and his mentorship and guidance were essential to the completion of my thesis.

Dr. James Duffin was a valuable mentor and committee member. He was always available to help, even on weekends and holidays, and his feedback was always useful. I would also like to thank Professor Scott Thomas, my other committed committee member. He always managed to make time to look over my drafts and attend my meetings, even on short notice or when on vacation.

I would like to acknowledge all the people who played instrumental roles in data collection for my studies. Dr. Keita Ikeda, Sonia Capps and Dr. Dave McLeod hosted me and collected data for Experiments 1 and 2 at Duke University. Then there were the members of my expedition to Bolivia. We worked long, gruelling hours together under hypoxic conditions and overcame many obstacles that stood in the way of completion of my study. They also provided me with continuing support as I analyzed and wrote up my data. These members are Dr. David Preiss, Dr. Alex Vesely, Professor Richard Greene, Alexandra Mardimae, Marat Slessarev and, of course, my supervisor. I would especially like to acknowledge the contributions of Dr. David Preiss, who was always willing to help me with data analysis and conceptualization, long after the expedition. On the topic of Bolivia, I must also thank the Zubietas, who provided us with a laboratory, equipment and subjects for our study. Their hospitality was greatly appreciated. I would also like to acknowledge the contribution of Cliff Ansel, the president of Thornhill Research, Inc., for supporting the expedition

Although they did not take part in the expedition, Cathie Kessler, Stephanie Dorner and David Le provided technical and logistical support for the expedition equipment. I also appreciate the contributions of my other lab mates, Jay Han, Matt Machina and Anne Battisti. I would like to extend a special thank you to Rosemary Regan, who started her MSc when I did and provided me with endless support throughout. 
I would also like to mention Dianne Fukanaga and Dr. Howard Mount of the Institute of Medical Science, who supported and assisted me in completing my thesis in a timely manner, despite the associated difficulties.

Lastly, I want to thank the people who influenced my success less directly. My former supervisors, Professors Laurie Wilcox and Laurence Harris, instilled in me a love for research and inspired me to pursue graduate studies. However, this would not have been done without the positive experiences I had in their labs, where I met students who continue to inspire and help me today. I would like single out Hassan Masoom, who was always willing to help me out despite having no affiliation with my lab or project. His editing and advice were invaluable. I would also like to mention my friends and especially my family, who have supported me unconditionally through the ups and downs of my graduate studies. They gave me advice and went through every experience with me, no matter how trivial or difficult. My parents and sisters (and their families) have always been at my side no matter how stressed or busy I became.

These and countless others have helped me get to where I am today. I could not have done it without them. 


\section{Table of Contents}

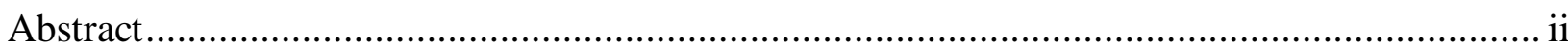

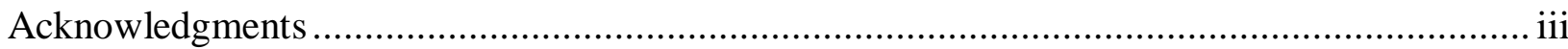

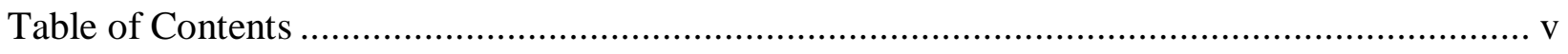

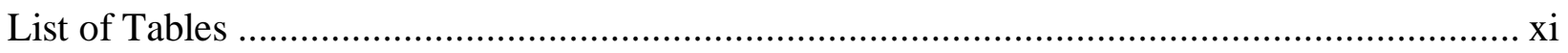

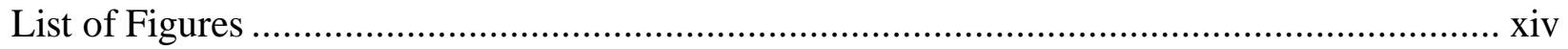

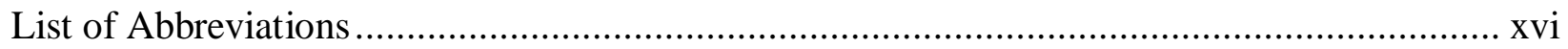

1 Literature Review ………………………………..................................................... 1

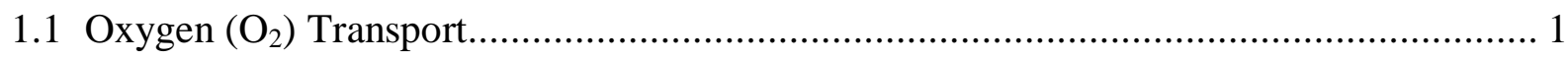

1.2 The Oxyhaemoglobin Dissociation Curve ................................................................. 2

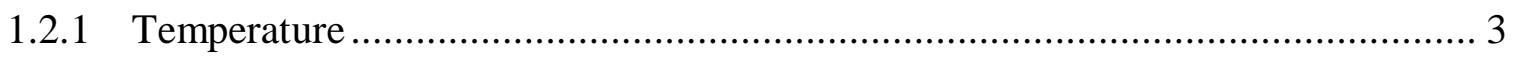

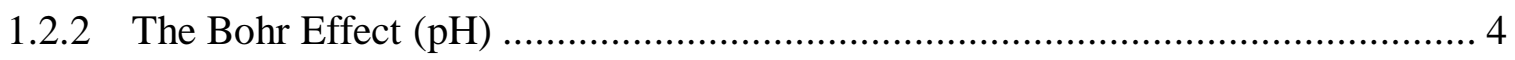

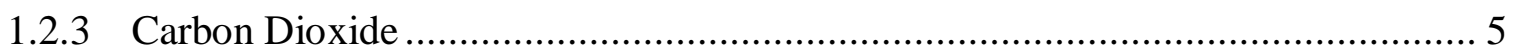

1.2.4 2,3-Diphosphoglycerate (2,3-DPG) .......................................................... 5

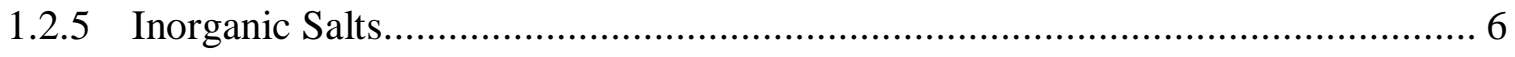

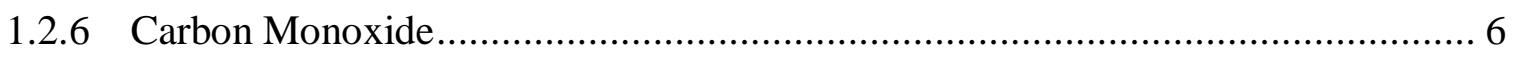

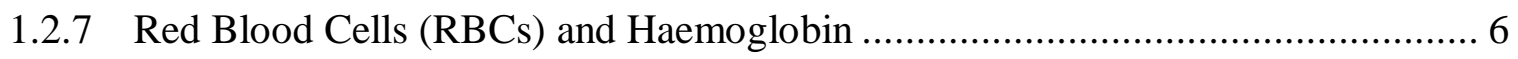

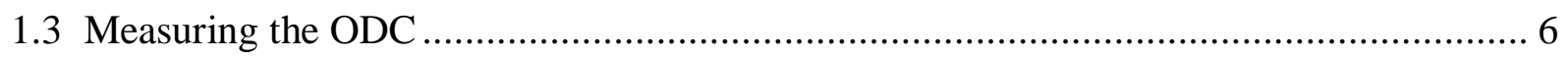

1.3.1 In vitro methods for measuring the shape and position of the ODC..................... 8

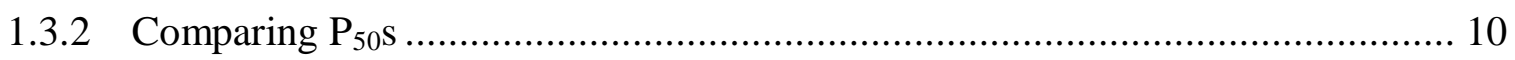

1.3.3 Predicting Saturation .................................................................................. 10

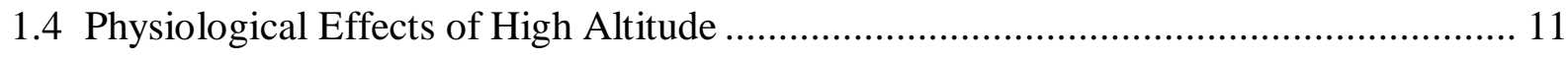

1.4.1 Hypoxic Ventilatory Response …………………......................................... 11

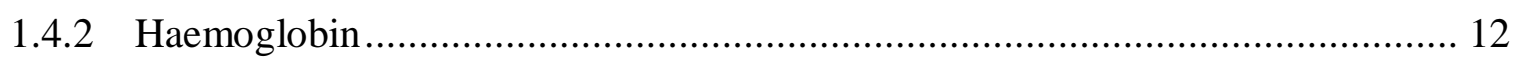

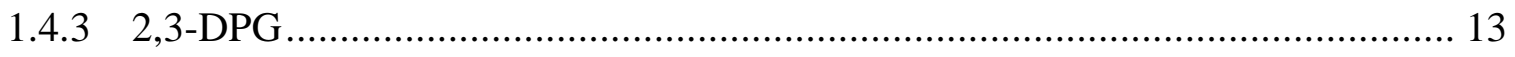




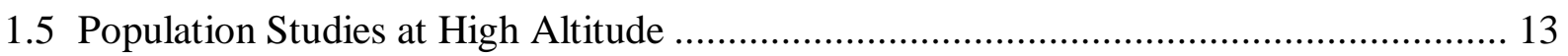

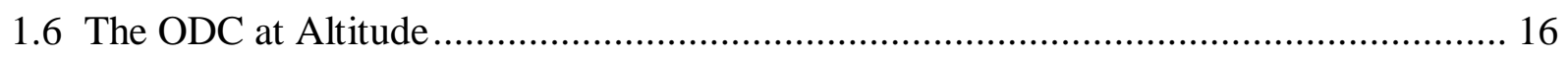

1.6.1 The ODC in Lowlanders at High Altitude....................................................... 16

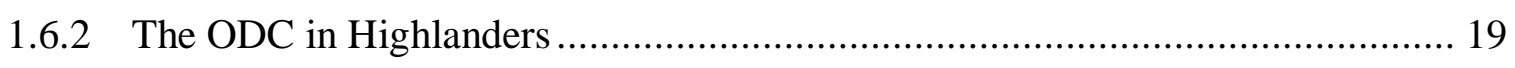

1.6.3 What type of shift is beneficial at altitude? .................................................... 22

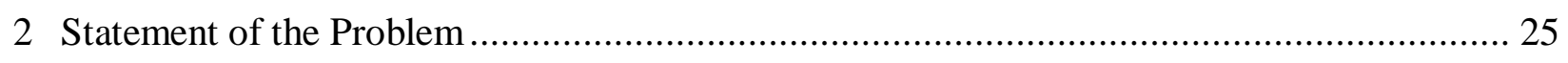

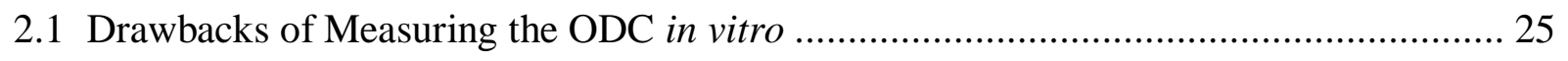

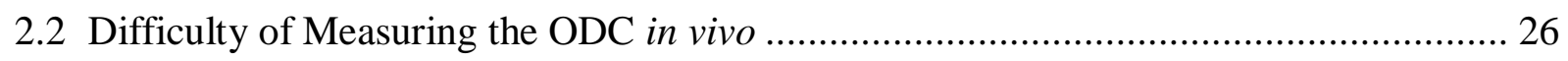

2.3 Using Prospective End-Tidal Targeting to Measure the ODC in vivo ……………........ 27

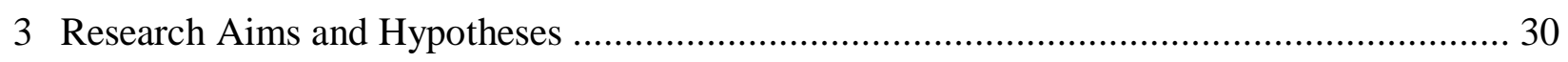

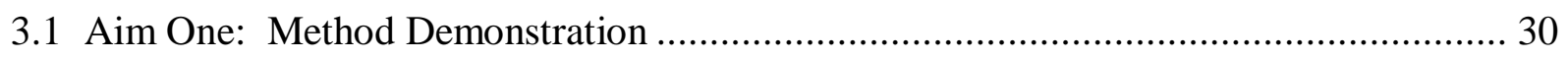

3.2 Aim Two: Characterization of in vivo Curves and Comparison to in vitro Predictions .. 30

3.3 Aim Three: Comparison of the in vivo ODC Across Experimental Groups................... 31

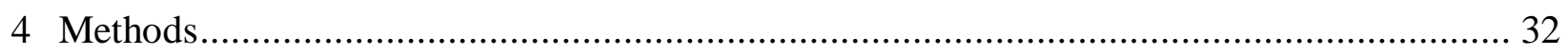

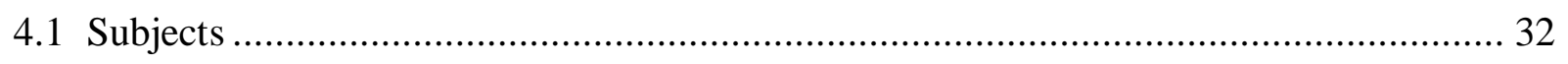

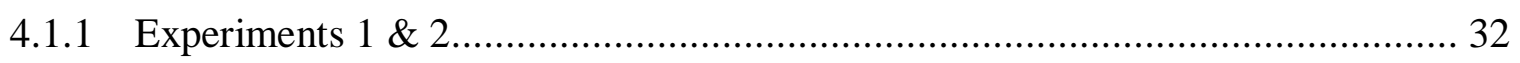

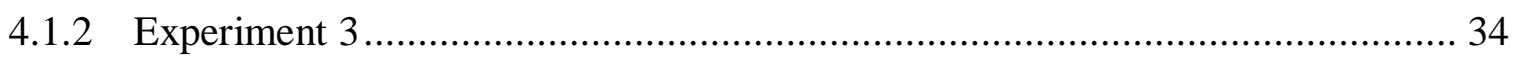

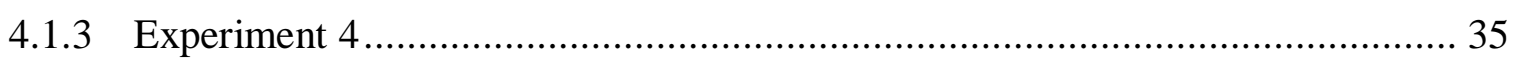

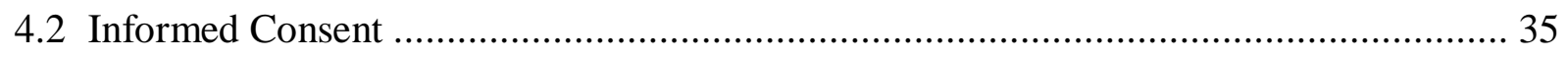

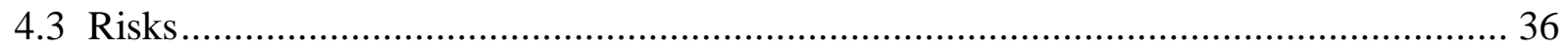

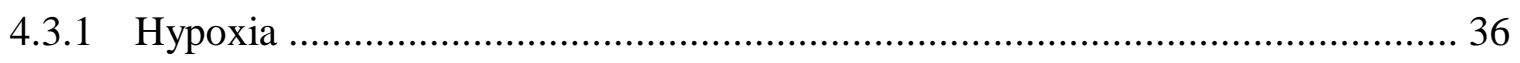

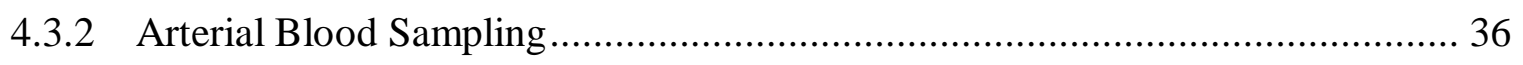

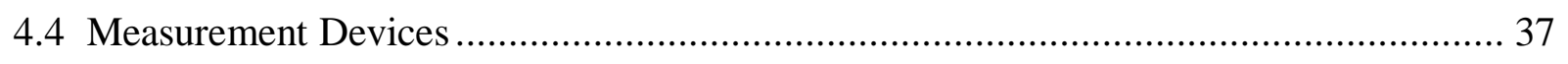

4.4.1 Arterial Blood Gases (ABG) ......................................................................... 37

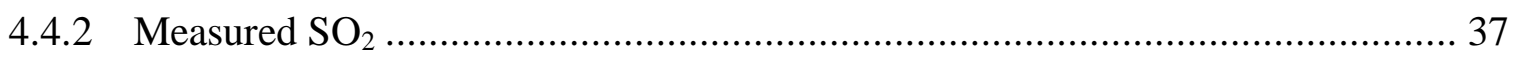

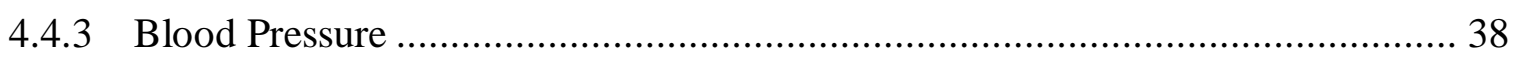




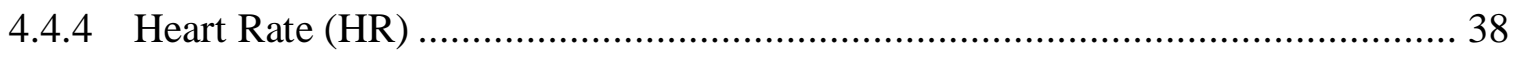

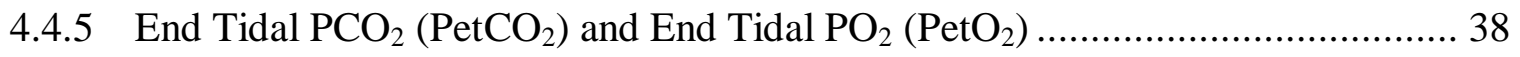

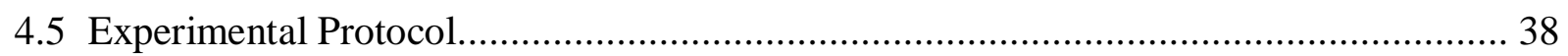

4.5.1 Subject Setup (common to all subjects) ………….......................................... 38

4.5.2 Equipment Setup (common to all subjects) ……….......................................... 39

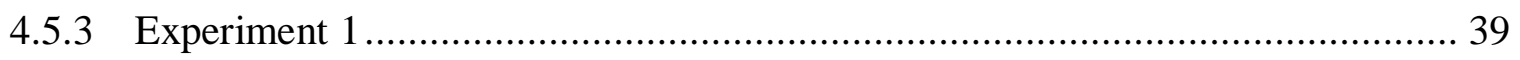

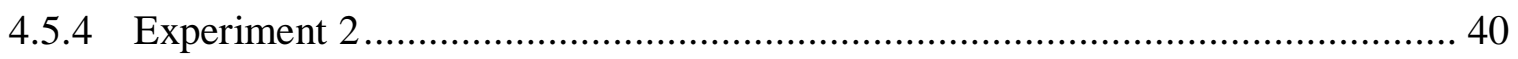

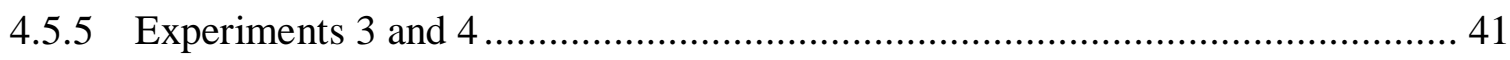

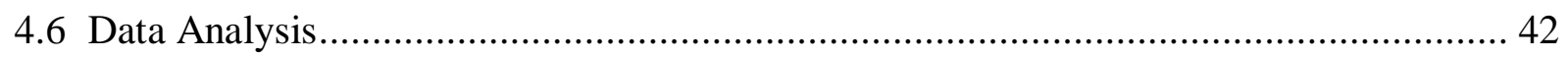

4.6.1 Comparing Subjects across Experimental Group ............................................. 42

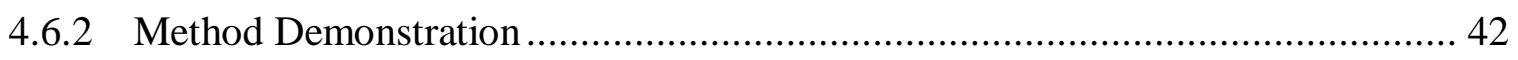

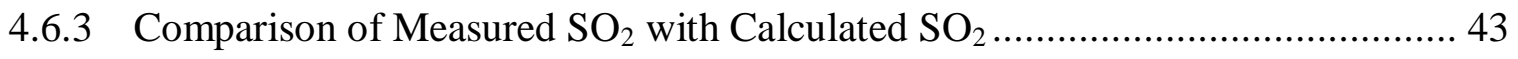

4.6.4 Hill Analysis and ODC Comparisons ……………......................................... 45

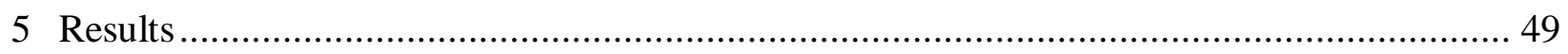

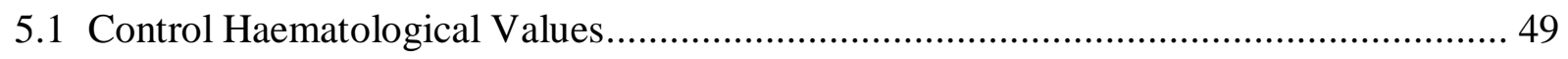

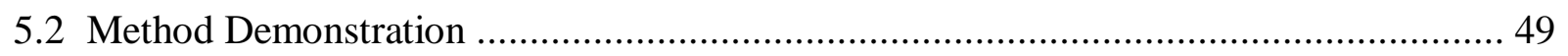

5.3 Comparison of Measured $\mathrm{SO}_{2}$ Values with those of Severinghaus and Kelman

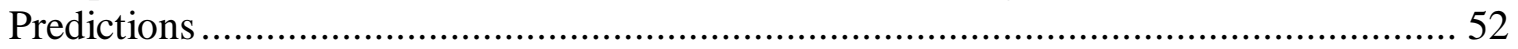

5.3.1 Lowlanders at Sea Level............................................................................. 57

5.3.2 Lowlanders at High Altitude....................................................................... 57

5.3.3 Andeans at High Altitude ……………………........................................ 57

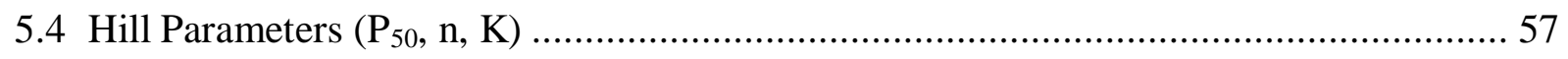

5.4.1 Comparison of Hill Parameters $\left(\mathrm{P}_{50}, \mathrm{n}, \mathrm{K}\right)$ Across $\mathrm{SO}_{2}$ Types (Measured, Severinghaus \& Kelman) within each Experiment ................................................ 58

5.4.2 Comparison of Hill Parameters $\left(\mathrm{P}_{50}, \mathrm{n}, \mathrm{K}\right)$ Across Normocapnia Groups

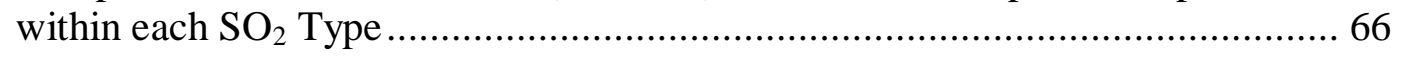

5.4.3 Composite ODC Comparison across Groups using Measured $\mathrm{SO}_{2} \ldots \ldots \ldots \ldots \ldots \ldots \ldots . . . .70$ 
5.4.4 Influence of $\mathrm{PCO}_{2}$ on the Hill Parameters..................................................... 73

5.4.5 Descending and Ascending $\mathrm{PO}_{2}$ Comparison............................................... 73

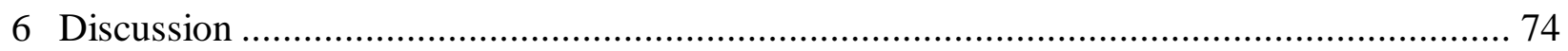

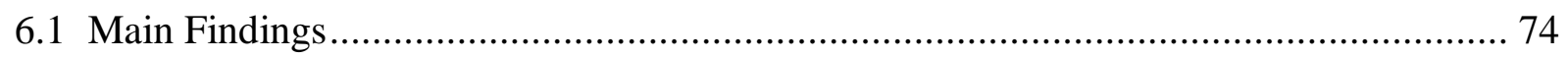

6.2 The in vivo Approach to Measuring the ODC ............................................................. 75

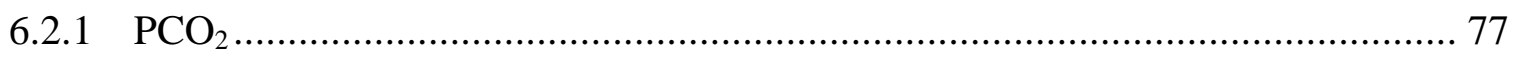

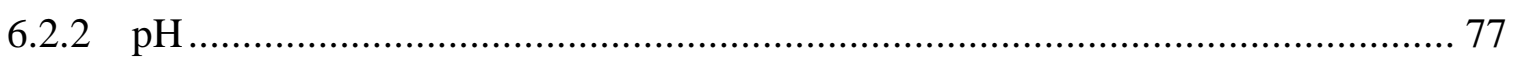

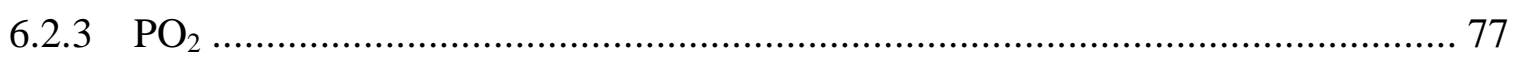

6.2.4 Blood Gas and $\mathrm{SO}_{2}$ Measurements ......................................................... 78

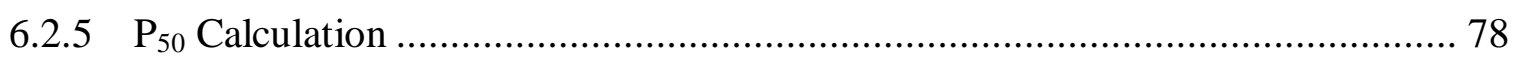

6.3 The in vivo ODC at Sea Level and High Altitude …………....................................... 79

6.3.1 Previous Studies in Lowlanders and Native Highlanders at High Altitude ......... 80

6.3.2 Adaptation to Hypoxia by Animals ................................................................. 82

6.4 Explanation for the in vivo Left Shift of the ODC at High Altitude................................ 83

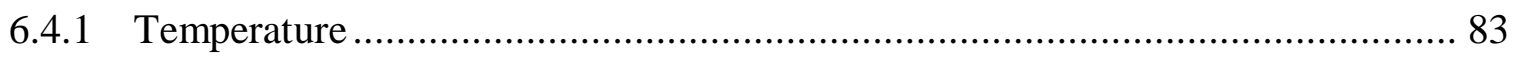

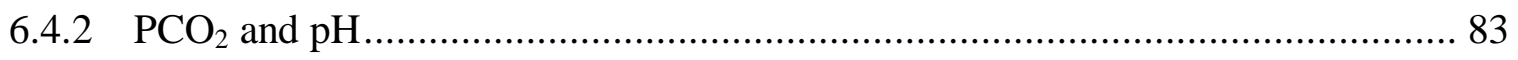

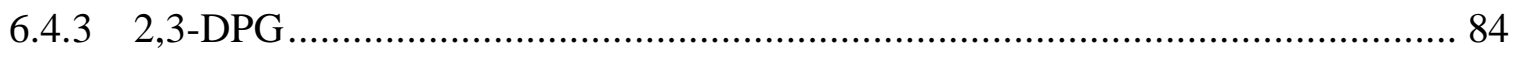

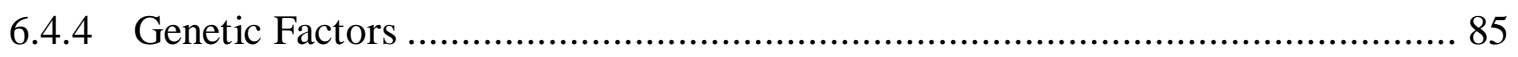

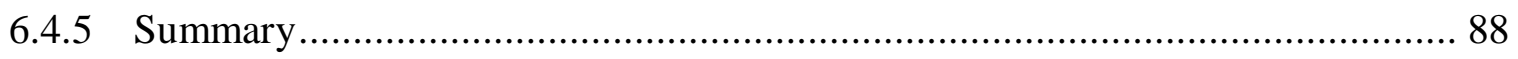

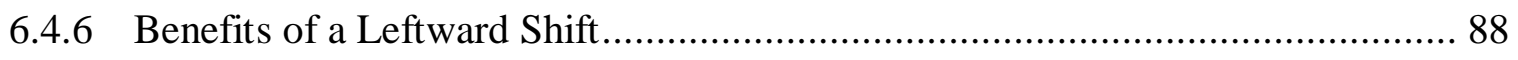

6.5 In vitro Methods of ODC Measurement and Prediction ................................................. 89

6.5.1 Comparison of in vivo data with in vitro Predictions ........................................ 90

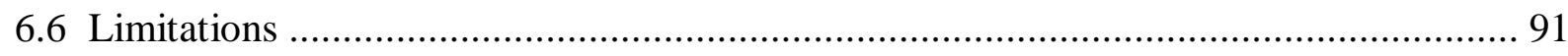

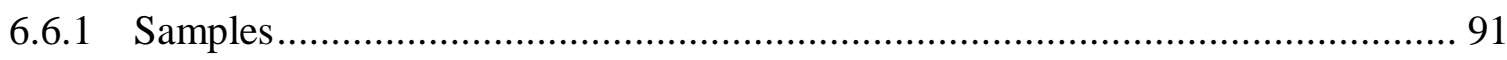

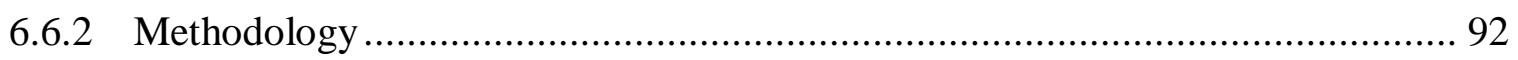

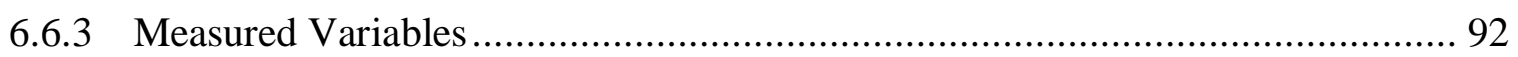




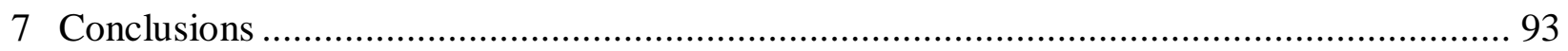

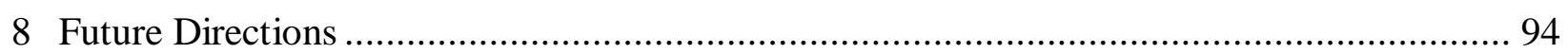

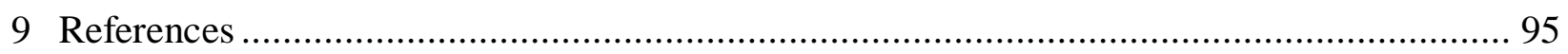

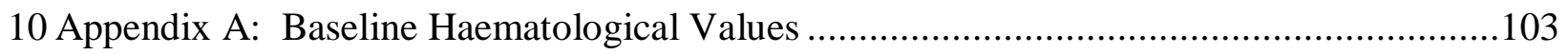

10.1Baseline Haematological Values by Experimental Group .............................................103

10.2Cross-Experimental Comparison of Baseline Haematological Values ...........................106

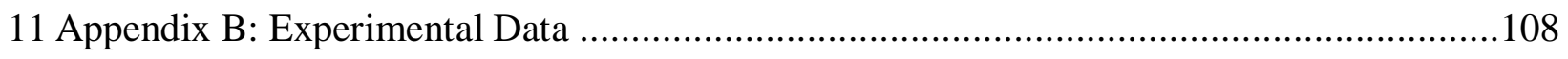

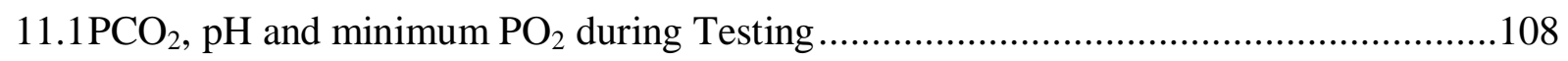

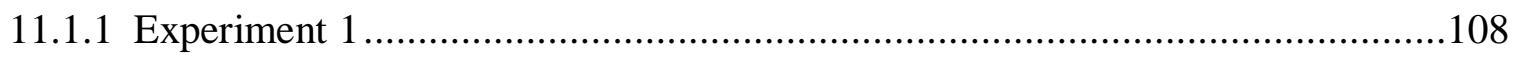

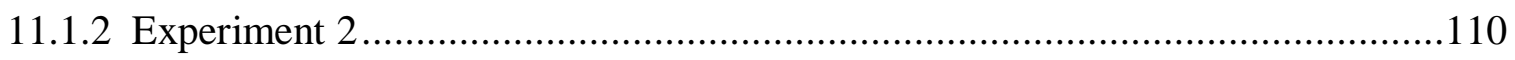

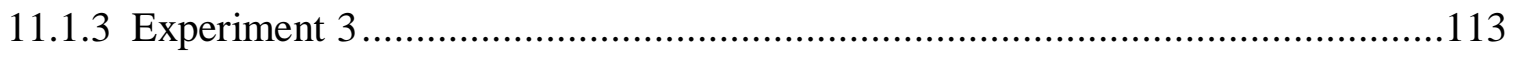

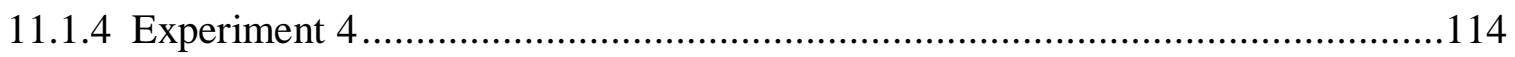

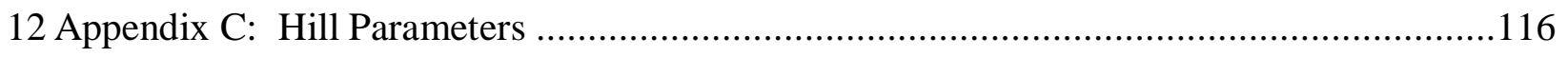

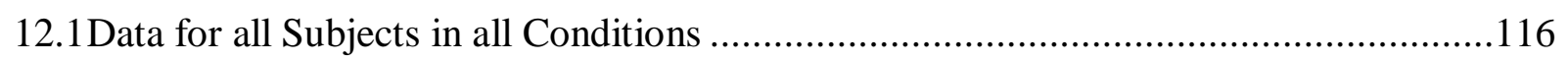

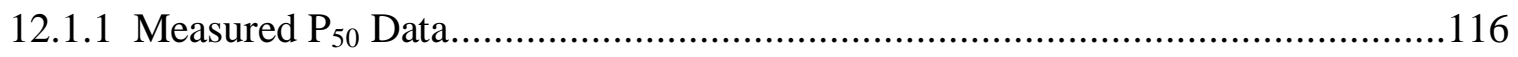

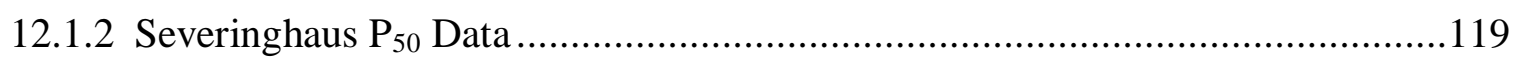

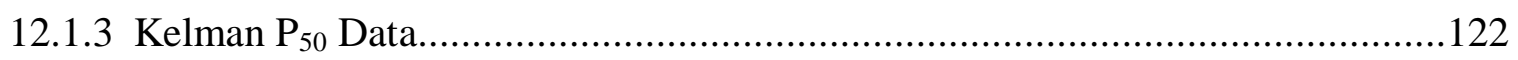

12.2Comparison of Hill Parameters $\left(\mathrm{P}_{50}, \mathrm{n}, \mathrm{K}\right)$ Across $\mathrm{SO}_{2}$ Types (Measured, Severinghaus \& Kelman) within each Experiment .......................................................125

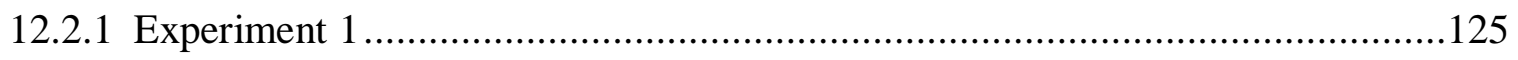

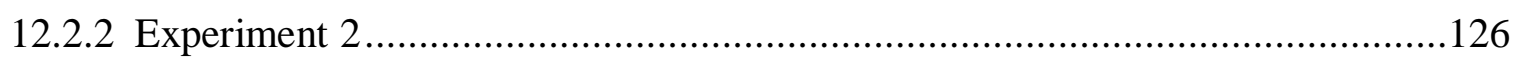

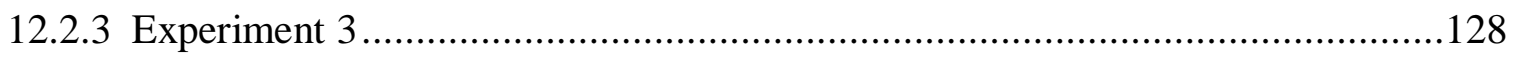

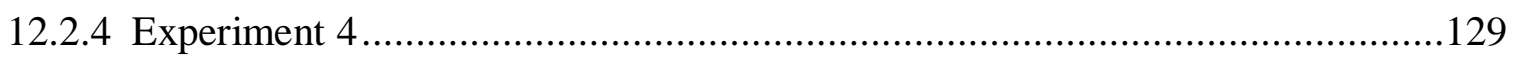

12.3Comparison of Hill Parameters $\left(\mathrm{P}_{50}, \mathrm{n}, \mathrm{K}\right)$ Across Normocapnia Conditions within

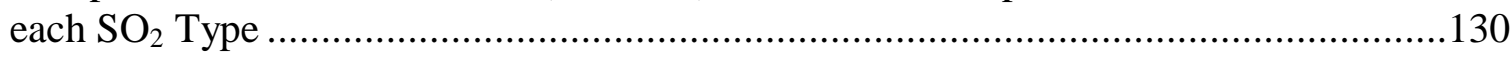

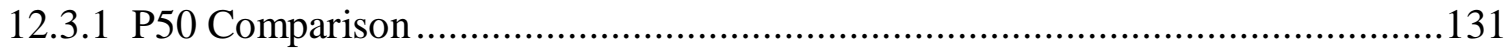

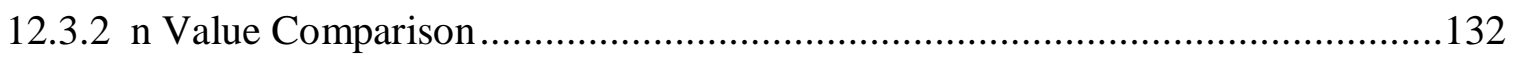


12.3.3 K Value Comparison ... 


\section{List of Tables}

Table 1: Anthropometric Data for Subjects in Experiment 1 ................................................... 33

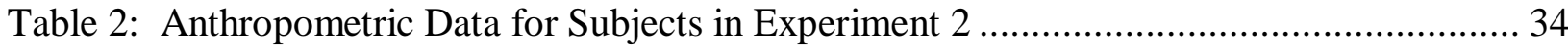

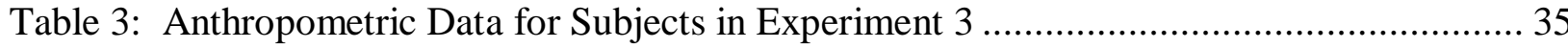

Table 4: Anthropometric Data for Subjects in Experiment 4 ................................................... 35

Table 5: Control Haematological Values (Mean \pm Std Dev) for Subjects in All Experiments ... 49

Table 6: Mean and Std Dev Data for $\mathrm{PaCO}_{2}$ and $\mathrm{pH}$ during in vivo ODC Testing .................... 51

Table 7: Average and Std Dev Data for Minimum $\mathrm{PaO}_{2}$ and Number of Samples during in vivo

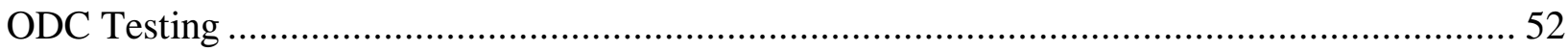

Table 8: Haematological Data for Subjects in Experiment 1 ................................................. 103

Table 9: Haematological Data for Subjects in Experiment 2 ................................................ 104

Table 10: Haematological Data for Subjects in Experiment 3 .............................................. 104

Table 11: Haematological Data for Subjects in Experiment 4 .............................................. 105

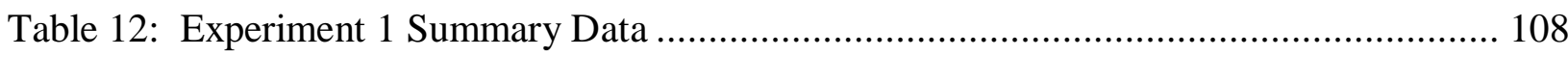

Table 13. Experiment 2 Summary Data: Hypocapnia.......................................................... 110

Table 14. Experiment 2 Summary Data: Normocapnia ..................................................... 111

Table 15. Experiment 2 Summary Data: Hypercapnia ......................................................... 112

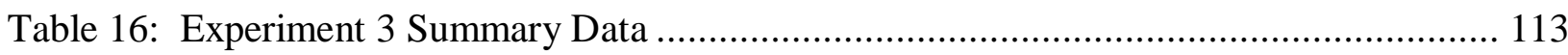

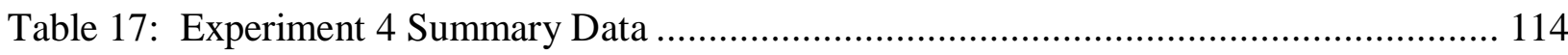

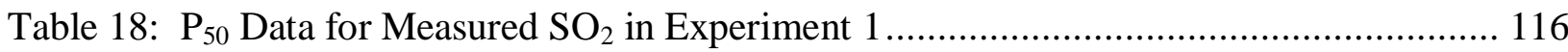

Table 19: $\mathrm{P}_{50}$ Data for Measured $\mathrm{SO}_{2}$ in Hypocapnia in Experiment 2 ................................ 117 
Table 20: $\mathrm{P}_{50}$ Data for Measured $\mathrm{SO}_{2}$ in Normocapnia in Experiment 2. 118

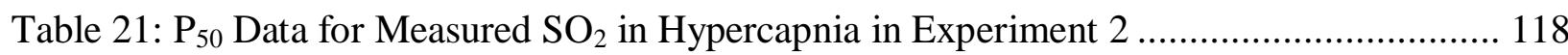

Table 22: $\mathrm{P}_{50}$ Data for Measured $\mathrm{SO}_{2}$ in Experiment 3...................................................... 119

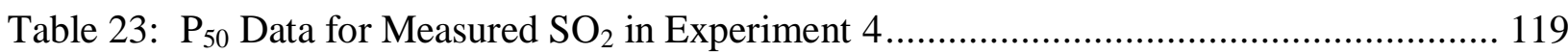

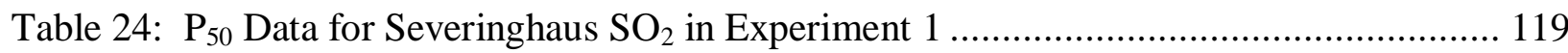

Table 25: $\mathrm{P}_{50}$ Data for Severinghaus $\mathrm{SO}_{2}$ in Hypocapnia in Experiment 2 …........................ 120

Table 26: $\mathrm{P}_{50}$ Data for Severinghaus $\mathrm{SO}_{2}$ in Normocapnia in Experiment 2 .......................... 121

Table 27: $\mathrm{P}_{50}$ Data for Severinghaus $\mathrm{SO}_{2}$ in Hypercapnia in Experiment 2........................... 121

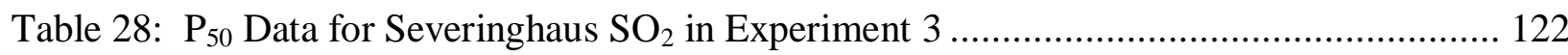

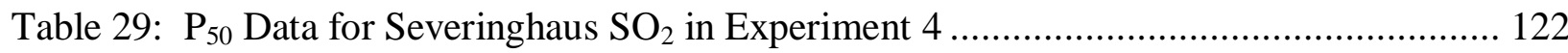

Table 30: $\mathrm{P}_{50}$ Data for Kelman $\mathrm{SO}_{2}$ in Experiment 1 ........................................................ 122

Table 31: $\mathrm{P}_{50}$ Data for Kelman $\mathrm{SO}_{2}$ in Hypocapnia in Experiment 2 ................................... 123

Table 32: $\mathrm{P}_{50}$ Data for Kelman $\mathrm{SO}_{2}$ in Normocapnia in Experiment 2................................ 123

Table 33: $\mathrm{P}_{50}$ Data for Kelman $\mathrm{SO}_{2}$ in Hypercapnia in Experiment 2 .................................. 124

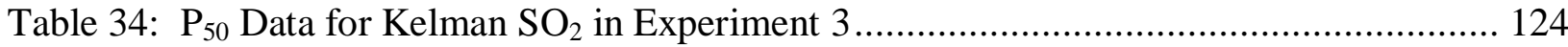

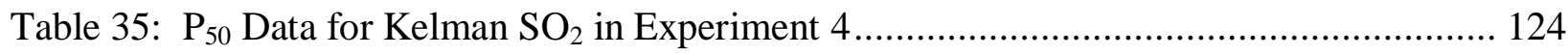

Table 36: Experiment $1 \mathrm{P}_{50}$ Values ................................................................................... 125

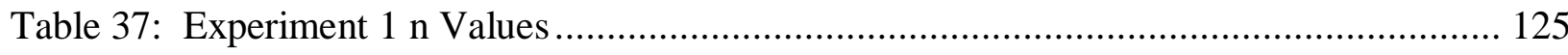

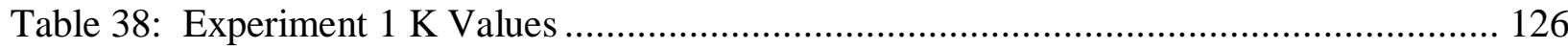

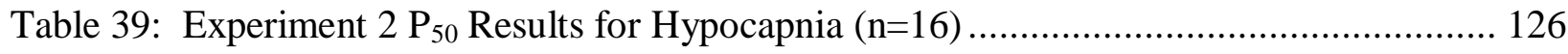


Table 40: Experiment $2 P_{50}$ Results for Normocapnia $(n=19)$....

Table 41: Experiment $2 \mathrm{P}_{50}$ Results for Hypercapnia ( $\left.\mathrm{n}=12\right)$ 127

Table 42: Experiment $3 \mathrm{P}_{50}$ Values 128

Table 43: Experiment 3 n Values 129

Table 44: Experiment $3 \mathrm{~K}$ Values

Table 45: Experiment $4 \mathrm{P}_{50}$ Values 129

Table 46: Experiment $4 \mathrm{n}$ Values 130

Table 47: Experiment $4 \mathrm{~K}$ Values 130

Table 48: Measured $\mathrm{P}_{50}$ Values for All Groups at Normocapnia 131

Table 49: Severinghaus $\mathrm{P}_{50}$ Values for All Groups at Normocapnia 131

Table 50: Kelman $\mathrm{P}_{50}$ Values for All Groups at Normocapnia. 132

Table 51: Measured n Values for All Groups at Normocapnia 132

Table 52: Severinghaus n Values for All Groups at Normocapnia 133

Table 53: Kelman n Values for All Groups at Normocapnia 133

Table 54: Measured K Values for All Groups at Normocapnia 134

Table 55: Severinghaus K Values for All Groups at Normocapnia 134

Table 56: Kelman K Values for All Groups at Normocapnia 135 


\section{List of Figures}

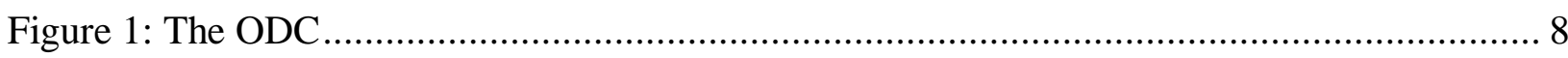

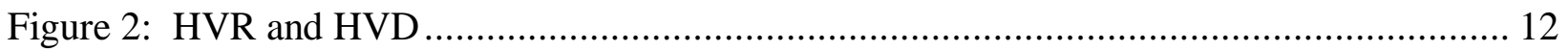

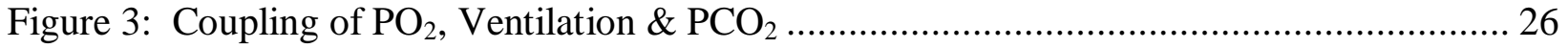

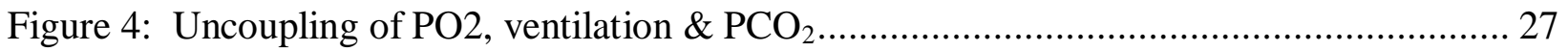

Figure 5: RespirAct ${ }^{\mathrm{TM}}$ Device and Breathing Circuit .................................................. 28

Figure 6: Raw Data Example: Breath by Breath End Tidal Data for a Typical Subject ........... 50

Figure 7: Graphs Showing the Correlation between Measured and Severinghaus $\mathrm{SO}_{2}$ Values .. 53

Figure 8: Graphs Showing the Correlation between Measured and Kelman $\mathrm{SO}_{2}$ Values.......... 54

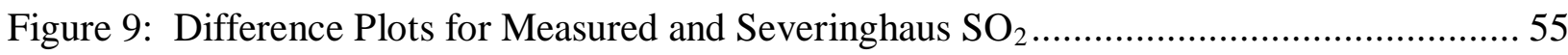

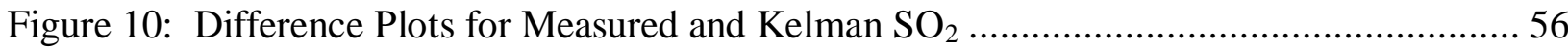

Figure 11: Comparing $\mathrm{P}_{50}$ Values (mean $\pm \mathrm{SEM}$ ) within Experimental Group across $\mathrm{SO}_{2}$ Types

Figure 12: Comparing n Values (mean \pm SEM) within Experimental Groups across $\mathrm{SO}_{2}$ Types

Figure 13: Comparing K Values within Experimental Groups across $\mathrm{SO}_{2}$ Types ................. 61

Figure 14: $\mathrm{P}_{50}$ Frequency Distributions across $\mathrm{SO}_{2}$ Type for each Subject Group.................. 63

Figure 15: n Value Frequency Distributions across $\mathrm{SO}_{2}$ Type for each Subject Group ........... 65

Figure 16: Comparing $\mathrm{P}_{50}$ Values (mean $\pm \mathrm{SEM}$ ) across Experimental Groups within $\mathrm{SO}_{2}$ Type

Figure 17: Comparing n Values (mean \pm SEM) across Experimental Groups within $\mathrm{SO}_{2}$ Type 68 
Figure 18: Comparing K Values across Experimental Groups within $\mathrm{SO}_{2}$ Type.....

Figure 19: Average ODCs for Each Experimental Group at Normocapnia using Measured $\mathrm{SO}_{2} 71$

Figure 20: $\mathrm{P}_{50}$ Frequency Distribution using Measured $\mathrm{SO}_{2}$ across Experimental Groups ........ 72

Figure 21: n Value Frequency Distribution using Measured $\mathrm{SO}_{2}$ across Experimental Groups . 72

Figure 22: Sample ODC Data in a Subject at Sea Level 


\section{List of Abbreviations}

[2,3-DPG] Concentration of 2,3-Diphosphoglycerate

[Hb] Haemoglobin Concentration

2,3-DPG 2,3-Diphosphoglycerate

ABG

AMREE

Arterial Blood Gases

ANOVA

ATP

BE

BUN

$\mathrm{CaO}_{2}$

Cl

$\mathrm{CO}$

$\mathrm{CO}_{2}$

American Medical Research Expedition to Everest

Analysis of Variance

Adenosine Triphosphate

Base Excess

Urea Nitrogen

Arterial Oxygen Content

Chloride

Carbon Monoxide

EPO

Carbon Dioxide

$\mathbf{H}^{+}$

$\mathrm{Hb}$

Erythropoietin

Hydrogen Ion

$\mathrm{HbO}_{2}$

Haemoglobin

$\mathrm{HCO}_{3}^{-}$

Oxyhaemoglobin

Het

Bicarbonate

HVD

Hematocrit

HVR

Hypoxic Ventilatory Decline

K

$\mathrm{Na}$

NIBP

Hypoxic Ventilatory Response

Potassium

NO

$\mathrm{O}_{2}$

Sodium

Non-Invasive Blood Pressure

Nitric Oxide

ODC

Oxygen

OE II

Oxyhaemoglobin Dissociation Curve

$\mathbf{P}_{50}$

$\mathrm{PaCO}_{2}$

$\mathrm{PaO}_{2}$

$\mathrm{PCO}_{2}$

PEEP

Operation Everest II

Partial Pressure of Oxygen at which Haemoglobin is 50\% Saturated

Arterial Partial Pressure of Carbon Dioxide

Arterial Partial Pressure of Oxygen

Partial Pressure of Carbon Dioxide

$\mathrm{PetCO}_{2}$ End Tidal Partial Pressure of Carbon Dioxide

$\mathrm{PetO}_{2}$

$\mathrm{PO}_{2}$

$\mathrm{RBC}$

$\mathrm{SaO}_{2}$

SEM

Positive End Expiratory Pressure

End Tidal Partial Pressure of Oxygen

Partial Pressure of Oxygen

Red Blood Cell

Arterial Haemoglobin Saturation

$\mathrm{SO}_{2}$

Standard Error of the Mean

Oxyhaemoglobin Saturation

$\mathrm{SpO}_{2} \quad$ Pulse Oximeter Haemoglobin-Oxygen Saturation 
Std Dev

$T$

$\mathrm{TCO}_{2}$

$\mathrm{VCO}_{2}$

$\mathrm{VO}_{2}$

$\mathrm{VO}_{2} \max$
Standard Deviation

Temperature

Total Carbon Dioxide

Rate of Carbon Dioxide Elimination

Rate of Oxygen Consumption

Maximal Oxygen Consumption 


\section{Literature Review}

\subsection{Oxygen $\left(\mathrm{O}_{2}\right)$ Transport}

$\mathrm{O}_{2}$ diffuses from the air into the blood through alveolar and endothelial cells in the lung alveoli. The $\mathrm{O}_{2}$ is then transported by the blood to the tissues, where it diffuses into the cells to be used in aerobic metabolism. The amount of $\mathrm{O}_{2}$ available to the tissues is determined by the cardiac output, the flow of blood moving through the body, and the arterial blood $\mathrm{O}_{2}$ content $\left(\mathrm{CaO}_{2}\right)$. $\mathrm{CaO}_{2}$ is dependent upon haemoglobin concentration $[\mathrm{Hb}]$, the volume of $\mathrm{O}_{2}$ dissolved in the plasma and arterial haemoglobin oxygen saturation $\left(\mathrm{SaO}_{2}\right)$. The $\mathrm{SaO}_{2}$ is dependent upon the arterial partial pressure of oxygen $\left(\mathrm{PaO}_{2}\right)$ and the affinity of haemoglobin $(\mathrm{Hb})$ for $\mathrm{O}_{2} \cdot \mathrm{CaO}_{2}$ can be calculated according to Equation 1:

\section{Equation 1}

$$
\mathrm{CaO}_{2}=\left(\mathrm{Hb} \times 1.34 \times\left(\frac{\mathrm{SaO}_{2}}{100}\right)\right)+\left(\mathrm{PaO}_{2} \times 0.0031\right)
$$

where $\mathrm{CaO}_{2}$ is the arterial $\mathrm{O}_{2}$ content in volume $\%, \mathrm{Hb}$ is in gram $\%$ and $\mathrm{PaO}_{2}$ is in $\mathrm{mmHg}$.

$\mathrm{O}_{2}$ is transported through the body in two ways (Sladen, 1981). A relatively small amount, approximately $1.5 \%$ of the total $\mathrm{O}_{2}$ available to the tissues of the body, is dissolved in the plasma according to Henry's law. That is, at any given temperature the volume of $\mathrm{O}_{2}$ dissolved in a volume of plasma is directly proportional to the partial pressure of $\mathrm{O}_{2}\left(\mathrm{PO}_{2}\right)$ in equilibrium with

the plasma. At a normal body temperature of $37^{\circ} \mathrm{C}$ and a $\mathrm{PaO}_{2}$ of $100 \mathrm{mmHg}$, the volume of $\mathrm{Hb}$ dissolved in $100 \mathrm{ml}$ of blood is $0.31 \mathrm{cc}$. The remainder of the body's $\mathrm{O}_{2}$ is transported by $\mathrm{Hb}$, which is found in red blood cells (RBC). Hb makes up approximately $35 \%$ of total RBC volume, and mean corpuscular $\mathrm{Hb}$ concentration is approximately $32-36 \mathrm{~g} / \mathrm{dl}$.

$\mathrm{Hb}$ consists of four heme groups attached to a globin protein. The primary structure of $\mathrm{Hb}$ is its genetically determined amino acid sequence while its secondary, tertiary and quaternary structures result from both intrinsic and environmental factors. Human $\mathrm{Hb}$ is made of four polypeptide chains, each of which contains one heme group, the binding site for molecular oxygen. A heme group is composed of a porphyrin ring with a ferrous ion that binds one $\mathrm{O}_{2}$ 
molecule (Juel \& Milam, 1979). The affinity of each heme group for molecular $\mathrm{O}_{2}$ is determined by the structure and spatial arrangement of the globin component.

$\mathrm{Hb} \mathrm{A}$, which is composed of two alpha and two beta $\mathrm{Hb}$ chains, constitutes $96 \%$ of the $\mathrm{Hb}$ in adult human red blood cells. The structures of the alpha and beta chains were discovered in 1961 (Braunitzer et al.;Konigsberg et al., 1961). The secondary structure of Hb A contains a large proportion of alpha helices, which are linked by stretches of amino acids that are in random coil arrangements. The arrangements of these helices lead to the creation of a hydrophobic cleft where the heme moiety is inserted. The tertiary structure of the $\mathrm{Hb}$ is defined by the spatial positions of the helical segments, while the quaternary $\mathrm{Hb}$ structure is defined by the positions of the four subunit chains.

The binding of $\mathrm{O}_{2}$ with each $\mathrm{Hb}$ subunit causes a conformational change in the $\mathrm{Hb}$. This was first described by Muirhead et al. (1967) who found that the reaction of $\mathrm{Hb}$ with $\mathrm{O}_{2}$ is accompanied by a change in the structure of $\mathrm{Hb}$. Perutz (1970) then described the structural changes that occur in the $\mathrm{Hb}$ molecule upon oxygenation. He documented that the combination of an $\mathrm{O}_{2}$ molecule with a heme group changes the position of the ferrous ion in the heme ring. This triggers a series of physicochemical events that change the position of the peptide chain, such that the salt bridge with a neighbouring chain is broken. This results in a change of the $\mathrm{O}_{2}$ affinity of the heme group in the neighbouring subunit chain. Through this sequence of events, each combination of an $\mathrm{O}_{2}$ molecule with a heme group facilitates the binding of the next one. This co-operativity is responsible for the sigmoidal relationship between $\mathrm{PO}_{2}$ and the degree of saturation of $\mathrm{Hb}$ with $\mathrm{O}_{2}$.

\subsection{The Oxyhaemoglobin Dissociation Curve}

The oxyhaemoglobin dissociation curve (ODC) is used to depict the relationship between $\mathrm{O}_{2}$ tension and the degree of $\mathrm{Hb}$ saturation with $\mathrm{O}_{2}$. Ward et al. (2000) provided a review of the early work on the ODC in the book High Altitude Medicine and Physiology. The early studies were published in French and German, so the information presented in this paragraph was taken from this review. In 1878 Bert created the first plot of $\mathrm{O}_{2}$ and carbon dioxide $\left(\mathrm{CO}_{2}\right)$ dissociation curves, in which he showed the relationship between partial pressure and blood gas concentrations for $\mathrm{CO}_{2}$ and $\mathrm{O}_{2}$ in animals. He did not discover the sigmoidal shape of the curve because he did not use a full range of $\mathrm{PO}_{2}$ values. In 1885 Bohr was the first to plot the ODC in 
its entirety, using dilute $\mathrm{Hb}$ solutions. His curves were hyperbolic and were not compatible with those of Bert. In 1890 Hüfner then published similar curves to those of Bohr. He attributed the hyperbolic shape of the curve to the association of $\mathrm{Hb}$ with $\mathrm{O}_{2}$ according to the equation $\mathrm{Hb}+\mathrm{O}_{2}$ $\rightarrow \mathrm{HbO}_{2}$ (oxyhaemoglobin). Barcroft and Camis confirmed these results in dilute $\mathrm{Hb}$ solutions (1909). Bohr finally discovered the sigmoidal shape of the curve by studying the ODC of whole blood.

The position of the ODC influences how easily $\mathrm{O}_{2}$ is taken up at the lungs, and how easily it is offloaded at the tissues. More specifically, a parallel shift of the ODC to the right reflects a decrease in oxyhaemoglobin affinity that facilitates $\mathrm{O}_{2}$ offloading at the tissues, while a parallel shift to the left reflects an increase in oxyhaemoglobin affinity that facilitates $\mathrm{O}_{2}$ uptake at the lungs. The $\mathrm{O}_{2}$ affinity of $\mathrm{Hb}$ is known to be influenced by a number of physiological parameters, which will be explained in detail below. Besides temperature, which affects the thermodynamics of the reaction between $\mathrm{Hb}$ and $\mathrm{O}_{2}$, these parameters primarily interact with either the reduced or oxygen-bound form of $\mathrm{Hb}\left(\mathrm{HbO}_{2}\right)$, thereby changing its affinity for $\mathrm{O}_{2}$.

Like other biological molecules, $\mathrm{Hb}$ can form bonds with ligands other than $\mathrm{O}_{2}$. These ligands bond with different groups in the globin molecule and usually have a greater affinity for one form of $\mathrm{Hb}$, binding either to $\mathrm{HbO}_{2}$ or reduced haemoglobin. The binding of these ligands to $\mathrm{Hb}$ alters the affinity of $\mathrm{Hb}$ for $\mathrm{O}_{2}$. There are a number of ligands that preferentially bind to reduced $\mathrm{Hb}$. These lower the affinity of $\mathrm{Hb}$ for $\mathrm{O}_{2}$ and shift the ODC to the right. These ligands are present in red blood cells in varying concentrations under different conditions. The most important ligands that bind readily to reduced $\mathrm{Hb}$ and thus lower the $\mathrm{Hb}$ affinity for $\mathrm{O}_{2}$ are hydrogen ions $\left(\mathrm{H}^{+}\right), \mathrm{CO}_{2}$, inorganic anions (such as chloride) and organic phosphates like 2,3diphosphoglycerate (2,3-DPG) and adenosine triphosphate (ATP). The ligands of Hb are interdependent, since ambient temperature and the concentration of each ligand affect the binding of other ligands to $\mathrm{Hb}$ (Hlastala, 1979).

\subsubsection{Temperature}

The first observation of the effect of temperature on the saturation of $\mathrm{Hb}$ with $\mathrm{O}_{2}\left(\mathrm{SO}_{2}\right)$ was attributed to Bert in 1872 (McConn, 1975) who noted that $\mathrm{SO}_{2}$ was $90 \%$ at a $\mathrm{PO}_{2}$ of $15 \mathrm{mmHg}$ at room temperature, but only 50\% at body temperature.. Barcroft and King (1909) confirmed these results and showed that increases in temperature shift the ODC to the right, decreasing the 
affinity of $\mathrm{Hb}$ for $\mathrm{O}_{2}$. As the combination of $\mathrm{Hb}$ and $\mathrm{O}_{2}$ is exothermic, an increase in temperature favours dissociation. The converse is true as well; if temperature falls, the exothermic association of $\mathrm{Hb}$ and $\mathrm{O}_{2}$ is favoured, and the ODC shifts to the left. In creating his slide rule gas calculator, Severinghaus (1966) described the changes in $\mathrm{PO}_{2}$ with temperature (T) at constant saturation (Equation 2):

\section{Equation 2}

$$
\Delta \log \mathrm{PO}_{2}=0.024 \times \Delta T
$$

\subsubsection{The Bohr Effect $(\mathrm{pH})$}

The relationship between hydrogen ion concentration $\left[\mathrm{H}^{+}\right]$and $\mathrm{O}_{2}$ binding to $\mathrm{Hb}$ is twofold. Firstly, $\mathrm{H}^{+}$can act as a ligand for $\mathrm{Hb}$, resulting in a conformational change in $\mathrm{Hb}$ that makes its $\mathrm{O}_{2}$ binding site less accessible, reducing the binding capacity of $\mathrm{Hb}$ for $\mathrm{O}_{2} \cdot \mathrm{H}^{+}$also reduces the affinity of $\mathrm{Hb}$ for $\mathrm{O}_{2}$ because reduced $\mathrm{Hb}$ is a weaker acid. This is because the binding of $\mathrm{Hb}$ with $\mathrm{O}_{2}$ breaks salt bridges, exposing acidic groups. For these reasons, reduced $\mathrm{Hb}$ is favoured over $\mathrm{HbO}_{2}$ in acidic environments, and a decrease in $\mathrm{pH}$ shifts the ODC to the right, favouring $\mathrm{Hb}$ reduction and the offloading of $\mathrm{O}_{2}$. This lowering of affinity in acidic environments is referred to as the Bohr Effect, since it was first documented by Bohr, Hasselbalch and Krogh in 1904 , though in this case they were referring to the general effects of $\mathrm{CO}_{2}$ on the position of the ODC.

The magnitude of the Bohr Effect can be expressed for a constant oxygen saturation by the change in $\log \mathrm{PO}_{2}$ caused by a unit change in $\mathrm{pH}$, as shown in Equation 3:

\section{Equation 3}

$$
\Delta \log \mathrm{PO}_{2}=-0.4
$$

where the $\mathrm{pH}$ change is induced by an acid or base other than $\mathrm{CO}_{2}$, and where the concentration of $\mathrm{CO}_{2}$ and the organic phosphate 2,3-DPG remains constant. 


\subsubsection{Carbon Dioxide}

$\mathrm{CO}_{2}$ is known to shift the ODC via two mechanisms. Firstly, most $\mathrm{CO}_{2}$ in the blood is converted into bicarbonate $\left(\mathrm{HCO}_{3}{ }^{-}\right)$and $\mathrm{H}^{+}$ions by the enzyme carbonic anhydrase. Increases in the partial pressure of $\mathrm{CO}_{2}\left(\mathrm{PCO}_{2}\right)$ therefore increase $\left[\mathrm{H}^{+}\right]$and shift the ODC to the right via the Bohr Effect. In addition, some $\mathrm{CO}_{2}$ combines with $\mathrm{Hb}$, as carbamino compounds. $\mathrm{CO}_{2}$ preferentially binds with reduced $\mathrm{Hb}$, resulting in a conformational change that reduces the affinity of the $\mathrm{Hb}$ for $\mathrm{O}_{2}$. This property is referred to as the Haldane Effect.

The reduction of $\mathrm{PCO}_{2}$ in the pulmonary capillaries augments the uptake of $\mathrm{O}_{2}$, while the increase in $\mathrm{PCO}_{2}$ at the tissues aids in the offloading of $\mathrm{O}_{2}$ from $\mathrm{Hb}$. The influence of $\mathrm{CO}_{2}$ on $\mathrm{SO}_{2}$ is therefore greatest at lower $\mathrm{SO}_{2}$, when it is most needed. When a change in $\mathrm{PCO}_{2}$ causes a change in $\mathrm{pH}$ at constant $\mathrm{PO}_{2}$, the relationship between the change in $\mathrm{pH}$ and the change in $\mathrm{O}_{2}$ saturation is defined according to Equation 4:

\section{Equation 4}

$$
\Delta \log \mathrm{PO}_{2}=-0.48
$$

\subsubsection{2,3-Diphosphoglycerate (2,3-DPG)}

2,3-DPG is a by-product of glycolysis and is the most abundant organic phosphate in RBCs. Like $\mathrm{CO}_{2}$ and $\mathrm{H}^{+}$, 2,3-DPG preferentially binds to, and stabilizes the reduced form of $\mathrm{Hb}$, decreasing saturation for any given $\mathrm{PO}_{2}$ (Benesch et al., 1968). 2,3-DPG also affects the position of the ODC via its effect on $\mathrm{pH}$; increases in 2,3-DPG lower $\mathrm{RBC} \mathrm{pH}$, and a decrease in $\mathrm{RBC} \mathrm{pH}$ has been shown to shift the ODC to the right (Bellingham et al., 1971). The binding of 2,3-DPG to $\mathrm{Hb}$ is dependent upon temperature (Benesch et al., 1969), $\mathrm{pH}$ (Garby \& De Verdier, 1971;Rorth et al., 1973), $\mathrm{PCO}_{2}$ (Bauer, 1969) and the presence of anions (Benesch et al., 1969), so the extent to which it shifts the ODC (though not the direction) is variable. 2,3-DPG concentration affects both the shape and the position of the ODC (Samaja \& Winslow, 1979). 


\subsubsection{Inorganic Salts}

Since $\mathrm{Hb}$ is a protein made up of polar and non-polar amino acids, changes in the concentrations of inorganic ions its environment, such as chloride $(\mathrm{Cl})$, may change the conformation of the protein, affecting the accessibility of the heme binding sites for $\mathrm{O}_{2}$,

\subsubsection{Carbon Monoxide}

The $\mathrm{O}_{2}$ binding site on $\mathrm{Hb}$ has more than 200 times the affinity for carbon monoxide (CO) as it does for $\mathrm{O}_{2}$, so the presence of $\mathrm{CO}$ interferes with the ability of $\mathrm{Hb}$ to bind with $\mathrm{O}_{2}$. Its presence also has the effect of shifting the ODC to the left (by increasing the affinity of free, neighbouring heme groups to $\mathrm{O}_{2}$ ), and it gives the ODC a more hyperbolic shape. $\mathrm{CO}$ therefore severely limits the availability of $\mathrm{O}_{2}$ to the tissues.

\subsubsection{Red Blood Cells (RBCs) and Haemoglobin}

Because RBC 2,3-DPG concentration [2,3-DPG] decreases with age, Hb within older RBCs tends to have a higher $\mathrm{O}_{2}$ affinity than $\mathrm{Hb}$ in young RBCs (Haidas et al., 1971;Edwards \& Rigas, 1967). It has been reported that high concentrations of $\mathrm{Hb}$ are associated with decreased $\mathrm{O}_{2}$

affinity (Bellingham et al., 1971). However, there does not appear to be a systematic relationship between $\mathrm{Hb}$ concentration and the position of the ODC (Winslow et al., 1978).

\subsection{Measuring the ODC}

Because the ODC is a product of the complex interplay of many different factors, its shape and position can only be determined by direct measurement. The entire ODC can be plotted by drawing one or more blood samples and analyzing them in vitro. Although it is useful to see the whole curve, the ODC is generally quantified by the $\mathrm{P}_{50}$, which is the $\mathrm{PO}_{2}$ at which $50 \%$ of the haemoglobin is saturated. $\mathrm{P}_{50}$ may be directly measured using one of the techniques discussed below, or it can be determined from a number of points using the Hill Equation, a three parameter equation that describes the relationship between $\mathrm{PO}_{2}$ and $\mathrm{SO}_{2}(\mathrm{Hill}, 1910)$. The linearized form of this equation is shown below (Equation 5). 


\section{Equation 5}

$$
\log \frac{\mathrm{SO}_{2}}{100-\mathrm{SO}_{2}}=\log \mathrm{K}+n \log \mathrm{PO}_{2}
$$

where $\mathrm{SO}_{2}$ is percent saturation, $\mathrm{K}$ is a constant, $\mathrm{n}$ is the slope of the linearized ODC (also known as the coefficient of co-operativity), and $\mathrm{PO}_{2}$ is the partial pressure of oxygen. First described in 1910, the Hill equation is still used to describe this relationship.

Traditionally, the "standard $\mathrm{P}_{50}$ " is that which is determined under standard conditions. These include a blood serum $\mathrm{pH}$ of 7.4 (which translates into a $\mathrm{RBC} \mathrm{pH}$ of approximately 7.1-7.2, due to excess of large anions in the cell) and a $\mathrm{T}$ of $37^{\circ} \mathrm{C}$; the standard $\mathrm{P}_{50}$ may also be corrected to a $\mathrm{PCO}_{2}$ of $40 \mathrm{mmHg}$. The "physiological $\mathrm{P}_{50}$ " is that which is measured at the $\mathrm{pH}, \mathrm{T}$ and $\mathrm{PCO}_{2}$ of the blood sample. The standard $\mathrm{P}_{50}$ is a useful tool with which to compare the $\mathrm{O}_{2}$ affinity of $\mathrm{Hb}$ of populations under different physiological conditions. At standard body temperature and $\mathrm{pH}$ and normal concentrations of 2,3-DPG, the standard $\mathrm{P}_{50}$ is $26-27 \mathrm{mmHg}$. A measured $\mathrm{P}_{50}$ value can be compared to reference value to determine whether an individual's ODC is "shifted." A lower $\mathrm{P}_{50}$ indicates a left-shifted ODC (with relatively increased $\mathrm{Hb}$ affinity for $\mathrm{O}_{2}$ ) that favours $\mathrm{O}_{2}$ uptake from the environment, while a higher $\mathrm{P}_{50}$ indicates a right-shifted curve (with relatively decreased $\mathrm{Hb}$ affinity for $\mathrm{O}_{2}$ ) that favours $\mathrm{O}_{2}$ offloading at the tissues. The ODC and some of the factors that influence its position are shown below, in Figure 1. 
Figure 1: The ODC
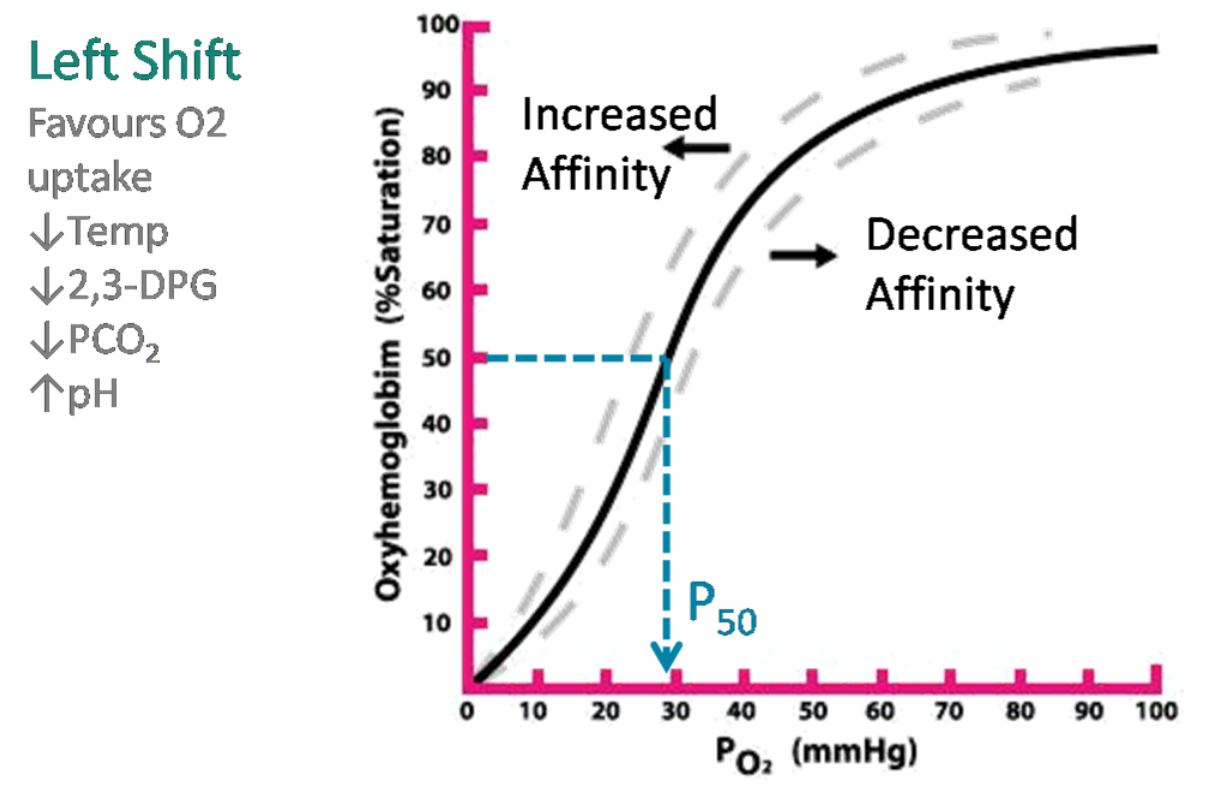

Right Shift

Favours $\mathrm{O} 2$

offloading

$\uparrow$ Temp

个 2,3-DPG

$\uparrow \mathrm{PCO}_{2}$

$\downarrow \mathrm{pH}$

\subsubsection{In vitro methods for measuring the shape and position of the ODC}

\subsubsection{In Vitro Equilibration}

Astrup et al. (1965) described a method for measuring the ODC in vitro. A small sample of blood is placed in a tonometer and exposed to a series of gases of varying $\mathrm{PO}_{2}$ tensions at constant $\mathrm{PCO}_{2}$, with the balance composed of nitrogen. Once the sample comes into equilibrium with each gas, the $\mathrm{pH}$ and saturation are measured. By using a wide range of gas compositions, the entire curve can be plotted. A few of these points can be used with the Hill equation to allow the calculation of the $\mathrm{P}_{50}$. 


\subsubsection{Mixing Technique}

An alternate method of designating $\mathrm{Hb}-\mathrm{O}_{2}$ affinity was described by Edwards and Martin (1966). In this method fully oxygenated and deoxygenated samples of blood are mixed in various proportions in order to produce samples of varying saturations. $\mathrm{P}_{50}$ is measured by mixing equal volumes of desaturated and saturated blood.

\subsubsection{Dissociation Curve Analyzer}

Duvelleroy et al. (1970) described a method that plots the entire ODC from a $10 \mathrm{ml}$ sample of blood by measuring the $\mathrm{O}_{2}$ uptake of completely deoxygenated blood. Blood is first completely desaturated by exposure to $95 \%$ nitrogen per $5 \% \mathrm{CO}_{2}$. It is then exposed to a gas mixture of $95 \% \mathrm{O}_{2}$ and $5 \% \mathrm{CO}_{2}$ while being stirred. Two oxygen electrodes take continuous readings of $\mathrm{PO}_{2}$ within both the gas and blood until the two phases are equilibrated.

\subsubsection{Canizaro's Nomogram}

This nomogram (Canizaro et al., 1974), which has been validated against the mixing technique mentioned above, estimates $\mathrm{P}_{50}$ based on the $\mathrm{PO}_{2}$ and $\mathrm{SO}_{2}$ values of a single venous blood sample. Because it relies on interpolation based on two measurements, the caveat of this method is that the two measurements must be extremely accurate, or the resulting $\mathrm{P}_{50}$ may be very inaccurate. Unfortunately, saturation monitors and gas analyzers vary in their accuracies at different saturation levels, so the estimated $\mathrm{P}_{50}$ may also be quite inaccurate.

\subsubsection{Severinghaus Equation and Slide Rule}

$\mathrm{P}_{50}$ can be found using the Severinghaus equation (Equation 6).

\section{Equation 6}

$$
P_{50}=26.6 \times \frac{P O_{2}}{P O_{2 s a t}}
$$

where the $\mathrm{PO}_{2 \text { sat }}$ is the $\mathrm{PO}_{2}$ on the standard dissociation curve that corresponds with the measured saturation. Alternatively, the Severinghaus (1966) slide rule can be used. The slide rule offers a simple method in which $\mathrm{P}_{50}$ is estimated by aligning $\mathrm{PO}_{2}$ on one scale with 
saturation on another. The $\mathrm{P}_{50}$ can then be read off as the $\mathrm{PO}_{2}$ on the first scale that corresponds with the $50 \%$ saturation mark on the second scale.

\subsubsection{Comparing $\mathrm{P}_{50} \mathrm{~S}$}

$\mathrm{P}_{50}$ values under standard conditions are calculated to facilitate comparisons of experimentally determined values. Blood gases are usually measured at $37.5^{\circ} \mathrm{C}$ so temperature need not be adjusted. On the other hand, $\mathrm{pH}$ may deviate from standard values (serum $\mathrm{pH}$ of 7.4 and $\mathrm{RBC}$ $\mathrm{pH}$ of 7.2), especially under conditions of illness or environmental stress. Therefore, $\mathrm{pH}$ of the serum and RBCs should be measured. If they deviate from the standard values, correction for $\mathrm{pH}$ is made using the Bohr equations. The magnitude of the Bohr Effect has been previously reported as 0.4 when the $\mathrm{pH}$ change is due to $\mathrm{H}^{+}$(Equation 3 ) and 0.48 when it is due to a change in $\mathrm{PCO}_{2}$ (Equation 4). The final $\mathrm{P}_{50}$ will also depend on the effect of other ligands in the $\mathrm{RBC}$, such as 2,3-DPG and inorganic salts. Correcting only for $\mathrm{pH}$ may not result in a correct $\mathrm{P}_{50}$.

\subsubsection{Predicting Saturation}

The accurate measurement of $\mathrm{SO}_{2}$ requires photometric equipment, which is expensive and can be difficult to use. A number of models have therefore been created to predict saturation from more readily available arterial blood measures, such as $\mathrm{PCO}_{2}, \mathrm{PO}_{2}$ and $\mathrm{pH}$. The Kelman model (Kelman, 1966) uses $\mathrm{PCO}_{2}, \mathrm{pH}$, and temperature to calculate a "virtual $\mathrm{PO}_{2}$ " (the $\mathrm{PO}_{2}$ that would lead to the same saturation if measured under standard conditions of $\mathrm{T}, \mathrm{PCO}_{2}$ and $\mathrm{pH}$ ), which is then used to predict $\mathrm{SO}_{2}$. This model was shown to be both reliable and valid at sea level (Breuer et al., 1989). Because it assumes normal acid-base status and 2,3-DPG levels, this model may be inaccurate at altitude.

A number of newer algorithms that incorporate additional variables have been recently introduced. Dash and Bassingthwaighte (2004) included temperature and 2,3-DPG. The latter addition makes this equation especially suitable for measurements taken at altitude, where changes in [2,3-DPG] becomes a significant influence on $\mathrm{SO}_{2}$. Results using their model correlate well with published values. Chiari et al. (1997) presented a comprehensive model taking into account ventilatory, circulatory and chemical parameters. This model is a useful simulation tool, but its practical use in predicting saturation is limited because of its complexity. 


\subsection{Physiological Effects of High Altitude}

Atmospheric pressure decreases with increasing altitude. This is associated with a decrease in $\mathrm{PO}_{2}$, despite a constant fractional percent of $\mathrm{O}_{2}$. This drop in atmospheric $\mathrm{PO}_{2}$ will lead to a decrease in $\mathrm{PaO}_{2}$ and thereby, without compensation, the amount of $\mathrm{O}_{2}$ available to the tissues. This is at least partially prevented by changes in ventilation and the presence of factors that influence the way that $\mathrm{O}_{2}$ binds to $\mathrm{Hb}$.

\subsubsection{Hypoxic Ventilatory Response}

The first response upon acute ascent is an increase in ventilation, which is known as the hypoxic ventilatory response (HVR). It is usually caused by both a decrease in the ventilatory recruitment threshold (as seen by a leftward shift of the isoxic relationship between $\mathrm{PCO}_{2}$ and ventilation as compared to normoxia), as well as an increase in sensitivity to $\mathrm{PCO}_{2}$ (as seen by an increase in the slope of the relationship between $\mathrm{PCO}_{2}$ and ventilation) (Mohan \& Duffin, 1997;Duffin \& Mahamed, 2003). HVR is followed by a ventilatory decline (HVD), which occurs with continued exposure to hypoxia.

The hyperventilation of $\mathrm{HVR}$ leads to a fall in $\mathrm{PCO}_{2}$ as the ratio of ventilation to $\mathrm{CO}_{2}$ production increases. Similarly, alveolar $\mathrm{PO}_{2}$ increases as the turn-over of air in the lungs increases while $\mathrm{O}_{2}$ consumption remains constant. The fall in $\mathrm{PCO}_{2}$ increases the affinity of $\mathrm{Hb}$ for $\mathrm{O}_{2}$ via the Haldane effect and the development of a respiratory alkalosis. HVR therefore increases $\mathrm{Hb}-\mathrm{O}_{2}$ saturation via increasing alveolar $\mathrm{PO}_{2}$ and the $\mathrm{Hb}$ affinity for $\mathrm{O}_{2}$. 
Figure 2: HVR and HVD
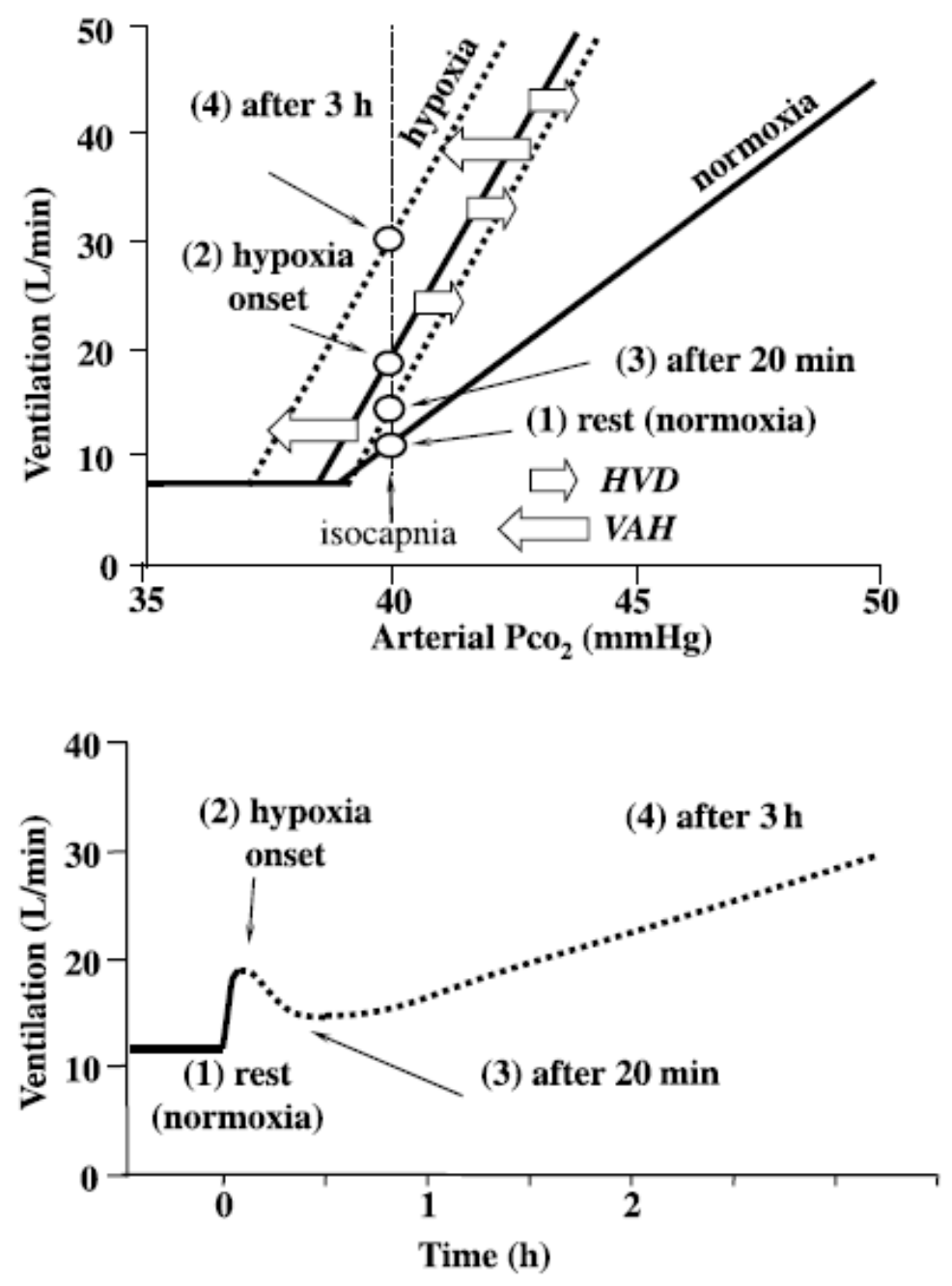

Figure 2, copied from Duffin and Mahamed (2003) shows the process of HVR and HVD in those acclimatizing to high altitude. The top graph shows both the change in threshold (depicted by the arrows pointing left and right) and the change in sensitivity (depicted by the changes in slope) that occur over time with exposure to hypoxic hypoxia. The lower graph shows the corresponding trends in ventilation over time during acclimatization to high altitude, caused by changes in threshold and sensitivity to $\mathrm{PCO}_{2}$.

\subsubsection{Haemoglobin}

Hypoxia, such as that of high altitude, leads to the release of erythropoietin (EPO). This stimulates the production of RBCs. If the $[\mathrm{Hb}]$ increases with the production of $\mathrm{RBCs}$, the $\mathrm{O}_{2}$ capacity of blood increases. However, the viscosity of the blood also increases as the [Hb] 
exceeds $17 \mathrm{~g} / \mathrm{dl}$, reducing tissue perfusion and offsetting the benefits with respect to tissue $\mathrm{O}_{2}$ delivery. As mentioned above, young Hb cells contain more 2,3-DPG than older cells, so accelerated erythropoesis results in RBCs with increases in [2,3-DPG], which reduces $\mathrm{Hb}-\mathrm{O}_{2}$ affinity. The benefit of this, if any, to overall tissue $\mathrm{O}_{2}$ delivery with hypoxia will be discussed in greater detail in the following sections.

\subsubsection{2,3-DPG}

2,3-DPG is a metabolic intermediate produced in the glycolytic pathway of RBCs. It is produced during the anaerobic Embden Meyerhof pathway by a side reaction called the Rapoport Leubering shuttle, which converts 1,3-diphosphoglycerate to 3-phosophoglycerate without the creation of ATP. This side reaction occurs in $20 \%$ of the glycolytic flux during RBC metabolism (Juel \& Milam, 1979). 2,3-DPG levels vary with the rate of glycolysis or with changes in the activity of the enzymes diphosphoglyceromutase and diphosphoglycerate phosphatase.

The rate of glycolysis can be affected by the internal milieu, such as $\mathrm{pH}, \mathrm{PO}_{2}$ and the concentration of inorganic phosphates. Acidosis decreases 2,3-DPG by down regulating phosphofructokinase and by altering the equilibrium between 1,3-DPG and 2,3-DPG. Inorganic phosphates stimulate glycolysis (and therefore 2,3-DPG production) independently of $\mathrm{pH}$. In renal disease, 2,3-DPG increases in proportion to the increase in serum inorganic phosphate levels. However, inorganic phosphates also have a small dampening effect on diphosphoglyceromutase, an enzyme involved in 2,3-DPG production from 1,3-DPG, though this effect must be small because the overall effect of inorganic phosphates is to increase [2,3-DPG].

Under hypoxic conditions there is an increase in reduced Hb levels. This increases the binding of 2,3-DPG to $\mathrm{Hb}$ and reduces the intracellular [2,3-DPG]. This results in less feedback inhibition of the enzyme diphosphoglyceromutase and subsequently leads to an increase in the conversion of 1,3-DPG to 2,3-DPG. Hypoxia also increases [2,3-DPG] through its induction of respiratory alkalosis, the major mechanism of increasing [2,3-DPG] in response to ascent to high altitude.

\subsection{Population Studies at High Altitude}

Andeans have been at high altitude for approximately 11,000 years and Tibetans for almost 25,000 years (Aldenderfer, 2003). These high altitude populations differ from each other, as 
well as from other high altitude populations and acutely acclimatized lowlanders, in a number of ways. The information presented below was reviewed by Beall (2007c).

While acutely acclimatized lowlanders show a decreased maximal $\mathrm{O}_{2}$ consumption and an increased basal metabolic rate (showing a limited capacity to increase $\mathrm{O}_{2}$ consumption), Andeans and Tibetans have a normal range of $\mathrm{O}_{2}$ consumption, with expected basal metabolic rates and expected $\mathrm{O}_{2}$ consumption capacity based on their age, sex and weight, which are comparable to those of lowlanders at sea level.

Lowlanders born at sea level exhibit increased ventilation at high altitude. This increase occurs immediately after initial exposure to high altitude and decreases over time, but resting ventilation tends to remain increased above sea level values while the lowlanders remain at altitude.

Tibetans born and raised at high altitude also retain an increase in ventilation over sea level values. Andeans, as well as Europeans and Chinese who were raised at high altitude, display a relative hypoventilation as compared to the other groups at high altitude, including Tibetans and lowlanders born at sea level.

With acute exposure to high altitude, lowlanders show an increased HVR as compared to sea level. Over a period of days their HVR returns to normal levels and after weeks or months it falls below normal levels. This is in contrast with Tibetan natives, who show an HVR that is similar to that of lowlanders at sea level, and Andeans, who show an HVR that is lower than that of lowlanders at sea level. The indefinite sustained HVR in Tibetans likely plays a role in their adaptation to life at high altitude.

Although Tibetans have relatively high ventilation and HVR responses that allow them to respond more to fluctuations in blood $\mathrm{O}_{2}$ levels, they have lower $\mathrm{CaO}_{2}$ than Andeans natives at high altitude, lowlanders at sea level, and Ethiopians at high altitude. Andean high altitude natives have increased $\mathrm{CaO}_{2}$ over the other three groups. This can be partially explained by their relatively high EPO and $\mathrm{Hb}$ levels. Blood $\mathrm{O}_{2}$ content in Andeans is also increased because of their relatively high $\mathrm{O}_{2}$ saturation. Andean and Tibetan natives at high altitude both have resting $\mathrm{SO}_{2}$ values that are lower than the normal sea level values. However, ambient Andean $\mathrm{SO}_{2}$ values have been found to be more than one standard deviation higher than those of Tibetans at high altitude. Surprisingly, Ethiopians at high altitude have $\mathrm{SO}_{2}$ values that are within the normal sea level range. 
Another mechanism that is involved in acclimatization and adaptation to high altitude is that of changes in blood flow. Along with $\mathrm{SO}_{2}$, tissue blood flow determines tissue $\mathrm{O}_{2}$ delivery. Lowlanders at high altitude often exhibit pulmonary hypertension, which results from hypoxic pulmonary vasoconstriction, a protective reflex that shunts blood away from areas of the lung with poor ventilation or oxygenation. At high altitude, the entire lung becomes hypoxic and widespread pulmonary arteriole constriction can lead to pulmonary hypertension. Tibetans do not usually exhibit pulmonary hypertension (they have normal or slightly elevated pulmonary artery pressure or hypoxic pulmonary vasoconstriction (they have normal pulmonary blood flow). This is probably due to increased levels of nitric oxide (NO) as compared to Andeans at high altitude, lowlanders at high altitude and lowlanders at sea level. Consistent with this is that nitric oxide synthesis tends to be down regulated in lowlanders at high altitude, and Andeans are known to exhibit a high incidence of pulmonary hypertension. Tibetans also increase blood flow through increased capillary density in muscles as compared to Andean high altitude natives. They therefore have greater diffusion capacity that can compensate for their decreased $\mathrm{CaO}_{2}$.

Muscle mitochondria levels also differ across populations at altitude and sea level. Lowlanders tend to lose leg muscle mitochondria during the first three weeks of exposure to high altitude. Similarly, leg muscle mitochondrial volume is lower in Andeans and Tibetans at high altitude than in lowlanders at sea level. Decreased mitochondria volume is even found in Tibetans who are born and raised closer to sea level, indicating that, in the Tibetan population, the decrease in mitochondria is not dependent upon exposure to high altitude. The functional benefit of a decrease in mitochondrial number at high altitude is not clear, since basal $\mathrm{O}_{2}$ metabolism is not lower. In Tibetans, this decrease in mitochondria somehow supports normal metabolic rates, perhaps indicating greater metabolic efficiency.

Effect size is equal to the mean difference between two samples, divided by their pooled variance. An effect size of 0.8 or greater is usually considered as large, and indicates that there is no overlap in almost $50 \%$ of the observations in the two samples that are being compared. Using this method, certain effect sizes between Tibetans and Andeans are large. These include the higher ventilation of Tibetans, the lower haematological traits of the Tibetans especially for $\mathrm{Hb}$, the higher $\mathrm{NO}$ and capillary density in Tibetans, lower Tibetan arterial $\mathrm{O}_{2}$ levels, lower Tibetan $\mathrm{SO}_{2}$, and lower Tibetan pulmonary artery pressure. It therefore seems that the two high altitude populations have evolved different sets of adaptations to life at high altitude. 


\subsection{The ODC at Altitude}

It has been known since the turn of the $20^{\text {th }}$ century that altitude hypoxia causes physiological stress. Many investigations have since been conducted in order to uncover the mechanisms with which the body is able to deal with this stress. A great focus of this research has been on the ODC. As mentioned above, there are a number of known physiological changes that occur with exposure to hypoxia. Many of these have the ability to influence the shape and position of the ODC. It is for this reason that the net effects of these changes on the ODC have been looked at in native highlanders and lowlanders sojourning at high altitude.

These studies have been carried out at various altitudes, in different populations with different acclimatization profiles. They involve either the calculation or in vitro measurement of $\mathrm{P}_{50}$. Because of different measurement methods and conditions, the results have not been consistent. A few key studies will be presented along with their results.

\subsubsection{The ODC in Lowlanders at High Altitude}

The position of the ODC in acclimatized lowlanders sojourning at high altitude was first measured by Barcroft (1911). He was aware that hypoxia is associated with hyperventilation and a fall in $\mathrm{PCO}_{2}$ that is associated with a leftward shift of the ODC. For that reason he expected to find that the ODCs of the lowlanders were left-shifted at altitude as compared to sea level. Instead, he found that the physiological curves were identical at sea level and altitudes of 2130 and $3000 \mathrm{~m}$, and that the standard curves (at a $\mathrm{PCO}_{2}$ of $40 \mathrm{mmHg}$ ) were right shifted. He posited that his data provided evidence for the presence of some acid that was compensating for the decrease in carbonic acid, and that the increase in this acid corresponded to increases in altitude so that it matched the change in carbonic acid and the physiological ODC would not be shifted.

In a subsequent study Barcroft et al.(1915) found that, above $3048 \mathrm{~m}$, the ODC at the prevailing $\mathrm{PCO}_{2}$ is slightly right-shifted. This was assumed to reflect an excess of lactic acid, which is present at high altitude due to the lack of oxygen and which counteracts the alkalosis caused by hyperventilation. He suggested that at lower altitudes there is the presence of some other acid, due to an acid-base adjustment performed by the kidneys. In yet another study Barcroft $e t$ al. (1923) reported a left-shifted ODC at altitude as measured at the prevailing $\mathrm{PCO}_{2}$, which in this particular study was between $25-30 \mathrm{mmHg}$. This leftward shift was attributed to alkalemia and 
was argued to be beneficial, as it would enhance $\mathrm{O}_{2}$ loading at the lung. These results were not reconciled with those previously reported.

Keys et al. (1936) studied the position of the ODC in acclimatizing lowlanders at six different altitudes, from sea level to $6140 \mathrm{~m}$. The ODCs of the subjects at altitude standardized for $\mathrm{pH}$ were right shifted $\left(\mathrm{P}_{50}\right.$ increase of $\left.3.5 \mathrm{mmHg}\right)$. At physiological $\mathrm{pH}$, the ODC's were left-shifted up to an altitude of approximately $4267 \mathrm{~m}$, above which they became increasingly right-shifted. This decrease in affinity at the higher altitudes was considered advantageous, as it would facilitate $\mathrm{O}_{2}$ unloading at the tissues.

Two groups of researchers simultaneously discovered the effects of 2,3-DPG on the ODC (Chanutin \& Curnish, 1967;Benesch \& Benesch, 1967). They discovered that this organic phosphate, a by-product of RBC metabolism, is an allosteric modulator of $\mathrm{Hb}$ that binds to its reduced form and decreases its affinity for $\mathrm{O}_{2}$ (Benesch et al., 1968). Soon thereafter, Lenfant $e t$ al. (1968) reported that the increase in the standard $\mathrm{P}_{50}$ in lowlanders during acclimatization to high altitude is accompanied by an increase in [2,3-DPG]. Both $\mathrm{P}_{50}$ and [2,3-DPG] normalized upon return to sea level. With this discovery, all previous speculation regarding the direction and cause of shifts of the ODC at altitude were rendered disputable, as they did not measure [2,3DPG]. In previous studies the blood samples were not always analyzed in a timely fashion. Therefore, the 2,3-DPG may have been metabolized before measurement, as [2,3-DPG] rapidly decreases under in vitro conditions.

Once it was established that [2,3-DPG] increases upon ascent to high altitude, Lenfant et al. (1971) conducted an experiment to determine the relationship between $\mathrm{pH}$ change, [2,3-DPG] and shifts of the ODC at high altitude. Two subjects were made acidotic with the carbonic anhydrase inhibitor acetazolamide before ascending to high altitude along with four control subjects, to whom no drugs were administered. The experimental group did not exhibit an increase in $\mathrm{pH}$, an increase in [2,3-DPG] or a shift of the ODC. Meanwhile, the control group developed a respiratory alkalosis and increased their $\mathrm{P}_{50}$ and [2,3-DPG]. Half of the changes in both $\mathrm{P}_{50}$ and [2,3-DPG] occurred within 15 hours of altitude exposure. They interpreted the similar time course as an indication the two changes were probably related. That the acidotic experimental group did not exhibit an increase in [2,3-DPG] or $\mathrm{P}_{50}$ provided further confirmation that the increase in $[2,3-\mathrm{DPG}]$ is a response to the respiratory alkalosis. A later study (Milles $e t$ 
$a l ., 1987)$ found that those receiving acetazolamide did have an increase of $\mathrm{pH}$ and [2,3-DPG] above baseline levels, though to less of an extent than those who did not. They also had greater $\mathrm{PO}_{2}$ levels than the controls.

According to the results of Lenfant et al. (1971), the increase in 2,3-DPG upon ascent to high altitude provides some metabolic compensation for the respiratory alkalosis, though this 'compensatory' mechanism does not seem to be complete be at extremely high altitudes. Blood $\mathrm{pH}$ does not return to the normal sea level value of 7.4, even after a few weeks at altitude (Lahiri \& Milledge, 1967) This issue was studied by Winslow et al. (1984) during the 1981 American Medical Research Expedition to Everest (AMREE). While [2,3-DPG] is assumed to be affected by $\mathrm{pH}$, above $6300 \mathrm{~m}$ they found large changes in $\mathrm{pH}$ but only small changes in [2,3-DPG]. They also found that up to $6300 \mathrm{~m}$ there is no physiological shift of the ODC, since 2,3-DPG counteracts the effect of respiratory alkalosis on the ODC. Above $6300 \mathrm{~m}$ the physiological ODC was shifted progressively to the left. This was primarily attributed to the respiratory alkalosis that overwhelmed the effect of increases in [2,3-DPG]. Meanwhile, standard $\mathrm{P}_{50}$ was slightly increased when measured at pH 7.4. Torrance et al. (1970a) showed that 2,3-DPG increases only up to $4500 \mathrm{~m}$ ). Incomplete compensation was thought to be beneficial because it protects against reductions in $\mathrm{SaO}_{2}$ at severe hypoxia. It should be noted that the data from above $6300 \mathrm{~m}$ was made in only one subject, and it was derived from blood samples collected at $6300 \mathrm{~m}$, which were adjusted based on alveolar gas samples collected on the summit.

Mairbaurl et al. (1990) looked at the physiological $\mathrm{P}_{50} \mathrm{~s}$ of lowlanders during progressive ascent to an altitude of $4559 \mathrm{~m}$. This was the first study to directly measure $\mathrm{P}_{50}$ under physiological acid-base conditions, where the normal Bohr and Hill coefficients may not be applicable. They found an initial decrease in physiological $\mathrm{P}_{50}$ with initial altitude exposure, followed by a return to the sea level value within a few days despite continued exposure to altitude, reflecting a balance between respiratory alkalosis and the effects of 2,3-DPG. Meanwhile, standard $\mathrm{P}_{50}$ increased upon altitude exposure and continued to increase with continued exposure. This is a reflection of the effect of the increase in [2,3-DPG] on the ODC. These data also confirmed that early acclimatization is associated with young RBCs that are high in 2,3-DPG, which is associated with decreased $\mathrm{Hb}-\mathrm{O}_{2}$ affinity. However, it was not clear whether the increased hematocrit itself or age of the RBCs or a combination of both was responsible for the decreased affinity and increase in [2,3-DPG]. 
The topic was re-examined during Operation Everest II (OE II), a simulated ascent of Mount Everest (Wagner et al., 2007). In this study there was a progressive increase in standard $\mathrm{P}_{50}$ as barometric pressure fell from 760 to $282 \mathrm{mmHg}$. This increase was attributed to a progressive increase in [2,3-DPG], assumed to be induced by progressive hypoxia, becausestandard $\mathrm{P}_{50}$ accounts for $\mathrm{PCO}_{2}$ and $\mathrm{pH}$. Meanwhile, physiological $\mathrm{P}_{50}$ was steady at the normal value (between 26-27 mmHg) despite decreases in atmospheric pressure. These data agree with those of AMREE up to an altitude of $6300 \mathrm{~m}$, but do not agree with the AMREE data from above 6300 m. This is because the $\mathrm{PCO}_{2}$ values at extreme altitude were higher, and $\mathrm{pH}$ lower, in the case of OE II. There are a number of possible reasons for this apparent contradiction. Firstly, the AMREE data beyond this altitude was based on only one subject, who may not have had a typical response. Alternatively, it could be due to differences in how the summit measurements were made, or due to the different ascent profiles of the participants of AMREE and OE II, since the OE II subjects "ascended" more quickly than those who participated in AMREE. Lastly, it could be because the AMREE subject had a greater reduction in $\mathrm{PCO}_{2}$ and a greater increase in $\mathrm{pH}$ than those in OE II, though these differences should only have translated to a $\mathrm{P}_{50}$ difference of $0.5 \mathrm{mmHg}$.

Based on these studies, it seems that the increase in [2,3-DPG] with exposure to high altitude is associated with an increased standard $\mathrm{P}_{50}$, while the physiological $\mathrm{P}_{50}$ remains at the normal sea level value and may become progressively lower at extreme altitudes.

\subsubsection{The ODC in Highlanders}

Previous studies have indicated that the extent of altitude exposure affects the degree of acclimatization to high altitude. Those who are native to high altitude, or those who have dwelled there for many years, may exhibit different responses to the altitude than do lowlanders who are acutely acclimatized. Additionally, those whose ancestors have been at altitude for thousands of years may have evolved adaptations that affect the affinity of $\mathrm{Hb}$ for $\mathrm{O}_{2}$. This is the case in genetically adapted animals, such as llamas and yaks (Beall, 2007b). Other instances of such genetic adaptations and their associated benefits will be discussed below.

The ODC was first measured in highlanders at altitude by Barcroft et al. (1923), who reported a left-shifted curve in Peruvian highlanders as compared to that of lowlanders at sea level. This was attributed to alkalemia of acclimatization, since a similar shift was observed in the 
lowlanders studied at the same altitude. Keys et al. (1936) conducted a similar study in Peruvian highlanders living at $5340 \mathrm{~m}$. They found that the standardized ODCs of the highlanders (measured at a cellular $\mathrm{pH}$ of 7.1) were right shifted with respect to lowlanders at sea level, but left shifted with respect to lowlanders at high altitude, the latter of which was attributed to a greater degree of acclimatization due to a longer period of exposure to high altitude. Because, however, the lowlanders at altitude exhibited a respiratory alkalosis (whereas the altitude residents had $\mathrm{pH}$ values similar to those of lowlanders at sea level), their ODCs at physiological $\mathrm{pH}$ were similar to those of the altitude residents.

A later study by Aste-Salazar and Hurtado (1944) looked at standard and physiological ODCs in Peruvian highlanders as well as in lowlanders at sea level and lowlanders at $4540 \mathrm{~m}$. They found that the high altitude residents had right-shifted curves as compared to lowlanders at sea level, both at standard serum $\mathrm{pH}$ of 7.4 and at physiological $\mathrm{pH}$. This was explained as being beneficial for offloading $\mathrm{O}_{2}$ at the tissues.

Morpurgo et al. (1970) conducted a study on Peruvian high altitude natives and found that their ODCs were right shifted with respect to lowlanders at sea level and with respect to Europeans native to similar altitudes (though the ODCs of the Europeans were also right shifted with respect to the normal sea level values). The Peruvian high altitude natives were also found to have a greater Bohr Effect. This was not found to be due to a genetic $\mathrm{Hb}$ modification, so it was attributed to the presence of some unknown factor that lowers $\mathrm{Hb}_{-} \mathrm{O}_{2}$ affinity. This higher Bohr Effect was seen as an evolutionary adaptive mechanism for increasing $\mathrm{O}_{2}$ delivery to the tissues, since it was present in those who grew up at altitude whose families had been at altitude for many years, but not in those who grew up at altitude but whose ancestors were from lowland regions. The right shift may also have been due to the increase of [2,3-DPG] (Benesch et al., 1968).

Morpurgo et al. (1976) later conducted a study of Sherpas native to an altitude of 3800-3900 m. Unlike Andean highlanders and Europeans residing at altitude, these Sherpas did not have increased haematological values (RBC number, $[\mathrm{Hb}]$ or [2,3-DPG]) as compared to lowlanders at sea level. Their ODCs were also shifted strongly to the left as compared to Caucasians living at sea level, and the fact that the standard ODCs of their haemolysed blood were similar to their standard whole blood ODCs gives evidence that the $\mathrm{Hb}-\mathrm{O}_{2}$ affinity of Sherpas at high altitude is 
not greatly affected by the RBC environment. Meanwhile, Sherpas permanently living at low altitudes (Kathmandu) exhibited a lower $\mathrm{Hb}-\mathrm{O}_{2}$ affinity than the Caucasian lowlander controls and they were found to be somewhat anaemic, as defined by lower Hb levels (however, their tissues were still well oxygenated because of the lower $\mathrm{Hb}-\mathrm{O}_{2}$ affinity). The lower affinity was attributed in part to an increased 2,3-DPG/Hb ratio. Meanwhile, Sherpas living at altitude had [2,3-DPG] similar to Caucasians living at sea level and much lower than Caucasians acclimatized to high altitude. They posited that Sherpas, unlike Andean natives, have genetically adapted to life at high altitude due to prolonged exposure over many more generations to the stress of hypoxic hypoxia, which would have increased the possibility of natural selection and evolution. However, some of the observations they made may have been physiological, and not genetic, in nature. While their findings were interesting, it must be noted that their blood samples were analyzed 5-6 days after being collected, so their results may not be valid. This is because in vitro $\mathrm{P}_{50}$ and 2,3-DPG are known to decrease over time.(Aberman et al., 1976)

Samaja et al. (1979) were dissatisfied with the conflicting results from previous studies. They identified possible sources of variation in the data - that previous studies may have overlooked certain factors that are known to influence $\mathrm{Hb}-\mathrm{O}_{2}$ affinity (for example, studies performed before the identification of the role of 2,3-DPG may have missed the influence of this important molecule). Another possible source is that blood collection, storing, transfer, and analysis techniques may have differed between studies. They therefore conducted their own studies on Sherpas living at high altitude $(3850 \mathrm{~m})$, high altitude Sherpas who had been living at $1450 \mathrm{~m}$ (tested at sea level), Caucasians temporarily dwelling at $3500 \mathrm{~m}$ and sea level controls. All blood samples were analyzed within 6 hours of being collected. Their results indicated no difference in the standard $\mathrm{P}_{50} \mathrm{~s}$ (at serum $\mathrm{pH} 7.4$ and $\mathrm{PCO}_{2}$ of $40 \mathrm{mmHg}$ ) of the different groups, despite the fact that the two groups at altitude had increased ratios of 2,3-DPG to Hb concentrations. Electrophoresis did not reveal the presence of any abnormal haemoglobin. This indicates that high altitude Sherpas do not have a genetic or acquired facilitated $\mathrm{O}_{2}$ transport mechanism.

Winslow et al. (1981) used a technique to plot the entire ODC rapidly and accurately under both standard and physiological conditions. This method was first applied to a population at sealevel, where it was found that there is great variation in $\mathrm{P}_{50}$ (Winslow et al., 1978). The study was then performed in a population of Peruvians who were native to $4540 \mathrm{~m}$ and in sea level 
controls. Results of this study indicated that the high altitude natives had elevated [2,3-DPG] and subsequently had standard $\mathrm{P}_{50} \mathrm{~s}$ that were higher than the sea level controls, but due to a compensated respiratory alkalosis the physiological $\mathrm{P}_{50} \mathrm{~s}$ of the two groups did not differ. As in their previous study, they found great variation in the $\mathrm{P}_{50} \mathrm{~S}$ of the sea level controls and the high altitude dwellers. The range of $\mathrm{P}_{50} \mathrm{~s}$ was greater for the altitude population than it was for the sea level population.

In summary, as was the case with lowlanders at high altitude, there is no consensus about the position of the ODC in native highlanders. However, since the discovery of the influence of 2,3DPG on the $\mathrm{Hb}$ affinity for $\mathrm{O}_{2}$, studies performed at physiological $\mathrm{pH}$ and $\mathrm{PCO}_{2}$ have not found a shift of the ODC. This has been attributed to a balance between alkalosis and an increase in [2,3-DPG]. Meanwhile, studies performed under standard conditions of $\mathrm{pH}$ and $\mathrm{PCO}_{2}$ tended to find a rightward shifted ODC, resulting from increases in [2,3-DPG].

\subsubsection{What type of shift is beneficial at altitude?}

Some animals native to hypoxic environments have adapted by developing increased $\mathrm{Hb}$ affinity for $\mathrm{O}_{2}$. High altitude ostriches and huallata have higher $\mathrm{O}_{2}$ affinities than bird species that are not native to high altitude. Similarly, the $\mathrm{P}_{50}$ of bar-headed geese, which fly over the Himalayas during migration, is more than $10 \mathrm{mmHg}$ lower than that of closely-related birds from moderate altitudes (Black \& Tenney, 1980). The degree of the change in affinity seems to be related to the degree of hypoxia, as determined from the case of deer mice (Snyder et al., 1982; Snyder, 1985). Those that live at higher altitudes have higher affinities than their lower altitude relatives, and when these mice are relocated to lower altitudes the changes persist into the next generation of animals. This genetic basis can also be seen in llamas, which exhibit a high $\mathrm{Hb}$ affinity for $\mathrm{O}_{2}$ for generations after being raised in zoos at sea level (Banchero et al., 1971;Banchero \& Grover, 1972).

Another interesting case is that of the tadpole. Tadpoles often live in stagnant water that is low in $\mathrm{O}_{2}$ and high in $\mathrm{CO}_{2}$. Tadpole $\mathrm{Hb}$ has a higher affinity for $\mathrm{O}_{2}$ than that of adult frogs and a smaller Bohr Effect, so the high $\mathrm{CO}_{2}$ in the stagnant water in which tadpoles usually live does not lead to further offloading of $\mathrm{O}_{2}$. 
The globin chain of human foetal $\mathrm{Hb}$ has a different amino acid sequence than the adult form. In dilute solutions the $\mathrm{P}_{50}$ of the foetal $\mathrm{Hb}$ is approximately the same as that of adult $\mathrm{Hb}$, but in whole blood solutions the foetal $\mathrm{P}_{50}$ is only $19 \mathrm{mmHg}$. In the foetal environment, the $\mathrm{PO}_{2}$ is less than $30 \mathrm{mmHg}$, equivalent to that faced by a climber on the summit of Everest. Interestingly, both the foetus and climber deal with this by increasing the affinity of their $\mathrm{Hb}$ for $\mathrm{O}_{2}$. In some mammalian foetuses (e.g. dog, horse, pig) the increase in affinity is due to a decrease in organic phosphate concentrations, while in others [2,3-DPG] is similar to that in the adult, but the $\mathrm{Hb}$ in foetal RBCs is less sensitive to it.

Given that these animals that live in low $\mathrm{O}_{2}$ environments have genetic adaptations that shift their ODCs to the left, it seems that this leftward shift confers an advantage at altitude. In one of their studies, Barcroft et al. (1923) found a slightly increased affinity of $\mathrm{Hb}$ for $\mathrm{O}_{2}$. They argued that this was beneficial, as it would enhance $\mathrm{O}_{2}$ loading from the atmosphere at the lungs. In contrast, Aste-Salazar and Hurtado (1944) reported a slightly decreased $\mathrm{Hb}$ affinity for $\mathrm{O}_{2}$ in high altitude natives. They argued that a decreased affinity is beneficial because it enhances $\mathrm{O}_{2}$ offloading at the tissues, where it is needed. This argument was also used by Lenfant and Sullivan (1971). They noted that the increased [2,3-DPG] leads to a decrease in Hb affinity for $\mathrm{O}_{2}$. They explained that this is beneficial, as it allows for peripheral $\mathrm{O}_{2}$ unloading. They posited that this decreased affinity plays an important role in the acclimatization of lowlanders to altitude, and in the genetic adaptations of those native to altitude.

Eaton et al. (1974) wished to test the hypothesis that decreased $\mathrm{Hb}$ affinity for $\mathrm{O}_{2}$ is advantageous at altitude. They manipulated $\mathrm{Hb}-\mathrm{O}_{2}$ affinity of rats, via carbamylation of the $\mathrm{Hb}$, to create high and low affinity groups. They then exposed both groups of rats to hypobaria to simulate altitude conditions. They found that those with higher $\mathrm{Hb}-\mathrm{O}_{2}$ affinity had better survival outcomes than those with decreased affinity.

During a theoretical study, Turek et al. (1978) showed that high $\mathrm{Hb}$ affinities for $\mathrm{O}_{2}$ are beneficial at altitude, especially during exercise. They then found that cyanate-treated rats maintained better oxygen transfer to tissues during severe hypoxia than did normal animals.

Hebbel et al. (1978) studied a family in which two out of the four children have mutant AndrewMinneapolis $\mathrm{Hb}$, with a $\mathrm{P}_{50}$ of $17.1 \mathrm{mmHg}$. The increased $\mathrm{O}_{2}$ affinity of the mutant $\mathrm{Hb}$ seemed to confer a sort of pre-adaptation to altitude; at a moderate altitude of $3100 \mathrm{~m}$, the mutant $\mathrm{Hb}$ 
siblings exhibited lower increases in resting heart rates than their normal siblings and minimal increases in plasma and urinary EPO levels, while they did not exhibit thrombocytopenia or decrements in $\mathrm{O}_{2}$ consumption. They had similar 2,3-DPG increases to their normal siblings.

A theoretical study by Bencowitz et al. (1982) examined the effects of changes in $\mathrm{Hb}-\mathrm{O}_{2}$ affinity on exercise tolerance at altitude to reconcile the conflicting evidence from previous studies. They determined that the effects of shifts in the ODC depend on whether or not diffusion limitation is present. When complete blood-gas equilibration is allowed to occur via diffusion, a rightward shift that favours $\mathrm{O}_{2}$ offloading at the tissues is beneficial. However, when diffusion limitation is present, such as during exercise at altitude, a leftward shift is beneficial, since it allows for greater $\mathrm{O}_{2}$ uptake. They demonstrated that a leftward shift can be beneficial, especially at higher altitudes and especially during exercise.

Wagner (1997) performed a theoretical modelling study to determine the optimal $\mathrm{P}_{50}$ for $\mathrm{O}_{2}$ transport during maximal exercise at varying altitudes (sea level, intermediate altitude and extreme altitude equivalent to the summit of Everest). He found that maximal oxygen consumption $\left(\mathrm{VO}_{2} \max \right)$ is insensitive to $\mathrm{P}_{50}$ at all altitudes (from sea level to extreme altitude), such that neither a right nor left shift of the ODC will enhance or compromise $\mathrm{VO}_{2}$ max during maximal exercise. However, as altitude increases, $\mathrm{VO}_{2}$ max technically peaks at decreasing $\mathrm{P}_{50} \mathrm{~S}$, as the difference between arterial and venous $\mathrm{PO}_{2}$ decreases.

Animals that have adapted to hypoxic conditions generally have $\mathrm{Hb}$ with a higher affinity for $\mathrm{O}_{2}$ than other animals. It therefore seems that increased affinity is adaptive. Indeed, a number of human and animal studies have found that an increased $\mathrm{Hb}-\mathrm{O}_{2}$ affinity can be beneficial under hypoxic conditions. However, no such shift has been found before in the ODC of human blood measured under physiological acid-base conditions. 


\section{Statement of the Problem}

\subsection{Drawbacks of Measuring the ODC in vitro}

While in vitro methods of measuring the ODC, when used properly, yield consistent and reliable results, they may not accurately represent what is actually happening physiologically, even if the measurements are taken under naturally occurring conditions. The actual position of the curve depends on the metabolic and respiratory status at the time of measurement. The human body is dynamic and the changes that take place in one system are highly dependent on others, but the physiological integration of the body systems cannot be easily captured in a test tube. To understand how the body interacts with the environment, one must take a more systemic approach that reflects the conditions present in a breathing human that is continuously responding to changes in the internal and external environment.

The limited potential of in vitro measurement becomes even more important under non-standard conditions. This is because in vitro measurement imposes specific constraints on the blood, which may not be realistic, without accounting for other factors that may be present. For example, it has already been mentioned that ions may interact with $\mathrm{Hb}$ and affect its affinity for $\mathrm{O}_{2}$. Many diseases are associated with ion imbalances, which will affect the shape and position of the ODC. In vitro analysis of blood samples taken under disease conditions may not consider the physiological interactions of such ions with the $\mathrm{Hb}-\mathrm{O}_{2}$ relationship and may therefore ignore factors that play important roles in $\mathrm{SO}_{2}$. Further, environmental factors, such as altitude hypoxia, may influence the ODC in ways other than those that are reflected by in vitro methods. In vitro methods of measurement may not be sensitive to the acute and chronic changes that occur with altitude hypoxia, and predictive methods often completely ignore the effects of 2,3-DPG, increased at altitude, on the shape and position of the ODC. Illnesses such as high altitude sickness, high altitude pulmonary oedema and high altitude cerebral oedema, which occur with acute exposure to hypobaric hypoxia, may be related to shifts in the ODC. Characteristic in vivo data of the shifts of the ODC are necessary for the understanding of the development of such illnesses.

In addition to not providing a full picture of how changes in $\mathrm{PO}_{2}$ are reflected in $\mathrm{SO}_{2}$, in vitro methods of measuring the ODC require highly specialized equipment, which is expensive to buy and can be difficult to operate. Meanwhile, predictive methods, which are based upon in vitro 
data, are subject to large errors because they rely on the accuracy of one or two samples to be used with extrapolation. Therefore, an in vivo method for studying the ODC would more faithfully reflect the natural changes of $\mathrm{O}_{2}$ affinity of $\mathrm{Hb}$ with progressive hypoxia.

\subsection{Difficulty of Measuring the ODC in vivo}

$\mathrm{PCO}_{2}, \mathrm{PO}_{2}$, and ventilation are usually coupled in a breathing human (as depicted in Figure 3). For example, hypoxia causes an increase in ventilation, which is subsequently associated with increased $\mathrm{PO}_{2}$ as well as with decreased $\mathrm{PCO}_{2}$.

Figure 3: Coupling of $\mathrm{PO}_{2}$, Ventilation \& $\mathrm{PCO}_{2}$

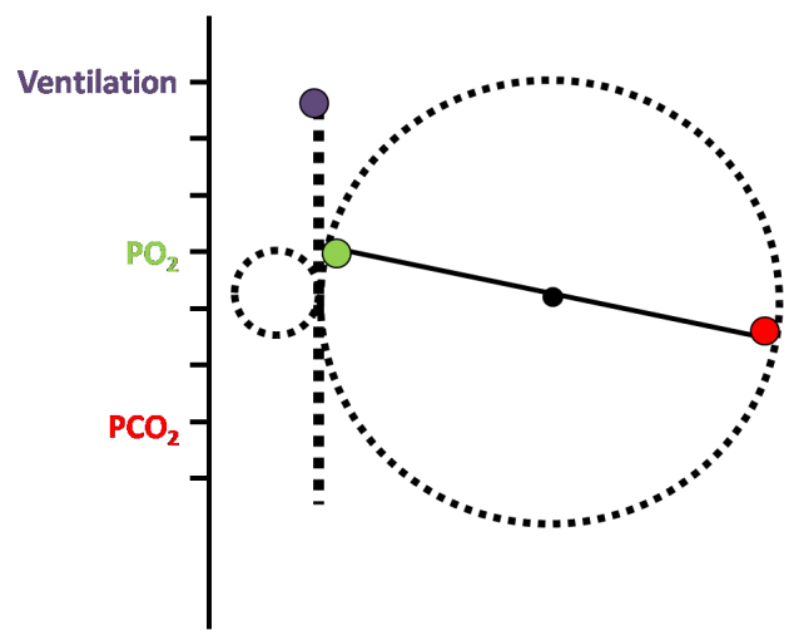

This coupling is what makes in vivo measurement of the ODC difficult; since $\mathrm{PCO}_{2}$ is known to shift the ODC via two mechanisms (through its effect on $\mathrm{pH}$ and through its direct effect on $\mathrm{Hb}$ ), a single ODC cannot be graphed unless $\mathrm{PCO}_{2}$ is kept constant at varying $\mathrm{PO}_{2}$ levels. Because $\mathrm{PCO}_{2}$ and $\mathrm{PO}_{2}$ are linked under normal in vivo conditions, such measurement cannot easily be done.

Without in vivo measurements of the ODC, it is not possible to gain a clear understanding of the shape and position of the ODC, either under normal conditions or those of physical or environmental stress. As well, because the different in vitro methods use different mechanisms for constraining the variables that affect the position and shape of the ODC, it is difficult to draw true conclusions from their data and to compare results from different studies. An in vivo method of measurement is therefore needed. 


\subsection{Using Prospective End-Tidal Targeting to Measure the ODC in vivo}

The problem of independent control of $\mathrm{PCO}_{2}$ and $\mathrm{PO}_{2}$ has been approached by researchers for almost 50 years. Early methods (Richardson et al., 1966; Weil et al., 1970) controlled inspired gas concentrations on a breath by breath basis in order to control end tidal values. Because these methods did not control for the effects of breathing frequency and tidal volume, they did not yield reliable end-tidal values for $\mathrm{PO}_{2}\left(\mathrm{PetO}_{2}\right)$ and $\mathrm{PCO}_{2}\left(\mathrm{PetCO}_{2}\right)$. More sophisticated methods of dynamic end-tidal forcing (Robbins et al., 1982) use new and improved algorithms to control $\mathrm{PetO}_{2}, \mathrm{PetCO}_{2}$ and ventilation independently of one another. However, these methods use high inspiratory flows and complex, expensive systems, so they are not suitable for use in clinical settings.

Our laboratory has developed a relatively portable, simple method and apparatus that can be used to prospectively target and control $\mathrm{PetCO}_{2}$ and $\mathrm{PetO}_{2}$ independently of each other and independently of the ventilatory response to $\mathrm{O}_{2}$ (Slessarev et al., 2007). Figure 4 depicts these variables dissociated.

Figure 4: Uncoupling of $\mathrm{PO}$, ventilation \& $\mathrm{PCO}_{2}$

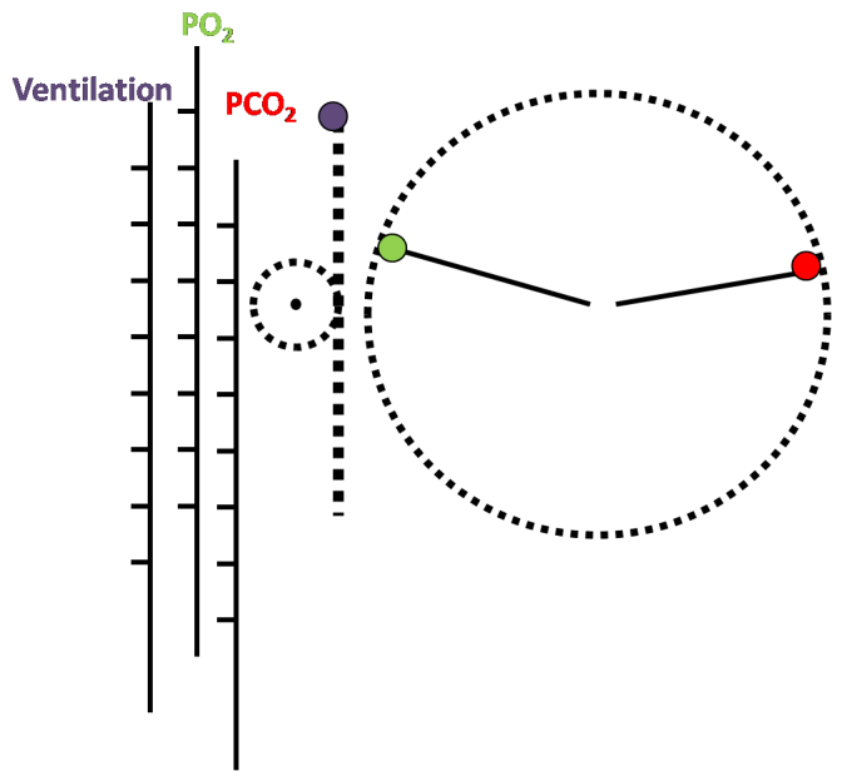

Prospective end-tidal targeting makes use of a gas-blending device, called the RespirAct ${ }^{\mathrm{TM}}$, in combination with a modified sequential gas delivery system. This system can be used to induce 
step changes in $\mathrm{PetCO}_{2}$ and $\mathrm{PetO}_{2}$, which take place in just a few breaths, independent of breathing rate or frequency. These changes can be sustained for the duration of a breathing sequence, within $\pm 2 \mathrm{mmHg}$. It has recently been shown that $\mathrm{PetCO}_{2}$ achieved while using this system is equal to arterial $\mathrm{PCO}_{2}\left(\mathrm{PaCO}_{2}\right)$ in healthy subjects (Ito et al., 2008). A full description of this method for prospective end-tidal targeting was described by Slessarev et al. (2007). A schematic of the system is pictured in the representation below, in Figure 5.

Figure 5: RespirAct ${ }^{\mathrm{TM}}$ Device and Breathing Circuit

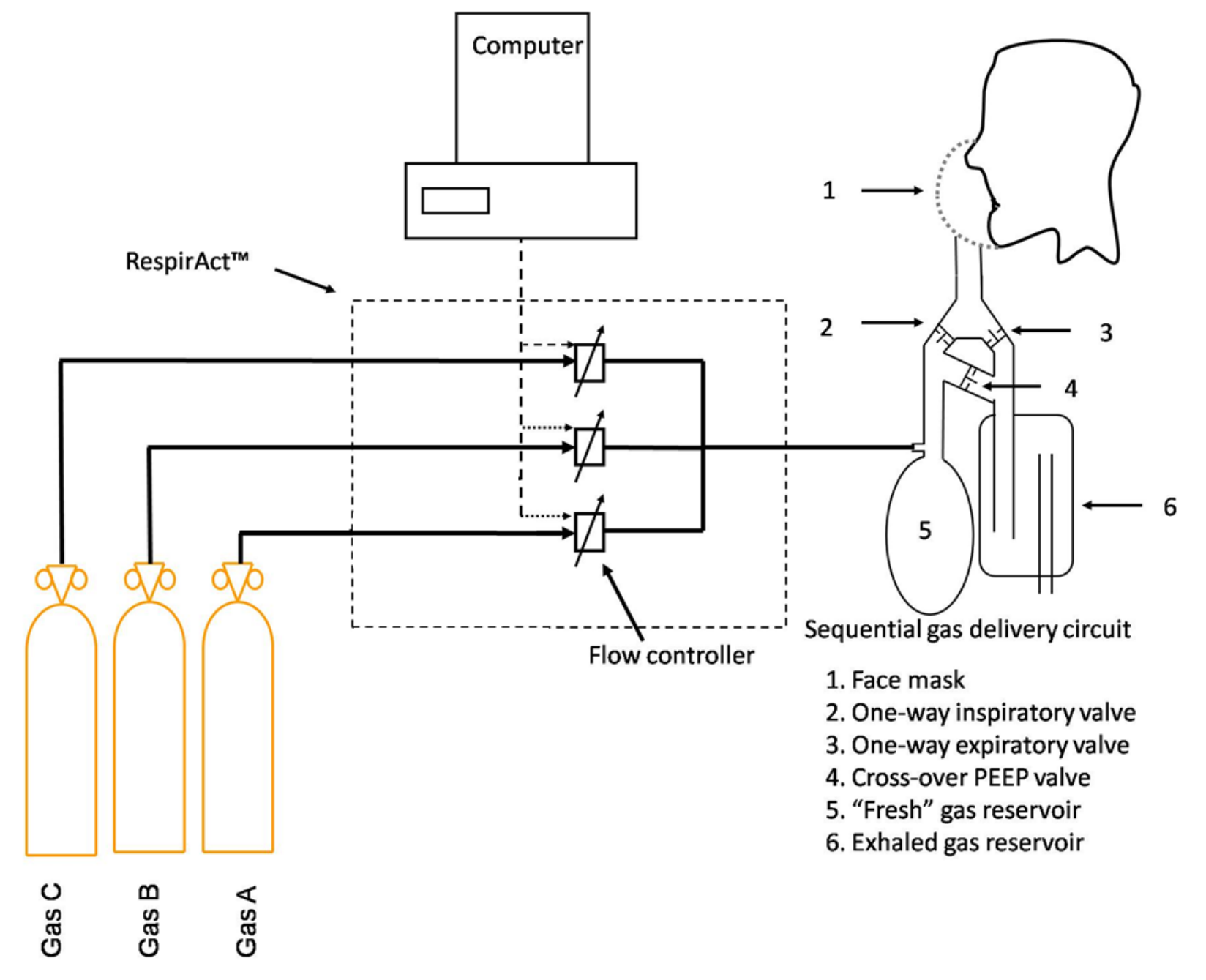

This method works by sequentially supplying the subject with a limited amount of fresh gas (from gas reservoir 5) followed by rebreathed gas (from gas reservoir 6), which is neutral with respect to gas exchange because it was previously exhaled and therefore equilibrated with the gas 
in the subject's lungs. Since this rebreathed gas does not contribute to gas exchange, only the fresh gas flow contributes to alveolar ventilation.

The sequential gas delivery circuit contains 3 one-way valves, which are used to control the flow of gas through the circuit. Expiration opens valve 3, a low-pressure valve, so the exhaled gas can enter the rebreathed gas reservoir (6) and the atmosphere. This valve closes upon inspiration, in which the negative inspiratory pressure initially opens valve 2, a low-pressure valve that controls the passage of gas from the fresh gas reservoir (5). Once the fresh gas reservoir collapses, further negative pressure opens valve 4, a cross-over valve, so the balance of the subject's breath is composed of previously rebreathed gas. Upon expiration the cycle repeats.

This system relies on the fact that alveolar ventilation is preset, so it can only be used to control end-tidal values when subjects consistently empty the fresh gas reservoir on every breath. Because any further inhalation does not affect gas exchange, subjects can breathe at any level beyond this minimum. It is for this reason that $\mathrm{PetCO}_{2}$ and $\mathrm{PetO}_{2}$ can be kept constant with this system, even with extreme hyperventilation.

The fresh gas flow is prospectively controlled by a computer in combination with the RespirAct ${ }^{\mathrm{TM}}$ gas blender. An algorithm in the computer takes into account the subjects $\mathrm{CO}_{2}$ production $\left(\mathrm{VCO}_{2}\right), \mathrm{O}_{2}$ consumption $\left(\mathrm{VO}_{2}\right)$, resting $\mathrm{PCO}_{2}$ and resting $\mathrm{PCO}_{2}$ (all which can be measured using the system) to maintain the subject's $\mathrm{PetCO}_{2}$ and $\mathrm{PetO}_{2}$ at predetermined values. This is done through fluctuations in fresh gas flow and through fluctuations in the amounts of each of the three input gases, which contain various combinations of $\mathrm{CO}_{2}, \mathrm{O}_{2}$ and nitrogen. 


\section{Research Aims and Hypotheses}

The ODC has not been previously studied in vivo because of the difficulty of controlling $\mathrm{PO}_{2}$ independently of $\mathrm{PCO}_{2}$ and independently of ventilation. We are the first laboratory to perform in vivo ODC mapping studies, using prospective end-tidal targeting. We hope that our method will eventually be helpful in understanding the role of the ODC in the development and effects of illness, both at sea level and high altitude.

\subsection{Aim One: Method Demonstration}

The first aim of this study is to demonstrate the ability to measure the ODC in vivo, using prospective end-tidal targeting. This will require the maintenance of normocapnia during progressive hypoxia. We will carry out this protocol in lowlanders at sea level as well as in lowlanders and highlanders at high altitude. We will also demonstrate the ability to shift the ODC in vivo by inducing progressive hypoxia while maintaining hypocapnia and hypercapnia in a sample of lowlanders at sea level. Based on the results of previous studies using prospective end-tidal targeting, we hypothesize that this method will allow the dissociation of $\mathrm{PetO}_{2}$ and $\mathrm{PetCO}_{2}$, such that $\mathrm{PetCO}_{2}$ may be kept constant during stepwise changes in $\mathrm{PetO}_{2}$ leading to progressive hypoxia. We also hypothesize that $\mathrm{PCO}_{2}$ can be maintained at hypocapnic and hypercapnic levels during a similar protocol, which will be carried out in lowlanders at sea level.

\subsection{Aim Two: Characterization of in vivo Curves and Comparison to in vitro Predictions}

The second aim of this study is to characterize physiological (at physiological $\mathrm{PCO}_{2}$ ) in vivo ODCs in lowlanders at sea level, lowlanders at high altitude, and native Andean highlanders at high altitude. We will also characterize the shifted in vivo curves (under conditions of hypocapnia and hypercapnia) in a group of lowlanders at sea level. Characterization will be done by calculating $\mathrm{P}_{50}, \mathrm{n}$ and $\mathrm{K}$ values for all subjects in each condition, using the Hill equation. It will also be done by comparing the $\mathrm{P}_{50} \mathrm{~s}$, $\mathrm{n}$ values and $\mathrm{K}$ values using the measured $\mathrm{SO}_{2}$ to those achieved by the Severinghaus and Kelman methods. We hypothesize that our data will fit the Hill equation and that we will be able to characterize our curves using $\mathrm{P}_{50}$, $\mathrm{n}$ and $\mathrm{K}$. We expect that our measured $\mathrm{SO}_{2}$ data will match the predicted $\mathrm{SO}_{2}$ data at sea level, though less so at lower saturations. This is because metabolic compensation for hypoxia will become 
influential in the lower ranges. These differences will be reflected in differences in $\mathrm{P}_{50}, \mathrm{n}$ and $\mathrm{K}$. At high altitude, we expect measured $\mathrm{SO}_{2}$ to be lower than predicted $\mathrm{SO}_{2}$. This is because [2,3DPG] increases at high altitude and decreases the $\mathrm{Hb}$ affinity for $\mathrm{O}_{2}$, but is not taken into account by these models. As a result, we expect that the $\mathrm{P}_{50} \mathrm{~S}$ of the subjects at high altitude using measured $\mathrm{SO}_{2}$ will be higher (right-shifted) than those achieved using the predicted $\mathrm{SO}_{2}$ values.

\subsection{Aim Three: Comparison of the in vivo ODC Across Experimental Groups}

The third aim of this study is to calculate and compare $\mathrm{P}_{50}$, $\mathrm{n}$ values and $\mathrm{K}$ values in lowlanders at sea level, lowlanders at high altitude and highlanders at high altitude. In vitro studies have found no shift of the physiological ODC at high altitude. This has been attributed to a balance between respiratory alkalosis and an increase in [2,3-DPG]. However, animals that are native to hypoxic environments have adapted by increasing their $\mathrm{Hb}$ affinity for $\mathrm{O}_{2}$. We therefore expect to find a leftward shift of the in vivo ODC in both groups of subjects at high altitude as compared to the position of the in vivo ODC in lowlanders at sea level. 


\section{Methods}

This study consists of four experiments that were conducted in different populations. The four groups underwent similar protocols, with differences only in the details. The four experiments were:

- Experiment 1: Lowlanders at sea level (at normocapnia)

- Experiment 2: Lowlanders at sea level (at hypocapnia, normocapnia and hypercapnia)

- Experiment 3: Lowlanders at $3600 \mathrm{~m}$ for two weeks (at normocapnia)

- Experiment 4: Native Andeans at $3600 \mathrm{~m}$ (at normocapnia)

\subsection{Subjects}

\subsubsection{Experiments $1 \& 2$}

Subjects in Experiment 1 were 13 healthy sea level residents ( 5 females), between the ages of 21 and 35. Subjects in Experiment 2 were 19 healthy sea level residents ( 8 females). Subjects were recruited by the means of ads placed on the campus of Duke University in Duke Hospital North and South Clinics. They contacted a study coordinator, who booked a screening session in which subjects were briefed about the requirements and risks of the study and tested for eligibility. The study took place on the campus of Duke University.

Exclusion criteria included allergies to lidocaine or heparin, haemoglobinopathy or gastroesophageal reflux, history of or anatomy suggestive of difficult airways, $\mathrm{Hb}<.12$, platelets $<150,000$, Hepatitis A, Hepatitis B, Hepatitis C, HIV, pregnancy, cardiac or pulmonary disease, coagulation abnormalities, tobacco, drugs or alcohol abuse, hypertension, abnormal electrocardiogram results, abnormal pulmonary function test results, abnormal diffusion capacity of the lung for carbon monoxide, abnormal arterial blood gases or any other conditions that would potentially increase subject risk.

Subjects who completed the study were reimbursed monetarily.

Anthropometric data for each subject in Experiments 1 and 2 are shown below, in Table 1 and Table 2. 
Table 1: Anthropometric Data for Subjects in Experiment 1

\begin{tabular}{llllll}
\hline Subject & Age & Sex & Ethnicity & Weight $(\mathbf{K g})$ & Height $(\mathbf{c m})$ \\
\hline $\mathbf{2 1}$ & 25 & F & Caucasian & 59.3 & 173 \\
$\mathbf{2 2}$ & 25 & M & Caucasian & 93.7 & 180 \\
$\mathbf{2 3}$ & 21 & M & African American & 80.5 & 178 \\
$\mathbf{2 4}$ & 29 & M & Caucasian & 85.3 & 180 \\
$\mathbf{2 5}$ & 23 & M & Caucasian & 72.5 & 172 \\
$\mathbf{2 6}$ & 24 & F & Caucasian & 57.2 & 168 \\
$\mathbf{2 7}$ & 21 & F & Caucasian & 58.4 & 155 \\
$\mathbf{2 8}$ & 21 & F & Caucasian & 56.5 & 162 \\
$\mathbf{2 9}$ & 34 & M & African American & 95.3 & 177 \\
$\mathbf{3 1}$ & 21 & M & Caucasian & 90.7 & 183 \\
$\mathbf{3 2}$ & 22 & M & Caucasian & 77.1 & 175 \\
$\mathbf{3 3}$ & 22 & F & African American & 58.9 & 157 \\
$\mathbf{3 4}$ & 22 & M & Caucasian & 79.4 & 172 \\
\hline
\end{tabular}


Table 2: Anthropometric Data for Subjects in Experiment 2

\begin{tabular}{llllll}
\hline Subject & Age & Sex & Ethnicity & Weight $\mathbf{( K g )}$ & Height $(\mathbf{c m})$ \\
\hline $\mathbf{1}$ & 26 & M & Caucasian & 67.4 & 183 \\
$\mathbf{3}$ & 21 & F & Caucasian & 56.6 & 163 \\
$\mathbf{5}$ & 24 & F & African American & 67.9 & 170 \\
$\mathbf{6}$ & 31 & M & Caucasian & 98.1 & 188 \\
$\mathbf{7}$ & 24 & F & Caucasian & 61.5 & 165 \\
$\mathbf{8}$ & 32 & M & Caucasian & 99.5 & 180 \\
$\mathbf{9}$ & 28 & M & Hispanic & 58.8 & 165 \\
$\mathbf{1 0}$ & 26 & F & Asian - Pacific Islander & 72.4 & 163 \\
$\mathbf{1 1}$ & 27 & M & Caucasian & 83.3 & 183 \\
$\mathbf{1 2}$ & 22 & M & Caucasian & 77.8 & 191 \\
$\mathbf{1 3}$ & 35 & F & Caucasian & 63.8 & 170 \\
$\mathbf{1 4}$ & 23 & F & Asian - Pacific Islander & 74.7 & 178 \\
$\mathbf{1 5}$ & 29 & M & Caucasian & 81.4 & 180 \\
$\mathbf{1 6}$ & 25 & M & Caucasian & 75.1 & 182 \\
$\mathbf{1 7}$ & 21 & M & Caucasian & 90.4 & 182 \\
$\mathbf{1 9}$ & 21 & M & Caucasian & 72.3 & 177 \\
$\mathbf{2 0}$ & 34 & M & African American & 94.3 & 177 \\
$\mathbf{2 1}$ & 24 & F & Caucasian & 56.5 & 167 \\
$\mathbf{2 2}$ & 25 & F & Caucasian & 58.8 & 165 \\
\hline
\end{tabular}

\subsubsection{Experiment 3}

Subjects were 6 healthy sea-level residents ( 2 females), who were taken to La Paz, Bolivia (3600 m) and tested at high altitude after two weeks of exposure to hypoxia. Due to the difficulty in bringing subjects to altitude, all of them also acted as co-investigators in the study. As such, they were not blind regarding the purposes and hypotheses of the experiment. Participation was strictly voluntary and the subjects were not compensated for their participation. However, they were reimbursed for any out of pocket expenses. All subjects were healthy, with no history of cardiopulmonary abnormalities or disease. None of the subjects exhibited acute altitude sickness.

Anthropometric data for each subject in Experiment 3 are shown below in Table 3. 
Table 3: Anthropometric Data for Subjects in Experiment 3

\begin{tabular}{llllll}
\hline Subject & Age & Sex & Ethnicity & Weight $(\mathbf{K g})$ & Height $(\mathbf{c m})$ \\
\hline $\mathbf{1}$ & 26 & F & Caucasian & 61 & 172 \\
$\mathbf{2}$ & 32 & M & Caucasian & 73 & 170 \\
$\mathbf{3}$ & 22 & F & Caucasian & 44 & 150 \\
$\mathbf{4}$ & 30 & M & Caucasian & 84 & 188 \\
$\mathbf{5}$ & 60 & M & Caucasian & 80 & 180 \\
$\mathbf{6}$ & 26 & M & Caucasian & 90 & 184 \\
\hline
\end{tabular}

\subsubsection{Experiment 4}

Subjects in this study were 8 healthy residents of high altitude ( 2 females) native to La Paz, Bolivia or the surrounding highlands of El Alto. They were recruited and screened by our collaborators in Bolivia, who run a clinic in La Paz that specializes in treatment of patients with altitude-related illness. Specific exclusion criteria included history of cardiopulmonary abnormalities, fingertip clubbing, and hematocrit $>50$. Subjects were not included if they exhibited any health risks or abnormalities that may have put them at risk or influenced the outcome of the study. Subjects received monetary remuneration for participation in the study of an amount that was appropriate by Bolivian standards.

Anthropometric data for each subject in Experiment 4 are shown below in Table 4.

\section{Table 4: Anthropometric Data for Subjects in Experiment 4}

\begin{tabular}{llllll}
\hline Subject & Age & Sex & Ethnicity & Weight $\mathbf{( K g )}$ & Height $(\mathbf{c m})$ \\
\hline $\mathbf{1}$ & 46 & M & South Amerindian & 70 & 160 \\
$\mathbf{2}$ & 41 & M & South Amerindian & 62 & 169 \\
$\mathbf{3}$ & 33 & M & South Amerindian & 70 & 160 \\
$\mathbf{4}$ & 30 & M & South Amerindian & 60 & 145 \\
$\mathbf{5}$ & 26 & F & South Amerindian & 56 & 150 \\
$\mathbf{6}$ & 50 & F & South Amerindian & missing & missing \\
$\mathbf{8}$ & 26 & M & South Amerindian & 60 & 169 \\
$\mathbf{9}$ & 34 & F & South Amerindian & 58 & 150 \\
\hline
\end{tabular}

\subsection{Informed Consent}

Consent was collected as per the requirements of the research ethics boards at Duke University, at the University Health Network in Toronto and in Bolivia. All participants in all experiments 
were briefed about the goals and procedures of the study and gave written informed consent before study participation. For those who spoke only Spanish, the consent form was verbally translated and then signed. Subjects were advised that there were no inherent benefits of participation in this study, and that the only benefit would be contribution to the existing knowledge-base.

\subsection{Risks}

All study participants were assessed prior to testing, in order to confirm that they did not exhibit any of the exclusion criteria, which would have increased study risks.

\subsubsection{Hypoxia}

The oxyhaemoglobin saturation range between 60 and 100\% is well tolerated and safe in most otherwise healthy people. At altitude of about $4500-6000 \mathrm{~m}, \mathrm{SO}_{2}$ typically ranges from 75 to $65 \%$. In those that climb higher (Mt. Everest is at $8000 \mathrm{~m}$ ) $\mathrm{SO}_{2}$ is even lower. $\mathrm{SO}_{2}$ in the range of $100-70 \%$ is frequently used in experimental protocols. At $\mathrm{O}_{2}$ concentrations resulting in $\mathrm{SO}_{2}$ approaching $65 \%$ with fixed $\mathrm{PCO}_{2}$, some subjects may experience shortness of breath and even some distress. In that case, the experiment was terminated and subject given $100 \% \mathrm{O}_{2}$. This terminated the distress within 2-3 breaths. Additionally, $\mathrm{SO}_{2}$ was continuously monitored with a

pulse oximeter (yielding $\mathrm{SpO}_{2}$ ). If $\mathrm{SpO}_{2}$ fell below $70 \%$, the study was immediately terminated and the subject received $100 \% \mathrm{O}_{2}$. Non invasive blood pressure and heart rate were also monitored throughout the study, and the study was terminated if the protocol was deemed too stressful. Decreased consciousness or alertness was immediately treated with $100 \% \mathrm{O}_{2}$.

\subsubsection{Arterial Blood Sampling}

Puncture of a radial artery to sample arterial blood is performed ubiquitously throughout the world and is considered a safe procedure. The discomfort of the puncture depends partly on the skill of the person drawing the blood and the size of the needle. In this study the arterial puncture was performed by anaesthesiologists who have performed thousands of such punctures over about 30 years. The puncture was performed using a smaller needle $(25 \mathrm{G})$ than is commonly used clinically (20 G) so as to lessen the discomfort. 


\subsection{Measurement Devices}

\subsubsection{Arterial Blood Gases (ABG)}

In Experiments 1 and 2, haematological parameters were analyzed using the Instrumentation Laboratory GEM Premier 4000, using cartridges with the part number 00027445008.

In Experiments 3 and 4, haematological parameters were analyzed using the i-STAT (Abbott Point of Care, Illinois, USA), a handheld, portable system. EC3+ cartridges were used to get baseline sodium $(\mathrm{Na})$, potassium $(\mathrm{K})$, hematocrit $(\mathrm{Hct})$ and $\mathrm{Hb}$ (calculated) in all subjects in Experiment 4 and two subjects in Experiment 3. For all subjects in Experiment 4 and two subjects in Experiment 3 the CG4+ cartridges were used to analyze blood samples. This cartridge measures $\mathrm{pH}, \mathrm{PCO}_{2}$ and $\mathrm{PO}_{2}$ and calculates total $\mathrm{CO}_{2}\left(\mathrm{TCO}_{2}\right)$, base excess $(\mathrm{BE}), \mathrm{HCO}_{3}{ }^{-}$ and $\mathrm{SO}_{2}$. For the other 4 subjects in Experiment 3, EC8+ cartridges were used. This cartridge measures $\mathrm{Na}, \mathrm{K}, \mathrm{Cl}$, urea nitrogen (BUN), glucose, $\mathrm{Hct}$, $\mathrm{pH}, \mathrm{PCO}_{2}, \mathrm{HCO}_{3}{ }^{-}, \mathrm{BE}$ (calculated), anion gap and $\mathrm{Hb}$ (calculated). $\mathrm{PO}_{2}$ was measured separately by Radiometer $\mathrm{PhMK} 2$ (Radiometer Co., Copenhagen, Denmark). Values with this device were equivalent to those measured by the i-STAT.

\subsubsection{Measured $\mathrm{SO}_{2}$}

In Experiments 1 and 2, $\mathrm{SaO}_{2}$ was measured by the co-oximeter in the Instrumentation Laboratory GEM Premier 4000. $\mathrm{SpO}_{2}$ was also measured by means of a pulse oximeter, which analyzes the pattern of absorption/transmission of infra-red light through a finger or ear lobe to determine non-invasive peripheral $\mathrm{SO}_{2}$. The device used in Experiments 1 and 2 was the Conmed $\mathrm{PRO}_{2}$ Monitor (Conmed, Utica, NY, USA), from which the data were continuously recorded. Only co-oximeter measurements were used for data analysis in these experiments because the co-oximeter provided direct invasive measurement of $\mathrm{SaO}_{2}$ in each blood sample and was therefore the most accurate measurement available. We did not have access to a cooximeter in Bolivia, where Experiments 3 and 4 were carried out. As such, a finger pulse oximeter, the Onyx II 9550 (Nonin Medical, Inc., Plymouth MN), was used to measure $\mathrm{SpO}_{2}$ in lieu of $\mathrm{SaO}_{2}$ in these experiments. This device is stated as accurate within $\pm 2 \%$ (this is the root mean square difference between the $\mathrm{SpO}_{2}$ values and reference $\mathrm{SaO}_{2}$ values from a co-oximeter) in the saturation range between $70-100 \%$. 


\subsubsection{Blood Pressure}

In Experiments 1 and 2 invasive blood pressure was measured continuously by a Propaq CS (Welch Allyn, Skaneateles Falls, NY, USA). In Experiments 3 and 4 non-invasive blood pressure (NIBP) was measured using an arm cuff, which inflated every minute. NIBP data was recorded manually.

\subsubsection{Heart Rate $(\mathrm{HR})$}

In all experiments, HR was measured non-invasively using pulse oximeters. In Experiments 1 and 2 the Conmed $\mathrm{PRO}_{2}$ Monitor (Conmed, Utica, NY, USA) was used and continuously recorded. In Experiments 3 and 4 the Onyx II was used. This information was recorded by hand at the time of blood sampling in Experiments 3 and 4.

\subsubsection{End Tidal $\mathrm{PCO}_{2}\left(\mathrm{PetCO}_{2}\right)$ and End Tidal $\mathrm{PO}_{2}\left(\mathrm{PetO}_{2}\right)$}

$\mathrm{PetCO}_{2}$ and $\mathrm{PetO}_{2}$ were continuously measured from a sampling port in the mask of the subject's sequential gas delivery system, using sensors in the RespirAct ${ }^{\mathrm{Tm}}$. The $\mathrm{CO}_{2}$ sensor within the RespirAct $^{\mathrm{TM}}$ (Ir3107, Servomex Group Ltd, Sugar Land, TX, USA) is accurate to within $\pm 0.1 \%$ of the $\mathrm{CO}_{2}$ within the range of $0-10 \% \mathrm{CO}_{2}$. The $\mathrm{O}_{2}$ sensor (UFO 130, Teledyne Analytical Instruments, City of Industry, CA, USA) is accurate within 1\%. Both sensors were calibrated, according to specifications, at least once a day, or between each subject. A computer program (Labview, National Instruments, Austin, TX, USA) was used to display these $\mathrm{PetCO}_{2}$ and $\mathrm{PetO}_{2}$ on a screen throughout testing. Breath-by-breath values were calculated by the program and displayed as well. The raw data and breath-by-breath values were continuously recorded.

\subsection{Experimental Protocol}

\subsubsection{Subject Setup (common to all subjects)}

A catheter and arterial line was inserted into the subject's radial artery, and a blood sample was taken and analyzed to get resting, baseline data. The pulse oximeter was placed on the index or middle finger of the hand with the arterial line. The modified sequential gas delivery apparatus was then affixed to the subject's face using Tagederm opsite (3M, London, ON, Canada), which prevented air from leaking in or out of the mask. Before any tests were started, the subject was allowed to sit for 5-10 minutes in order to acclimatize to wearing the mask. During this time, the 
subject either breathed room air (by opening the port in the mask) or medical air (the equivalent of dry room air, from compressed gas cylinders) with a flow greater than the subject's alveolar ventilation, according to the subject's preference. The subject was told to relax and breathe at a level of ventilation that was most comfortable.

\subsubsection{Equipment Setup (common to all subjects)}

The subject's age, height and weight were entered into the computer program. A computer algorithm was used to automatically compute $\mathrm{VCO}_{2}$ and $\mathrm{VO}_{2}$ from these parameters. Once the subject began breathing into the sequential gas delivery system, $\mathrm{PetO}_{2}$ and $\mathrm{PetCO}_{2}$ were measured over ten breaths using the RespirAct ${ }^{\mathrm{TM}}$ software. These values were saved to the RespirAct ${ }^{\mathrm{TM}}$ program.

\subsubsection{Experiment 1}

The subject was told to get as comfortable as possible while semi-reclining on a bed. Once the subject's breathing became steady, a test sequence was run with the RespirAct ${ }^{\mathrm{TM}}$. This test sequence had two purposes: to determine the subject's tolerance for hypoxia and to determine whether the estimated $\mathrm{VO}_{2}$ and $\mathrm{VCO}_{2}$ were correct. This sequence involved maintaining $\mathrm{PetCO}_{2}$ at $40 \mathrm{mmHg}$ while targeting a series of $\mathrm{PetO}_{2}$ steps, starting at $100 \mathrm{mmHg}$, leading to a minimum of $35 \mathrm{mmHg}$. Each step lasted approximately 1 minute in length. If the subject's end tidal values were not stable at the targeted values, the resting parameters $\left(\mathrm{VCO}_{2}, \mathrm{VO}_{2}\right.$, resting $\mathrm{PetCO}_{2}$ and resting $\mathrm{PetO}_{2}$ ) were adjusted accordingly. The subject was told to indicate as soon as the test became too uncomfortable. If the $\mathrm{PetO}_{2}$ at that point was above $35 \mathrm{mmHg}$, this value was then used as the minimum $\mathrm{PetO}_{2}$ during testing. Once the proper resting values and the minimum $\mathrm{PetO}_{2}$ were determined, the experiment commenced.

The protocol was initiated with baseline measurements followed by the study protocol. The delivered gas mixture was adjusted by the RespirAct ${ }^{\mathrm{TM}}$ to maintain a $\mathrm{PetCO}_{2}$ of $40 \pm 3 \mathrm{mmHg}$, while progressively decreasing $\mathrm{PetO}_{2}$ from $100 \mathrm{mmHg}$ to a predetermined minimum value (either $35 \mathrm{mmHg}$ or the lowest value above $35 \mathrm{mmHg}$ that would be tolerated by the subject). Once the minimum value was achieved, $\mathrm{PetO}_{2}$ was progressively brought back to $100 \mathrm{mmHg}$ in a manner that mirrored the steps taken to bring the subject from $\mathrm{PetO}_{2}$ of $100 \mathrm{mmHg}$ to that of the minimum value. This was done in 9 steps (e.g. 100, 60, 45, 40, 35, 40, 45, 60, $100 \mathrm{mmHg}$ ), 
for which the target values depended on what the minimum $\mathrm{PetO}_{2}$ would be. In those who had low tolerance to hypoxia, the minimum $\mathrm{PetO}_{2}$ was increased (e.g. to $42 \mathrm{mmHg}$ ) but the number of steps was kept constant, such that the $\mathrm{PetO}_{2}$ increments were smaller. The protocol was followed by the administration of $100 \%$ oxygen. The subject was then allowed to rest while breathing room air, to allow $\mathrm{PetCO}_{2}, \mathrm{PetO}_{2}$ and $\mathrm{SpO}_{2}$ to return to baseline levels.

Each step lasted 4 minutes. During the last 30 seconds of each $\mathrm{PetO}_{2}$ step one arterial sample was taken. All blood samples were analyzed immediately by co-oximetry. $\mathrm{PetO}_{2}, \mathrm{PetCO}_{2}$ and $\mathrm{SpO}_{2}$ were continuously measured and automatically recorded.

Upon completion of the study all catheters were removed and sites inspected for haematoma. Pressure dressing was applied to the radial arterial catheter site.

\subsubsection{Experiment 2}

The subject was told to get as comfortable as possible while semi-reclining on a bed. Once the subject's breathing became steady, a test sequence was run with the RespirAct ${ }^{\mathrm{TM}}$. This test sequence had two purposes: to determine the subject's tolerance for hypoxia and to determine whether the estimated $\mathrm{VO}_{2}$ and $\mathrm{VCO}_{2}$ were correct. This sequence involved maintaining $\mathrm{PetCO}_{2}$ at $40 \mathrm{mmHg}$ while targeting a series of $\mathrm{PetO}_{2}$ steps, starting at $100 \mathrm{mmHg}$, leading to a minimum of $35 \mathrm{mmHg}$. Each step lasted approximately 1 minute in length. If the subject's end tidal values were not stable at the targeted values, the resting parameters were adjusted accordingly. The subject was told to indicate as soon as the test became too uncomfortable. If the $\mathrm{PetO}_{2}$ at that point was above 35 , this value was then used as the minimum $\mathrm{PetO}_{2}$ during testing. Once the proper resting values and the minimum $\mathrm{PetO}_{2}$ were determined, the experiment commenced.

The protocol started with baseline measurements followed by two study stages. For the first study stage the delivered gas mixture was adjusted by the RespirAct ${ }^{\mathrm{TM}}$ to maintain a $\mathrm{PetCO}_{2}$ of $40 \pm 3 \mathrm{mmHg}$, while reducing $\mathrm{SpO}_{2}$ in increments of approximately $5 \%$ from baseline of 95 $100 \%$ (e.g. $95 \%, 90 \%, 85 \%, 80 \%, 75 \%$ and $70 \%$ ). This was done using a series of $\mathrm{PetO}_{2}$ targets (e.g. $100,80,60,48,42,38,35 \mathrm{mmHg}$ ). In those who had low tolerance to hypoxia, the minimum $\mathrm{PetO}_{2}$ was increased (e.g. to $42 \mathrm{mmHg}$ ) but the number of steps was kept constant, such that the $\mathrm{SpO}_{2}$ increments were smaller. After the last hypoxic step an ascent to room air was carried out to return the $\mathrm{SpO}_{2}$ to $100 \%$. This was followed by the administration of $100 \%$ 
oxygen. The subject was then allowed to rest while breathing room air (by removing the plug from the mask) for 10 minutes before starting the second stage of the study, to allow $\mathrm{PetCO}_{2}$, $\mathrm{PetO}_{2}$ and $\mathrm{SpO}_{2}$ to return to baseline levels.

For the second stage of the study, the delivered gas mixture was adjusted to provide descending $\mathrm{SpO}_{2}$ steps, this time in $10 \%$ increments, using a series of $\mathrm{PetO}_{2}$ targets (eg. 100, 60, 42, 35 $\mathrm{mmHg}$ ). At each step there were two sub-steps to provide a $\mathrm{PetCO}_{2}$ of 35 and $45 \mathrm{mmHg}$. The $70 \% \mathrm{SpO}_{2}$ step was followed by a return to baseline $\mathrm{SpO}_{2}$ and then administration of $100 \%$ oxygen.

Each step lasted 3 minutes. During the last 30 seconds of each step of progressive hypoxia, two arterial samples were taken. All blood samples were analyzed immediately by co-oximetry. $\mathrm{PetO}_{2}, \mathrm{PetCO}_{2}$ and $\mathrm{SpO}_{2}$ were continuously measured and automatically recorded.

Upon completion of the study all catheters were removed and sites inspected for haematoma. Pressure dressing was applied to the radial arterial catheter site.

\subsubsection{Experiments 3 and 4}

The subject was seated comfortably in an armchair. Once the subject's breathing became steady, the experimental sequence was started. This sequence entailed the maintenance of $\mathrm{PCO}_{2}$ at the subject's resting level (as determined from the arterial sample) during progressive hypoxia. There were $6 \mathrm{PO}_{2}$ targets, 100, 70, 60, 50, 40, $35 \mathrm{mmHg}$. If $\mathrm{PCO}_{2}$ or $\mathrm{PO}_{2}$ drifted up or down during the sequence or if the targets were not hit, the test was aborted and the subject's parameters $\left(\mathrm{VCO}_{2}, \mathrm{VO}_{2}\right.$, resting $\mathrm{PetO}$ and resting $\left.\mathrm{PetCO}_{2}\right)$ were adjusted in order to correct for the problem. The sequence was then restarted and completed. The test ended when saturation fell below $70 \%$ or when the subject felt too uncomfortable to continue. Each $\mathrm{PetO}_{2}$ step was 2 minutes in length, and a blood sample was drawn at the end of each step. $\mathrm{PetCO}_{2}$ and $\mathrm{PetO}_{2}$ were continuously measured and recorded during testing. $\mathrm{SpO}_{2}, \mathrm{HR}$ and $\mathrm{BP}$ were manually recorded when blood samples were drawn, at the end of each $\mathrm{PetO}_{2}$ step. 


\subsection{Data Analysis}

\subsubsection{Comparing Subjects across Experimental Group}

Control haematological values $\left(\mathrm{pH}, \mathrm{PCO}_{2}, \mathrm{PO}_{2}, \mathrm{BE}, \mathrm{HCO}_{3}{ }^{-}\right.$, $\mathrm{Hct}$ and $\mathrm{Hb}$ ) were collected for each subject. One-way ANOVA tests with an alpha level of 0.05 were used to compare these parameters across experimental groups in order to characterize the differences between the lowlanders at sea level (all were put into one group, since they came from the same population), lowlanders at high altitude and native Andeans at high altitude. Tukey pair-wise tests were used for post-hoc analysis.

\subsubsection{Method Demonstration}

\subsubsection{Stability and Control of $\mathrm{PCO}_{2}$ and $\mathrm{pH}$}

$\mathrm{PCO}_{2}$ and $\mathrm{pH}$ are known to affect the position of the ODC. $\mathrm{PCO}_{2}$ is one variable that influences $\mathrm{pH}$, but $\mathrm{pH}$ can still change independently of changes in $\mathrm{PCO}_{2}$. Our method of measuring the ODC has means of controlling $\mathrm{PCO}_{2}$. However, the efficacy of the device in maintaining $\mathrm{PCO}_{2}$ at the desired level is dependent on the diligence and ability of the operator. If $\mathrm{PCO}_{2}$ is not maintained at a single level throughout a test, the resulting saturations may not fall on a single ODC. Similarly, if $\mathrm{PCO}_{2}$ is not maintained at similar levels between subjects, it will be difficult to define the effect of $\mathrm{PCO}_{2}$ on the in vivo ODC. $\mathrm{pH}$ cannot be controlled by the RespirAct ${ }^{\mathrm{TM}}$ independently of $\mathrm{PCO}_{2}$. $\mathrm{pH}$ variability also influences the ability to graph a single ODC, so it was measured throughout the experiment. In order to determine the efficacy of our method for measuring the $\mathrm{ODC}, \mathrm{PCO}_{2}$ and $\mathrm{pH}$ variability were tracked throughout each subject's data. Average and standard deviation of both variables for all subjects have been reported. We also reported the $\mathrm{PetO}_{2}$ and $\mathrm{PetCO}_{2}$ stability during the last $60 \mathrm{~s}$ of each $\mathrm{PO}_{2}$ step during testing at high altitude, as well as the $\mathrm{PetCO}_{2}$ stability throughout testing for these same subjects. Such data is not available for the lowlanders at sea level, but similar variability is expected.

\subsubsection{Minimum $\mathrm{PO}_{2}$}

Because the ODC has a sigmoidal shape, the steep part of the curve is that which is most important. In order to characterize the curve, it is therefore imperative to achieve a number of $\mathrm{PaO}_{2}$ values that fall on the steep part of the ODC. If $\mathrm{PaO}_{2}$ is not reduced enough in the 
protocol, there may not be sufficient information to characterize the curve. It is for this reason that the minimum $\mathrm{PaO}_{2}$ values achieved have been reported for each subject in each condition.

\subsubsection{Number of $\mathrm{PO}_{2}$ Steps/Number of Blood Samples}

Our in vivo ODCs were constructed by linearizing a number of $\mathrm{PaO}_{2} / \mathrm{SO}_{2}$ data pairs for each subject and finding the parameters of the line that best fits the data using the Hill Equation (Equation 12). The process by which this was done will be explained, in detail, below. The more data pairs that are available, the better the line of best fit will represents the data. We have therefore presented the number of $\mathrm{PO}_{2}$ steps or blood samples for each subject.

\subsubsection{Comparison of Measured $\mathrm{SO}_{2}$ with Calculated $\mathrm{SO}_{2}$}

One of the aims of this study is to compare our in vivo method to previously used in vitro methods, by comparing our measured saturations to those predicted by some of the models that were created from in vitro data. There were two models chosen for the sake of this comparison, that of Severinghaus and that of Kelman. These models will be shown, in detail, below. $\mathrm{SO}_{2}$ was calculated using each of the two models, and results were compared graphically. Scatter plots were used to compare Measured $\mathrm{SO}_{2}$ and Severinghaus $\mathrm{SO}_{2}$ for each of the four experimental groups, and a second set of scatter plots were used to compare Measured $\mathrm{SO}_{2}$ and Kelman $\mathrm{SO}_{2}$ for each of the four groups. Bland and Altman difference plots were also used to separately compare all Measured $\mathrm{SO}_{2}$ values to all Severinghaus values and all Measured $\mathrm{SO}_{2}$ values to all Kelman values. The Bland and Altman plots show the bias and $95 \%$ confidence intervals for each set of data.

\subsubsection{Severinghaus $\mathrm{SO}_{2}$}

The Severinghaus (1979) model was chosen because it is widely used to predict saturation from blood gas measurements. It is a modification of the Hill equation that has been reported as being accurate within $0.55 \%$. The Severinghaus equation (Equation 7) calculates $\mathrm{SO}_{2}$ from $\mathrm{PO}_{2}$ under standard conditions ( $\mathrm{pH}$ of 7.4 and $\mathrm{T}$ of $\left.37^{\circ}\right)$.

\section{Equation 7}

$$
\mathrm{SO}_{2}=100 \div\left[1+\left(\frac{23400}{\left(\mathrm{PO}_{2}\right)^{3}+\left(150 \times \mathrm{PO}_{2}\right)}\right)\right] \%
$$


where $\mathrm{PO}_{2}$ is the partial pressure of $\mathrm{O}_{2}$ in $\mathrm{mmHg}$.

However, most measurements are not made under standard conditions. Severinghaus therefore provided an alternate form of the equation that takes into account the Bohr Effect, factoring in the difference between the in vivo $\mathrm{pH}$ and standard $\mathrm{pH}$. His adjustment for the Bohr Effect takes into account the changes in the ODC due to both $\mathrm{pH}$ and $\mathrm{PCO}_{2}$. When the Bohr Effect is present, the above equation is used, but $\mathrm{PO}_{2}$ is substituted with Equation 8:

\section{Equation 8}

$$
P O_{2} \times e^{\left[\left(\left(\frac{P O_{2}}{26.7}\right)^{0.184}+0.003 \times B E-2.2\right) \times(7.4-p H)\right]}
$$

If base excess cannot be directly measured, it can be derived using an equation from Sigaard Andersen (Equation 9).

\section{Equation 9}

$$
B E=[1-(0.014 \times t H b)] \times\left[H_{C O}^{-}-24.8+(1.43 \times t H b+7.7) \times(p H-7.4)\right]
$$

where $\mathrm{THb}$ is the total concentration of $\mathrm{Hb}(\mathrm{g} / \mathrm{dL})$ and $\mathrm{HCO}_{3}{ }^{-}(\mathrm{mmol} / \mathrm{L})$ is the concentration of bicarbonate.

These equations were also used by our co-oximeter to calculate $\mathrm{SO}_{2}$ in Experiments 1 and 2.

\subsubsection{Kelman $\mathrm{SO}_{2}$}

The other model that was used with our data is that of Kelman (1966). This model preceded that of Severinghaus. It is robust because it uses $\mathrm{PO}_{2}, \mathrm{PCO}_{2}, \mathrm{~T}$ and $\mathrm{pH}$ to calculate a "virtual $\mathrm{PO}_{2}$," which it then uses to predict saturation. It is a popular model because it allows for easy calculation of $\mathrm{SO}_{2}$ and is thus very convenient. This is a mathematical model in which coefficients were found by using the least squares method on a data set containing 38 pairs of $\mathrm{PO}_{2} / \mathrm{SO}_{2}$ data. The model equation is shown in Equation 10. 


\section{Equation 10}

$$
S O_{2}=\frac{100 \times\left(a_{1} x+a_{2} x^{2}+a_{3} x^{3}+x^{4}\right)}{\left(a_{4}+a_{5} x+a_{6} x^{2}+a_{7} x^{3}+x^{4}\right)}
$$

The coefficients have the following values:

$$
\begin{aligned}
& a_{1}=-8.5322289 \times 10^{3} \\
& a_{2}=2.1214010 \times 10^{3} \\
& a_{3}=-6.7073989 \times 10^{1} \\
& a_{4}=9.3596087 \times 10^{5} \\
& a_{5}=-3.1346258 \times 10^{4} \\
& a_{6}=2.3961674 \times 10^{3} \\
& a_{7}=-6.7104406 \times 10^{1}
\end{aligned}
$$

Lastly, the $\mathrm{x}$ in the Kelman model represents the "virtual $\mathrm{PO}_{2}$ ", which accounts for changes in saturation due to deviation from standard conditions (Equation 11).

\section{Equation 11}

$$
P \mathrm{O}_{2} \text { vir }=\mathrm{PO}_{2} \times 10^{\left\{0.024(37-\mathrm{T})+0.40(\mathrm{pH}-7.40)+0.06\left(\log 40-\log P C \mathrm{O}_{2}\right)\right\}}
$$

This model works under the assumption that, besides for $\mathrm{pH}$ at high saturations, these variables that are part of the "virtual $\mathrm{PO}_{2}$ " change the scale, but not the shape of the $\mathrm{PO}_{2}$ axis. The factors used here were originally suggested by Severinghaus in formulating his nomogram (1966).

\subsubsection{Hill Analysis and ODC Comparisons}

The ODC is usually quantified by a single value, the $\mathrm{P}_{50}$. While some in vitro systems can measure the $\mathrm{PO}_{2}$ at which $\mathrm{Hb}$ is $50 \%$ saturated, this cannot be done safely in vivo. We therefore calculated $\mathrm{P}_{50}$ by using the linearized form of the Hill equation (Equation 12), which was mathematically used to fit the data. 


\section{Equation 12}

$$
\log \frac{\mathrm{SO}_{2}}{100-\mathrm{SO}_{2}}=\log \mathrm{K}+n \log \mathrm{PO}_{2}
$$

The linearized Hill equation was used in the following manner:

In each condition $\log \left(\mathrm{PaO}_{2}\right)$ was graphed on the $\mathrm{x}$ axis against $\log \left[\mathrm{SO}_{2} /\left(100-\mathrm{SO}_{2}\right)\right]$ for all cases where $\mathrm{PaO}_{2}$ was less than $90 \mathrm{mmHg}$. Data where $\mathrm{PaO}_{2}$ was greater than $90 \mathrm{mmHg}$ were excluded because there tends to be $\mathrm{SO}_{2}$ variability in this range, and this variability has the potential to greatly influence $\mathrm{P}_{50}$ even though it falls on the flattest part of the ODC. A line of best fit was drawn through the data in order to determine the values for $\mathrm{K}$ and $\mathrm{n}$, the Hill coefficient of sigmoidicity, which represents the co-operativity of $\mathrm{Hb}$. Genetics and the environment will influence the $\mathrm{n}$ value and strength of co-operativity of the binding of $\mathrm{Hb}$ and $\mathrm{O}_{2}$. These values were then used with the Hill equation to determine the $\mathrm{P}_{50}$. For each data set

$\mathrm{R}^{2}$ was calculated in order to determine how well the line of best fit matched the linearized data. The $\mathrm{n}$ and $\mathrm{K}$ values were then used in the non-linearized form of the equation and $\mathrm{R}^{2}$ was calculated to see how well the resulting curve fit the non-linearized data. This linearization process was not used on data sets with fewer than $3 \mathrm{PaO}_{2} / \mathrm{SO}_{2}$ pairs, because one or two sets of points may not be characteristic of the entire curve.

Not only was the Hill equation used to determine $\mathrm{P}_{50}$ using measured $\mathrm{SO}_{2}$ values, it was also used with the Kelman and Severinghaus $\mathrm{SO}_{2}$ values to determine the $\mathrm{P}_{50}$ s that would be predicted by these models. The above method yielded a $\mathrm{P}_{50}, \mathrm{n}$ and $\mathrm{K}$ value for each subject in each condition using each type of $\mathrm{SO}_{2}$ (measured, Severinghaus, Kelman).

We used bar graphs to show the average and standard errors of $\mathrm{P}_{50}$ and $\mathrm{n}$ values for each experimental group at normocapnia, using each $\mathrm{SO}_{2}$ type. $\mathrm{K}$ values were also graphed, but medians, $25 \%$ and $75 \%$ were shown instead of averages because the $\mathrm{K}$ value data were not normally distributed.

We attempted to apply a mathematical exponential fit to the data, but this idea was discarded because, while an exponential often fit our data well, this good fit was only in the measured part of the curve, as an exponential does not reflect the sigmoidal shape of the ODC. 


\subsubsection{Comparison within Groups, across $\mathrm{SO}_{2}$ Type}

A one-way repeated measures ANOVA with an alpha level of .05 was used to compare the three types of each value within each subject of each condition. Thus, for each experiment, 3 such tests were done; one on $\mathrm{P}_{50}$, one on $\mathrm{n}$, and one on $\mathrm{K}$. These were performed in order to further assess how our data compares with predictions based on in vitro data. If differences were found between measurement types, the appropriate post-hoc test was used to determine which $\mathrm{SO}_{2}$ types differed significantly from one another. If the normality test failed, a Kruskal-Wallis test was done on ranks. Frequency distributions were also used to show how the three $\mathrm{SO}_{2}$ types influenced $\mathrm{P}_{50}$ and $\mathrm{n}$ values for each experimental group. The two groups of lowlanders at sea level were combined for the graphical representation.

\subsubsection{Comparison across Groups, within $\mathrm{SO}_{2}$ Type}

$\mathrm{P}_{50}$, $\mathrm{n}$, and $\mathrm{K}$ were compared across groups, using measured, Severinghaus, and Kelman $\mathrm{SO}_{2}$ types. This was done in order to address the third aim of this thesis, which was comparison of lowlanders at sea level, lowlanders at high altitude, and highlanders at high altitude. These were compared using 1 way ANOVAs, with an alpha level of .05. If normality tests failed, a KruskalWallis test was done on ranks. If differences were found between groups, the appropriate posthoc test was used to determine which groups significantly differed from one another.

\subsubsection{Composite ODC Comparison across Groups using Measured $\mathrm{SO}_{2}$}

Graphs were also used to compare the experimental groups, using Measured $\mathrm{SO}_{2}$. Average ODCs for each group were drawn by using the average Hill parameters. Outliers were excluded so the parameters would be normally distributed. Frequency distributions for $\mathrm{P}_{50}$ and $\mathrm{n}$ values were also created.

\subsubsection{Influence of $\mathrm{PCO}_{2}$ on Hill Parameters}

In Experiment 2 we explored the influence of $\mathrm{PCO}_{2}$ on the in vivo $\mathrm{ODC}$ by having three $\mathrm{PCO}_{2}$ conditions: hypocapnia, normocapnia and hypercapnia. We assessed the influence of $\mathrm{PCO}_{2}$ on the ODC by performing a two-way repeated measures ANOVA at an alpha level of 0.05 on each of the three Hill parameters $\left(\mathrm{P}_{50}, \mathrm{n}\right.$ and $\left.\mathrm{K}\right)$, using $\mathrm{SO}_{2}$ type and $\mathrm{PCO}_{2}$ condition as factors. The appropriate post-hoc tests were used for pair-wise comparison. 


\subsubsection{Descending and Ascending $\mathrm{PO}_{2}$ Comparison}

The protocol for Experiment 1 entailed progressive hypoxia followed by a progressive return to normoxia in lowlanders at sea level. We assessed whether the order of the $\mathrm{PO}_{2}$ steps influenced the position of the ODC by splitting the data into descending and ascending $\mathrm{PO}_{2}$ segments. Hill parameters were calculated separately for each segment, and a two-tailed paired t-test was used to compare them at an alpha level of 0.05 . 


\section{Results}

\subsection{Control Haematological Values}

Control haematological parameters for each subject are shown in Appendix A. In order to characterize our samples and determine how their haematological environments differed from one another, these were compared across groups using a one way ANOVA at an alpha level of 0.05. Because the two groups of lowlanders at sea level (Experiments 1 and 2) were from the same population and did not differ from one another, they were combined into one group for the sake of comparison. For all variables a Tukey pair-wise test was performed in order to determine which experimental group averages differed significantly from one another. Averages and standard deviations for each parameter for each experimental group are shown below, in Table 5. An asterisk $(*)$ denotes that the group differs significantly from the lowlanders at sea level. A double dagger $(\$)$ in the column for Andeans at Altitude denotes that the two high altitude groups (Experiments 3 and 4) differed significantly from one another. Detailed ANOVA results can also be found in Appendix A.

Table 5: Control Haematological Values (Mean \pm Std Dev) for Subjects in All Experiments

\begin{tabular}{|c|c|c|c|}
\hline & $\begin{array}{c}\text { Lowlanders at Sea Level } \\
\text { Experiments } 1 \text { \& } 2\end{array}$ & $\begin{array}{c}\text { Lowlanders at Altitude } \\
\text { Experiment } 3\end{array}$ & $\begin{array}{l}\text { Andeans at Altitude } \\
\text { Experiment } 4\end{array}$ \\
\hline pH & 0.03 & $7.44 \pm 0.02 *$ & $7.44 \pm 0.02 *$ \\
\hline $\mathrm{PCO}_{2}(\mathrm{mmHg})$ & 41.0 & $29.1 \pm$ & 28.9 \\
\hline $\mathrm{PO}_{2}(\mathrm{mmHg})$ & 104.6 & $15.3 *$ & $4.3 *+$ \\
\hline BE & 1.9 & $1.9 *$ & $-4.8 \pm$ \\
\hline $\mathrm{HCO}_{3}^{-}(\mathrm{mmol} / \mathrm{L})$ & 25.6 & $1.7 *$ & $2.1 *$ \\
\hline Het $(\%)$ & 41.0 & $43.8 \pm$ & $46.9 \pm 3.0^{*}$ \\
\hline $\mathrm{Hb}(\mathrm{g} / \mathrm{dL})$ & \pm 1.5 & $14.9 \pm 1.3$ & $16.0 \pm 1.0 *$ \\
\hline
\end{tabular}

The above data provide evidence that the high altitude groups differed haematologically from the sea level groups. Such significant differences under baseline conditions may lead to different ODC positions across groups if the differences are not compensated for.

\subsection{Method Demonstration}

The current method for measuring the in vivo ODC involves progressive hypoxia during isocapnia. This was done by maintaining $\mathrm{PetCO}_{2}$ while inducing square-wave changes in $\mathrm{PetO}_{2}$. 
Figure 6 shows breath by breath $\mathrm{PetCO}_{2}$ and $\mathrm{PetO}_{2}$ data for a typical subject during ODC testing. It demonstrates the precision with which $\mathrm{PetCO}_{2}$ and $\mathrm{PetO}_{2}$ can be independently controlled using this method.

For all subjects in Experiments 3 and 4, $\mathrm{PetO}_{2}$ remained within $\pm 1.5 \mathrm{mmHg}$ standard deviation (Std Dev) during at least the last $60 \mathrm{~s}$ of each step, while $\mathrm{PetCO}_{2}$ remained within $\pm 0.5 \mathrm{mmHg}$. Throughout testing, $\mathrm{PetCO}_{2}$ remained within $\pm 1.0 \mathrm{mmHg}$ for all subjects. Similar data are not available for those in Experiments 1 and 2, but the methodology and technology was the same so the extent of control is expected to be similar.

\section{Figure 6: Raw Data Example: Breath by Breath End Tidal Data for a Typical Subject}

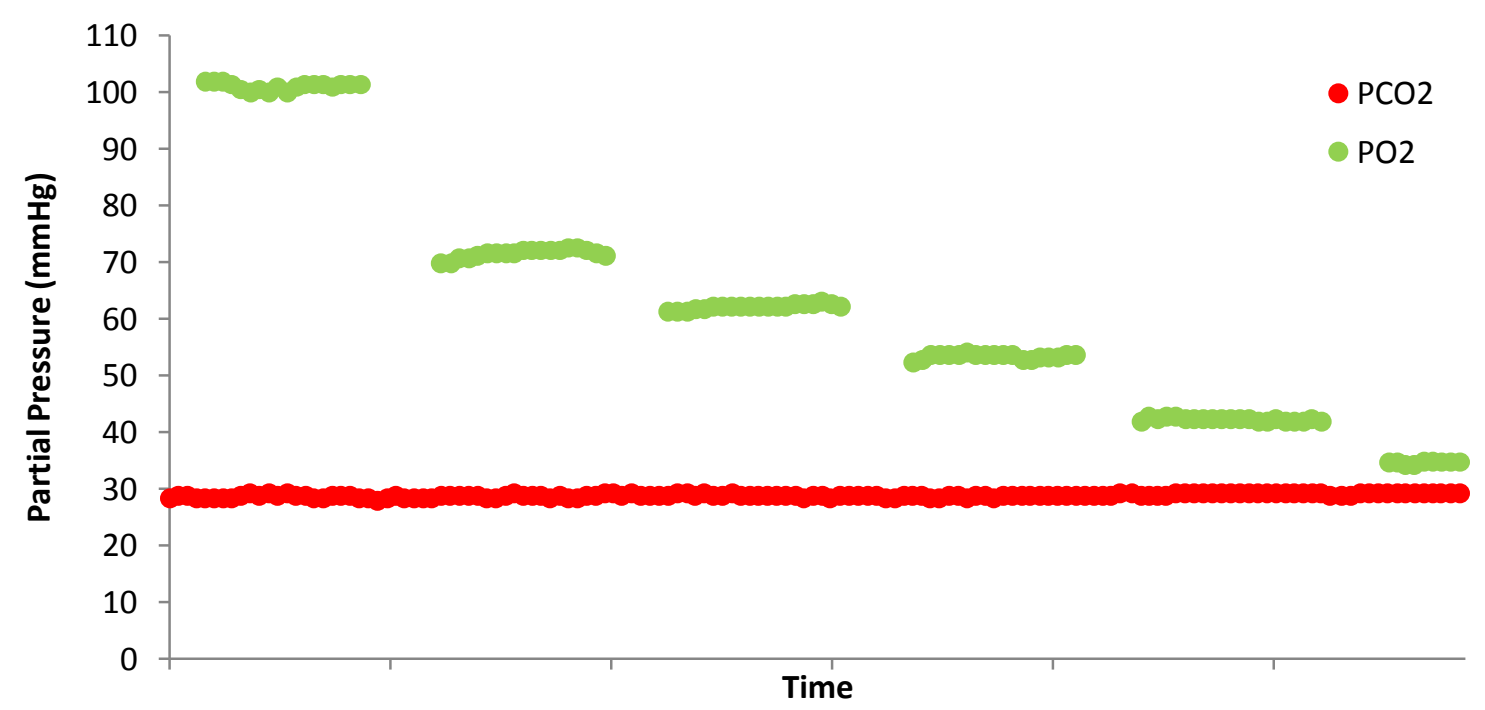

In vivo study of the $\mathrm{ODC}$ requires the maintenance of $\mathrm{PCO}_{2}$ and $\mathrm{pH}$ during progressive hypoxia, despite changes in ventilation. This is important because arterial samples taken at different times will not lie on the same ODC if $\mathrm{PCO}_{2}$ and $\mathrm{pH}$ are allowed to vary. While $\mathrm{PCO}_{2}$ influences $\mathrm{pH}$, $\mathrm{pH}$ can also be influenced by metabolism, ion shifts and other factors. $\mathrm{PCO}_{2}$ was specifically controlled in this study, while $\mathrm{pH}$ was not. For each subject in each group, averages and standard deviations were calculated for both $\mathrm{PaCO}_{2}$ and $\mathrm{pH}$. The standard deviations reflect how well the parameters were controlled. The means \pm standard deviations for each group, based on the individual means and standard deviations are presented in Table 6, below. Individual data are provided in Appendix B. 
Table 6: Mean and Std Dev Data for $\mathrm{PaCO}_{2}$ and $\mathrm{pH}$ during in vivo ODC Testing

\begin{tabular}{ccccccccccccc}
\hline Experiment & Avg PaCO & $(\mathbf{m m H g})$ & Std Dev $\mathbf{P a C O}_{\mathbf{2}}(\mathbf{m m H g})$ & \multicolumn{2}{c}{ Avg pH } & \multicolumn{3}{c}{ Std Dev pH } \\
\hline $\mathbf{1}$ & 42.2 & \pm & 2.0 & 1.5 & \pm & 0.6 & 7.39 & \pm & 0.03 & 0.01 & \pm & 0.01 \\
2 Hypocap & 38.1 & \pm & 1.5 & 1.7 & \pm & 1.0 & 7.40 & \pm & 0.03 & 0.02 & \pm & 0.01 \\
2 Normocap & 42.4 & \pm & 1.4 & 1.6 & \pm & 0.6 & 7.37 & \pm & 0.04 & 0.01 & \pm & 0.01 \\
2 Hypercap & 46.8 & \pm & 1.6 & 1.7 & \pm & 0.9 & 7.33 & \pm & 0.03 & 0.01 & \pm & 0.01 \\
$\mathbf{3}$ & 27.4 & \pm & 2.7 & 0.6 & \pm & 0.2 & 7.47 & \pm & 0.03 & 0.01 & \pm & 0.00 \\
4 & 26.9 & \pm & 3.4 & 1.1 & \pm & 0.3 & 7.43 & \pm & 0.02 & 0.02 & \pm & 0.00 \\
\hline
\end{tabular}

Mean $\mathrm{PaCO}_{2}$ and $\mathrm{pH}$ varied by experimental condition in a manner that was consistent with the experimental protocol. In Experiments 1, 2 normocapnia, 3 and 4 the $\mathrm{PaCO}_{2}$ and $\mathrm{pH}$ were maintained roughly at control levels. $\mathrm{PaCO}_{2}$ was lower in the hypocapnia condition of Experiment 2 than in the normocapnia condition, so the $\mathrm{pH}$ in the hypocapnia condition was consequently increased. $\mathrm{PaCO}_{2}$ was higher in the hypercapnia condition of Experiment 2 than in the normocapnia condition, so the $\mathrm{pH}$ was consequently decreased.

Standard deviation for $\mathrm{PaCO}_{2}$ was greatest in the hypocapnia and hypercapnia conditions of Experiment 2. This is probably due to the fact that $\mathrm{PCO}_{2}$ alternated with each $\mathrm{PO}_{2}$ step for the two conditions, while the other conditions and experiments had only a single $\mathrm{PCO}_{2}$ target. Standard deviation for $\mathrm{pH}$ was greatest in the hypocapnia condition of Experiment 2 as well as in Experiment 4. It is not known whether the standard deviations of $\mathrm{PaCO}_{2}$ and $\mathrm{pH}$ for these conditions were physiologically significant, but it is possible that they impacted the accuracy of ODC measurement in the studies.

Because the ODC is best constrained by data on its steep portion, it is important to achieve some low $\mathrm{PO}_{2}$ levels in vivo in order to characterize the in vivo curve. The greater the number of samples, the better the characterization can be. Table 7 shows the minimum $\mathrm{PaO}_{2}$ and number of samples taken for each experiment. Data for each subject are presented in Appendix B. 
Table 7: Average and Std Dev Data for Minimum $\mathrm{PaO}_{2}$ and Number of Samples during in vivo ODC Testing

\begin{tabular}{|c|c|c|}
\hline Experiment & Minimum $\mathrm{PaO}_{2}(\mathrm{mmHg})$ & Number of Samples \\
\hline 1 & 42.85 & 8.38 \\
\hline 2 Hypocapnia & 45.76 & 6.29 \\
\hline 2 Normocapnia & 39.00 & 25.21 \\
\hline 2 Hypercapnia & 50.83 & 6.17 \\
\hline 3 & 34.83 & 5.33 \\
\hline 4 & 35.88 & 5.75 \\
\hline
\end{tabular}

\subsection{Comparison of Measured $\mathrm{SO}_{2}$ Values with those of Severinghaus and Kelman Predictions}

In order to determine how our in vivo $\mathrm{SO}_{2}$ data compared to predictions based on previous in vitro studies, we then compared our in vivo $\mathrm{SO}_{2}$ results to those calculated using the Severinghaus (1966) and Kelman (1966) methods.

Graphs depicting the correlation between the Measured $\mathrm{SO}_{2}$ values and the Severinghaus $\mathrm{SO}_{2}$ values are shown below for each experiment (Figure 7). The diagonal lines represent the lines of identity. In Experiments 1 through 3 the line of identity generally fits the data, except at the topmost $\mathrm{SO}_{2}$ points where the Measured $\mathrm{SO}_{2}$ values tend to be slightly higher than the Severinghaus $\mathrm{SO}_{2}$ values. The data are heteroskedastic, with increased variability at low $\mathrm{SO}_{2}$ values. 
Figure 7: Graphs Showing the Correlation between Measured and Severinghaus $\mathrm{SO}_{2}$ Values
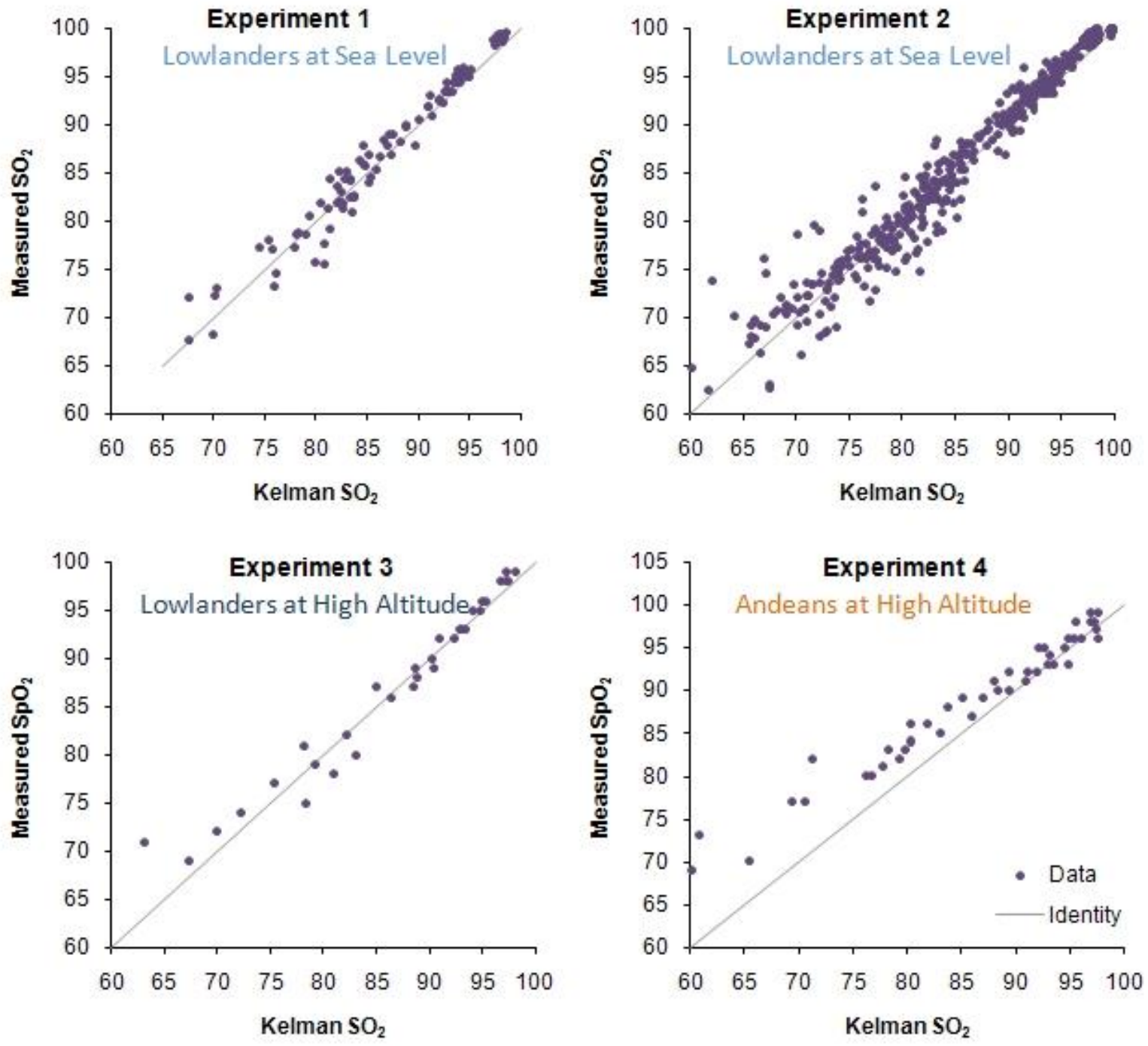

Graphs depicting the correlation between the Measured $\mathrm{SO}_{2}$ values and the $\mathrm{Kelman} \mathrm{SO}_{2}$ values are shown below for each experiment (Figure 8). The data comparing Measured $\mathrm{SO}_{2}$ and that predicted by Kelman generally follow what was seen above, in the comparison of the Measured and Severinghaus $\mathrm{SO}_{2}$ data. In Experiments 1 through 3 the line of identity generally fits the data, except at the topmost $\mathrm{SO}_{2}$ points where the Measured $\mathrm{SO}_{2}$ values tend to be slightly higher than the Severinghaus $\mathrm{SO}_{2}$ values. In Experiment 4 the data clearly depart from the line of 
identity, especially towards lower $\mathrm{SO}_{2}$ values, where measured $\mathrm{SO}_{2}$ tends to be higher than the Severinghaus $\mathrm{SO}_{2}$.

Figure 8: Graphs Showing the Correlation between Measured and Kelman $\mathrm{SO}_{2}$ Values
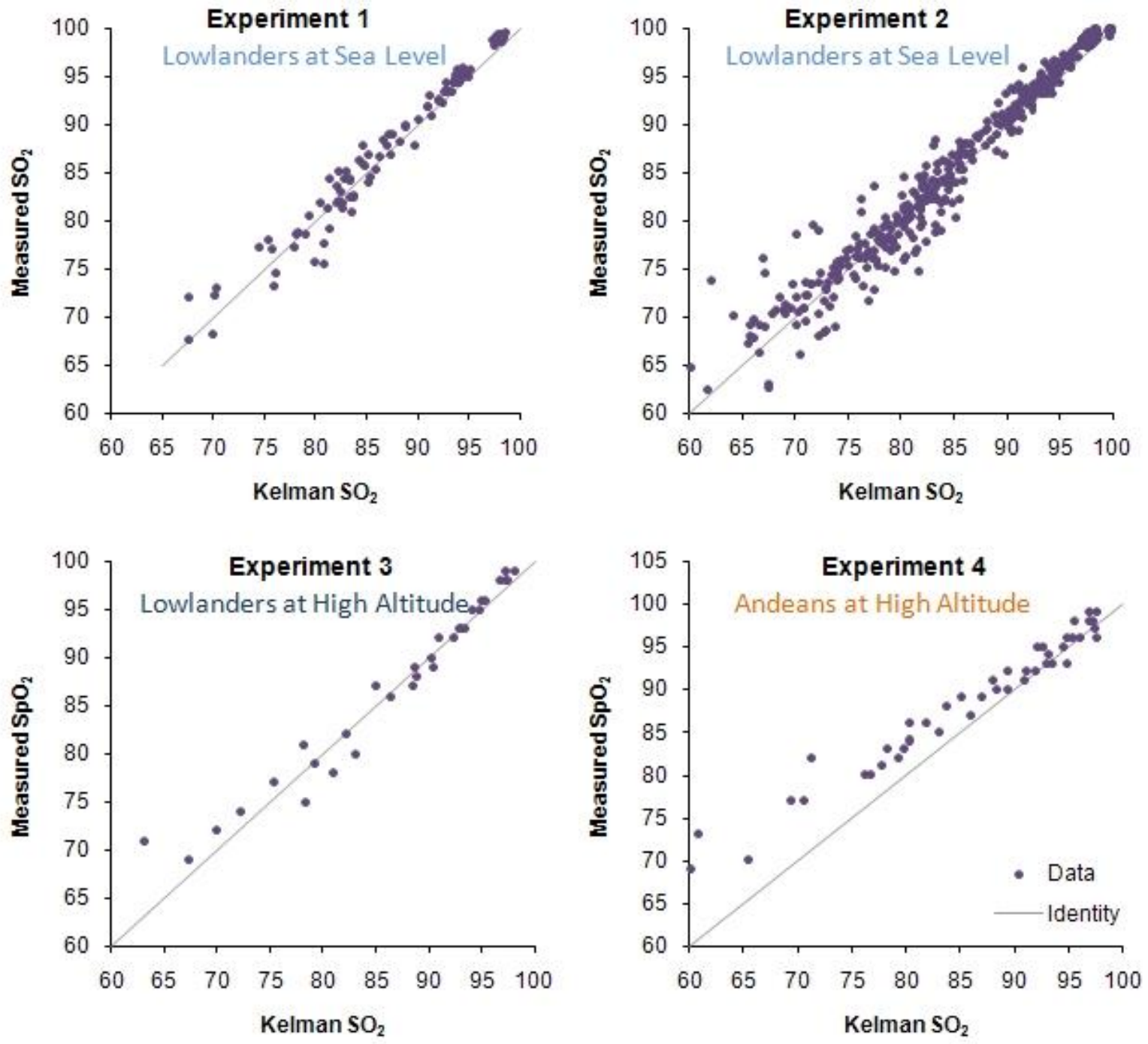

Shown below (Figure 9 and Figure 10) are the Bland \& Altman difference plots for the data shown above. These show the bias and $95 \%$ confidence intervals for each data set. These plots offer an alternate depiction of the above data. 
Figure 9: Difference Plots for Measured and Severinghaus $\mathrm{SO}_{2}$
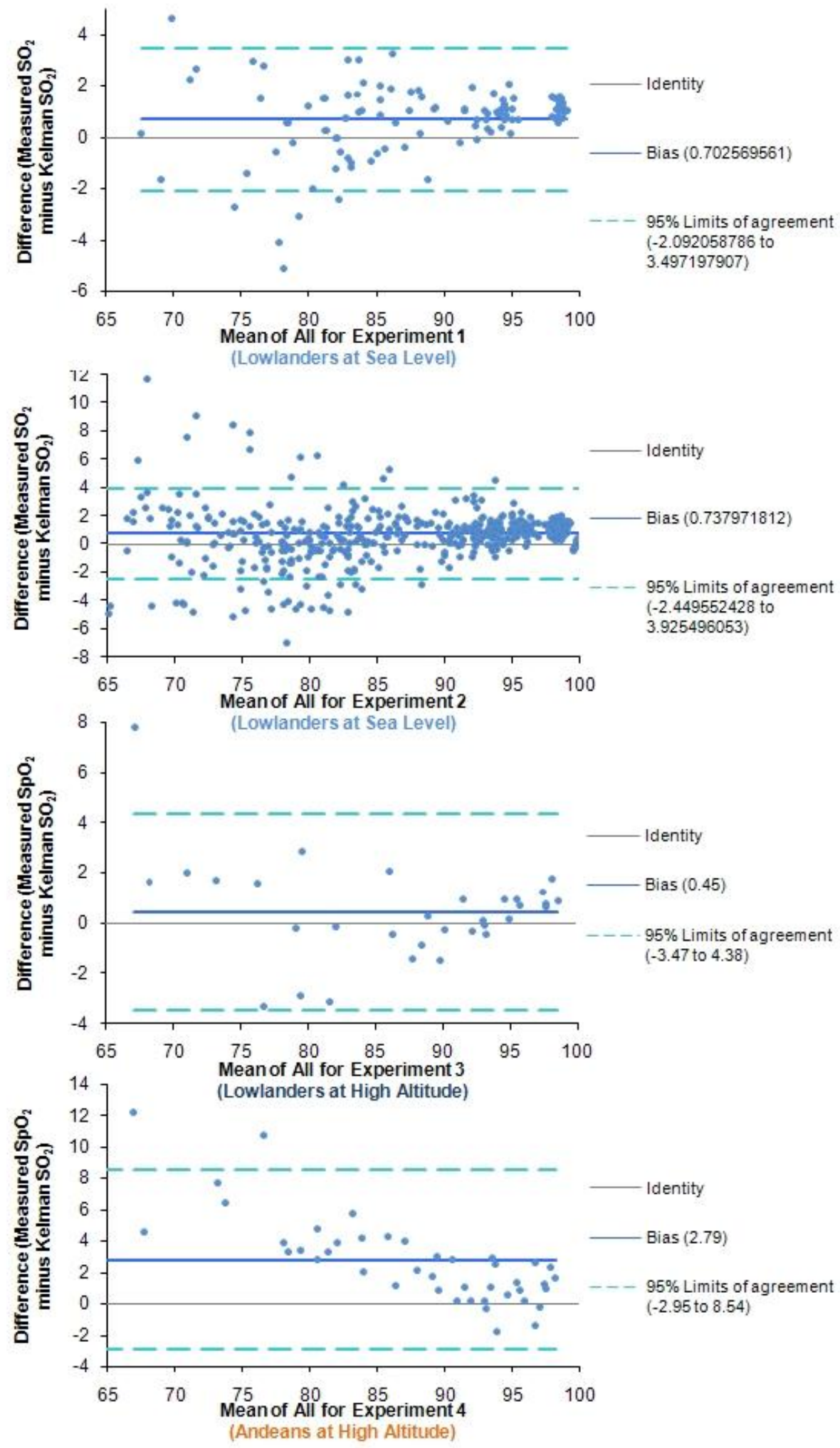
Figure 10: Difference Plots for Measured and Kelman $\mathrm{SO}_{2}$
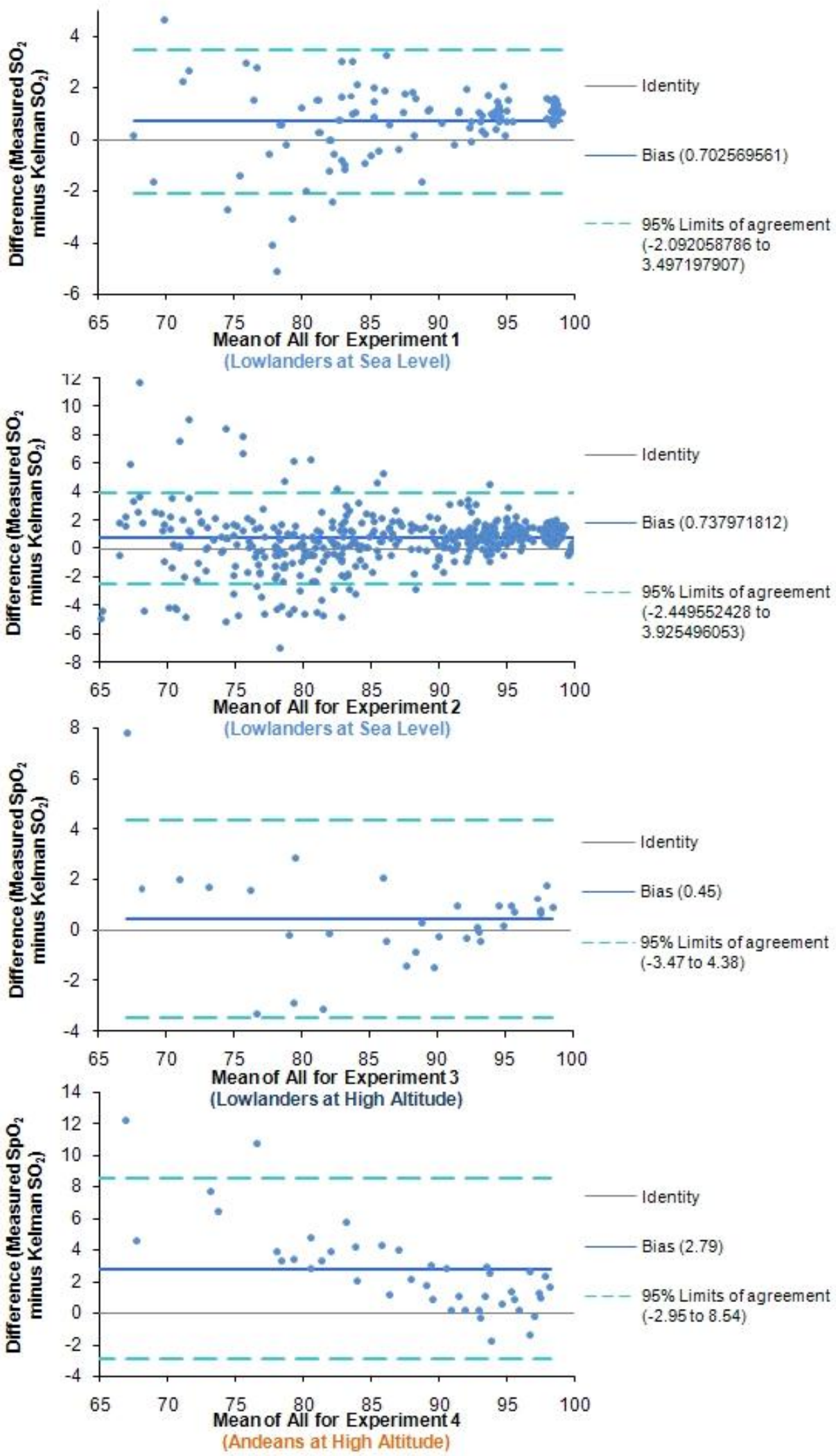


\subsubsection{Lowlanders at Sea Level}

There was no difference between measured $\mathrm{SO}_{2}$ and those predicted by the Kelman and Severinghaus models. The data were heteroskedastic, showing greater variability at low $\mathrm{SO}_{2}$ values.

\subsubsection{Lowlanders at High Altitude}

We expected the measured $\mathrm{SO}_{2}$ values to be lower than the Severinghaus and Kelman values in the sample of Lowlanders at high altitude. This is because [2,3-DPG], which has been shown in vitro to decrease the affinity of $\mathrm{Hb}$ for $\mathrm{O}_{2}$, is increased at high altitude and is not taken into account by these models for predicting $\mathrm{SO}_{2}$. Contrary to our expectations, there was no difference between the measured $\mathrm{SO}_{2}$ and predicted $\mathrm{SO}_{2}$ in the sample of lowlanders at high altitude. The data are heteroskedastic, with greater variability at low $\mathrm{SO}_{2}$ values.

\subsubsection{Andeans at High Altitude}

In Andeans at high altitude predicted $\mathrm{SO}_{2}$ values are consistently lower than the measured values. At high $\mathrm{SO}_{2}$ values the predictions are very close to the measured values, with a few of the measured values even falling below the predicted values (as opposed to the other two groups, in which high $\mathrm{SO}_{2}$ values were associated with a more consistent positive measured $\mathrm{SO}_{2}$ bias). As $\mathrm{SO}_{2}$ decreased, the difference between measured and predicted $\mathrm{SO}_{2}$ became progressively greater. Some measured values are more than 10 units above the predicted values at low saturations. Our data for this sample strongly suggest a true difference between measured $\mathrm{SO}_{2}$ and predicted $\mathrm{SO}_{2}$ (both Severinghaus and Kelman) in our sample of Andeans at high altitude.

\subsection{Hill Parameters $\left(P_{50}, n, K\right)$}

For each experimental group, the three Hill parameters $\left(\mathrm{P}_{50}, \mathrm{n}\right.$ and $\left.\mathrm{K}\right)$ were determined in three different ways, using measured $\mathrm{SO}_{2}$, Severinghaus $\mathrm{SO}_{2}$ and Kelman $\mathrm{SO}_{2}$. This was done linearizing our data using the Hill Equation (Equation 12). We then drew a line of best fit in order to determine the $\mathrm{P}_{50}$ for the curve, in addition to the $\mathrm{n}$ and $\mathrm{K}$ values that characterize it. A detailed explanation of this process is explained above in the methods. This analysis was not conducted on data sets that included fewer than 3 pairs of $\mathrm{PaO}_{2} / \mathrm{SO}_{2}$. Hill parameters for each individual in each experimental condition are presented in Appendix C. 


\subsubsection{Comparison of Hill Parameters $\left(\mathrm{P}_{50}, \mathrm{n}, \mathrm{K}\right)$ Across $\mathrm{SO}_{2}$ Types (Measured, Severinghaus \& Kelman) within each Experiment}

In order to further assess how my data compare to those from in vitro studies, we compared the Hill parameters for our in vivo ODCs to those predicted using the Kelman and Severinghaus $\mathrm{SO}_{2}$ values. This was done on each variable within each experimental group, using one-way repeated measures ANOVA, with an alpha level of 0.05. However, in the case of Experiment 2, a two way repeated measures ANOVA was done, in order to take into account the effects of both $\mathrm{PCO}_{2}$ and $\mathrm{SO}_{2}$ type on the Hill Parameters. Some of the $\mathrm{K}$ value data was not normally distributed, so the ANOVA was carried out on ranks instead of on means. Tukey-post hoc tests were used for pair-wise comparisons.

ANOVA results for all experiments comparing all parameters are presented in Appendix C. The data for $\mathrm{P}_{50}$ and $\mathrm{n}$ value (Hill Coefficient) will be summarized below.

The graphs below (Figure 11, Figure 12, and Figure 13) show the Hill Parameters for all normocapnic conditions, using all three $\mathrm{SO}_{2}$ types. Significant differences within experimental group across each $\mathrm{SO}_{2}$ type are indicated. 
Figure 11: Comparing $\mathrm{P}_{50}$ Values (mean \pm SEM) within Experimental Group across $\mathrm{SO}_{2}$ Types

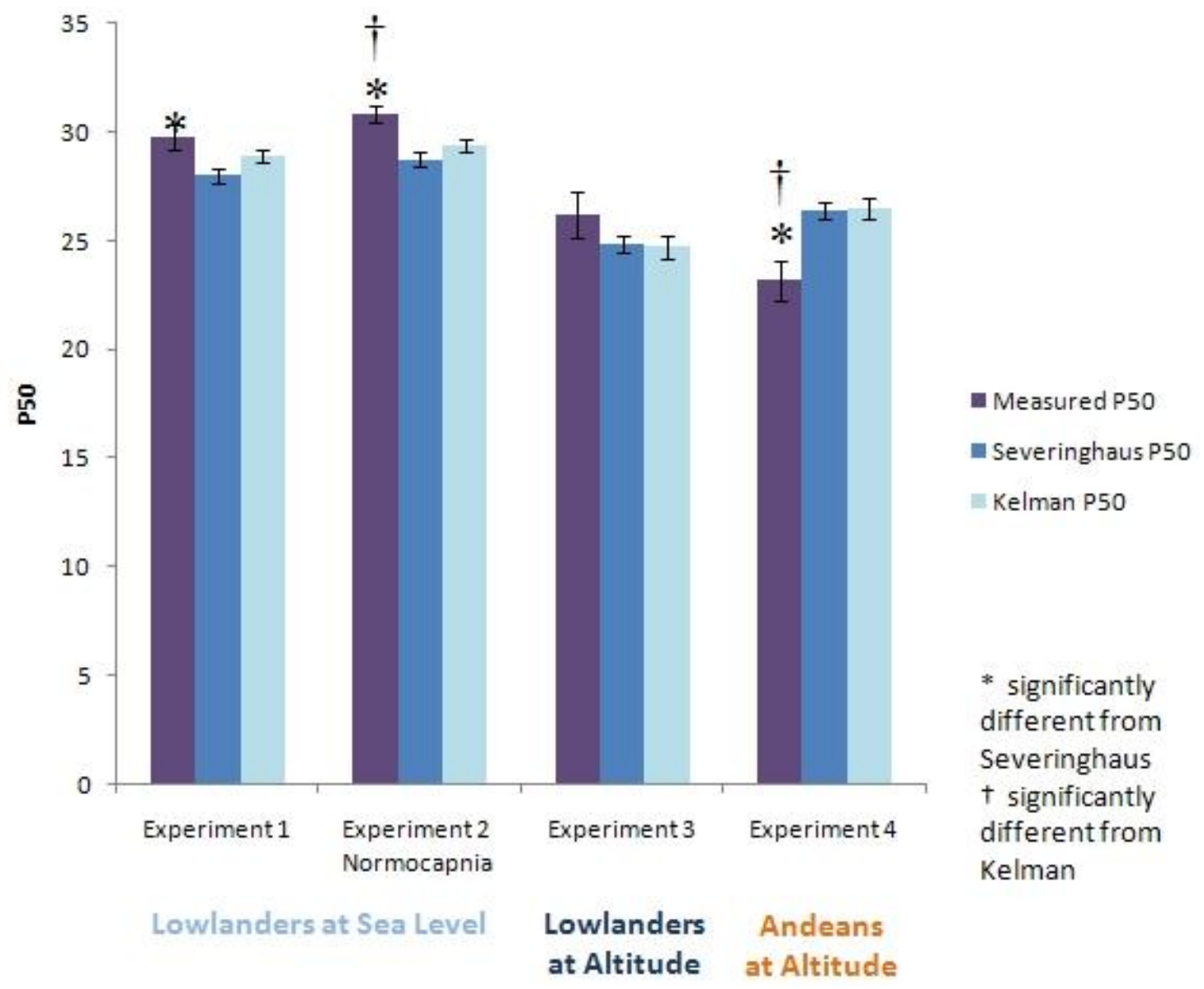


Figure 12: Comparing $n$ Values (mean $\pm \mathrm{SEM}$ ) within Experimental Groups across $\mathrm{SO}_{2}$ Types

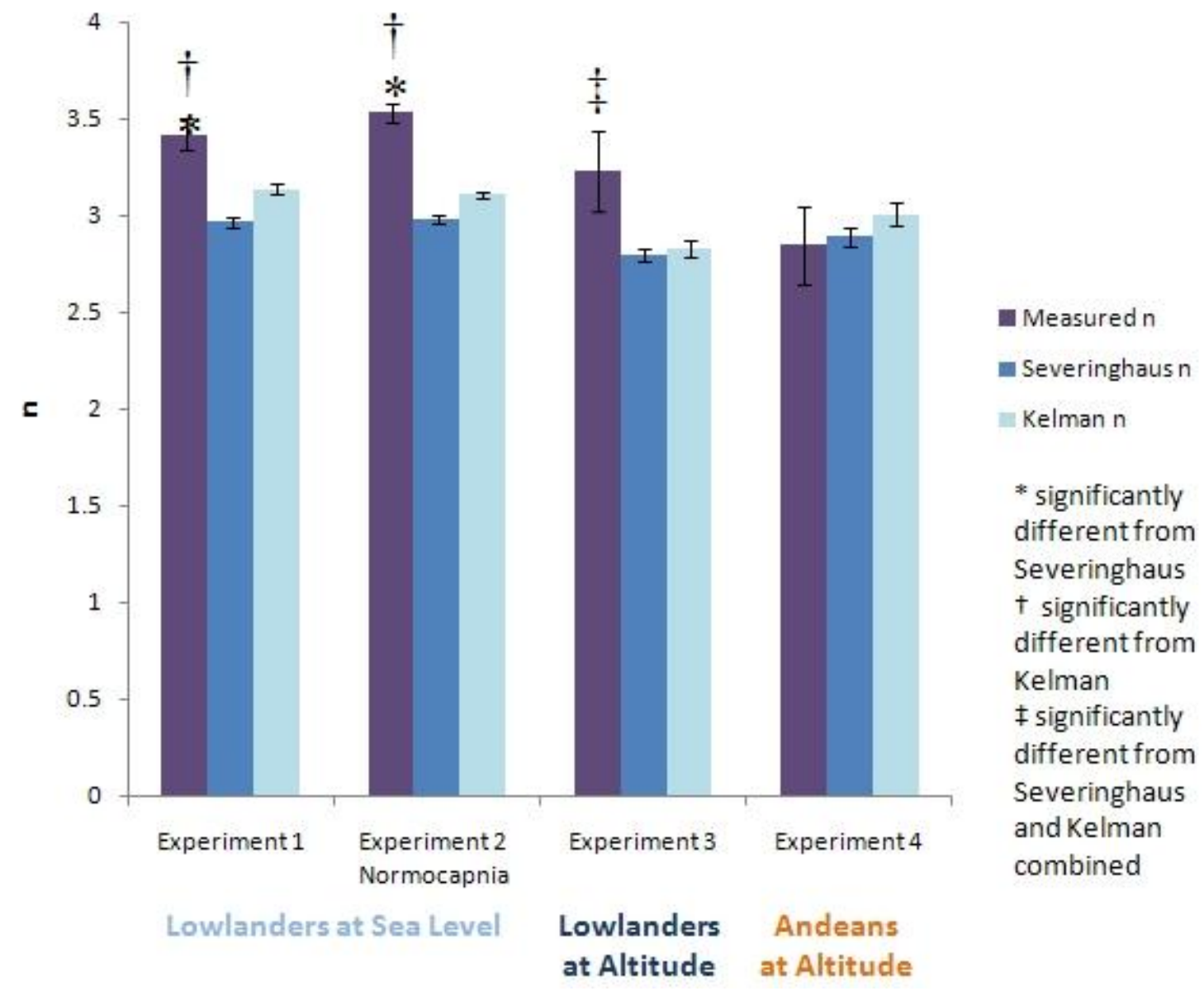


Figure 13: Comparing $\mathrm{K}$ Values within Experimental Groups across $\mathrm{SO}_{2}$ Types

(This graph shows the medians and $25 \%$ and $75 \%$ as the error bars)

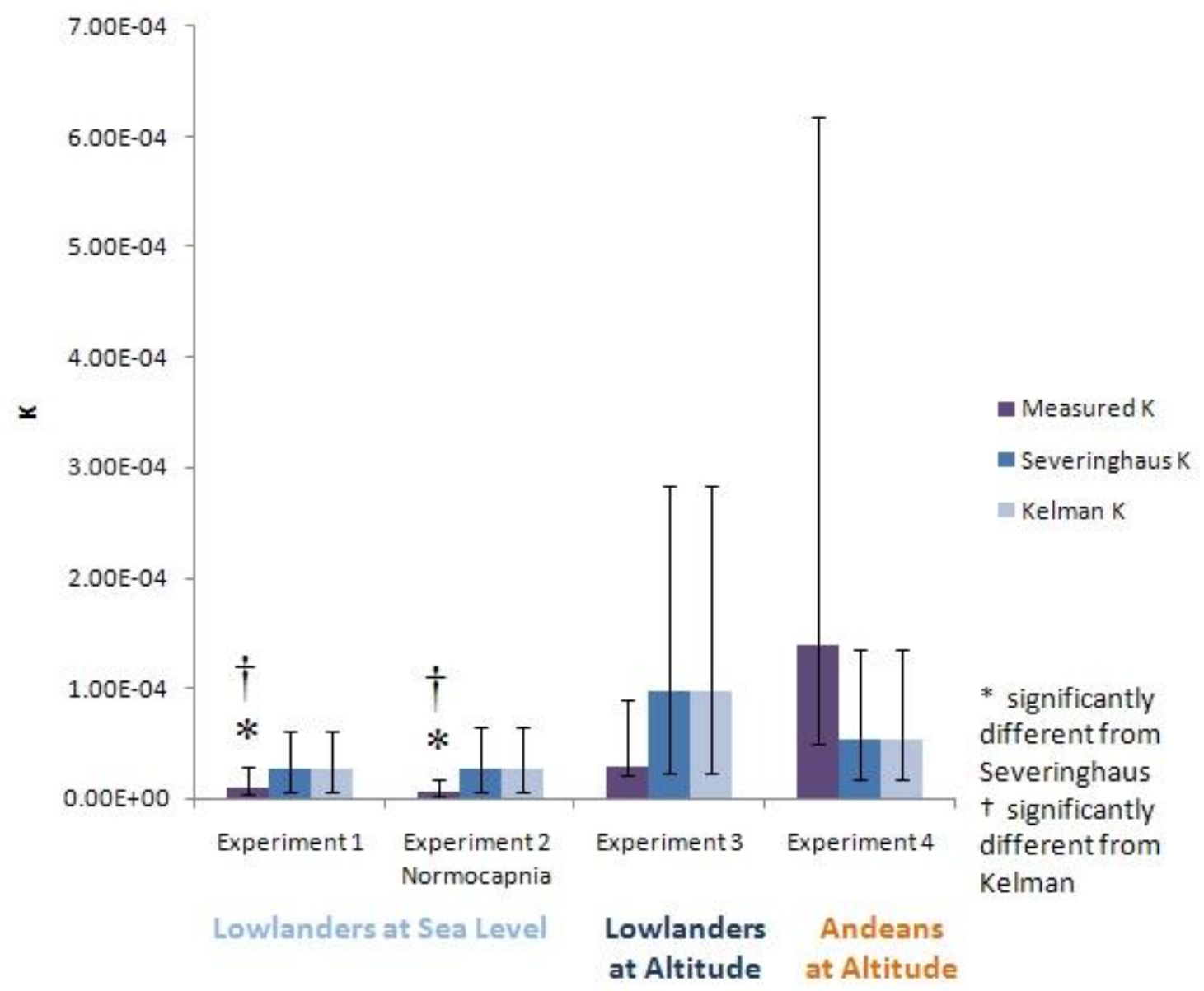

\subsubsection{1 $\quad \mathrm{P}_{50}$ Comparison}

In Experiments 1, 2 and 3, Measured $\mathrm{P}_{50}$ values were higher than those of Severinghaus and Kelman predictions, indicating that the curves were right shifted with respect to the predicted curves. In Experiment 1 the difference was significant only between Measured and Severinghaus ( $\mathrm{p}=0.003$ ). In Experiment 2 the difference was significant between Measured and Severinghaus $(\mathrm{p}<0.001)$ as well as between Measured and Kelman ( $\mathrm{p}<0.001)$. In Experiment 3, neither predicted $\mathrm{P}_{50}$ was significantly lower than the measured $\mathrm{P}_{50}$, despite the presence of 2,3DPG which would be expected to shift the Measured curve rightward from its predicted position. In the case of Experiment 4, Measured $\mathrm{P}_{50}$ was significantly lower than that of Severinghaus 
$(\mathrm{p}=0.016)$ and that of Kelman $(\mathrm{p}=0.014)$, indicating a significant left shift of the curve with respect to its expected position.

It is unexpected that the curves in Experiments 1 and 2 were right shifted with respect to those predicted by the Severinghaus and Kelman models while that of Experiment 3 was not. This is because the models do not take into account the increase in [2,3-DPG] that occurs at high altitude (as in Experiment 3) and should further shift the ODC to the right. The fact that such a shift was not seen in this data may be a reflection of the low power (the data set had only 6 subjects), or it may reflect the presence of some in vivo factor that compensates for the increase in [2,3-DPG] at high altitude and shifts the ODC in the opposite direction of where it is expected to be. The fact that the in vivo curve from Experiment 4 was left shifted as compared to those predicted by the models further supports this possibility.

Figure 14 shows the frequency distributions for $\mathrm{P}_{50}$ according to $\mathrm{SO}_{2}$ type, for each group of subjects at normocapnia. The lowlanders at sea level were combined into a single group. 
Figure 14: $\mathrm{P}_{50}$ Frequency Distributions across $\mathrm{SO}_{2}$ Type for each Subject Group
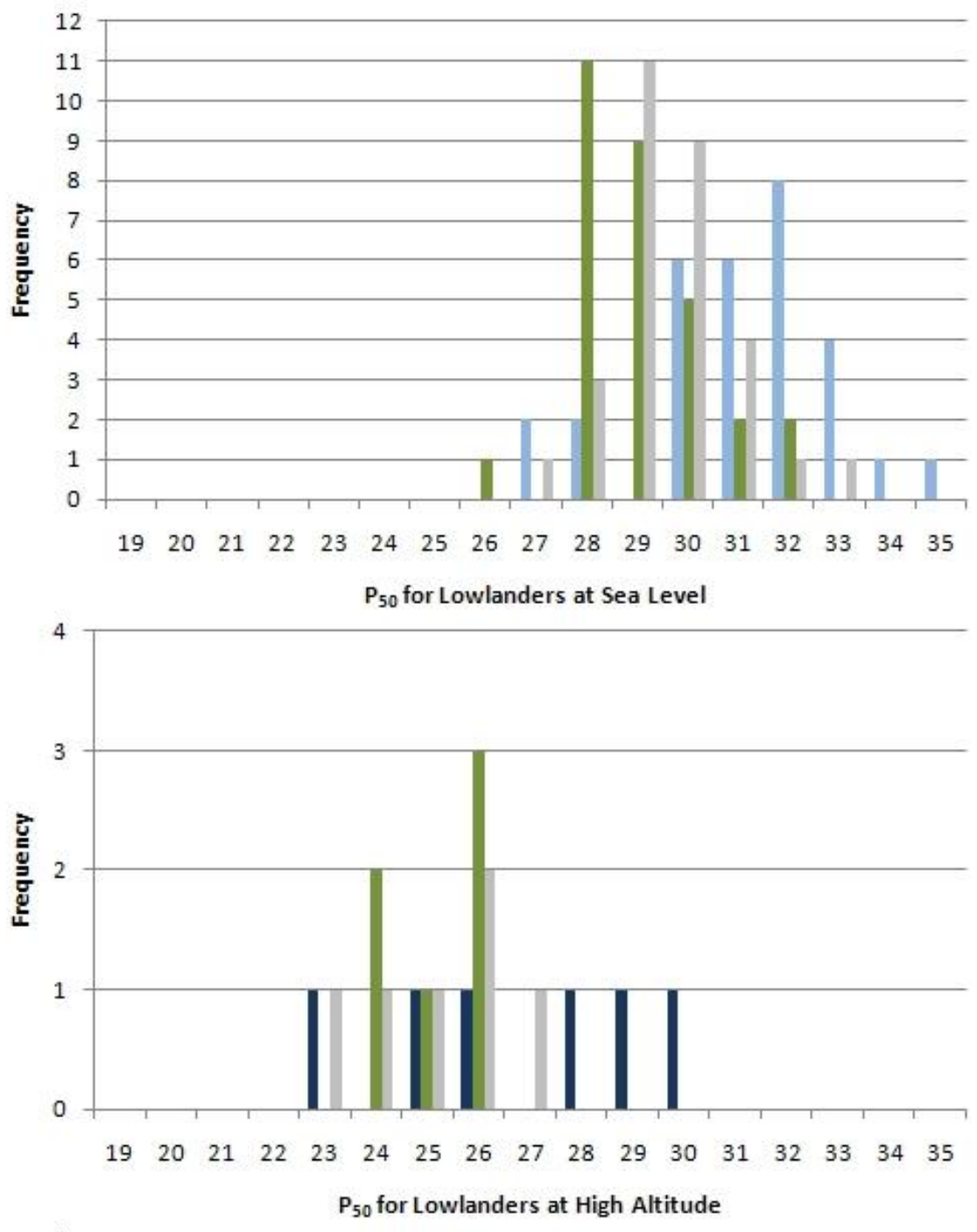

$$
\begin{aligned}
& \text { Weasured } \\
& \text { - Severinghaus } \\
& \text { = Kelman }
\end{aligned}
$$

- Measured

- Severinghaus

Kelman

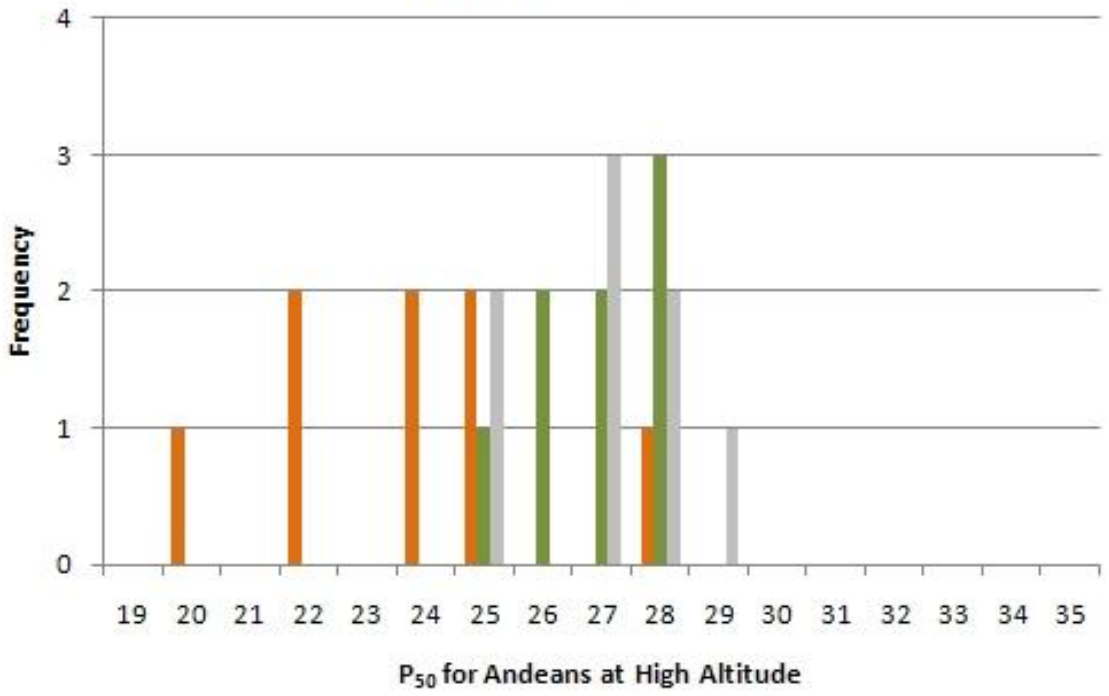

$$
\begin{aligned}
& \text { Measured } \\
& \text { - Severinghaus } \\
& \text { " Kelman }
\end{aligned}
$$




\subsubsection{Hill Coefficient (n Value) Comparison}

As was the case with $\mathrm{P}_{50}$, the Hill Coefficients using Measured $\mathrm{SO}_{2}$ values in Experiments 1, 2 and 3 were higher than those predicted using Severinghaus and Kelman $\mathrm{SO}_{2}$ values. Measured n was significantly higher in Experiment 1 than both Severinghaus and Kelman $\mathrm{n}$ (both at $\mathrm{p}<0.001)$. It was also significantly higher in Experiment 2 than both Severinghaus $(\mathrm{p}<0.001)$ and Kelman $\mathrm{n}(\mathrm{p}=0.025)$. While the overall effect of $\mathrm{SO}_{2}$ type was significant in Experiment 3 $(\mathrm{p}=0.043)$, none of the pair-wise comparisons were significant at the 0.05 level. However, the test had low power and the differences approached significance in the cases of Measured $\mathrm{n}$ and Severinghaus $n(p=0.056)$ and Measured $n$ and Kelman $n(p=0.079)$. The Measured Hill Coefficient in Experiment 4 was lower than both predicted values, but the difference was not significant.

The Measured and Kelman Hill Coefficients in Experiments 1, 2 and 3 were all higher than have been previously reported in the literature (2.8-3), while the Severinghaus values tended to fall in this range.

Figure 15 shows the frequency distributions for $\mathrm{n}$ value according to $\mathrm{SO}_{2}$ type, for each group of subjects at normocapnia. The lowlanders at sea level were combined into a single group. 
Figure 15: $n$ Value Frequency Distributions across $\mathrm{SO}_{2}$ Type for each Subject Group

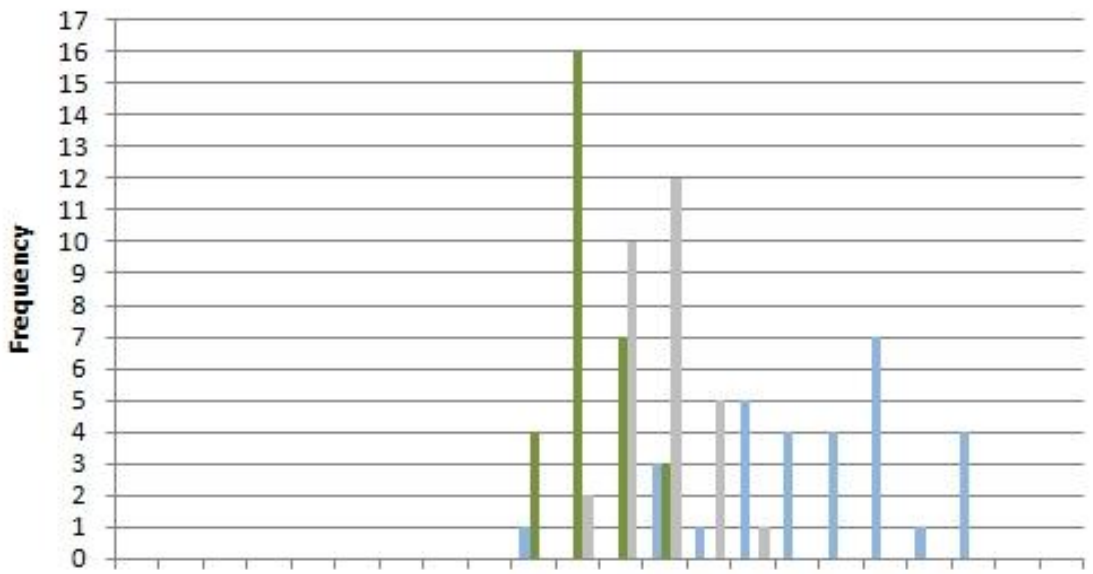

Measured

- Severinghaus

Kelman

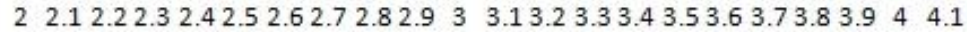

$\mathrm{n}$ value for Lowlanders at Sea Level

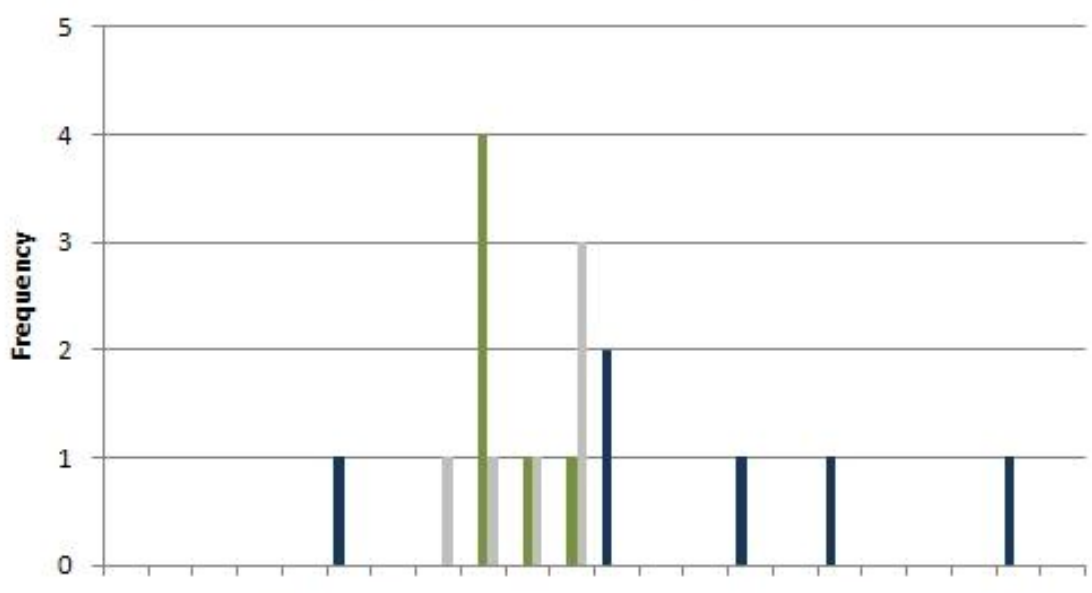

- Measured

Eeveringhaus

Kelman

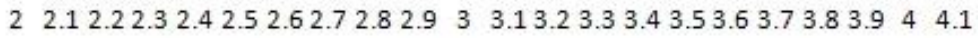

$\mathrm{n}$ value for Lowlanders at High Altitude

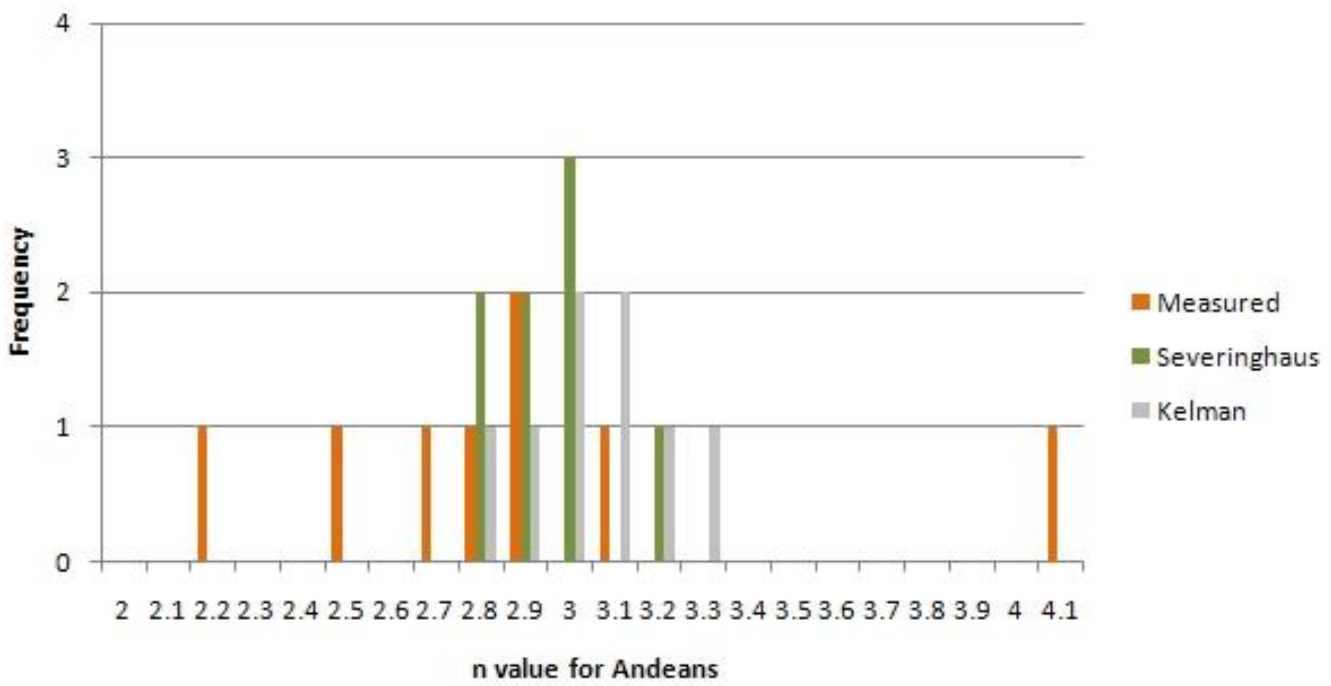




\subsubsection{Comparison of Hill Parameters $\left(\mathrm{P}_{50}, \mathrm{n}, \mathrm{K}\right)$ Across Normocapnia Groups within each $\mathrm{SO}_{2}$ Type}

The comparisons of the results for each parameter within each group were presented above. This section deals only with comparisons across groups, within each $\mathrm{SO}_{2}$ method. One-way ANOVA tests were used to compare $\mathrm{P}_{50}$ and Hill Coefficients across groups, with an alpha level of 0.05

for each $\mathrm{SO}_{2}$ type. Tukey pair-wise tests were used for post-hoc analysis. We did not expect to find any differences between those in Experimental Group 1 and Experimental Group 2, since both groups comprised of lowlanders at sea-level. However, the method of testing varied slightly between these two groups, so differences reflecting the method are possible. The results are summarized below for $\mathrm{P}_{50}$ and $\mathrm{n}$ values. Detailed ANOVA results are provided in Appendix C.

The graphs below (Figure 16, Figure 17 and Figure 18) show the Hill Parameters for all normocapnic conditions, using all three $\mathrm{SO}_{2}$ types. Significant differences across experimental groups within each $\mathrm{SO}_{2}$ type are indicated. 
Figure 16: Comparing $\mathrm{P}_{50}$ Values (mean \pm SEM) across Experimental Groups within $\mathrm{SO}_{2}$ Type

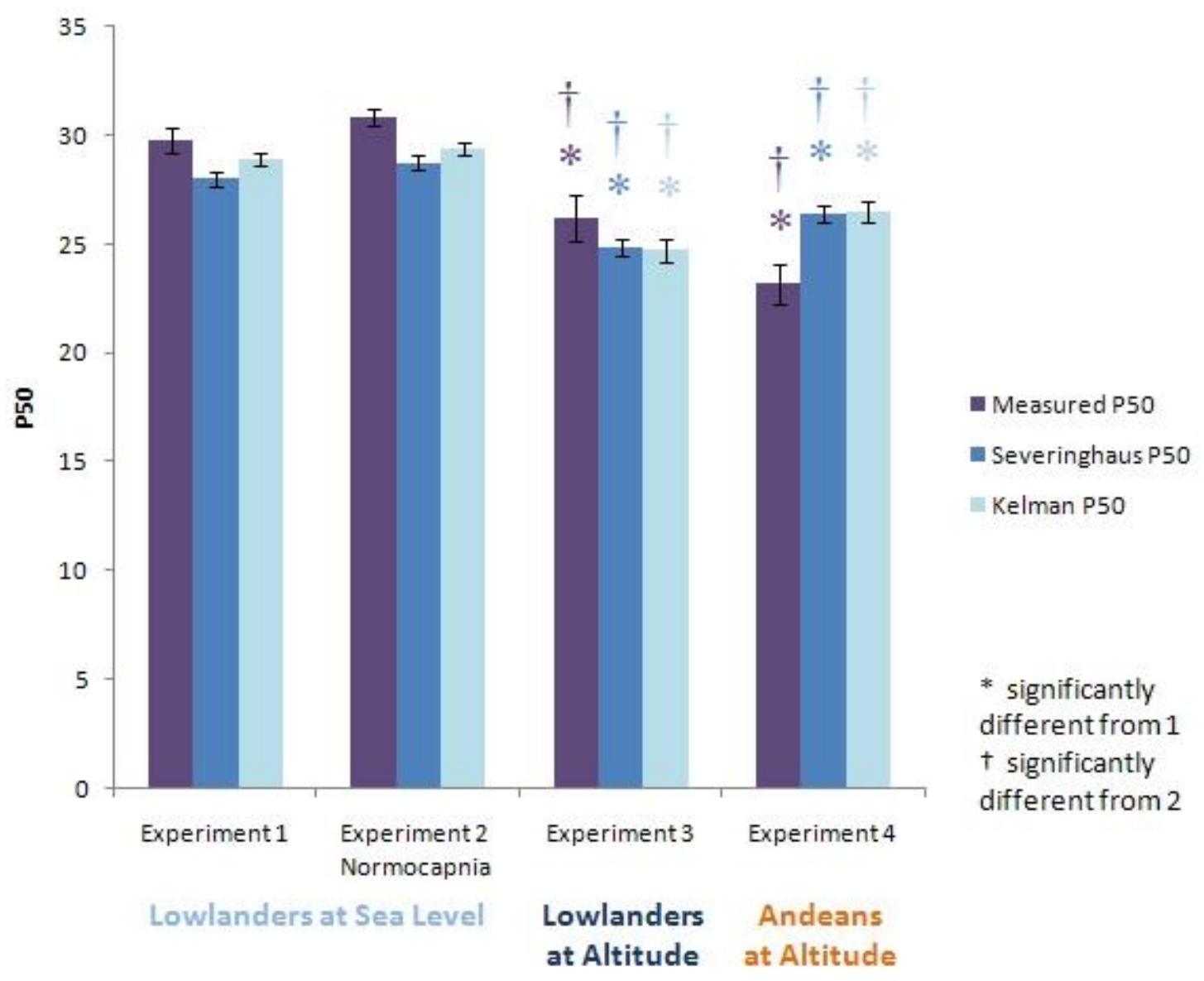


Figure 17: Comparing $n$ Values (mean \pm SEM) across Experimental Groups within $\mathrm{SO}_{2}$ Type

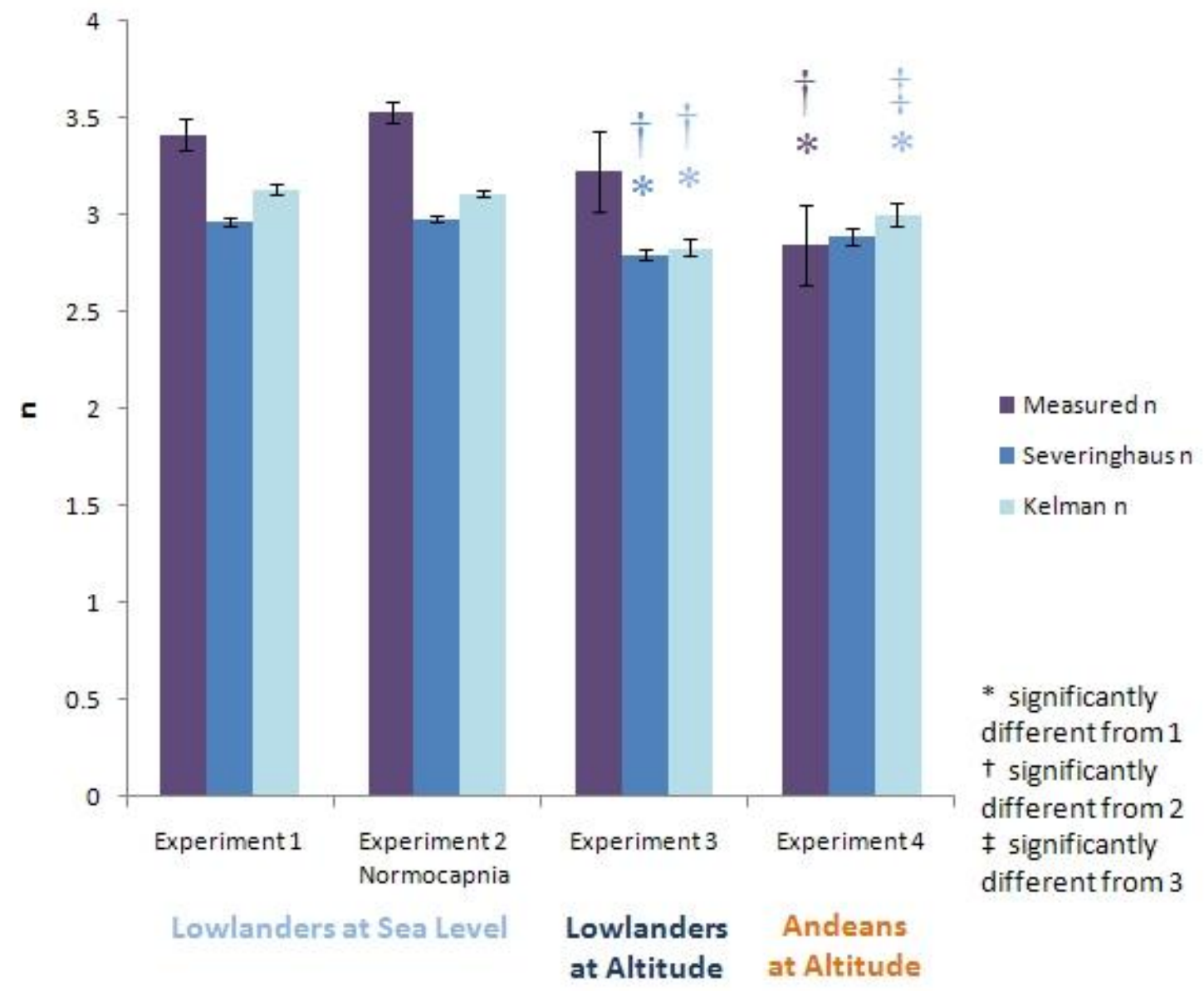


Figure 18: Comparing $\mathrm{K}$ Values across Experimental Groups within $\mathrm{SO}_{2}$ Type

(This graph shows the medians and $25 \%$ and $75 \%$ as the error bars)

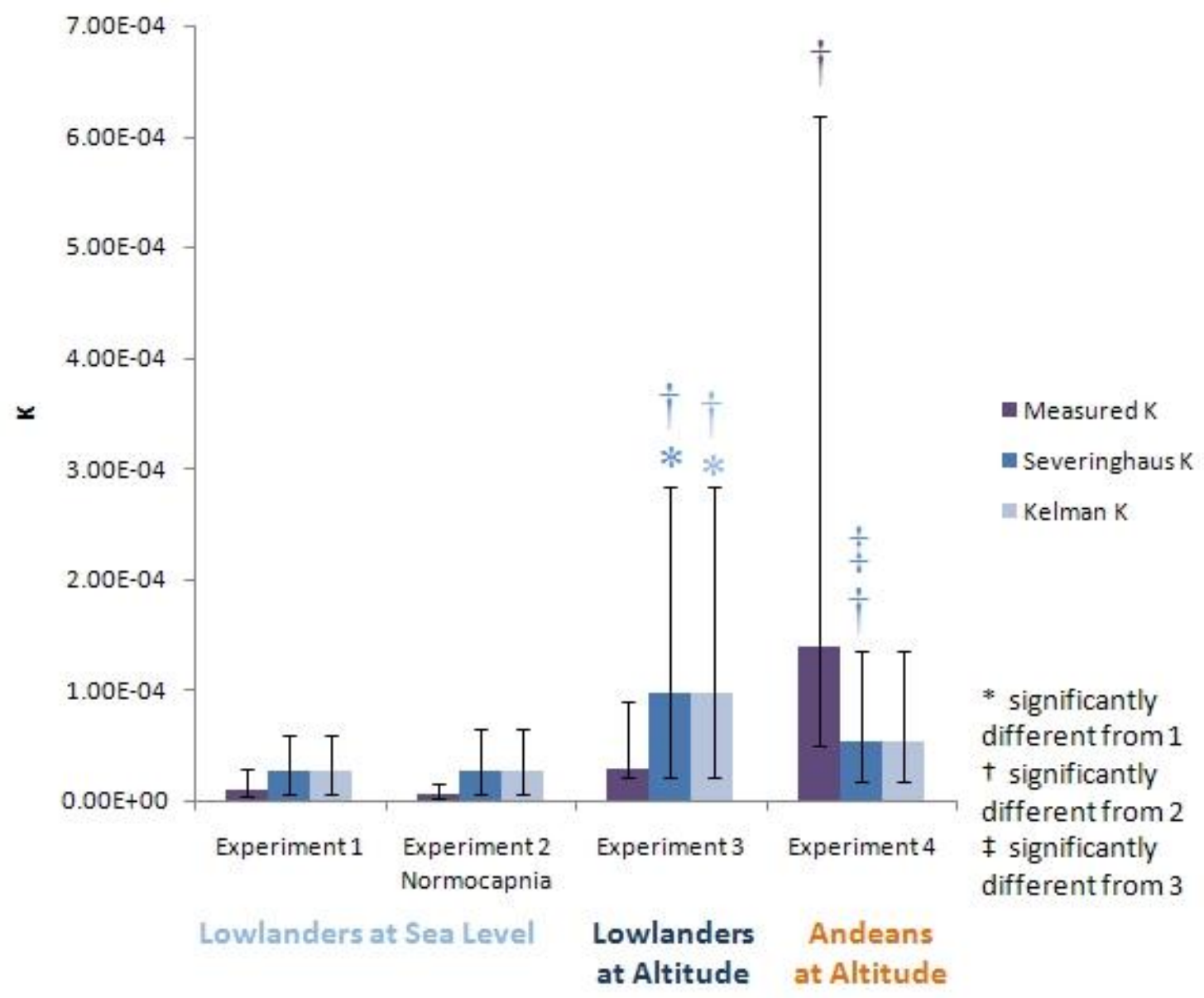

\subsubsection{1 $\quad \mathrm{P}_{50}$ Comparison}

$\mathrm{P}_{50}$ values were compared across Experiments. For all $\mathrm{SO}_{2}$ types, $\mathrm{P}_{50}$ values in Experiments 1 and 2 were significantly higher than those in Experiments 3 and 4, indicating that those at high altitude had significantly left shifted curves with respect to those at sea level. In the cases of Measured and Kelman, $\mathrm{P}_{50}$ in Experiment 4 was almost significantly lower than that in Experiment 3 ( $\mathrm{p}=0.054$ and $\mathrm{p}=0.67$ ). With more subjects, these differences would probably have been significant. This seems to indicate that chronically acclimatized Andeans have a left- 
shifted curve with respect to that of acutely acclimatized lowlanders who have been at high altitude for two weeks.

\subsubsection{Hill Coefficient (n Value) Comparison}

Hill Coefficients in Experiments 1 and 2 were higher than those in experiments 3 and 4, using all $\mathrm{SO}_{2}$ types. For Measured $\mathrm{SO}_{2}$ the Hill Coefficients in Experiments 1 and 2 differed significantly from those in Experiment 4. For Severinghaus $\mathrm{SO}_{2}$ those in Experiments 1 and 2 differed significantly from those in Experiment 3. For Kelman $\mathrm{SO}_{2}$, those in Experiment 1 differed significantly from those in Experiments 3 and 4. Those in Experiment 4 also had higher $n$ values than those in Experiment 3 when using Kelman $\mathrm{SO}_{2}$.

The Hill Coefficient data is less consistent than the $\mathrm{P}_{50}$ data, and seems to depend on $\mathrm{SO}_{2}$ type.

\subsubsection{Composite ODC Comparison across Groups using Measured $\mathrm{SO}_{2}$}

The average ODCs for each normocapnic experiment are show below, in Figure 19. Measured $\mathrm{SO}_{2}$ was used in order to generate $\mathrm{n}$ and $\mathrm{K}$ values for each subject in each condition. The average $\mathrm{n}$ and $\mathrm{K}$ value for each condition were used to create a curve. A few subjects were excluded from this analysis because they were outliers (had data more than 3 interquartile ranges from the mean). Figure 19 
Figure 19: Average ODCs for Each Experimental Group at Normocapnia using Measured $\mathrm{SO}_{2}$

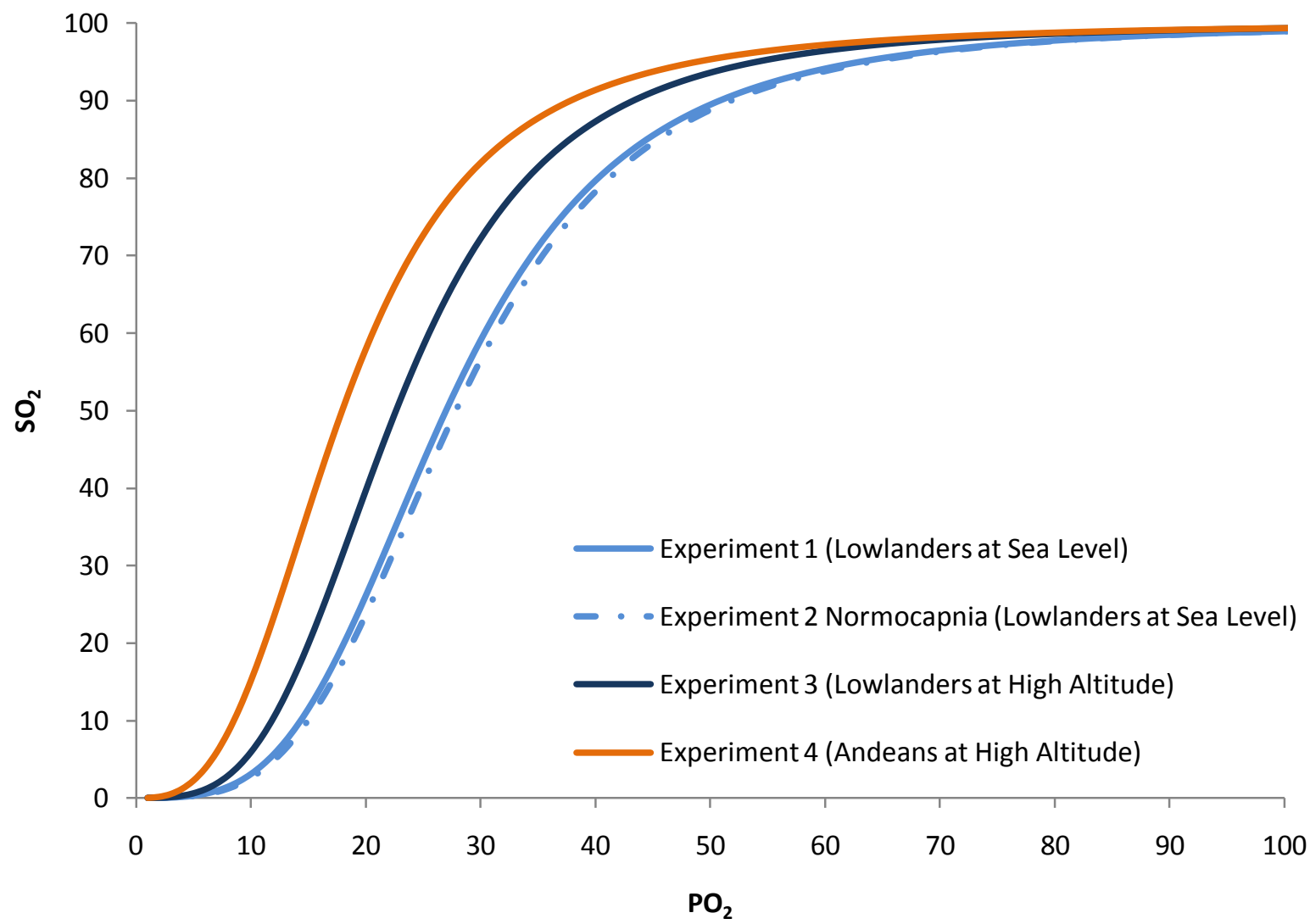

Figure 20 shows the frequency distribution for $\mathrm{P}_{50}$, using measured $\mathrm{SO}_{2}$, comparing across experimental groups. Figure 21 shows the frequency distribution for $n$ value, using measured $\mathrm{SO}_{2}$, comparing across experimental groups. Lowlanders at sea level were combined into a single group for these graphs. 
Figure 20: $\mathbf{P}_{50}$ Frequency Distribution using Measured $\mathrm{SO}_{2}$ across Experimental Groups

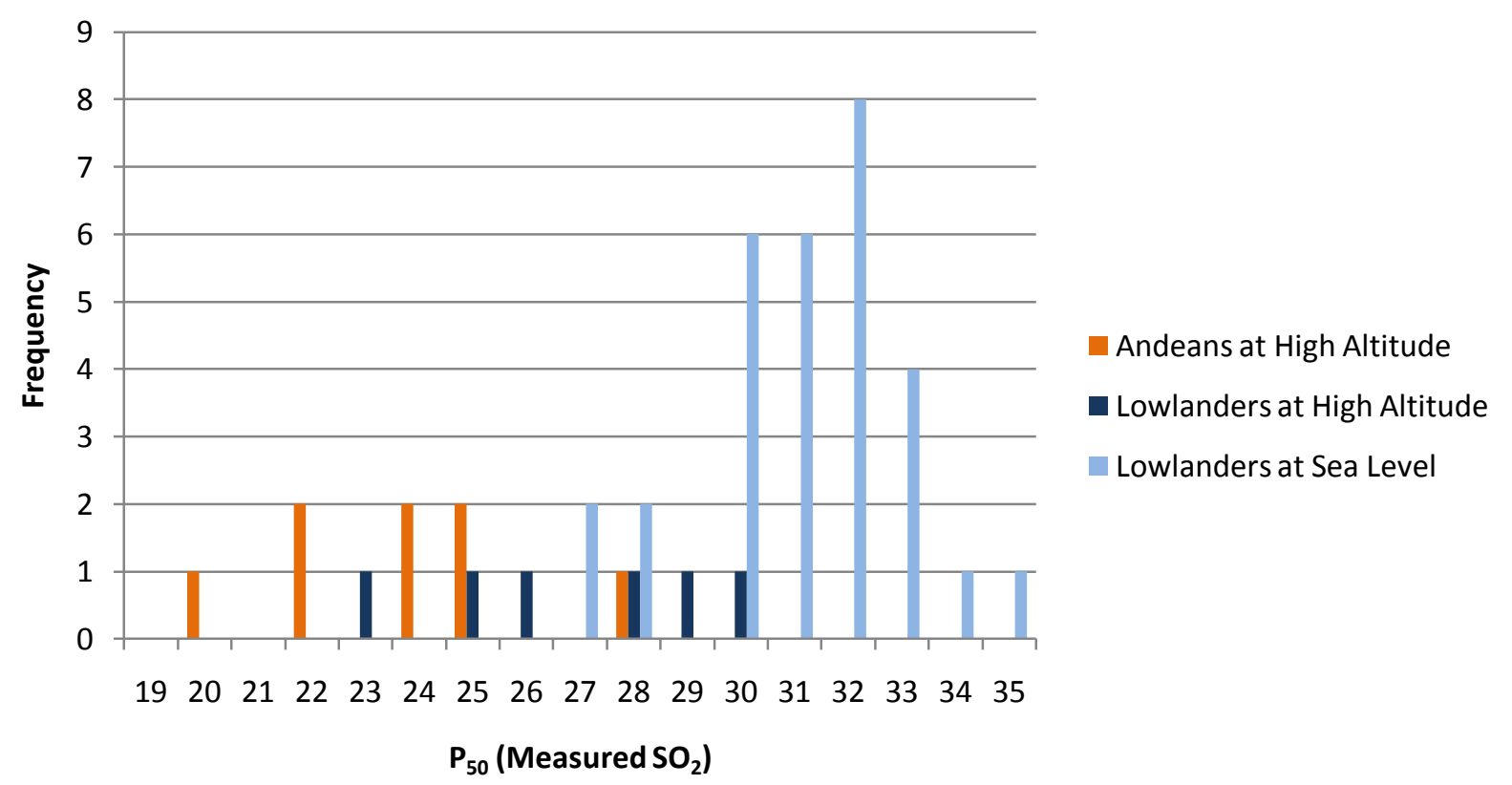

Figure 21: n Value Frequency Distribution using Measured $\mathrm{SO}_{2}$ across Experimental Groups

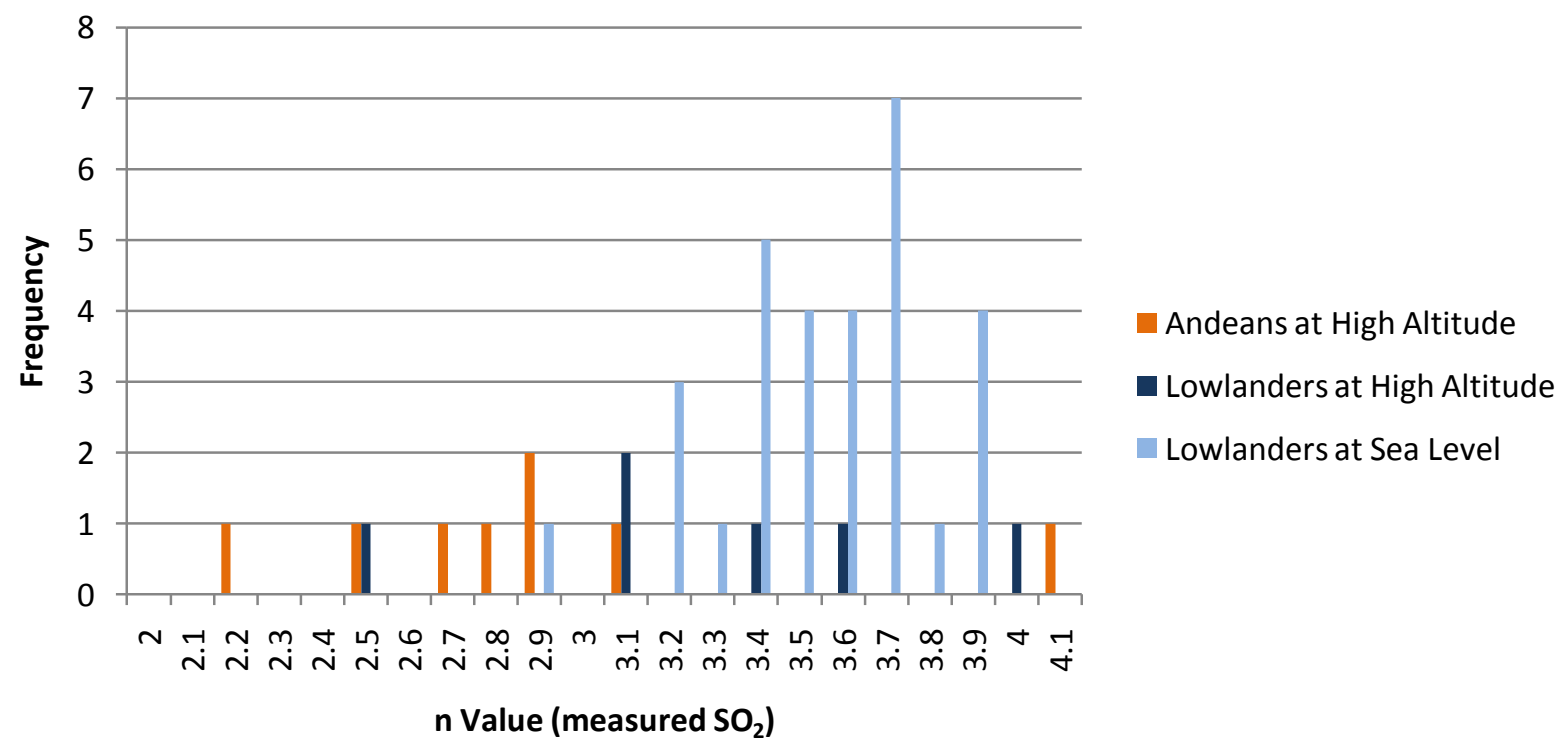




\subsubsection{Influence of $\mathrm{PCO}_{2}$ on the Hill Parameters}

The influence of $\mathrm{PCO}_{2}$ on the Hill parameters was investigated in Experiment 2, in which subjects were tested under three $\mathrm{PCO}_{2}$ conditions. A two-way repeated measures ANOVA was done on the data from this group in order to assess the influence of both $\mathrm{SO}_{2}$ type and $\mathrm{PCO}_{2}$ level on the Hill Parameters. The detailed ANOVA results are presented in Appendix C. This analysis showed that there was a main effect of $\mathrm{PCO}_{2}$ on $\mathrm{P}_{50} . \mathrm{P}_{50}$ in the hypercapnia condition was significantly higher (right-shifted) from those in the hypocapnia $(\mathrm{p}<0.001)$ and normocapnia conditions $(\mathrm{p}<0.001)$. The difference between $\mathrm{P}_{50}$ in the normocapnia and hypocapnia conditions was not significant, even though the $\mathrm{PCO}_{2}$ difference was greater between these two conditions than between normocapnia and hypercapnia. $\mathrm{PCO}_{2}$ did not significantly influence the Hill Coefficient (n value).

\subsubsection{Descending and Ascending $\mathrm{PO}_{2}$ Comparison}

The protocol for Experiment 1 included progressive hypoxia followed by a reversal of $\mathrm{PO}_{2}$ steps to return to a $\mathrm{PO}_{2}$ of $100 \mathrm{mmHg}$. It was hypothesized that each subject's descent profile might differ from his or her ascent profile due to carryover effects of hypoxia. To test this hypothesis each subject's data was split into descending and ascending data. The lowest $\mathrm{PO}_{2}$ value appeared in both data sets. $\mathrm{P}_{50}$ analysis was then separately conducted on each data set, and a paired t-test was used to compare results for the $3 \mathrm{P}_{50}$ parameters. Two subjects were excluded from this analysis. One subject had only one data set while the other subject's data did not fit the Hill equation. Analysis for the other subjects did not reveal any significant differences between descending and ascending $\mathrm{P}_{50}(t(10)=0.797, p=0.444), \mathrm{n}(t(10)=0.0715, p=0.944)$ and $\mathrm{K}$ $(t(10)=0.445, p=0.666)$. It was therefore concluded that the in vivo ODC does not depend on the order of $\mathrm{PO}_{2}$ steps. 


\section{Discussion}

\subsection{Main Findings}

Our knowledge about the $\mathrm{O}_{2}$ affinity of $\mathrm{Hb}$ comes from in vitro studies in which the temperature, $\mathrm{PCO}_{2}$ and $\mathrm{pH}$ of blood are maintained while $\mathrm{PO}_{2}$, the independent variable, is changed over a wide range of partial pressures and the corresponding $\mathrm{SO}_{2}$ values are recorded. This method allows the characterization of the $\mathrm{PO}_{2}-\mathrm{SO}_{2}$ relationship of blood for an animal species or human ethnic-genetic pool, which may be subdivided by age (including foetal versus post natal differentiation), sex and altitude exposure history. The curve showing the $\mathrm{Hb}$ affinity for $\mathrm{O}_{2}$ over a range of $\mathrm{PO}_{2}$ values is not linear; it is sigmoidal as a result of increased cooperative binding of $\mathrm{Hb}$ subunits at low $\mathrm{PO}_{2}$ values and reduced cooperative binding as $\mathrm{Hb}$ becomes saturated with $\mathrm{O}_{2}$. By varying the $\mathrm{PO}_{2}$ while holding constant the temperature, $\mathrm{PCO}_{2}$ and $\mathrm{pH}$, the intrinsic $\mathrm{O}_{2}$ affinity of $\mathrm{Hb}$, usually presented as an oxyhaemoglobin dissociation curve, can then be designated by a single $\mathrm{PO}_{2}-\mathrm{SO}_{2}$ point. By convention this point has been the $\mathrm{P}_{50}$, the $\mathrm{PO}_{2}$ at which $50 \%$ saturation occurs. Temperature, $\mathrm{pH}, \mathrm{PCO}_{2},[2,3-\mathrm{DPG}]$ and other factors have the ability to offset the position of the ODC by increasing or decreasing the $\mathrm{O}_{2}$ affinity of $\mathrm{Hb}$ throughout the $\mathrm{PO}_{2}$ range. $\mathrm{P}_{50}$ measured under standard conditions can then be used to quantitate the change in affinity (i.e., offset) or to identify any intrinsic differences of the $\mathrm{O}_{2}$ affinity of $\mathrm{Hb}$ in different study populations.

The great advantage of mapping out the ODC by applying progressive reductions of $\mathrm{PO}_{2}$ to blood in a test tube is that it allows the maintenance of standard conditions without uncontrolled exposure to the products of body processes that are triggered by hypoxia, which may independently affect the $\mathrm{P}_{50}$. By the same token, the great limitation of these in vitro methods is that they cannot be used to measure the $\mathrm{O}_{2}$ affinity of $\mathrm{Hb}$ in response to progressive hypoxia in vivo. The results of studies showing increased $\mathrm{P}_{50}$ in animals adapted to chronic hypoxia and high altitude led us to propose that despite in vitro evidence to the contrary, similar changes in the $\mathrm{O}_{2}$ affinity of $\mathrm{Hb}$ take place in humans. We proposed to study the question in vivo in anticipation that this approach would support our hypothesis; a negative study would support the previous in vitro results.

This is the first study to characterize the ODC in vivo. In this study we exposed volunteers to progressive isocapnic hypoxia while measuring $\mathrm{PaO}_{2}, \mathrm{PaCO}_{2}$ and $\mathrm{pH}$ and monitoring the 
corresponding $\mathrm{SO}_{2}$ as measured directly, by co-oximetry, or non-invasively, by pulse oximetry. We found that the $\mathrm{P}_{50}$ of lowlanders at sea level is greater than those previously reported using in vitro blood analysis. Whereas the same in vitro methods have led us to believe that the $\mathrm{P}_{50}$ in native Andeans living at $3600 \mathrm{~m}$ is near that of lowlanders living near sea level, our in vivo measurements indicate a marked relative left shift of the Andean ODCs. This shift was even present, to a significant, but lesser extent, in acclimatized lowlanders who spent two weeks at the same altitude.

When two of the most widely accepted models of in vitro ODC data, those of Severinghaus and Kelman, were applied to sets of our in vivo data, the models poorly predicted the in vivo ODC. Even at sea level, where we expected the Severinghaus and Kelman models to be accurate, they both over-predicted the $\mathrm{P}_{50}$ values. We expected the models, which assume sea level [2,3-DPG], to underestimate $\mathrm{P}_{50}$ at high altitude (Benesch \& Benesch, 1967). Meanwhile, the $\mathrm{P}_{50}$ values predicted by the models were considerably greater than those measured in vivo for the Andeans at high altitude, while the $\mathrm{P}_{50}$ values measured in vivo were similar to those predicted by the models for the lowlanders acclimatized for two weeks to an altitude of $3600 \mathrm{~m}$. Overall, these findings suggest that during progressive hypoxia in vivo there is at least one other mechanism that controls the $\mathrm{O}_{2}$ affinity of $\mathrm{Hb}$ but is not taken into account in the models of in vitro ODC prediction.

I will now discuss my in vivo findings and then return to further discussions regarding in vitro studies.

\subsection{The in vivo Approach to Measuring the ODC}

This in vivo study provides evidence that, like the animals mentioned above, humans respond to hypoxia by increasing their $\mathrm{Hb}$ affinity for $\mathrm{O}_{2}$. This new finding is not supported by previous studies that were done using in vitro methods, probably because it reflects in vivo conditions that cannot be attained during progressive hypoxia in a blood sample. Using an in vivo approach to study the ODC is advantageous because it highlights the changes that happen in the body during progressive hypoxia. However, it is very difficult to measure the ODC under in vivo conditions because in vivo hypoxia leads to hyperventilation, which leads to a fall in $\mathrm{PCO}_{2}$ and an increase in $\mathrm{pH}$. Because both $\mathrm{PCO}_{2}$ and $\mathrm{pH}$ influence the position of the ODC, it is impossible to measure a single ODC if these factors are allowed to change. $\mathrm{PCO}_{2}$ and $\mathrm{pH}$ can be held stable in 
the blood during progressive hypoxia in vitro, but doing so excludes any effects induced by hypoxia on the other tissues of the body, singly or in concert. In vivo manipulation of $\mathrm{PO}_{2}$ and $\mathrm{SO}_{2}$ would provide a more natural method of examining the ODC. However, it is very difficult to carry out because of the tight link between $\mathrm{PO}_{2}$, ventilation, $\mathrm{PCO}_{2}$ and $\mathrm{pH}$. There are few practical methods of dissociating these variables in the laboratory, and there are no methods that are suitable for studies at altitude. It is for this reason that the ODC has not been previously studied in vivo.

We used an automated method using previously described principles to control $\mathrm{PetCO}_{2}$ and $\mathrm{PetO}_{2}$ independently of one another and of ventilation (Slessarev et al., 2007). The method was used to hold $\mathrm{PetCO}_{2}$ steady at a predetermined level while inducing step changes in $\mathrm{PetO}_{2}$ that led to progressive hypoxia. Both $\mathrm{PetO}_{2}$ and $\mathrm{PetCO}_{2}$ were held stable independent of ventilation. Below (Figure 22) is an example of such a study in a subject at sea level. Because $\mathrm{PCO}_{2}$ is one of the factors that influence in vivo $\mathrm{pH}$, by controlling $\mathrm{PetCO}_{2}$ we are able to hold $\mathrm{pH}$ roughly constant. However, $\mathrm{pH}$ may still vary due to changes in metabolism and other factors that may occur during in vivo hypoxia. Some considerations and caveats of measuring the ODC in vivo, with respect to $\mathrm{PCO}_{2}, \mathrm{pH}$ and $\mathrm{PO}_{2}$, will be discussed below.

Figure 22: Sample ODC Data in a Subject at Sea Level

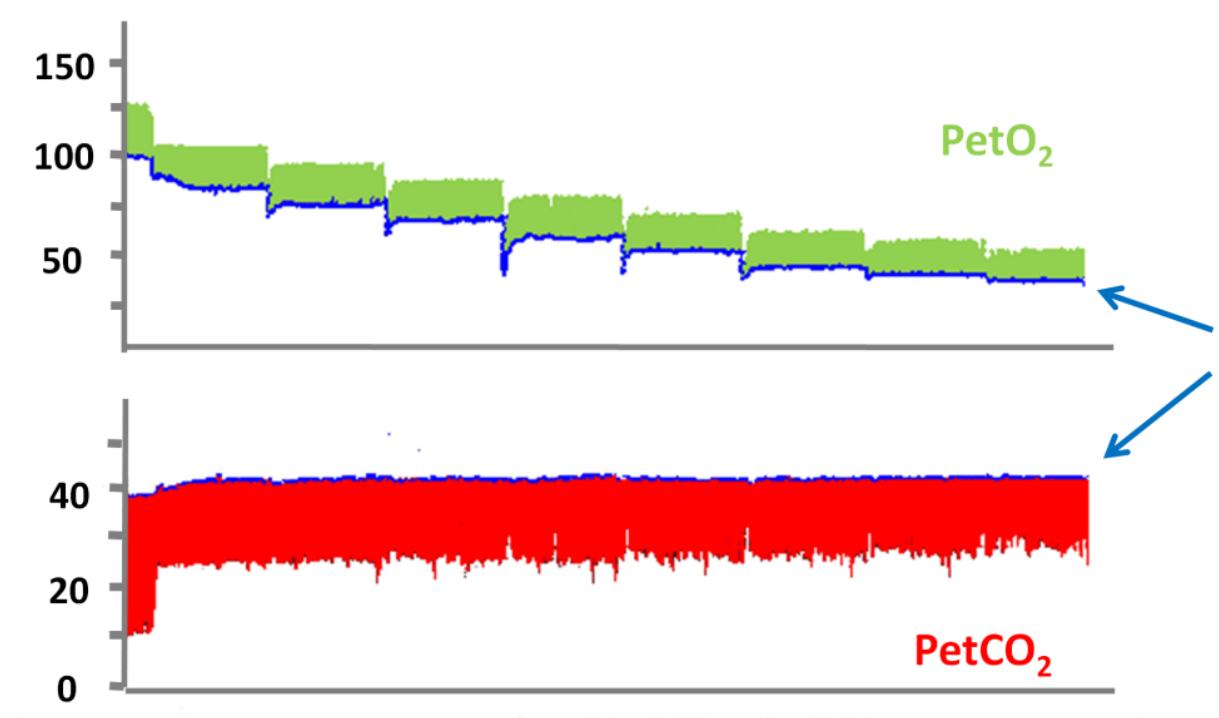

End-Tidal Values 


\subsection{1 $\quad \mathrm{PCO}_{2}$}

In order to successfully target a specific $\mathrm{PetCO}_{2}$ and prevent $\mathrm{PetCO}_{2}$ drift, it is important to ensure that the subject's resting parameters, resting $\mathrm{PetCO}_{2}, \mathrm{PetO}_{2}, \mathrm{VCO}_{2}$ and $\mathrm{VO}_{2}$, have been properly measured (Slessarev et al., 2007). However, these parameters may change after they are measured, as speaking, subject movement or exertion can influence $\mathrm{VCO}_{2}, \mathrm{VO}_{2}$, resting $\mathrm{PetO}_{2}$ and resting $\mathrm{PetCO}_{2}$. For all subjects at altitude, $\mathrm{PetCO}_{2}$ remained within $\pm 0.5 \mathrm{mmHg}(\mathrm{Std}$ Dev) during at least the last $60 \mathrm{~s}$ of each step. Throughout testing, $\mathrm{PetCO}_{2}$ remained within \pm 1.0 $\mathrm{mmHg}$ for all subjects. Similar data were not calculated for the lowlanders at sea level in Experiments 1 and 2, but the methodology and technology was the same so the extent of control is expected to be similar. $\mathrm{PetCO}_{2}$ with this method was shown to be equal to $\mathrm{PaCO}_{2}$ (Ito et al., 2008), but we did not depend on this and measured $\mathrm{PaCO}_{2}$ as well. The difference between $\mathrm{PetCO}_{2}$ and $\mathrm{PaCO}_{2}$ for lowlanders at altitude was $2.09 \pm 0.89 \mathrm{mmHg}$ and for Andeans at altitude it was $3.47 \pm 1.70 \mathrm{mmHg}$.

\subsection{2 $\mathrm{pH}$}

$\mathrm{pH}$ directly influences the position of the ODC via the Bohr effect. One factor that affects $\mathrm{pH}$ is $\mathrm{PCO}_{2}$. $\mathrm{pH}$ can also be influenced by hypoxia, via lactic acid production, and by other factors such as strong ion difference and organic phosphate levels. As such, even if $\mathrm{PCO}_{2}$ is controlled perfectly, pH may still change throughout the study, especially with progressive hypoxia, affecting the position of the ODC. In this study, $\mathrm{pH}$ was kept constant and no progressive changes in $\mathrm{pH}$ were seen in subjects. For each subject, $\mathrm{pH}$ varied less than \pm 0.02 (Std Dev) within a trial. These $\mathrm{pH}$ changes were minor and too small to account for the observed left shift of ODC.

\subsection{3 $\quad \mathrm{PO}_{2}$}

Unlike in vitro methods, in vivo measurement of the ODC is limited by the safety of the subject and the ability of the subject to withstand progressive hypoxia. Because the steep portion of the ODC is what defines it, it is important to achieve $\mathrm{SO}_{2}$ values that fall on this part of the curve. A limitation of in vivo measurement of the ODC is the tolerance of subjects for hypoxia. Another caveat of this method is that physical discomfort of in vivo hypoxia may influence the study results. 
Unlike the case of $\mathrm{PetCO}_{2}$ being equal to $\mathrm{PaCO}_{2}$ and independent of shunt fraction, when using the RespirAct ${ }^{\mathrm{TM}}$ (Ito et al., 2008), targeting $\mathrm{PaO}_{2}$ is more problematic because the size the shunt fraction cannot be anticipated. Nevertheless, we found that at $\mathrm{PetO}_{2}$ less than $80 \mathrm{mmHg}$, the average difference between $\mathrm{PetO}_{2}$ and $\mathrm{PaO}_{2}$ was $6.89 \pm 2.9 \mathrm{mmHg}$ for the lowlanders at high altitude and $3.69 \pm 3.07 \mathrm{mmHg}$ for the Andeans. For all subjects at high altitude, $\mathrm{PetO}_{2}$ remained within $\pm 1.5 \mathrm{mmHg}$ (Std Dev) during at least the last $60 \mathrm{~s}$ of each step. Similar data were not calculated for the lowlanders at sea level in Experiments 1 and 2, but the methodology and technology was the same so the extent of control is expected to be similar. As the $\mathrm{PaO}_{2}$ was taken from invasive values, the $\mathrm{PetO}_{2}$ did not affect the characterization of the in vivo ODCs.

\subsubsection{Blood Gas and $\mathrm{SO}_{2}$ Measurements}

$\mathrm{PetCO}_{2}$ and $\mathrm{PetO}_{2}$ were continuously measured by gas sensors in the RespirAct ${ }^{\mathrm{TM}}$ during in vivo ODC testing. The $\mathrm{CO}_{2}$ sensor within the RespirAct ${ }^{\mathrm{TM}}$ (Ir3107, Servomex Group Ltd, Sugar Land, TX, USA) is accurate to within $\pm 0.1 \%$ of the $\mathrm{CO}_{2}$ within the range of $0-10 \% \mathrm{CO}_{2}$. The $\mathrm{O}_{2}$ sensor (UFO 130, Teledyne Analytical Instruments, City of Industry, CA, USA) is accurate to within $1 \%$. Both sensors were calibrated prior to each experiment.

Each $\mathrm{PetO}_{2}$ step in our experiments lasted at least 2 minutes (in Experiment 1 they lasted 4 minutes and in Experiment 2 they lasted 3 minutes), and blood samples were drawn at the very end of each step. In the experiments at sea level the blood samples were analyzed using the Instrumentation Laboratory GEM Premier 4000, and in the experiments at high altitude the blood samples were analyzed using the the i-STAT (Abbott Point of Care, Illinois, USA), a handheld, portable system. These are commercially available devices that conform to required

specifications. In the case of the lowlanders at sea level $\mathrm{SO}_{2}$ was directly measured in the blood sample using the Gem 4000 device. We did not have access to a co-oximeter at high altitude. We instead used a finger pulse oximeter, the Onyx II 9550 (Nonin Medical, Inc., Plymouth MN). This device is rated as accurate $\pm 2 \%$ in the saturation range between $70-100 \%$. $\mathrm{SpO}_{2}$ was recorded manually from this device at the time of each blood sampling.

\subsection{5 $\mathrm{P}_{50}$ Calculation}

The Hill equation (Hill, 1910) was used in this study to describe the in vivo ODCs and compare them across conditions and across methods of measurement. This equation describes the 
relationship between a ligand and its enzyme or receptor. The Hill coefficient, $\mathrm{n}$, defines whether there is cooperative binding, negative cooperative binding, or non-cooperative binding between the two molecules. Traditionally, the Hill co-efficient for the association of $\mathrm{Hb}$ and $\mathrm{O}_{2}$ has been taken to be some value between 2.8 and 3, indicating co-operative binding between the two molecules. This is consistent with the observation that the ODC has a sigmoidal shape. The actual value of the Hill coefficient will depend upon the conditions under which the blood was taken and analyzed. This robust equation is still widely used to describe the $\mathrm{Hb}-\mathrm{O}_{2}$ relationship and calculate the $\mathrm{P}_{50}$.

This is the first time that the Hill equation has been used to describe the ODC using multiple data points obtained in vivo. As such, the question remains as to how well it fits such data, especially given that the data in this study were only taken from the top-most portion of the ODC. While this is the physiological range of the curve, using only data from this range may decrease the accuracy with which this equation represents the in vivo ODC.

When we first fit our data to the Hill equation, it became apparent that data points at high $\mathrm{PO}_{2}$ values greatly reduced the fit of the equation. Fit was assessed by calculating the $\mathrm{R}^{2}$ value describing the relationship between the measured data and the line of best fit. When using the data points at high $\mathrm{PO}_{2}$ values the $\mathrm{R}^{2}$ was often below 0.90 . When these data points were removed, the $\mathrm{R}^{2}$ value was, in most cases, greater than 0.95 . Because the highest data points fall on the flat part of the curve and are therefore less representative of the curve than the points that fall on the steeper portion, these data points were removed for the $\mathrm{P}_{50}$ analysis. This was specifically done because, if they were included, the curve-fitting program would accommodate these points to the exclusion of the points in the middle range.

\subsection{The in vivo ODC at Sea Level and High Altitude}

In this study we used the Hill equation to identify the $\mathrm{P}_{50}$ from the data generated in vivo. We found that the $\mathrm{P}_{50}$ values of both the lowlanders at high altitude $(26.2 \pm 2.59 \mathrm{mmHg})$ and the Andeans at high altitude $(23.2 \pm 2.66 \mathrm{mmHg})$ were significantly left-shifted from those of the lowlanders at sea level $(30.5 \pm 1.85 \mathrm{mmHg})$. There was also a strong trend for the $\mathrm{P}_{50}$ of the Andeans at high altitude to be lower (left-shifted) than those of the lowlanders at high altitude $(\mathrm{p}=0.054)$. It is possible that a larger sample would provide the power to confirm such a difference. 
The difference in the position of the ODCs of Andeans and lowlanders at high altitude may have been due to the duration of acclimatization (two weeks vs. a lifetime, including a pre-natal period). On the other hand, as the mechanism that increases $\mathrm{O}_{2}$ affinity of the $\mathrm{Hb}$ in the course of progressive hypoxia is unknown, it is possible that there are inducible responses to hypoxia in lowlanders and genetic or epigenetic factors acquired by the highlanders over the potentially 11,000 years of residency at altitude. This conjecture is still appropriate even though at the moment there is no proof of such adaptation in this population. On the other hand, such a mechanism may not have been previously discernable because there has not been a means of detecting the left shift of the ODC using in vitro methods.

\subsubsection{Previous Studies in Lowlanders and Native Highlanders at High Altitude}

Previous in vitro studies performed on the blood of both highlanders and lowlanders at high altitude have not always found a shift of the ODC and, when a shift was found, its direction was inconsistent. Since the discovery of 2,3-DPG, most in vitro studies have not found a shift in the ODC in blood of either lowlanders or high altitude natives at high altitude. The lack of a shift of the ODC at high altitude has been attributed to a balance between the leftward shift caused by respiratory alkalosis resulting from the hypoxic ventilatory response, and the rightward shift caused by hypoxia-induced increases in [2,3-DPG].

During AMREE, Winslow et al. (1984) measured $\mathrm{P}_{50}$ in vitro from blood taken at sea level and on Mount Everest, at $6300 \mathrm{~m}, 8050 \mathrm{~m}$ and the summit, at $8848 \mathrm{~m}$. There was no shift in the physiological ODC of lowlanders up to an altitude of $6300 \mathrm{~m}$. However, above this altitude, the ODC was found to be shifted progressively leftward (in two subjects at $8050 \mathrm{~m}$ and only one subject at $8848 \mathrm{~m}$ ). They attributed the leftward shift above $6300 \mathrm{~m}$ to the fact that above 6300 $\mathrm{m}$ there is a marked uncompensated respiratory alkalosis that dominates over the effect of increased [2,3-DPG]. The leftward shift at extreme altitude was considered to be an adaptive mechanism that preserves arterial $\mathrm{Hb}$ by enhancing lung $\mathrm{O}_{2}$ uptake in the presence of severe reductions in atmospheric $\mathrm{PO}_{2}$.

During OE II (Wagner et al., 2007), which took place in 1985, five subjects were decompressed in a hypobaric chamber to the equivalent altitude of the summit of Mount Everest over a period of 42 days. The ODCs measured in the blood of those who participated in OE II, defined by 
their $\mathrm{P}_{50}$ values, were not shifted from their sea level control values at any altitude, even beyond $6300 \mathrm{~m}$. These $\mathrm{P}_{50}$ results, published in 2007, differed from those gathered above $6300 \mathrm{~m}$ during AMREE. The authors gave a few possible reasons for the discrepancy between the data from AMREE and OE II. Firstly, AMREE only had data from one subject at the summit of Everest and two subjects at $8050 \mathrm{~m}$, while OE II had multiple samples from each of the 5 subjects above $6300 \mathrm{~m}$. With such a small sample size and only one data sample per subject, the data from above $6300 \mathrm{~m}$ for the subjects in AMREE may not have been representative. Furthermore, the data from above $6300 \mathrm{~m}$ in AMREE were from venous samples, so arterial $\mathrm{pH}$ was calculated and not directly measured. Lastly, the ascent profiles of the two groups were different, with those in OE II ascending more quickly than those who reached the summit in AMREE. The difference in ascent profiles may account for the fact that those in AMREE had a greater degree of respiratory alkalosis, which would have led to a greater shift in their physiological $\mathrm{P}_{50} \mathrm{~S}$.

In 1990, Mairbaurl et al., (1990) published the first study of the physiological ODC in acclimatizing lowlanders under natural acid-base conditions. They tested 11 mountaineers at sea level and after 1 and 5 days at an altitude of $4559 \mathrm{~m}$, and measured the in vitro ODC at physiological $\mathrm{pH}, \mathrm{PCO}_{2}$ and [2,3-DPG] without assuming any relationship between these variables and $\mathrm{Hb}-\mathrm{O}_{2}$ affinity. On the first night after arrival at $4559 \mathrm{~m}$ the physiological $\mathrm{P}_{50} \mathrm{~S}$ were significantly lower than their sea level values, but by the fifth day of altitude exposure the $\mathrm{P}_{50} \mathrm{~s}$ returned to baseline levels. The initial decrease in $\mathrm{P}_{50}$ upon exposure to high altitude was attributed to a respiratory alkalosis in the beginning stages of metabolic compensation. Although the compensation for the alkalosis remained incomplete with continued exposure, the $\mathrm{P}_{50}$ returned to the sea level value under the influence of increased [2,3-DPG]. Another interesting finding from this study is that the Bohr Effect is increased in sojourners at high altitude. This means that both $\mathrm{O}_{2}$ uptake at the lungs and $\mathrm{O}_{2}$ offloading at the tissues are enhanced, because $\mathrm{PCO}_{2}$ is low at the lungs and high at the tissues.

Few studies have examined the ODC in native highlanders under their physiological acid-base conditions. In one such study, Winslow et al. (1981) measured the complete ODCs of 46 Peruvian highlanders at $4540 \mathrm{~m}$ and 25 controls at sea level. When the ODC measurements for the Peruvians were corrected to physiological $\mathrm{pH}(7.439 \pm 0.065)$, there was no difference between the $\mathrm{P}_{50}$ values of the Peruvians at altitude and the sea level controls. Great variability was found in both groups, but the range of $\mathrm{P}_{50}$ values was greater at high altitude. As with the 
instances above of acclimatized lowlanders, the similarity between the $\mathrm{P}_{50}$ values of the high altitude natives and sea level controls was attributed to an in vivo balance of the influences of alkalosis and increased [2,3-DPG] on the affinity of $\mathrm{Hb}$ for $\mathrm{O}_{2}$. A later study by Winslow et al. (1989) showed similar results in a group of high altitude Sherpas living at $3700 \mathrm{~m}$, whose physiological ODCs were not shifted as compared to controls.

\subsubsection{Adaptation to Hypoxia by Animals}

In contrast to what previous in vitro studies have concluded about the ODC in humans, there is consistent evidence of left shift of ODC in animals adapted to hypoxia. It has been postulated that a leftward shift in hypoxic animals can be due to a) an intrinsically high $\mathrm{Hb}_{-} \mathrm{O}_{2}$ affinity, b) an decrease in organic phosphate concentration, or c) a decrease in sensitivity to organic phosphates (Petschow et al., 1977).

The bar headed goose flies over the Himalayas and has remarkably adapted to high altitude hypoxia (Petschow et al., 1977). This bird is native to high altitude and has an $\mathrm{Hb}-\mathrm{O}_{2}$ affinity (standard $\mathrm{P}_{50}=29.7 \mathrm{mmHg}$ ) that is much greater than its relatives that are native to sea level (e.g. Canada goose standard $\mathrm{P}_{50}=42 \mathrm{mmHg}$ ). In the case of the bar headed goose, the difference in $\mathrm{Hb}-\mathrm{O}_{2}$ affinity is not due to intrinsic characteristics of the $\mathrm{Hb}$. Rather, it is due to reduced interaction between $\mathrm{Hb}$ and organic phosphates, such as 2,3-DPG.

High altitude camelids, such as llamas and alpacas, have a number of adaptations to hypoxia. These animals have a relatively high number of RBCs but low hematocrit because their RBCs are small. Their RBCs are elliptical in shape, and live only around 60 days. Despite similar amounts of 2,3-DPG, the ODCs of camelids are left-shifted with respect to those of lowlanders at sea level ( $\mathrm{P}_{50}$ of llamas is approximately $21 \mathrm{mmHg}$ ), and this shift persists even in llamas that are born and raised at sea level (Banchero et al., 1971;Reynafarje et al., 1975). This left shift is at least partly due to a persistence into adulthood of foetal $\mathrm{Hb}(55 \%$ foetal $\mathrm{Hb})$, which has higher $\mathrm{O}_{2}$ affinity than adult $\mathrm{Hb}$. It has also been shown that llamas have lower venous $\mathrm{PO}_{2}$ and $\mathrm{SO}_{2}$ than humans, indicating a greater capacity for $\mathrm{O}_{2}$ extraction (Banchero et al., 1971). Thus, despite an increase in affinity, camelids do not seem to have difficulty extracting $\mathrm{O}_{2}$ at the tissues. 
Tadpoles tend to live in stagnant water that is high in $\mathrm{CO}_{2}$ and low in $\mathrm{O}_{2}$. However, they still manage to have a significantly higher $\mathrm{Hb}-\mathrm{O}_{2}$ affinity than adult bull frogs (Pinder \& Burggren, 1983). The difference in $\mathrm{Hb}-\mathrm{O}_{2}$ affinity that occurs with metamorphosis results from a change from larval $\mathrm{Hb}$ to adult $\mathrm{Hb}$. It cannot be due to changes in organic phosphate, as organic phosphate levels are actually lower in adult frogs than in tadpoles. The increased affinity of tadpole $\mathrm{Hb}$ for $\mathrm{O}_{2}$ may be due to a latent or reversed Bohr Effect, which has also been referred to as an "acid" Bohr Effect (Watt et al., 1980). In addition, binding of organic phosphates to tadpole $\mathrm{Hb}$ does not seem to greatly influence the affinity of $\mathrm{Hb}$ for $\mathrm{O}_{2}$ (Pinder \& Burggren, 1983).

\subsection{Explanation for the in vivo Left Shift of the ODC at High Altitude}

The purpose of this study was to determine the in vivo position of the ODC at sea level and high altitude. It was not designed to address the causes of the observed left shift of the ODC at high altitude, which was greater in chronically acclimatized Andeans than in acutely acclimatized lowlanders after two weeks of exposure to an altitude of $3600 \mathrm{~m}$. However, I can discuss possible causes for the left shift based on information from the published literature.

A number of factors are known to increase the affinity of $\mathrm{Hb}$ for $\mathrm{O}_{2}$ in humans: increased $\mathrm{pH}$, decreased temperature, decreased $\mathrm{PCO}_{2}$ and decreased [2,3-DPG]. These and perhaps other factors are controlled and regulated during exposure to high altitude and influence the shift of the ODC in both lowlanders and native Andeans. In native Andeans, genetic and epigenetic mechanisms may also be at work.

\subsubsection{Temperature}

The combination of $\mathrm{Hb}$ with $\mathrm{O}_{2}$ is an exothermic reaction, so when temperature is high the reverse reaction, which is endothermic, predominates. Temperature was not measured in the current study. However, it was assumed to be normal throughout. Hence, it is not expected that temperature played a role in the results of this study.

\subsection{2 $\quad \mathrm{PCO}_{2}$ and $\mathrm{pH}$}

$\mathrm{CO}_{2}$ binds to $\mathrm{Hb}$ and reduces its affinity for $\mathrm{O}_{2}$ via the Haldane Effect. Additionally, it lowers $\mathrm{pH}$ and decreases the affinity of $\mathrm{Hb}$ for $\mathrm{O}_{2}$ via the Bohr Effect. Oxyhaemogobin is more acidic 
than reduced haemoglobin, so decreases in $\mathrm{pH}$ decrease the affinity of $\mathrm{Hb}$ for $\mathrm{O}_{2} \cdot \mathrm{H}^{+}$can also act as a ligand that binds to reduced $\mathrm{Hb}$, thereby decreasing its affinity for $\mathrm{O}_{2} . \mathrm{pH}$ can influence the position of the ODC via these mechanisms, independently of changes in $\mathrm{PCO}_{2}$. These factors act as offsets that affect the ODC throughout the range of $\mathrm{PO}_{2}$.

Exposure to high altitude is associated with the hypoxic ventilatory response. The increase in ventilation influences $\mathrm{O}_{2}$ transport in two ways. It increases $\mathrm{PaO}_{2}$ by increasing gas exchange with the atmosphere and it leads to a decrease in $\mathrm{PCO}_{2}$ and an associated respiratory alkalosis, both of which facilitate $\mathrm{O}_{2}$ loading from the atmosphere at the lungs by increasing $\mathrm{Hb}$ affinity for $\mathrm{O}_{2}$. While the alkalosis caused by hyperventilation is compensated for metabolically by renal excretion of the base $\mathrm{HCO}_{3}{ }^{-}$, this compensation is usually incomplete.

Compared to lowlanders at sea level $\left(\mathrm{PCO}_{2} 41.0 \pm 2.7 \mathrm{mmHg}\right) \mathrm{PCO}_{2}$ was reduced in lowlanders after two weeks at high altitude $(29.1 \pm 2.9 \mathrm{mmHg})$ and in native Andeans $(28.9 \pm 3.4 \mathrm{mmHg})$. Neither group at high altitude had complete metabolic compensation for respiratory alkalosis. Compared to the $\mathrm{pH}$ values of the lowlanders at sea level $(7.40 \pm 0.03)$, lowlanders after two weeks at high altitude and native Andeans had higher $\mathrm{pH}$ values $(7.44 \pm 0.02$ and $7.44 \pm 0.02$ respectively), which would tend to shift the ODC to the left. It is therefore likely that these factors contributed to the left shifts of the ODC that were seen in both groups of subjects at high altitude in this study. However, there were clearly additional factors involved, as the small degree of alkalosis was insufficient to account for the extent of the shift.

\subsubsection{2,3-DPG}

The relationship between [2,3-DPG] and $\mathrm{Hb}$ affinity for $\mathrm{O}_{2}$ was first discovered by Benesch and Benesch (1967) and Chanutin and Curnish (1967), who demonstrated the allosteric modulation of the $\mathrm{Hb}-\mathrm{O}_{2}$ relationship by 2,3-DPG. Lenfant et al. (1968) then found that exposure to high altitude is associated with both an increase in in vitro $\mathrm{P}_{50}$ and a parallel increase in [2,3-DPG]. While this study provided evidence of a correlation between exposure to high altitude, $\mathrm{P}_{50}$ and [2,3-DPG], causality was not explored.

Evidence of a causal relationship between [2,3-DPG] and ODC position at high altitude came from a later study by Lenfant et al. (1971), in which subjects made acidotic by acetazolamide before exposure to high altitude did not show the rightward shift in ODC position that was seen 
in the group members who were not given the drug. It was also shown that the respiratory alkalosis in response to hypoxia at high altitude increases the activity of phosphofructokinase (Minakami \& Yoshikawa, 1966), a rate limiting enzyme of glycolysis, increasing 2,3-DPG production. Hypoxia also increases the concentration of reduced Hb (Juel \& Milam, 1979), which has a higher affinity for 2,3-DPG than does $\mathrm{HbO}_{2}$. The reduced $\mathrm{Hb}$ binds to the available 2,3-DPG in the RBC, decreasing the concentration of free 2,3-DPG in the cell. Free 2,3-DPG inhibits one of the enzymes in its synthetic pathway, diphosphoglyceromutase (Rose, 1968), so when the concentration of free 2,3-DPG in the RBC decreases, the production of 2,3-DPG is increased.

The high altitude subjects in this study were tested at $3600 \mathrm{~m}$, where atmospheric pressure is roughly $495 \mathrm{mmHg}$ and atmospheric $\mathrm{PO}_{2}$ is roughly $100 \mathrm{mmHg}$. Despite increases in ventilation at high altitude and the associated beneficial effect on $\mathrm{PaO}_{2}$, the subjects were nevertheless hypoxic as compared to sea level. In the group of lowlanders the average $\mathrm{PaO}_{2}$ was $70.2 \pm 15.3$ $\mathrm{mmHg}$, and in the group of Andeans the average $\mathrm{PaO}_{2}$ was only $57.5 \pm 4.3 \mathrm{mmHg}$. These values were significantly lower than $104.6 \pm 8.3 \mathrm{mmHg}$, the average $\mathrm{PaO}_{2}$ in the subjects at sea level, so high altitude hypoxia was likely.

2,3-DPG was not measured in our studies, but previous data suggest that its concentration was increased in both the lowlanders and highlanders at high altitude (Lenfant et al., 1968;Torrance et al., 1970b). It is possible that the lowlanders at high altitude had a higher [2,3-DPG] than the Andean natives, as this trend has been shown in other samples of lowlanders and highlanders in the Andes (Torrance et al., 1970b). This might explain a higher $\mathrm{Hb}_{-} \mathrm{O}_{2}$ affinity in the Andeans as compared to the lowlanders at high altitude.

\subsubsection{Genetic Factors}

Genetic factors play a role in increasing $\mathrm{O}_{2}$ affinity in a variety of animals. Animals native to high altitude (such as llamas and yaks), but not animals that have recently been introduced to high altitude (such as sheep and cows), exhibit high haemoglobin affinity (Beall, 2007a) that is retained, to a large extent, when they are taken lower altitudes. Increased affinity has been achieved by changes in haemoglobin structure, as in deer mice in the Rocky Mountains (Storz et al., 2007) and high altitude chickens that were introduced to the Andes only 500 years ago (Velarde et al., 1991). Alternatively, it has also been achieved by a decrease in [2,3-DPG], as in 
Tibetan pika (Ge et al., 1998), or by decreased influence of 2,3-DPG, as in bar-headed geese (Petschow et al., 1977).

Given the prevalence of genetic changes in some organisms native to hypoxic conditions, it seems possible that part of the in vivo left shift of the ODCs of our Andean subjects at high altitude may have been caused by genetic or epigenetic factors. The presence of genetic adaptation could explain the greater left shift in Andean natives than in acutely acclimatized lowlanders, although the difference between the positions of the ODCs in the two groups may simply be a function of more complete acclimatization in the Andean group due a greater extent of altitude exposure.

Genetic changes have been shown to occur in less than 500 years in Andean chickens (Velarde $e t$ al., 1991), so it therefore seems possible that natural selection could have occurred since people arrived in the Andes 11,000 years ago. However, if genetic adaptations have occurred in human high altitude natives, they do not seem to be manifested in $\mathrm{Hb}$ or [2,3-DPG] changes. Tibetans and Andeans are reported to have normal $\mathrm{Hb} \mathrm{A}$ (Beall et al., 1998), and high altitude natives have been shown to have increased [2,3-DPG], which is associated with a rightward shift of the ODC (Torrance et al., 1970b).

An autosomal dominant major gene (an inferred genetic locus whose alleles have a large quantitative effect) for increased $\mathrm{Hb}-\mathrm{O}_{2}$ affinity has been found in the Tibetan population (Beall et al., 2004), which has been at altitude for approximately 25,000 years. Tibetans with the autosomal dominant allele have higher resting $\mathrm{SO}_{2}$ values than those at the same altitude who are homozygous for the low saturation allele. Similarly, those who are homozygous or heterozygous for the high $\mathrm{SO}_{2}$ allele have greater reproductive fitness, having more surviving children, primarily due to lower infant mortality. When the Darwinian fitness of those with the high saturation genotype was assigned as 1.0, the relative Darwinian fitness of those with the low saturation genotype was only 0.44 . For the sake of comparison, those who are homozygous for $\mathrm{Hb}$ A have a Darwinian fitness coefficient of 0.66 in the case of Malaria. This indicates that the low saturation allele may be decreasing rapidly in the Tibetan population.

No such gene has been found in the Andean population, though Andean natives have greater $\mathrm{SO}_{2}$ values than expected under conditions of ambient hypoxia (this should not be confused with a left-shifted ODC, which has not been shown in vitro) (Beall, 2007c). The average $\mathrm{SO}_{2}$ in native 
Andeans at $4000 \mathrm{~m}$ has been reported as $92 \%$, which is greater than the average $\mathrm{SO}_{2}$ of $88 \%$ in Tibetans at a similar altitude. Quantitative genetic techniques, which calculate the heritability for a trait by collecting phenotypic data from large samples of genetic relatives, have not shown that there is significant heritability for the trait of high resting $\mathrm{SO}_{2}$ in Andean natives (Beall et $a l ., 1999)$. While the lack of heritability indicates that natural selection is not currently acting on the trait for $\mathrm{Hb}-\mathrm{O}_{2}$ affinity, it does not indicate whether or not the trait has been acted upon in the past. As seen in the case of Tibetans, the low saturation allele is decreasing rapidly. If this is the case, it is possible that natural selection has already occurred in the Andean population, such that the current population is now relatively homozygous for the trait.

One pathway that may be responsible for adaptation and acclimatization to high altitude is that of the hypoxia-induced transcription factor, HIF1 (Semenza, 2000). The oxygen dependent subunit of HIF1 is HIF1 $\alpha$. HIF $1 \alpha$ is constantly being synthesized and degraded when $\mathrm{PO}_{2}$ is normal. Hypoxia stabilizes HIF $1 \alpha$ and it is allowed to combine with HIF1 $\beta$ to form HIF1. Hypoxia therefore leads to the increase of HIF1. This gene is often called the "master regulator" of homeostasis of oxygen because it induces more than 70 genes that respond to hypoxia. It is for this reason that HIF1 $\alpha$ and HIF1 have been implicated as important in acclimatization and adaptation to high altitude.

While it is possible that changes in the gene for HIF1 are responsible for physiological differences across high altitude populations (for example, there are differences in the HIF1 nucleotide sequence of Tibetans and Japanese controls, though not in the sequences of Andeans vs. controls), it is more likely that such differences are due to downstream, less global changes in the HIF1 pathway. This may include changes in the many genes induced by this factor or in the biochemical pathways that they influence. HIF1 is known to influence the production of erythropoietin (stimulates RBC production), vascular endothelial growth factor (stimulates blood vessel growth and permeability), endothelin (a vasoconstrictor produced in the blood vessels), and many other factors (Beall, 2007b). HIF1 also increases the rate of glycolysis and subsequently the production of 2,3-DPG. If HIF1 does influence the affinity of $\mathrm{Hb}$ for $\mathrm{O}_{2}$ during in vivo hypoxia, its influence would not be discovered through in vitro methods. This is because the role of HIF1 is confined to genetic material, and such material is not contained in RBCs. 


\subsubsection{Summary}

Altitude hypoxia is known to be associated with a decrease in $\mathrm{PCO}_{2}$, an increase in $\mathrm{pH}$, and an increase in [2,3-DPG]. While the increase in $\mathrm{pH}$ and decrease in $\mathrm{PCO}_{2}$ are known to shift the ODC to the left, increases in [2,3-DPG] are known to shift the ODC to the right. Previous studies that were performed in vitro have reported that these effects cancel each other out under physiological conditions at high altitude (Winslow et al., 1981; Winslow et al., 1984; Wagner et $a l ., 2007)$. However, both of our groups of subjects at high altitude exhibited marked leftward shifts in their in vivo ODCs. Furthermore, the leftward shift of the Andean natives was greater than that of the acutely acclimatized lowlanders. The in vivo leftward shift may indicate that 2,3DPG does not balance out the influence of the respiratory alkalosis. Alternatively, it is likely that there are previously undiscovered factors that influence the position of the ODC during in vivo progressive hypoxia. $\mathrm{Hb}$ is an unstable molecule that is made up of charged amino acids. Its conformation is highly dependent on its environment, so any changes in the RBC environment, such as during metabolism, have the potential to influence the way $\mathrm{Hb}$ binds to $\mathrm{O}_{2}$. Additionally, the ODCs of the Andeans may have been influenced by genetic or epigenetic factors that become important during progressive hypoxia in vivo. However, it is impossible to know at this time whether the differences between Andean natives and acclimatized lowlanders were due to differences in the extent of acclimatization or the influence of adaptation in the native subjects.

\subsubsection{Benefits of a Leftward Shift}

Because a leftward shift of the ODC enhances $\mathrm{O}_{2}$ uptake at the lungs, it increases the $\mathrm{O}_{2}$ carrying capacity of the blood at high altitude. The benefit of increased $\mathrm{Hb}$ affinity for $\mathrm{O}_{2}$ was assessed during an investigation of two children with mutant Andrew-Minneapolis Hb, which has a higher than normal affinity for $\mathrm{O}_{2}$, and their two siblings with normal $\mathrm{Hb}$ (Hebbel et al., 1978). When taken to high altitude the children with mutant $\mathrm{Hb}$ had better exercise tolerance, as indicated by lower increments in resting heart rate. They had no decrease in maximal $\mathrm{O}_{2}$ consumption, no increase in plasma or urinary EPO and no thrombocytopenia.

Some animal studies have confirmed such benefits of increased $\mathrm{Hb}-\mathrm{O}_{2}$ affinity. In one study, Eaton et al. (1974) investigated how increased $\mathrm{Hb}-\mathrm{O}_{2}$ affinity influences rat survival after exposure to extreme and sudden hypoxia. The ODCs of the experimental rats were shifted leftward by their ingestion of sodium cyanate. The $\mathrm{P}_{50}$ of these rats became $21 \mathrm{mmHg}$, much 
lower than the $\mathrm{P}_{50}$ of the control rats $(37.3 \mathrm{mmHg})$. These and control rats were then exposed to an atmospheric pressure of $223 \mathrm{mmHg}$ (equivalent to $9180 \mathrm{~m}$ ) over a 12 minute period and remained there for 78 minutes. The experimental rats had significantly lower increases in HR than the controls. They also had better survival, as all experimental rats survived the experimental protocol while only $2 / 10$ of the control rats survived. Based on these studies and the fact that many high altitude animals have developed genetic adaptations that shift their ODCs to the left, this shift seems beneficial.

One potential problem created by a leftward shift of the ODC is reduced $\mathrm{O}_{2}$ release at the tissues, since the $\mathrm{Hb}$ has a higher affinity for $\mathrm{O}_{2}$. It seems that a number of animals with left-shifted curves have mechanisms that manage to shift the curve leftward while enhancing offloading at the tissues. Evidence of this is that some animals with left-shifted curves, such as llamas, have especially low venous $\mathrm{PO}_{2}$ and $\mathrm{SO}_{2}$ (Banchero et al., 1971). This indicates that they are able to extract the $\mathrm{O}_{2}$ well, but does not explain how it is done. One possible way that has been shown in both animal and human studies is through an increased Bohr effect (Mairbaurl et al., 1990), which may be linked to increases in [2,3-DPG] (Benesch et al., 1969;Samaja \& Winslow, 1979). An increased Bohr Effect facilitates binding of $\mathrm{O}_{2}$ at the lungs where $\mathrm{PCO}_{2}$ is low and facilitates $\mathrm{O}_{2}$ offloading at the tissues where $\mathrm{PCO}_{2}$ is high. Thus, while a leftward shift of the ODC causes a greater $\mathrm{Hb}-\mathrm{O}_{2}$ affinity, $\mathrm{O}_{2}$ need not be impaired. Rather, a leftward shift may be advantageous for both $\mathrm{O}_{2}$ loading and offloading under hypoxic conditions.

\subsection{In vitro Methods of ODC Measurement and Prediction}

In vitro methods of ODC measurement are stable and repeatable. They involve the measurement

of $\mathrm{SO}_{2}$ during manipulation of $\mathrm{PO}_{2}$ in a blood sample under controlled and constant conditions of $\mathrm{pH}$ and $\mathrm{PCO}_{2}$, which can be set to standard or physiological levels. While some methods, such as in vitro equilibration, are used to measure the ODC over its entire range, others, like the Canizaro Nomogram, rely on previous results to predict the position of the ODC under current conditions. Predictive methods of determining the position of the ODC are less reliable than direct measurement because they necessarily make assumptions about relationships between the variables that are known to contribute to the position of the ODC. Our in vivo data measured the net effect of these variables plus any other unmeasured influences on the ODC. 
Measurement of $\mathrm{Hb}$ saturation in arterial blood can be difficult and expensive. A number of methods have therefore been created from in vitro data to allow the prediction of $\mathrm{SO}_{2}$ for the entire range of the ODC. These predictions may be physiological or mathematical in nature, and predict $\mathrm{SO}_{2}$ based on specific parameters, such as temperature and acid base status. Two such models are those of Severinghaus (1979) and Kelman (1966). The Severinghaus model is a modification of the Hill equation (1910), which describes the sigmoidal shape of the ODC for a given set of points that lie on a single ODC. This widely used model predicts $\mathrm{SO}_{2}$ from $\mathrm{PO}_{2}$, base excess, $\mathrm{pH}$ and temperature. It is reported as accurate within $0.55 \%$ saturation. The Kelman model is robust because it uses $\mathrm{PO}_{2}, \mathrm{PCO}_{2}, \mathrm{~T}$ and $\mathrm{pH}$ to calculate a "virtual $\mathrm{PO}_{2}$," which it then uses to predict saturation. It is a popular model because it allows for easy calculation of $\mathrm{SO}_{2}$ and is thus very convenient. This is a mathematical model in which coefficients were found by using the least squares method on a data set containing 38 pairs of $\mathrm{PO}_{2} / \mathrm{SO}_{2}$ data. This model works under the assumption that, besides for $\mathrm{pH}$ at high saturations, these variables that are part of the "virtual $\mathrm{PO}_{2}$ " change the scale, but not the shape of the $\mathrm{PO}_{2}$ axis. The factors used here were originally suggested by Severinghaus in formulating his nomogram (1966).

The Severinghaus and Kelman models were both created from in vitro data and are considered highly accurate (Breuer et al., 1989). We therefore used these models to compare our in vivo data to what would have been expected if we measured our ODCs in vitro. We expected our in vivo data to differ from the model predictions because progressive hypoxia in a blood sample does not induce metabolic and other changes that are present during in vivo hypoxia. Similarly, these models do not take into account the increase in [2,3-DPG] that occurs with exposure to high altitude.

\subsubsection{Comparison of in vivo data with in vitro Predictions}

We graphically compared our in vivo $\mathrm{SO}_{2}$ values to those predicted using the Kelman and Severinghaus models. We found that the predicted $\mathrm{SO}_{2}$ values closely matched those measured in vivo, except in the case of the Andeans at high altitude, where in vivo $\mathrm{SO}_{2}$ became progressively greater than predicted $\mathrm{SO}_{2}$ as hypoxia became more severe. This finding is consistent with the in vivo leftward shift of the ODCs in this group.

We then used the Kelman and Severinghaus $\mathrm{SO}_{2}$ values with the Hill Equation to predict where in vitro $\mathrm{P}_{50}$ would be under our measurement conditions. Not only was the Hill equation used to 
determine $\mathrm{P}_{50}$ using measured $\mathrm{SO}_{2} \mathrm{~S}$, it was also used with the Kelman and Severinghaus $\mathrm{SO}_{2}$ values to determine the $\mathrm{P}_{50} \mathrm{~s}$ that would be predicted by these models. In lowlanders at sea level the predicted $\mathrm{P}_{50} \mathrm{~S}$ were lower than in vivo measured $\mathrm{P}_{50} \mathrm{~s}$, signifying that the in vivo affinity of $\mathrm{Hb}$ for $\mathrm{O}_{2}$ was lower than expected despite the fact that the $\mathrm{SO}_{2}$ values were similar. In native Andeans at high altitude the opposite was true, and in vivo $\mathrm{P}_{50}$ was significantly lower than those predicted by in vitro models.

We used the Kelman and Severinghaus predictions to compare in vivo and in vitro methods of measurement. The difference between the in vivo and in vitro results show that in vitro methods are not able to fully explore the ODC as it exists in a breathing subject, even in lowlanders at sea level. Further, the discrepancy between the two types of methods demonstrates why the in vivo leftward shift of the ODC has not been previously found in humans at high altitude. In vivo methods better reflect human physiology and provide new and exciting results.

\subsection{Limitations}

\subsubsection{Samples}

Due to the demanding protocol, the samples in this study were relatively small. This meant that many of the statistical tests had low power, such that it was difficult to detect differences between the groups and conditions. Another consequence of this factor is that some of the variables that were used in the analysis were not normally distributed. This would probably have been less of an issue had there been more subjects that provided a more complete spectrum of measurements.

The sample size issue was especially problematic in the cases of Experiments 3 and 4, which were performed at high altitude. Due to logistical problems of running an expedition, the only lowlanders who participated in the study at high altitude were those were researchers in the study. As such, there were only six subjects making up this non-random sample. While the lack of random sampling would not necessarily influence the data, in a sample of six the potential for associated error is much greater.

With regards to the Andean population, the genetic backgrounds of the participants were not known. It is likely that they came from mixed backgrounds, including Native American, European and West African. While there is not yet proof that the ODC of Andeans is influenced 
by genetic factors, when dealing with such a population it would be desirable to know the ethnic background of the participants. We also relied on word of mouth in order to get subjects, so the sample was not necessarily representative. Again, because there were only eight subjects in the Andean protocol, this may have influenced the data set. The small sample size also meant that the data was less normally distributed, and the statistical tests had low power.

\subsubsection{Methodology}

The four groups in these experiments did not go through identical protocols. Experiment 1 entailed progressive hypoxia followed by a return to baseline $\mathrm{PO}_{2}$. Experiment 2 included a protocol in which $\mathrm{PCO}_{2}$ alternated between 35 and $45 \mathrm{mmHg}$. Experiments 3 and 4, as well as the normocapnia condition of experiment two had normocapnic progressive hypoxia. It was assumed that the protocol would not influence the results. As mentioned above, in the case of Experiment 1, where data from the progressive hypoxia was analyzed together with the return to baseline data in order to get a single $\mathrm{P}_{50}$, a comparison was done to ensure that the two types of data did not differ. There was no statistical difference between the two, so we combined them for statistical analysis. We also assumed that alternation of $\mathrm{PCO}_{2}$ would not influence study results in Experiment 2.

\subsubsection{Measured Variables}

One of the major limitations of this study is the lack of analysis for factors affecting $\mathrm{P}_{50}$. Although we did not measure 2,3-DPG, previous studies have consistently shown that its concentration is increased at altitude in both lowlanders and altitude natives. That the two groups of subjects at high altitude showed significant leftward shifts of the in vivo ODC despite presumed increases in [2,3-DPG] indicates that one or more powerful factor(s) are overwhelming its effect on the ODC. It is disconcerting that the literature does not provide a hint as to what this/these factor(s) may be. If the ions and molecules in the Hb environment were measured at each $\mathrm{PO}_{2}$ step, a multiple regression analysis may have allowed for the discovery of new influences on the in vivo ODC. However, if the leftward shift was due to gene up-regulation invoking other molecules not mediated by these ions, having more haematological values would not have provided any advantage. 


\section{Conclusions}

This is the first study to investigate the in vivo ODC. $\mathrm{PO}_{2}-\mathrm{SO}_{2}$ predictions (using the Severinghaus and Kelman models) based on in vitro data provided good approximations of the measured $\mathrm{SO}_{2}$ values in lowlanders at sea level and lowlanders at high altitude, but these predictions failed to describe in vivo $\mathrm{SO}_{2}$ values and left shift of the ODCs of Andean natives at high altitude. Although measured $\mathrm{SO}_{2}$ was not very different from predicted $\mathrm{SO}_{2}$ in the case of the lowlanders at sea level, these lowlanders had in vivo ODCs that were statistically right shifted as compared to the predicted positions using $\mathrm{SO}_{2}$ values from the two models. The other significant finding in this study was that, contrary to data from previous in vitro studies, the in vivo ODCs of the lowlanders and Andeans at high altitude were significantly left-shifted as compared to those of lowlanders at sea level. Additionally, the curves of the Andeans were leftshifted as compared to those of the lowlanders at high altitude. This difference approached significance using all three $\mathrm{SO}_{2}$ types, and would likely have been significant had the power of the tests been slightly increased. The observed shifts in this study were likely due to a combination of acclimatization, in vivo reactions to acute, progressive hypoxia, and, in the case of the Andeans, adaptation to high altitude. Future studies will be able to address the causes of these leftward shifts in the in vivo ODC at high altitude. 


\section{Future Directions}

Due to a small sample size, some of our statistical tests had low power and our results may not be representative (especially in comparing lowlanders and Andeans at high altitude). It would therefore be useful to repeat the study in more subjects at high altitude, to better characterize the responses. In order to generalize our findings, similar tests should be carried out in the high altitude natives of the Himalayas and Ethiopia in addition to the Andes. This would allow us to investigate if and how the different populations of high altitude natives have adapted to hypoxia, and whether they are similar in their adaptations. During these studies, more haematological and genetic studies may identify the mechanisms by which the ODC is affected at altitude. Because such studies will be expensive and logistically difficult, it may be useful to first come up with more sea level experiments that would point to the causes of the in vivo shifts. 


\section{References}

Aberman A, Cavanilles JM, Michaels S, Shubin SH, \& Weil MH (1976). In vitro changes in blood P50 and erythrocyte 2,3-diphosphoglycerate concentration. Clin Chem 22, 1073-1077.

Aldenderfer MS (2003). Moving up in the world: archaeologists seek to understand how and when people came to occupy the Andean and Tibetan plateaus. American Scientist 91, 542.

Aste-Salazar H \& Hurtado A (1944). The affinity of hemoglobin for oxygen at sea level and at high altitudes. Am J Physiol 142, 733-743.

Astrup P, Engel K, Severinghaus JW, \& Munson E (1965). The influence of temperature and pH on the dissociation curve of oxyhemoglobin of human blood. Scand J Clin Lab Invest 17, 515523.

Banchero N \& Grover RF (1972). Effect of different levels of simulated altitude on O2 transport in llama and sheep. Am J Physiol 222, 1239-1245.

Banchero N, Grover RF, \& Will JA (1971). Oxygen transport in the llama (Lama glama). Respir Physiol 13, 102-115.

Barcroft J (1911). The effect of altitude on the dissociation curve of blood. $J$ Physiol 42, 44-63.

Barcroft J, Binger CA, Bock AV, Doggart JH, Forbes HS, Harrop G, Meakins JC, Redfield AC, Davies HW, Duncan Scott JM, Fetter WJ, Murray CD, \& Keith A (1923). Observations upon the effect of high altitude on the physiological processes of the human body, carried out in the Peruvian Andes, chiefly at Cerro de Pasco. Philosophical Transactions of the Royal Society of London Series B, Containing Papers of a Biological Character 211, 351-480.

Barcroft J \& Camis M (1909). The dissociation curve of blood. J Physiol 39, 118-142.

Barcroft J, Camis M, Mathison CG, Roberts F, \& Ryffel JH (1915). Report of the Monte Rosa Expedition of 1911. Philosophical Transactions of the Royal Society of London Series B, Containing Papers of a Biological Character 206, 49-102.

Barcroft J \& King WO (1909). The effect of temperature on the dissociation curve of blood. $J$ Physiol 39, 374-384.

Bauer C (1969). Change of the Bohr effect by 2,3-diphosphoglycerate. Pflugers Arch 307, R10. 
Beall CM (2007a). Detecting natural selection in high-altitude human populations. Respir Physiol Neurobiol 158, 161-171.

Beall CM (2007b). Detecting natural selection in high-altitude human populations. Respir Physiol Neurobiol 158, 161-171.

Beall CM (2007c). Two routes to functional adaptation: Tibetan and Andean high-altitude natives. Proc Natl Acad Sci U S A 104 Suppl 1, 8655-8660.

Beall CM, Almasy LA, Blangero J, Williams-Blangero S, Brittenham GM, Strohl KP, Decker MJ, Vargas E, Villena M, Soria R, Alarcon AM, \& Gonzales C (1999). Percent of oxygen saturation of arterial hemoglobin among Bolivian Aymara at 3,900-4,000 m. Am J Phys Anthropol 108, 41-51.

Beall CM, Brittenham GM, Strohl KP, Blangero J, Williams-Blangero S, Goldstein MC, Decker MJ, Vargas E, Villena M, Soria R, Alarcon AM, \& Gonzales C (1998). Hemoglobin concentration of high-altitude Tibetans and Bolivian Aymara. Am J Phys Anthropol 106, 385400 .

Beall CM, Song K, Elston RC, \& Goldstein MC (2004). Higher offspring survival among Tibetan women with high oxygen saturation genotypes residing at 4,000 m. Proc Natl Acad Sci U S A 101, 14300-14304.

Bellingham AJ, Detter JC, \& Lenfant C (1971). Regulatory mechanisms of hemoglobin oxygen affinity in acidosis and alkalosis. J Clin Invest 50, 700-706.

Bencowitz HZ, Wagner PD, \& West JB (1982). Effect of change in P50 on exercise tolerance at high altitude: a theoretical study. J Appl Physiol 53, 1487-1495.

Benesch R \& Benesch RE (1967). The effect of organic phosphates from the human erythrocyte on the allosteric properties of hemoglobin. Biochem Biophys Res Commun 26, 162-167.

Benesch R, Benesch RE, \& Yu CI (1968). Reciprocal binding of oxygen and diphosphoglycerate by human hemoglobin. Proc Natl Acad Sci U S A 59, 526-532.

Benesch RE, Benesch R, \& Yu CI (1969). The oxygenation of hemoglobin in the presence of 2,3-diphosphoglycerate. Effect of temperature, $\mathrm{pH}$, ionic strength, and hemoglobin concentration. Biochemistry 8, 2567-2571. 
Black CP \& Tenney SM (1980). Oxygen transport during progressive hypoxia in high-altitude and sea-level waterfowl. Respir Physiol 39, 217-239.

Braunitzer G, Gehring-Mueller R, Hilschmann N, Hilse K, Hobom G, Rudloff V, \& WittmannLiebold B (1961). The structure of normal adult human hemoglobins. Hoppe Seylers Z Physiol Chem 325, 283-286.

Breuer HW, Groeben H, Breuer J, \& Worth H (1989). Oxygen saturation calculation procedures: a critical analysis of six equations for the determination of oxygen saturation. Intensive Care Med 15, 385-389.

Canizaro PC, Nelson JL, Hennessy JL, \& Bright PB (1974). A technique for estimating the position of the oxygen-hemoglobin dissociation curve. Ann Surg 180, 364-367.

Chanutin A \& Curnish RR (1967). Effect of organic and inorganic phosphates on the oxygen equilibrium of human erythrocytes. Arch Biochem Biophys 121, 96-102.

Chiari L, Avanzolini G, \& Ursino M (1997). A comprehensive simulator of the human respiratory system: validation with experimental and simulated data. Ann Biomed Eng 25, 985999.

Dash RK \& Bassingthwaighte JB (2004). Blood $\mathrm{HbO} 2$ and $\mathrm{HbCO} 2$ dissociation curves at varied O2, CO2, pH, 2,3-DPG and temperature levels. Ann Biomed Eng 32, 1676-1693.

Duffin J \& Mahamed S (2003). Adaptation in the respiratory control system. Can J Physiol Pharmacol 81, 765-773.

Duvelleroy MA, Buckles RG, Rosenkaimer S, Tung C, \& Laver MB (1970). An oxyhemoglobin dissociation analyzer. $J$ Appl Physiol 28, 227-233.

Eaton JW, Skelton TD, \& Berger E (1974). Survival at extreme altitude: protective effect of increased hemoglobin-oxygen affinity. Science 183, 743-744.

Edwards MJ \& Martin RJ (1966). Mixing technique for the oxygen-hemoglobin equilibrium and Bohr effect. J Appl Physiol 21, 1898-1902.

Edwards MJ \& Rigas DA (1967). Electrolyte-labile increase of oxygen affinity during in vivo aging of hemoglobin. J Clin Invest 46, 1579-1588. 
Garby L \& De Verdier CH (1971). Affinity of human hemoglobin A to 2,3--diphosphoglycerate. Effect of hemoglobin concentration and of pH. Scand J Clin Lab Invest 27, 345-350.

Ge RL, Kubo K, Kobayashi T, Sekiguchi M, \& Honda T (1998). Blunted hypoxic pulmonary vasoconstrictive response in the rodent Ochotona curzoniae (pika) at high altitude. Am J Physiol 274, H1792-H1799.

Haidas S, Labie D, \& Kaplan JC (1971). 2,3-diphosphoglycerate content and oxygen affinity as a function of red cell age in normal individuals. Blood 38, 463-467.

Hebbel RP, Eaton JW, Kronenberg RS, Zanjani ED, Moore LG, \& Berger EM (1978). Human llamas: adaptation to altitude in subjects with high hemoglobin oxygen affinity. J Clin Invest $\mathbf{6 2}$, 593-600.

Hill AV (1910). The possible effects of the aggregation of the molecules of haemoglobin on its dissociation curves. J Physiol 40, iv-vii.

Hlastala MP (1979). Physiological significance of the interaction of oxygen and carbon dioxide in blood. Crit Care Med 7, 374-379.

Ito S, Mardimae A, Han J, Duffin J, Wells G, Fedorko L, Minkovich L, Katznelson R, Meineri M, Arenovich T, Kessler C, \& Fisher JA (2008). Non-invasive prospective targeting of arterial PCO2 in subjects at rest. $J$ Physiol 586, 3675-3682.

Juel R \& Milam JO (1979). 2,3-Diphosphoglycerate: its role in health and disease. CRC Crit Rev Clin Lab Sci 10, 113-146.

Kelman GR (1966). Digital computer subroutine for the conversion of oxygen tension into saturation. J Appl Physiol 21, 1375-1376.

Keys A, Hall FG, \& Barron ESG (1936). The position of the oxygen dissociation curve of human blood at high altitude. Am J Physiol 115, 292-307.

Konigsberg W, Guidotti G, \& HILL RJ (1961). The amino acid sequence of the alpha chain of human hemoglobin. J Biol Chem 236, C55-C56.

Lahiri S \& Milledge JS (1967). Acid-base in Sherpa altitude residents and lowlanders at $4880 \mathrm{~m}$. Respir Physiol 2, 323-334. 
Lenfant C \& Sullivan K (1971). Adaptation to high altitude. N Engl J Med 284, 1298-1309.

Lenfant C, Torrance J, English E, Finch CA, Reynafarje C, Ramos J, \& Faura J (1968). Effect of altitude on oxygen binding by hemoglobin and on organic phosphate levels. J Clin Invest 47, 2652-2656.

Lenfant C, Torrance JD, \& Reynafarje C (1971). Shift of the O2-Hb dissociation curve at altitude: mechanism and effect. $J$ Appl Physiol 30, 625-631.

Mairbaurl H, Schobersberger W, Oelz O, Bartsch P, Eckardt KU, \& Bauer C (1990). Unchanged in vivo P50 at high altitude despite decreased erythrocyte age and elevated 2,3diphosphoglycerate. J Appl Physiol 68, 1186-1194.

McConn R (1975). The oxyhemoglobin dissociation curve in acute disease. Surg Clin North Am 55, 627-658.

Milles JJ, Chesner IM, Oldfield S, \& Bradwell AR (1987). Effect of acetazolamide on blood gases and 2,3 DPG during ascent and acclimatization to high altitude. Postgrad Med J 63, 183184.

Minakami S \& Yoshikawa H (1966). Studies on erythrocyte glycolysis. 3. The effects of active cation transport, $\mathrm{pH}$ and inorganic phosphate concentration on erythrocyte glycolysis. $J$ Biochem 59, $145-150$.

Mohan R \& Duffin J (1997). The effect of hypoxia on the ventilatory response to carbon dioxide in man. Respir Physiol 108, 101-115.

Morpurgo G, Arese P, Bosia A, Pescarmona GP, Luzzana M, Modiano G, \& Krishna rS (1976). Sherpas living permanently at high altitutde: a new pattern of adaptation. Proc Natl Acad Sci U S A 73, 747-751.

Morpurgo G, Battaglia P, Bernini L, Paolucci AM, \& Modiano G (1970). Higher Bohr effect in Indian natives of Peruvian Highlands as compared with Europeans. Nature 227, 387-388.

Muirhead H, Cox JM, Mazzarella L, \& Perutz MF (1967). Structure and function of haemoglobin. 3. A three-dimensional fourier synthesis of human deoxyhaemoglobin at 5.5 Angstrom resolution. $J$ Mol Biol 28, 117-156.

Perutz MF (1970). Stereochemistry of cooperative effects in haemoglobin. Nature 228, 726-739. 
Petschow D, Wurdinger I, Baumann R, Duhm J, Braunitzer G, \& Bauer C (1977). Causes of high blood $\mathrm{O} 2$ affinity of animals living at high altitude. J Appl Physiol 42, 139-143.

Pinder A \& Burggren W (1983). Respiration during chronic hypoxia and hyperoxia in larval and adult bullfrogs (Rana catesbeiana). II. Changes in respiratory properties of whole blood. $J$ Exp Biol 105, 205-213.

Reynafarje C, Faura J, Villavicencio D, Curaca A, Reynafarje B, Oyola L, Contreras L, Vallenas E, \& Faura A (1975). Oxygen transport of hemoglobin in high-altitude animals (Camelidae). $J$ Appl Physiol 38, 806-810.

Richardson DW, Kontos HA, Shapiro W, \& Patterson JL, Jr. (1966). Role of hypocapnia in the circulatory responses to acute hypoxia in man. J Appl Physiol 21, 22-26.

Robbins PA, Swanson GD, Micco AJ, \& Schubert WP (1982). A fast gas-mixing system for breath-to-breath respiratory control studies. J Appl Physiol 52, 1358-1362.

Rorth M, Nygaard SF, Parving HH, Hansen V, \& Kalsig T (1973). Human red cell metabolism and in vivo oxygen affinity of red cells during 24 hours' exposure to simulated high altitude (4500 m). Scand J Clin Lab Invest 31, 447-452.

Rose ZB (1968). The purification and properties of diphosphoglycerate mutase from human erythrocytes. J Biol Chem 243, 4810-4820.

Samaja M, Veicsteinas A, \& Cerretelli P (1979). Oxygen affinity of blood in altitude Sherpas. J Appl Physiol 47, 337-341.

Samaja M \& Winslow RM (1979). The separate effects of H+ and 2,3-DPG on the oxygen equilibrium curve of human blood. Br J Haematol 41, 373-381.

Semenza GL (2000). HIF-1: mediator of physiological and pathophysiological responses to hypoxia. J Appl Physiol 88, 1474-1480.

Severinghaus JW (1966). Blood gas calculator. J Appl Physiol 21, 1108-1116.

Severinghaus JW (1979). Simple, accurate equations for human blood O2 dissociation computations. J Appl Physiol 46, 599-602.

Sladen RN (1981). The oxyhemoglobin dissociation curve. Int Anesthesiol Clin 19, 39-70. 
Slessarev M, Han J, Mardimae A, Prisman E, Preiss D, Volgyesi G, Ansel C, Duffin J, \& Fisher JA (2007). Prospective targeting and control of end-tidal CO2 and O2 concentrations. J Physiol 581, 1207-1219.

Snyder LR (1985). Low P50 in deer mice native to high altitude. J Appl Physiol 58, 193-199.

Snyder LR, Born S, \& Lechner AJ (1982). Blood oxygen affinity in high- and low-altitude populations of the deer mouse. Respir Physiol 48, 89-105.

Storz JF, Sabatino SJ, Hoffmann FG, Gering EJ, Moriyama H, Ferrand N, Monteiro B, \& Nachman MW (2007). The molecular basis of high-altitude adaptation in deer mice. PLoS Genet 3, e45.

Torrance JD, Lenfant C, Cruz J, \& Marticorena E (1970a). Oxygen transport mechanisms in residents at high altitude. Respir Physiol 11, 1-15.

Torrance JD, Lenfant C, Cruz J, \& Marticorena E (1970b). Oxygen transport mechanisms in residents at high altitude. Respir Physiol 11, 1-15.

Turek Z, Kreuzer F, \& Ringnalda BE (1978). Blood gases at several levels of oxygenation in rats with a left-shifted blood oxygen dissociation curve. Pflugers Arch 376, 7-13.

Velarde FL, Espinoza D, Monge C, \& de MC (1991). A genetic response to high altitude hypoxia: high hemoglobin-oxygen affinity in chicken (Gallus gallus) from the Peruvian Andes. C R Acad Sci III 313, 401-406.

Wagner PD (1997). Insensitivity of VO2max to hemoglobin-P50 at sea level and altitude. Respir Physiol 107, 205-212.

Wagner PD, Wagner HE, Groves BM, Cymerman A, \& Houston CS (2007). Hemoglobin P50 during a simulated ascent of Mt. Everest, Operation Everest II. High Alt Med Biol 8, 32-42.

Ward MP, Milledge JS, \& West JB (2000). High Altitude Medicine and Physiology, 3rd ed.

Watt KW, Maruyama T, \& Riggs A (1980). Hemoglobins of the tadpole of the bullfrog, Rana catesbeiana. Amino acid sequence of the beta chain of a major component. J Biol Chem $\mathbf{2 5 5}$, 3294-3301. 
Weil JV, Byrne-Quinn E, Sodal IE, Friesen WO, Underhill B, Filley GF, \& Grover RF (1970). Hypoxic ventilatory drive in normal man. J Clin Invest 49, 1061-1072.

Winslow RM, Chapman KW, Gibson CC, Samaja M, Monge CC, Goldwasser E, Sherpa M, Blume FD, \& Santolaya R (1989). Different hematologic responses to hypoxia in Sherpas and Quechua Indians. J Appl Physiol 66, 1561-1569.

Winslow RM, Monge CC, Statham NJ, Gibson CG, Charache S, Whittembury J, Moran O, \& Berger RL (1981). Variability of oxygen affinity of blood: human subjects native to high altitude. J Appl Physiol 51, 1411-1416.

Winslow RM, Morrissey JM, Berger RL, Smith PD, \& Gibson CC (1978). Variability of oxygen affinity of normal blood: an automated method of measurement. J Appl Physiol 45, 289-297.

Winslow RM, Samaja M, \& West JB (1984). Red cell function at extreme altitude on Mount Everest. J Appl Physiol 56, 109-116. 


\section{Appendix A: Baseline Haematological Values}

10.1 Baseline Haematological Values by Experimental Group

Table 8: Haematological Data for Subjects in Experiment 1

\begin{tabular}{rrrrrrrr}
\hline Subject & $\mathbf{p H}$ & $\mathbf{P C O}_{\mathbf{2}}$ & $\mathbf{P O}_{\mathbf{2}}$ & $\mathbf{B E}$ & $\mathbf{H C O}_{\mathbf{3}}{ }^{-}$ & $\mathbf{H c t}$ & $\mathbf{H b}$ \\
\hline $\mathbf{2 1}$ & 7.41 & 41 & 122 & 1.2 & 26 & 36 & 12.4 \\
$\mathbf{2 2}$ & 7.41 & 41 & 99 & 1.2 & 26 & 36 & 12.5 \\
$\mathbf{2 3}$ & 7.37 & 45 & 100 & 0.2 & 26 & 43 & 15.5 \\
$\mathbf{2 4}$ & 7.37 & 40 & 107 & -2 & 23.1 & 42 & 15.3 \\
$\mathbf{2 5}$ & 7.45 & 32 & 130 & -0.9 & 22.2 & 44 & 15.7 \\
$\mathbf{2 6}$ & 7.43 & 39 & 105 & 1.5 & 25.9 & 38 & 13.1 \\
$\mathbf{2 7}$ & 7.42 & 35 & 112 & -1.3 & 22.7 & 38 & 13.7 \\
$\mathbf{2 8}$ & 7.44 & 42 & 111 & 3.9 & 28.5 & 40 & 13.8 \\
$\mathbf{2 9}$ & 7.4 & 45 & 99 & 2.5 & 27.9 & 47 & 14.7 \\
$\mathbf{3 1}$ & 7.4 & 41 & 106 & 0.5 & 25.4 & 36 & 12.7 \\
$\mathbf{3 2}$ & 7.36 & 44 & 104 & -0.8 & 24.9 & 43 & 14.7 \\
$\mathbf{3 3}$ & 7.41 & 42 & 125 & 1.7 & 26.6 & 36 & 11.7 \\
$\mathbf{3 4}$ & 7.42 & 45 & 99 & 4 & 29.2 & 36 & 12.8 \\
\hline Average & 7.41 & 40.9 & 109.2 & 0.9 & 25.7 & 39.6 & 13.7 \\
Std Dev & 0.03 & 3.9 & 10.5 & 1.9 & 2.1 & 3.8 & 1.3 \\
\hline
\end{tabular}


Table 9: Haematological Data for Subjects in Experiment 2

\begin{tabular}{rrrrrrrr}
\hline Subject & $\mathbf{p H}$ & $\mathbf{P C O}_{\mathbf{2}}$ & $\mathbf{P O}_{\mathbf{2}}$ & $\mathbf{B E}$ & $\mathbf{H C O}_{\mathbf{3}}{ }^{-}$ & $\mathbf{H c t}$ & $\mathbf{H b}$ \\
\hline $\mathbf{1}$ & 7.44 & 42 & 98 & 3.8 & 28.5 & 44 & 16.2 \\
$\mathbf{3}$ & 7.41 & 40 & 105 & 0.7 & 25.4 & 38 & 13.5 \\
$\mathbf{5}$ & 7.37 & 40 & 107 & -2 & 23.1 & 42 & 15.3 \\
$\mathbf{6}$ & 7.42 & 39 & 97 & 0.9 & 25.3 & 43 & 15.8 \\
$\mathbf{7}$ & 7.37 & 42 & 96 & -1.1 & 24.3 & 46 & 16.1 \\
$\mathbf{8}$ & 7.39 & 40 & 98 & -0.7 & 24.2 & 43 & 15.3 \\
$\mathbf{9}$ & 7.36 & 44 & 103 & -0.9 & 24.9 & 45 & 16.7 \\
$\mathbf{1 0}$ & 7.4 & 41 & 101 & 0.5 & 25.4 & 42 & 15.1 \\
$\mathbf{1 1}$ & 7.39 & 42 & 97 & 0.2 & 25.4 & 45 & 15.9 \\
$\mathbf{1 2}$ & 7.43 & 41 & 105 & 2.6 & 27.2 & 46 & 16.6 \\
$\mathbf{1 3}$ & 7.34 & 41 & 99 & -3.5 & 22.1 & 36 & 12.5 \\
$\mathbf{1 4}$ & 7.43 & 40 & 99 & 2 & 26.5 & 39 & 12.2 \\
$\mathbf{1 5}$ & 7.42 & 41 & 99 & 1.9 & 26.6 & 41 & 14.6 \\
$\mathbf{1 6}$ & 7.4 & 44 & 100 & 2 & 27.3 & 43 & 14.4 \\
$\mathbf{1 7}$ & 7.4 & 41 & 113 & 0.5 & 25.4 & 39 & 14.1 \\
$\mathbf{1 9}$ & 7.42 & 42 & 99 & 2.4 & 27.2 & 45 & 15.2 \\
$\mathbf{2 0}$ & 7.43 & 42 & 102 & 3.1 & 27.9 & 47 & 15.4 \\
$\mathbf{2 1}$ & 7.4 & 41 & 109 & 0.5 & 25.4 & 35 & 11.7 \\
$\mathbf{2 2}$ & 7.38 & 38 & 101 & -2.3 & 22.5 & 39 & 13.4 \\
\hline Average & 7.40 & 41.1 & 101.5 & 0.6 & 25.5 & 42.0 & 14.7 \\
Std Dev & 0.03 & 1.5 & 4.5 & 2.0 & 1.8 & 3.5 & 1.5 \\
\hline
\end{tabular}

Table 10: Haematological Data for Subjects in Experiment 3

\begin{tabular}{lrrrrrrr}
\hline Subject & $\mathbf{p H}$ & $\mathbf{P C O}_{\mathbf{2}}$ & $\mathbf{P O}_{\mathbf{2}}$ & $\mathbf{B E}$ & $\mathbf{H C O}_{\mathbf{3}}{ }^{-}$ & $\mathbf{H c t}$ & $\mathbf{H b}$ \\
\hline $\mathbf{1}$ & 7.43 & 27.9 & 58 & -6 & 18.6 & 42 & 14.3 \\
$\mathbf{2}$ & 7.44 & 33.9 & 56 & -1 & 22.8 & 45 & 15.3 \\
$\mathbf{3}$ & 7.47 & 26.7 & 57 & -4 & 19.6 & 40 & 13.6 \\
$\mathbf{4}$ & 7.44 & 26 & 87 & -6 & 17.9 & 40 & 13.6 \\
$\mathbf{5}$ & 7.42 & 30.3 & 74 & -5 & 19.5 & 48 & 16.3 \\
$\mathbf{6}$ & 7.44 & 30 & 89 & -4 & 20.3 & 48 & 16.3 \\
\hline Average & 7.44 & 29.1 & 70.2 & -4.3 & 19.8 & 43.8 & 14.9 \\
Std Dev & 0.02 & 2.9 & 15.3 & 1.9 & 1.7 & 3.7 & 1.2 \\
\hline
\end{tabular}

It should be noted that the $\mathrm{pH}$ values for all subjects were relatively alkaline, with the average $\mathrm{pH}$ being $7.44 \pm 0.02$. This is not surprising given that the average $\mathrm{PCO}_{2}$ was $29.1 \pm 2.9$, which is below the normal range. The increased $\mathrm{pH}$ is therefore probably a reflection of a respiratory 
alkalosis due to the hypoxic ventilatory response of high altitude. The base excess is below the normal arterial range, which is -2 to +3 .

Table 11: Haematological Data for Subjects in Experiment 4

\begin{tabular}{rrrrrrrr}
\hline Subject & $\mathbf{p H}$ & $\mathbf{P C O}_{\mathbf{2}}$ & $\mathbf{P O}_{\mathbf{2}}$ & $\mathbf{B E}$ & $\mathbf{H C O}_{\mathbf{3}}{ }^{-}$ & $\mathbf{H c t}$ & $\mathbf{H b}$ \\
\hline $\mathbf{1}$ & 7.46 & 26 & 63 & -6 & 18.2 & 49 & 16.7 \\
$\mathbf{2}$ & 7.44 & 27 & 57 & -6 & 18.2 & 47 & 16 \\
$\mathbf{3}$ & 7.45 & 25.8 & 59 & -6 & 17.8 & 50 & 17 \\
$\mathbf{4}$ & 7.44 & 28 & 61 & -5 & 19.1 & 51 & 17.3 \\
$\mathbf{5}$ & 7.41 & 28.6 & 57 & -7 & 18 & 44 & 15 \\
$\mathbf{6}$ & 7.43 & 35.5 & 50 & -1 & 23.5 & 44 & 15 \\
$\mathbf{8}$ & 7.44 & 32.7 & 53 & -2 & 22.2 & 47 & 16 \\
$\mathbf{9}$ & 7.45 & 27.2 & 60 & -5 & 18.9 & 43 & 14.6 \\
\hline Average & 7.44 & 28.8 & 57.5 & -4.8 & 19.5 & 46.9 & 16.0 \\
Std Dev & 0.01 & 3.4 & 4.3 & 2.1 & 2.2 & 3.0 & 1.0 \\
\hline
\end{tabular}

The average control $\mathrm{pH}$ value is on the upper range of normal and, like the lowlanders at altitude, is probably reflective of a respiratory alkalosis, as a result of the low $\mathrm{PCO}_{2}$ of $28.5 \pm 3.6 \mathrm{mmHg}$. The low $\mathrm{PCO}_{2}$ was also reflected in the low $\mathrm{TCO}_{2}$, which was $20.2 \pm 2.4 \mathrm{mmol} / \mathrm{L}$ instead of 23$27 \mathrm{mmol} / \mathrm{L}$, and the low bicarbonate, which was $19.1 \pm 2.2 \mathrm{mmol} / \mathrm{L}$ instead of the normal range of 22-26 mmol/L. Base excess was outside the normal range of -2 to $+3 \mathrm{mmol} / \mathrm{L}$, at an average of $-5.2 \pm 2.1$. Average hematocrit and hemoglobin levels fell within the normal range, except in the case of subject 4 who was slightly above normal, which is $12-17 \mathrm{~g} / \mathrm{dL}$. 


\subsection{Cross-Experimental Comparison of Baseline Haematological Values}

Seven control parameters $\left(\mathrm{pH}, \mathrm{PCO}_{2}, \mathrm{PO}_{2}, \mathrm{BE}, \mathrm{HCO}_{3}{ }^{-}\right.$, $\mathrm{Hct}$ and $\left.\mathrm{Hb}\right)$ were compared across experimental groups, using a one way ANOVA, with an alpha level of 0.05. All results were significant, so a Tukey post-hoc test was used for pair-wise comparisons. Baseline $\mathrm{pH}, \mathrm{PCO}_{2}$, $\mathrm{PO}_{2}$, base excess and bicarbonate for lowlanders at sea level were significantly different from those of both groups at high altitude. Those in Experiments 3 and 4 also had significantly different $\mathrm{PO}_{2} \mathrm{~S}$ from one another. Baseline hematocrit and haemoglobin of the lowlanders at sea level were significantly lower than those of the Andeans at high altitude. Individual $p$ values for each test will be shown below.

Differences in baseline $\mathrm{pH}$ values were significant across groups $(F(2,43)=10.529, p<0.001) . \mathrm{pH}$ for the lowlanders at sea level was significantly lower than those of Experiments $3(p=0.004)$ and $4(p=0.002)$. There was no significant difference between baseline $\mathrm{pH}$ values of the two groups at high altitude.

Differences in baseline $\mathrm{PCO}_{2}$ values were significant across groups $(F(2,43)=87.916, p<0.001)$. $\mathrm{PCO}_{2}$ for the lowlanders at sea level was significantly higher than those of Experiments 3 $(p<0.001)$ and $4(p<0.001)$. There was no significant difference between baseline $\mathrm{PCO}_{2}$ values of the two groups at high altitude.

Differences in baseline base excess were significant across groups $(F(2,43)=36.284, p<0.001)$. Base excess for the lowlanders at sea level was significantly lower than for those of Experiments $3(p<0.001)$ and $4(p<0.001)$. There was no significant difference between baseline base excess values of the two groups at high altitude.

Differences in baseline bicarbonate values were significant across groups $(F(2,43)=47.486$, $p<0.001)$. Bicarbonate for the lowlanders at sea level was significantly higher than those of Experiments $3(p<0.001)$ and $4(p<0.001)$. There was no significant difference between baseline Bicarbonate values of the two groups at high altitude.

Differences in baseline $\mathrm{PO}_{2}$ values were significant across groups $(F(2,43)=109.089, p<0.001)$. $\mathrm{PO}_{2}$ for the lowlanders at sea level was significantly higher than those of Experiments 3 
$(p<0.001)$ and $4(p<0.001) . \mathrm{PO}_{2}$ for the lowlanders at altitude was also significantly higher than that of the Andeans at high altitude $(\mathrm{p}=0.032)$.

Differences in baseline hematocrit were significant across groups $(F(2,43)=8.789, p<0.001)$. Hematocrit for the lowlanders at sea level was significantly lower than for those of Experiment 4 $(p<0.001)$. The lowlanders at sea level did not have different hematocrit from the lowlanders at altitude, nor did the lowlanders at altitude have different hematocrit from the Andeans at altitude.

Differences in baseline $\mathrm{Hb}$ were significant across groups $(F(2,43)=4.4, p=0.018)$. Hb for the lowlanders at sea level was significantly lower than for those of Experiment $4(p=0.014)$. The lowlanders at sea level did not have different $\mathrm{Hb}$ from the lowlanders at altitude, nor did the lowlanders at altitude have different $\mathrm{Hb}$ from the Andeans at altitude. 


\section{Appendix B: Experimental Data}

\section{1 $\mathrm{PCO}_{2}, \mathrm{pH}$ and minimum $\mathrm{PO}_{2}$ during Testing}

A summary of the experimental data for each subject is shown below. The tables include the average and standard deviation for $\mathrm{PCO}_{2}$ and $\mathrm{pH}$, the minimum $\mathrm{PO}_{2}$ achieved and the number of samples taken.

\subsubsection{Experiment 1}

Table 12: Experiment 1 Summary Data

\begin{tabular}{|c|c|c|c|c|}
\hline Subject & Average $\mathrm{PCO}_{2} \pm$ Std Dev & Average pH \pm Std Dev & $\operatorname{Min} \mathrm{PO}_{2}$ & \# of Samples \\
\hline 21 & $42.9 \quad \pm \quad 0.8$ & $7.39 \pm 0.01$ & 49 & 8 \\
\hline 22 & $44.6 \pm 2.2$ & $7.37 \pm 0.02$ & 48 & 9 \\
\hline 23 & $44.0 \pm 0.7$ & $7.38 \pm 0.01$ & 44 & 9 \\
\hline 24 & $43.0 \pm 0.7$ & $7.40 \pm 0.01$ & 46 & 9 \\
\hline 25 & $41.6 \pm 1.9$ & $7.37 \pm 0.02$ & 45 & 8 \\
\hline 26 & $\pm \quad 1.2$ & $7.37 \pm 0.02$ & 39 & 9 \\
\hline 27 & $42.7 \pm 1.5$ & $7.35 \pm 0.02$ & 52 & 3 \\
\hline 28 & $42.6 \pm 1.5$ & $7.41 \pm 0.02$ & 36 & 9 \\
\hline 29 & $42.3 \pm 2.2$ & $7.43 \pm 0.01$ & 37 & 9 \\
\hline 31 & $\pm \quad 1.9$ & $7.38 \pm 0.01$ & 37 & 9 \\
\hline 32 & $\pm \quad 0.9$ & $7.40 \pm 0.01$ & 44 & 9 \\
\hline 33 & $\pm \quad 1.2$ & \pm 0.01 & 45 & 9 \\
\hline 34 & $\pm \quad 2.0$ & $7.45 \pm 0.00$ & 35 & 9 \\
\hline Average & \pm 1.46 & 0.01 & 42.8 & 8.4 \\
\hline Std Dev & 0.55 & 0.00 & 5.3 & 1.6 \\
\hline
\end{tabular}




\subsubsection{1 $\quad \mathrm{PCO}_{2}$ Summary}

In this experiment the target $\mathrm{PCO}_{2}$ was $40 \mathrm{mmHg}$, while the average achieved $\mathrm{PCO}_{2}$ across all subjects was $42.2 \mathrm{mmHg}$, with only two subjects having $\mathrm{PCO}_{2}$ averages that fell below the target value, and one subject having a $\mathrm{PCO}_{2}$ average that was $5 \mathrm{mmHg}$ above the target value.

\subsubsection{2 pH Summary}

The average $\mathrm{pH}$ was 7.39 with an average standard deviation of $0.01 \mathrm{pH}$ units. The $\mathrm{pH}$ specification for the device is $0.02 \mathrm{pH}$ units, though the reported accuracy for the measurement device is less than 0.01 in this range $\mathrm{pH}$ range. Nine subjects had standard deviations greater than 0.01 , while two subjects had standard deviations equal to or greater than $0.02 \mathrm{pH}$ units.

\subsubsection{3 $\quad \mathrm{PO}_{2}$ Summary}

The lowest $\mathrm{PO}_{2}$ achieved in this experiment was $35 \mathrm{mmHg}$, and the average minimum $\mathrm{PO}_{2}$ was $42.8 \mathrm{mmHg}$. Except for one subject who achieved only three $\mathrm{PO}_{2}$ targets, all subjects had 8 or 9 samples. 


\subsubsection{Experiment 2}

Table 13. Experiment 2 Summary Data: Hypocapnia




Table 14. Experiment 2 Summary Data: Normocapnia

\begin{tabular}{|c|c|c|c|c|}
\hline Subject & Average $\mathrm{PCO}_{2} \pm \mathrm{Std}$ Dev & Average pH \pm Std Dev & Min $\mathbf{P O}_{2}$ & \# of Samples \\
\hline 1 & $\begin{array}{lll}41.4 & \pm & 2.0\end{array}$ & $7.42 \pm 0.02$ & 36 & 26 \\
\hline 3 & $40.2 \pm 1.0$ & $7.39 \pm 0.01$ & 43 & 26 \\
\hline 5 & $41.8 \pm 3.6$ & $7.35 \pm 0.03$ & 41 & 22 \\
\hline 6 & $42.9 \pm 1.5$ & $7.38 \pm 0.02$ & 44 & 22 \\
\hline 7 & $45.3 \pm 1.7$ & $7.31 \pm 0.02$ & 39 & 25 \\
\hline 8 & $43.0 \pm 2.0$ & $7.35 \pm 0.02$ & 38 & 26 \\
\hline 9 & $42.2 \pm 1.9$ & $7.35 \pm 0.02$ & 34 & 25 \\
\hline 10 & $44.1 \pm 1.7$ & $7.36 \pm 0.02$ & 39 & 26 \\
\hline 11 & $42.5 \pm 0.9$ & $7.37 \pm 0.01$ & 36 & 24 \\
\hline 12 & $41.5 \pm 1.2$ & $7.41 \pm 0.01$ & 43 & 26 \\
\hline 13 & $44.1 \pm 1.9$ & $7.29 \pm 0.02$ & 44 & 26 \\
\hline 14 & $42.1 \pm 1.0$ & $7.40 \pm 0.01$ & 40 & 26 \\
\hline 15 & $40.5 \pm 1.0$ & $7.41 \pm 0.01$ & 36 & 25 \\
\hline 16 & $44.0 \pm 1.0$ & $7.37 \pm 0.01$ & 40 & 25 \\
\hline 17 & $44.0 \pm$ & $7.37 \pm 0.01$ & 37 & 26 \\
\hline 19 & $40.8 \pm$ & $7.42 \pm 0.01$ & 35 & 26 \\
\hline 20 & $41.9 \pm 1.7$ & $7.42 \pm 0.01$ & 39 & 25 \\
\hline 21 & $43.1 \pm$ & $7.35 \pm 0.01$ & 42 & 26 \\
\hline 22 & $40.7 \pm$ & $7.34 \pm 0.01$ & 35 & 26 \\
\hline Average & 42.6 & 0.01 & 38.9 & 25.1 \\
\hline Std Dev & 0.6 & 0.01 & 3.1 & 1.3 \\
\hline
\end{tabular}


Table 15. Experiment 2 Summary Data: Hypercapnia

\begin{tabular}{|c|c|c|c|c|c|c|}
\hline Subject & Average PCC & $\mathrm{O}_{2} \pm$ Std Dev & Average $\mathrm{p}$ & $\mathrm{H} \pm$ Std Dev & $\operatorname{Min} \mathbf{P O}_{2}$ & \# of Samples \\
\hline 1 & 48.3 & $\begin{array}{ll} \pm 1.9 \\
\end{array}$ & 7.37 & \pm 0.02 & 47 & 6 \\
\hline 3 & 45.0 & \pm 1.8 & 7.32 & \pm 0.01 & 45 & 10 \\
\hline 5 & 47.8 & \pm 3.6 & 7.30 & \pm 0.03 & 64 & 4 \\
\hline 6 & 47.8 & $\pm \quad 2.0$ & 7.34 & \pm 0.02 & 41 & 8 \\
\hline 7 & 49.2 & $\pm \quad 2.0$ & 7.29 & $\pm \quad 0.02$ & 62 & 4 \\
\hline 8 & 48.0 & 2.9 & 7.32 & \pm 0.01 & 67 & 4 \\
\hline 9 & 45.3 & $\pm \quad 2.4$ & 7.33 & \pm 0.01 & 38 & 6 \\
\hline 10 & 47.5 & $\pm \quad 3.2$ & 7.32 & \pm 0.03 & 36 & 8 \\
\hline 11 & 46.3 & $\pm \quad 1.0$ & 7.34 & \pm 0.01 & 44 & 7 \\
\hline 12 & 45.5 & \pm 1.3 & 7.36 & \pm 0.01 & 47 & 10 \\
\hline 13 & 47.2 & \pm 1.9 & 7.27 & \pm 0.01 & 49 & 6 \\
\hline 14 & 46.7 & $\pm \quad 0.8$ & 7.36 & \pm 0.01 & 41 & 7 \\
\hline 15 & 44.3 & 1.1 & 7.38 & \pm 0.01 & 38 & 7 \\
\hline 16 & 48.2 & \pm 1.0 & 7.33 & \pm 0.01 & 49 & 6 \\
\hline 17 & 47.8 & 1.0 & 7.35 & 0.01 & 66 & 4 \\
\hline 19 & 44.0 & 1.1 & 7.38 & \pm 0.01 & 41 & 6 \\
\hline 21 & 48.8 & 1.0 & 7.30 & 0.01 & 78 & 4 \\
\hline 22 & 45.5 & \pm 0.6 & 7.31 & \pm 0.01 & 62 & 4 \\
\hline Average & 46.8 & 1.7 & 7.33 & 0.01 & 51.1 & 6.2 \\
\hline Std Dev & 1.6 & 0.9 & 0.03 & 0.01 & 12.4 & 2.0 \\
\hline
\end{tabular}

\subsubsection{1 $\quad \mathrm{PCO}_{2}$ Summary}

The average $\mathrm{PCO}_{2} \mathrm{~s}$ in each condition were higher than intended. In the hypocapnic condition it was $38.11 \pm 1.53$ instead of $35 \mathrm{mmHg}$, in the normocapnic condition it was $42.63 \pm 1.38$ instead of $40 \mathrm{mmHg}$, and in the hypercapnic condition it was $46.75 \pm 1.57$ instead of $45 \mathrm{mmHg}$. There was greater variability in the hypo and hypercapnic conditions. There was a mean difference between groups of almost $5 \mathrm{mmHg}$. A 1-way RMANOVA revealed that, as intended, $\mathrm{PCO}_{2}$ differed significantly across groups $(\mathrm{p}<0.0001)$.

\subsubsection{2 pH Summary}

The three $\mathrm{PCO}_{2}$ conditions were not surprisingly associated with different $\mathrm{pH}$ levels. The hypocapnic condition was associated with "standard" $\mathrm{pH}$ of $7.4 \pm 0.3$. The normocapnic condition, in which $\mathrm{PCO}_{2}$ was slightly above "normal", was associated with slight acidity, having an average $\mathrm{pH}$ of $7.37 \pm 0.03$. The further $\mathrm{PCO}_{2}$ increase in the hypercapnic condition 
was associated with a more acidic $\mathrm{pH}$ of $7.33 \pm 0.03$. A repeated measures ANOVA revealed that the $\mathrm{pH}$ differences were significant across conditions $(\mathrm{p}<0.0001)$.

\subsubsection{3 $\quad \mathrm{PO}_{2}$ Summary}

A 1-way repeated measures ANOVA revealed that the minimum $\mathrm{PO}_{2}$ was significantly different in the three conditions $(\mathrm{p}=0.0004)$, with people tending to quit before the final $\mathrm{PO}_{2}$ target in the hypocapnia and hypercapnia conditions.

\subsubsection{Experiment 3}

Table 16: Experiment 3 Summary Data

\begin{tabular}{|c|c|c|c|c|}
\hline Subject & Average $\mathrm{PCO}_{2} \pm$ Std Dev & Average $\mathrm{pH} \pm$ Std Dev & $\mathrm{Min} \mathrm{PO}_{2}$ & \# of Samples \\
\hline 1 & $\begin{array}{lll}25.7 & \pm & 0.9\end{array}$ & $7.49 \pm 0.02$ & 36 & 5 \\
\hline 2 & $32.0 \pm 0.5$ & $7.45 \pm 0.00$ & 35 & 5 \\
\hline 3 & $24.6 \pm 0.4$ & $7.50 \pm 0.01$ & 38 & 6 \\
\hline 4 & $25.4 \pm 0.5$ & $7.46 \pm 0.01$ & 33 & 5 \\
\hline 5 & $28.4 \pm 0.8$ & $7.42 \pm 0.02$ & 32 & 5 \\
\hline 6 & $28.0 \pm$ & $7.47 \pm 0.01$ & 35 & 6 \\
\hline Average & $27.35 \pm 0.6$ & 7.46 & 34.8 & 5.3 \\
\hline Std Dev & $2.74 \pm$ & 0.02 & 2.0 & 0.5 \\
\hline
\end{tabular}

\subsubsection{1 $\quad \mathrm{PCO}_{2}$ Summary}

While efforts were made to target baseline $\mathrm{PCO}_{2}$, a paired t-test revealed that experimental $\mathrm{PCO}_{2}$ differed significantly from control $\mathrm{PCO}_{2}$, whereby the control values were on average higher than the experimental values $\mathrm{t}(5)=7.44, \mathrm{p}=0.0007$. This may be due, in part, to the fact that we focused on maintaining stable $\mathrm{PCO}_{2}$ rather than attaining the exact $\mathrm{PCO}_{2}$ target. The average $\mathrm{PCO}_{2}$ for all subjects during testing was $27.35 \pm 2.74$, while the average standard deviation was $0.61 \pm 0.16 \mathrm{mmHg}$.

\subsubsection{2 pH Summary}

Like $\mathrm{PCO}_{2}, \mathrm{pH}$ during testing differed significantly from the control value during testing $\mathrm{t}(5)=-$ 3.37, $\mathrm{p}=0.0199$. $\mathrm{pH}$ during the experiment tended to be higher than the control values, which makes sense given that $\mathrm{PCO}_{2}$ tended to be lower during the experiment than the control value. 
The average $\mathrm{pH}$ during testing was $7.46 \pm 0.02$, while the average standard deviation for $\mathrm{pH}$ was $0.012 \pm 0.005$.

\subsubsection{3 $\mathrm{PO}_{2}$ Summary}

While only 2 of the 6 subjects reached the final $\mathrm{PO}_{2}$ target, the average minimum $\mathrm{PO}_{2}$ achieved in this study was $34.83 \pm 1.95 \mathrm{mmHg}$. This is because the main concern regarding $\mathrm{PO}_{2}$ was that there would be a range of $\mathrm{PO}_{2}$ targets that fell on the steep part of the ODC. The study was terminated if the subject was too uncomfortable or if $\mathrm{SO}_{2}$ fell around or below $70 \%$, so the subjects who reached a $\mathrm{PO}_{2}$ of $\sim 35$ on the second last step did not complete the last target. However, we were still able to attain a complete data set for each subject.

\subsubsection{Experiment 4}

\section{Table 17: Experiment 4 Summary Data}

\begin{tabular}{|c|c|c|c|c|}
\hline Subject & Average $\mathrm{PCO}_{2} \pm$ Std Dev & Average $\mathrm{pH} \pm$ Std Dev & Min $\mathrm{PO}_{2}$ & \# of Samples \\
\hline 1 & $30.7 \pm 1.1$ & $7.40 \pm 0.01$ & 31 & 6 \\
\hline 2 & $25.4 \pm 1.1$ & $7.43 \pm 0.01$ & 35 & 6 \\
\hline 3 & $21.1 \pm 1.1$ & $7.47 \pm 0.02$ & 40 & 6 \\
\hline 4 & $24.6 \pm 1.3$ & $7.41 \pm 0.02$ & 40 & 6 \\
\hline 5 & $25.7 \pm 1.5$ & $7.45 \pm$ & 40 & 6 \\
\hline 6 & 31.8 & $7.43 \pm$ & 37 & 5 \\
\hline 8 & $27.7 \pm$ & $7.43 \pm$ & 33 & 6 \\
\hline 9 & $28.2 \pm$ & $7.42 \pm$ & 31 & 5 \\
\hline Average & 26.6 & 0.02 & 37.2 & 5.8 \\
\hline Std Dev & 4.0 & 0.02 & 3.7 & 0.43 \\
\hline
\end{tabular}

\subsubsection{1 $\quad \mathrm{PCO}_{2}$ Summary}

A paired samples t-test did not reveal a significant difference between the mean $\mathrm{PCO}_{2} \mathrm{~S}$ during testing versus the control values them, $\mathrm{t}(7)=1.68, \mathrm{p}=0.1364$. The average $\mathrm{PCO}_{2}$ for all subjects during testing was $26.55 \pm 4.00$, while the average standard deviation was $1.20 \pm 0.25$. Thus, the variation in $\mathrm{PCO}_{2}$ was within the range of error for the $\mathrm{PCO}_{2}$ sensors.

\subsubsection{2 pH Summary}

The $\mathrm{PCO}_{2}$ difference between control and the experiment did not translate to a $\mathrm{pH}$ difference, as revealed by a paired samples t-test, $\mathrm{t}(7)=0.67, \mathrm{p}=0.5263$. The average $\mathrm{pH}$ during testing was 
$7.43 \pm 0.02 \mathrm{pH}$ units, while the average standard deviation was $0.019 \pm 0.004$. For the most part, such variation falls within the specification of the $\mathrm{pH}$ sensor.

\subsubsection{3 $\quad \mathrm{PO}_{2}$ Summary}

Only two of the 8 subjects did not reach the final $\mathrm{PO}_{2}$ target. However, not all of the subjects who reached the final target got to a $\mathrm{PO}_{2}$ of 35 . It is for this reason that the average minimum $\mathrm{PO}_{2}$ was $37.17 \pm 3.71 \mathrm{mmHg}$. Again, this is because we were not concerned about hitting the specific targets. Rather, we were concerned about having a range of $\mathrm{PO}_{2}$ targets that fell on the steep part of the ODC. The study was terminated if the subject was too uncomfortable or if $\mathrm{SO}_{2}$ fell around or below $70 \%$. 


\section{Appendix C: Hill Parameters}

\subsection{Data for all Subjects in all Conditions}

The $\mathrm{P}_{50}$ results for each condition, using Measured $\mathrm{SO}_{2}$ values, are shown below. The data are first organized by $\mathrm{SO}_{2}$ type and then by experiment. $\mathrm{P}_{50}$ analysis was not conducted on data sets that included fewer than 3 pairs of $\mathrm{PO}_{2} / \mathrm{SO}_{2}$. A similar analysis was done using calculated $\mathrm{SO}_{2}$ using the Severinghaus and Kelman methods These sets were chosen in order to show where $\mathrm{P}_{50}$ was expected to be, based on previous in vitro studies.

\subsubsection{Measured $\mathrm{P}_{50}$ Data}

Table 18: $\mathrm{P}_{50}$ Data for Measured $\mathrm{SO}_{2}$ in Experiment 1

\begin{tabular}{rrrrrr}
\hline Subject & Linearized R $^{\mathbf{2}}$ & Non-Linearized $\mathbf{R}^{\mathbf{2}}$ & $\mathbf{n}$ & $\mathbf{K}$ & $\mathbf{P}_{\mathbf{5 0}}$ \\
\hline $\mathbf{2 1}$ & 0.961 & 0.949 & 3.32 & $1.30 \mathrm{E}-05$ & 29.6 \\
$\mathbf{2 2}$ & 0.991 & 0.982 & 3.341 & $1.23 \mathrm{E}-05$ & 29.5 \\
$\mathbf{2 3}$ & 0.990 & 0.988 & 3.602 & $4.54 \mathrm{E}-06$ & 30.4 \\
$\mathbf{2 4}$ & 0.988 & 0.981 & 3.61 & $4.01 \mathrm{E}-06$ & 31.2 \\
$\mathbf{2 5}$ & 0.972 & 0.943 & 3.656 & $3.40 \mathrm{E}-06$ & 31.3 \\
$\mathbf{2 6}$ & 0.985 & 0.971 & 3.443 & $6.43 \mathrm{E}-06$ & 32.1 \\
$\mathbf{2 8}$ & 0.987 & 0.981 & 3.362 & $1.14 \mathrm{E}-05$ & 29.5 \\
$\mathbf{2 9}$ & 0.989 & 0.984 & 3.188 & $2.59 \mathrm{E}-05$ & 27.4 \\
$\mathbf{3 1}$ & 0.977 & 0.906 & 2.816 & $9.46 \mathrm{E}-05$ & 26.8 \\
$\mathbf{3 2}$ & 0.992 & 0.978 & 3.598 & $4.57 \mathrm{E}-06$ & 30.4 \\
$\mathbf{3 3}$ & 0.993 & 0.996 & 3.9 & $1.23 \mathrm{E}-06$ & 32.7 \\
$\mathbf{3 4}$ & 0.980 & 0.977 & 3.179 & $3.05 \mathrm{E}-05$ & 26.3 \\
\hline
\end{tabular}


Table 19: $\mathrm{P}_{50}$ Data for Measured $\mathrm{SO}_{2}$ in Hypocapnia in Experiment 2

\begin{tabular}{rrrrrr}
\hline Subject & Linearized R $^{\mathbf{2}}$ & Non-Linearized $\mathbf{R}^{\mathbf{2}}$ & $\mathbf{n}$ & $\mathbf{K}$ & $\mathbf{P}_{\mathbf{5 0}}$ \\
\hline $\mathbf{1}$ & 0.935 & 0.856 & 3.471 & $7.82 \mathrm{E}-06$ & 29.6 \\
$\mathbf{3}$ & 0.996 & 0.988 & 3.351 & $1.29 \mathrm{E}-05$ & 28.7 \\
$\mathbf{5}$ & 0.988 & 0.987 & 2.606 & $1.76 \mathrm{E}-04$ & 27.6 \\
$\mathbf{6}$ & 0.964 & 0.976 & 3.638 & $3.12 \mathrm{E}-06$ & 32.5 \\
$\mathbf{8}$ & 0.998 & 0.998 & 3.169 & $2.04 \mathrm{E}-05$ & 30.2 \\
$\mathbf{9}$ & 0.999 & 0.998 & 3.16 & $2.74 \mathrm{E}-05$ & 27.7 \\
$\mathbf{1 0}$ & 0.931 & 0.958 & 2.515 & $3.35 \mathrm{E}-04$ & 24 \\
$\mathbf{1 1}$ & 0.992 & 0.989 & 3.275 & $1.73 \mathrm{E}-05$ & 28.4 \\
$\mathbf{1 2}$ & 0.989 & 0.978 & 3.444 & $9.43 \mathrm{E}-06$ & 28.7 \\
$\mathbf{1 3}$ & 0.995 & 0.993 & 3.292 & $1.20 \mathrm{E}-05$ & 31.2 \\
$\mathbf{1 4}$ & 0.983 & 0.972 & 4.394 & $1.71 \mathrm{E}-07$ & 34.6 \\
$\mathbf{1 5}$ & 1.000 & 1.000 & 3.474 & $8.05 \mathrm{E}-06$ & 29.2 \\
$\mathbf{1 6}$ & 0.999 & 0.999 & 3.876 & $1.38 \mathrm{E}-06$ & 32.4 \\
$\mathbf{1 7}$ & 0.994 & 0.986 & 3.453 & $8.56 \mathrm{E}-06$ & 29.3 \\
$\mathbf{1 9}$ & 0.997 & 0.999 & 3.158 & $2.77 \mathrm{E}-05$ & 27.7 \\
$\mathbf{2 2}$ & 0.998 & 0.999 & 3.487 & $8.60 \mathrm{E}-06$ & 28.3 \\
\hline
\end{tabular}


Table 20: $\mathbf{P}_{50}$ Data for Measured $\mathrm{SO}_{2}$ in Normocapnia in Experiment 2

\begin{tabular}{rrrrrr}
\hline Subject & Linearized R $^{2}$ & Non-Linearized $\mathbf{R}^{\mathbf{2}}$ & $\mathbf{n}$ & $\mathbf{K}$ & $\mathbf{P}_{\mathbf{5 0}}$ \\
\hline $\mathbf{1}$ & 0.996 & 0.991 & 3.528 & $5.41 \mathrm{E}-06$ & 31.1 \\
$\mathbf{3}$ & 0.986 & 0.988 & 3.611 & $4.46 \mathrm{E}-06$ & 30.3 \\
$\mathbf{5}$ & 0.988 & 0.982 & 3.501 & $5.22 \mathrm{E}-06$ & 32.2 \\
$\mathbf{6}$ & 0.997 & 0.997 & 3.494 & $4.76 \mathrm{E}-06$ & 33.3 \\
$\mathbf{7}$ & 0.986 & 0.985 & 3.212 & $1.59 \mathrm{E}-05$ & 31.1 \\
$\mathbf{8}$ & 0.988 & 0.979 & 3.428 & $7.42 \mathrm{E}-06$ & 31.3 \\
$\mathbf{9}$ & 0.991 & 0.989 & 3.193 & $2.02 \mathrm{E}-05$ & 29.5 \\
$\mathbf{1 0}$ & 0.994 & 0.990 & 3.45 & $7.85 \mathrm{E}-06$ & 30.1 \\
$\mathbf{1 1}$ & 0.985 & 0.967 & 3.324 & $1.28 \mathrm{E}-05$ & 29.6 \\
$\mathbf{1 2}$ & 0.997 & 0.992 & 3.891 & $1.47 \mathrm{E}-06$ & 31.5 \\
$\mathbf{1 3}$ & 0.993 & 0.991 & 3.84 & $1.30 \mathrm{E}-06$ & 34.1 \\
$\mathbf{1 4}$ & 0.994 & 0.989 & 3.673 & $3.07 \mathrm{E}-06$ & 31.6 \\
$\mathbf{1 5}$ & 0.987 & 0.970 & 3.627 & $4.70 \mathrm{E}-06$ & 29.4 \\
$\mathbf{1 6}$ & 0.997 & 0.992 & 3.618 & $4.09 \mathrm{E}-06$ & 30.8 \\
$\mathbf{1 7}$ & 0.993 & 0.985 & 3.574 & $5.08 \mathrm{E}-06$ & 30.3 \\
$\mathbf{1 9}$ & 0.957 & 0.873 & 3.131 & $3.22 \mathrm{E}-05$ & 27.2 \\
$\mathbf{2 0}$ & 0.986 & 0.970 & 3.809 & $1.93 \mathrm{E}-06$ & 31.6 \\
$\mathbf{2 1}$ & 0.988 & 0.967 & 3.742 & $2.07 \mathrm{E}-06$ & 33 \\
$\mathbf{2 2}$ & 0.988 & 0.967 & 3.396 & $1.28 \mathrm{E}-05$ & 27.5 \\
\hline
\end{tabular}

Table 21: $\mathbf{P}_{50}$ Data for Measured $\mathrm{SO}_{2}$ in Hypercapnia in Experiment 2

\begin{tabular}{rrrrrr}
\hline Subject & Linearized $\mathbf{R}^{\mathbf{2}}$ & Non-Linearized $\mathbf{R}^{\mathbf{2}}$ & $\mathbf{n}$ & $\mathbf{K}$ & $\mathbf{P}_{\mathbf{5 0}}$ \\
\hline $\mathbf{1}$ & 0.860 & 0.956 & 4.946 & $1.90 \mathrm{E}-08$ & 36.2 \\
$\mathbf{3}$ & 0.990 & 0.975 & 3.209 & $1.75 \mathrm{E}-05$ & 30.3 \\
$\mathbf{6}$ & 0.946 & 0.959 & 3.567 & $3.48 \mathrm{E}-06$ & 33.8 \\
$\mathbf{9}$ & 0.997 & 0.999 & 3.022 & $3.53 \mathrm{E}-05$ & 29.7 \\
$\mathbf{1 0}$ & 0.972 & 0.966 & 3.262 & $1.39 \mathrm{E}-05$ & 30.8 \\
$\mathbf{1 1}$ & 0.994 & 0.996 & 3.164 & $2.21 \mathrm{E}-05$ & 29.5 \\
$\mathbf{1 2}$ & 0.981 & 0.945 & 3.542 & $5.25 \mathrm{E}-06$ & 30.9 \\
$\mathbf{1 3}$ & 0.990 & 0.994 & 3.753 & $1.69 \mathrm{E}-06$ & 34.5 \\
$\mathbf{1 4}$ & 0.995 & 0.994 & 3.573 & $3.93 \mathrm{E}-06$ & 32.5 \\
$\mathbf{1 5}$ & 0.993 & 0.988 & 3.815 & $2.03 \mathrm{E}-06$ & 31 \\
$\mathbf{1 6}$ & 1.000 & 1.000 & 3.757 & $1.91 \mathrm{E}-06$ & 33.3 \\
$\mathbf{1 9}$ & 0.998 & 0.998 & 3.278 & $1.52 \mathrm{E}-05$ & 29.4 \\
\hline
\end{tabular}


Table 22: $\mathbf{P}_{50}$ Data for Measured $\mathrm{SO}_{2}$ in Experiment 3

\begin{tabular}{rrrrrr}
\hline Subject & Linearized R $^{2}$ & Non-Linearized R $^{2}$ & $\mathbf{n}$ & $\mathbf{K}$ & $\mathbf{P}_{\mathbf{5 0}}$ \\
\hline $\mathbf{1}$ & 0.996 & 0.993 & 3.032 & $6.19 \mathrm{E}-05$ & 24.4 \\
$\mathbf{2}$ & 0.991 & 0.983 & 3.366 & $1.46 \mathrm{E}-05$ & 27.3 \\
$\mathbf{3}$ & 0.994 & 0.995 & 3.515 & $7.97 \mathrm{E}-06$ & 28.2 \\
$\mathbf{4}$ & 0.959 & 0.881 & 3.932 & $1.72 \mathrm{E}-06$ & 29.2 \\
$\mathbf{5}$ & 0.997 & 0.998 & 2.437 & $5.19 \mathrm{E}-04$ & 22.2 \\
$\mathbf{6}$ & 0.993 & 0.983 & 3.094 & $4.23 \mathrm{E}-05$ & 25.9 \\
\hline
\end{tabular}

Table 23: $P_{50}$ Data for Measured $\mathrm{SO}_{2}$ in Experiment 4

\begin{tabular}{rrrrrr}
\hline Subject & Linearized $\mathbf{R}^{2}$ & Non-Linearized $\mathbf{R}^{\mathbf{2}}$ & $\mathbf{n}$ & $\mathbf{K}$ & $\mathbf{P}_{\mathbf{5 0}}$ \\
\hline $\mathbf{1}$ & 0.976 & 0.976 & 2.830 & $1.17 \mathrm{E}-04$ & 24.5 \\
$\mathbf{2}$ & 0.956 & 0.969 & 2.123 & $1.90 \mathrm{E}-03$ & 19.1 \\
$\mathbf{3}$ & 0.974 & 0.965 & 3.085 & $5.83 \mathrm{E}-05$ & 23.5 \\
$\mathbf{4}$ & 0.975 & 0.979 & 2.785 & $1.52 \mathrm{E}-04$ & 23.5 \\
$\mathbf{5}$ & 0.995 & 0.985 & 4.074 & $1.27 \mathrm{E}-06$ & 27.9 \\
$\mathbf{6}$ & 0.958 & 0.964 & 2.622 & $3.24 \mathrm{E}-04$ & 21.4 \\
$\mathbf{8}$ & 0.998 & 0.999 & 2.817 & $1.24 \mathrm{E}-04$ & 24.3 \\
$\mathbf{9}$ & 0.959 & 0.966 & 2.412 & $6.36 \mathrm{E}-04$ & 21.1 \\
\hline
\end{tabular}

12.1.2 Severinghaus $\mathrm{P}_{50}$ Data

Table 24: $P_{50}$ Data for Severinghaus $\mathrm{SO}_{2}$ in Experiment 1

\begin{tabular}{rrrrrr}
\hline Subject & Linearized R $^{\mathbf{2}}$ & Non-Linearized $\mathbf{R}^{\mathbf{2}}$ & $\mathbf{n}$ & $\mathbf{K}$ & $\mathbf{P}_{\mathbf{5 0}}$ \\
\hline $\mathbf{2 1}$ & 0.997 & 0.997 & 2.892 & $6.56 \mathrm{E}-05$ & 27.9 \\
$\mathbf{2 2}$ & 0.985 & 0.987 & 3.167 & $2.08 \mathrm{E}-05$ & 30 \\
$\mathbf{2 3}$ & 0.998 & 0.998 & 2.933 & $5.54 \mathrm{E}-05$ & 28.2 \\
$\mathbf{2 4}$ & 0.997 & 0.996 & 2.911 & $6.41 \mathrm{E}-05$ & 27.5 \\
$\mathbf{2 5}$ & 0.991 & 0.983 & 3.065 & $3.14 \mathrm{E}-05$ & 29.4 \\
$\mathbf{2 6}$ & 0.994 & 0.997 & 2.997 & $4.11 \mathrm{E}-05$ & 29 \\
$\mathbf{2 8}$ & 0.999 & 0.999 & 2.924 & $6.18 \mathrm{E}-05$ & 27.4 \\
$\mathbf{2 9}$ & 0.999 & 0.999 & 2.968 & $5.56 \mathrm{E}-05$ & 27.1 \\
$\mathbf{3 1}$ & 0.999 & 0.997 & 3.02 & $3.89 \mathrm{E}-05$ & 28.8 \\
$\mathbf{3 2}$ & 0.999 & 0.998 & 2.979 & $4.88 \mathrm{E}-05$ & 28 \\
$\mathbf{3 3}$ & 0.999 & 0.999 & 2.905 & $6.62 \mathrm{E}-05$ & 27.4 \\
$\mathbf{3 4}$ & 0.999 & 0.999 & 2.806 & $1.15 \mathrm{E}-04$ & 25.3 \\
\hline
\end{tabular}


Table 25: $\mathbf{P}_{50}$ Data for Severinghaus $\mathrm{SO}_{2}$ in Hypocapnia in Experiment 2

\begin{tabular}{rrrrrr}
\hline Subject & Linearized R $^{\mathbf{2}}$ & Non-Linearized $\mathbf{R}^{\mathbf{2}}$ & $\mathbf{n}$ & $\mathbf{K}$ & $\mathbf{P}_{\mathbf{5 0}}$ \\
\hline $\mathbf{1}$ & 0.993 & 0.989 & 2.889 & $8.65 \mathrm{E}-05$ & 25.4 \\
$\mathbf{3}$ & 0.995 & 0.993 & 2.933 & $5.84 \mathrm{E}-05$ & 27.7 \\
$\mathbf{5}$ & 0.984 & 0.988 & 2.42 & $3.52 \mathrm{E}-04$ & 26.7 \\
$\mathbf{6}$ & 0.992 & 0.995 & 2.533 & $2.94 \mathrm{E}-04$ & 24.8 \\
$\mathbf{8}$ & 0.998 & 0.996 & 2.838 & $8.20 \mathrm{E}-05$ & 27.5 \\
$\mathbf{9}$ & 0.999 & 0.999 & 2.871 & $7.54 \mathrm{E}-05$ & 27.3 \\
$\mathbf{1 0}$ & 0.998 & 0.998 & 3.133 & $2.45 \mathrm{E}-05$ & 29.6 \\
$\mathbf{1 1}$ & 0.999 & 0.998 & 2.983 & $4.75 \mathrm{E}-05$ & 28.1 \\
$\mathbf{1 2}$ & 0.999 & 0.999 & 2.951 & $5.88 \mathrm{E}-05$ & 27.1 \\
$\mathbf{1 3}$ & 0.998 & 0.997 & 2.898 & $5.17 \mathrm{E}-05$ & 30.1 \\
$\mathbf{1 4}$ & 0.998 & 0.997 & 2.988 & $4.99 \mathrm{E}-05$ & 27.5 \\
$\mathbf{1 5}$ & 1.000 & 1.000 & 2.81 & $1.04 \mathrm{E}-04$ & 26.1 \\
$\mathbf{1 6}$ & 0.998 & 0.999 & 2.699 & $1.48 \mathrm{E}-04$ & 26.2 \\
$\mathbf{1 7}$ & 1.000 & 0.999 & 2.851 & $7.98 \mathrm{E}-05$ & 27.3 \\
$\mathbf{1 9}$ & 1.000 & 1.000 & 2.827 & $1.00 \mathrm{E}-04$ & 25.9 \\
$\mathbf{2 2}$ & 1.000 & 1.000 & 2.906 & $5.79 \mathrm{E}-05$ & 28.7 \\
\hline
\end{tabular}


Table 26: $\mathbf{P}_{50}$ Data for Severinghaus $\mathrm{SO}_{2}$ in Normocapnia in Experiment 2

\begin{tabular}{rrrrrr}
\hline Subject & Linearized $\mathbf{R}^{2}$ & Non-Linearized $\mathbf{R}^{\mathbf{2}}$ & $\mathbf{n}$ & $\mathbf{K}$ & $\mathbf{P}_{\mathbf{5 0}}$ \\
\hline $\mathbf{1}$ & 0.998 & 0.996 & 2.96 & $5.67 \mathrm{E}-05$ & 27.2 \\
$\mathbf{3}$ & 0.999 & 0.999 & 3.006 & $4.29 \mathrm{E}-05$ & 28.3 \\
$\mathbf{5}$ & 0.999 & 0.998 & 3.112 & $2.40 \mathrm{E}-05$ & 30.5 \\
$\mathbf{6}$ & 0.998 & 0.996 & 3.01 & $3.98 \mathrm{E}-05$ & 28.9 \\
$\mathbf{7}$ & 0.998 & 0.997 & 3.084 & $2.47 \mathrm{E}-05$ & 31.1 \\
$\mathbf{8}$ & 0.998 & 0.995 & 3.103 & $2.54 \mathrm{E}-05$ & 30.2 \\
$\mathbf{9}$ & 0.995 & 0.996 & 2.866 & $6.73 \mathrm{E}-05$ & 28.5 \\
$\mathbf{1 0}$ & 1.000 & 0.999 & 2.994 & $4.14 \mathrm{E}-05$ & 29.1 \\
$\mathbf{1 1}$ & 0.999 & 0.998 & 2.923 & $5.73 \mathrm{E}-05$ & 28.2 \\
$\mathbf{1 2}$ & 0.999 & 0.998 & 2.983 & $4.94 \mathrm{E}-05$ & 27.7 \\
$\mathbf{1 3}$ & 0.997 & 0.995 & 3.043 & $2.73 \mathrm{E}-05$ & 31.6 \\
$\mathbf{1 4}$ & 0.999 & 0.998 & 2.928 & $6.06 \mathrm{E}-05$ & 27.5 \\
$\mathbf{1 5}$ & 0.999 & 0.999 & 2.879 & $7.47 \mathrm{E}-05$ & 27.1 \\
$\mathbf{1 6}$ & 0.999 & 0.999 & 2.979 & $4.49 \mathrm{E}-05$ & 28.7 \\
$\mathbf{1 7}$ & 0.998 & 0.998 & 2.966 & $4.73 \mathrm{E}-05$ & 28.7 \\
$\mathbf{1 9}$ & 0.998 & 0.997 & 2.834 & $9.18 \mathrm{E}-05$ & 26.5 \\
$\mathbf{2 0}$ & 0.998 & 0.997 & 2.947 & $5.95 \mathrm{E}-05$ & 27.1 \\
$\mathbf{2 1}$ & 0.999 & 0.998 & 3.03 & $3.43 \mathrm{E}-05$ & 29.7 \\
$\mathbf{2 2}$ & 0.999 & 0.998 & 2.96 & $4.40 \mathrm{E}-05$ & 29.6 \\
\hline
\end{tabular}

Table 27: $\mathbf{P}_{50}$ Data for Severinghaus $\mathrm{SO}_{2}$ in Hypercapnia in Experiment 2

\begin{tabular}{rrrrrr}
\hline Subject & Linearized $\mathbf{R}^{2}$ & Non-Linearized $\mathbf{R}^{\mathbf{2}}$ & $\mathbf{n}$ & $\mathbf{K}$ & $\mathbf{P}_{\mathbf{5 0}}$ \\
\hline $\mathbf{1}$ & 0.995 & 0.997 & 3.068 & $3.07 \mathrm{E}-05$ & 29.5 \\
$\mathbf{3}$ & 0.998 & 0.997 & 2.949 & $4.30 \mathrm{E}-05$ & 30.2 \\
$\mathbf{6}$ & 0.993 & 0.992 & 2.96 & $4.32 \mathrm{E}-05$ & 29.8 \\
$\mathbf{9}$ & 0.999 & 1.000 & 2.946 & $4.39 \mathrm{E}-05$ & 30.1 \\
$\mathbf{1 0}$ & 0.999 & 0.999 & 3.181 & $1.68 \mathrm{E}-05$ & 31.7 \\
$\mathbf{1 1}$ & 0.999 & 1.000 & 2.972 & $4.22 \mathrm{E}-05$ & 29.6 \\
$\mathbf{1 2}$ & 1.000 & 1.000 & 2.962 & $4.67 \mathrm{E}-05$ & 28.9 \\
$\mathbf{1 3}$ & 0.998 & 0.998 & 3.101 & $1.94 \mathrm{E}-05$ & 33.1 \\
$\mathbf{1 4}$ & 0.999 & 0.999 & 3.004 & $3.95 \mathrm{E}-05$ & 29.2 \\
$\mathbf{1 5}$ & 1.000 & 1.000 & 2.958 & $5.03 \mathrm{E}-05$ & 28.3 \\
$\mathbf{1 6}$ & 0.999 & 0.999 & 3.005 & $3.56 \mathrm{E}-05$ & 30.2 \\
$\mathbf{1 9}$ & 0.999 & 0.998 & 2.908 & $6.14 \mathrm{E}-05$ & 28 \\
\hline
\end{tabular}


Table 28: $\mathbf{P}_{50}$ Data for Severinghaus $\mathrm{SO}_{2}$ in Experiment 3

\begin{tabular}{rrrrrr}
\hline Subject & Linearized R & Non-Linearized $\mathbf{R}^{2}$ & $\mathbf{n}$ & $\mathbf{K}$ & $\mathbf{P}_{\mathbf{5 0}}$ \\
\hline $\mathbf{1}$ & 0.997 & 0.996 & 2.724 & $1.86 \mathrm{E}-04$ & 23.4 \\
$\mathbf{2}$ & 0.997 & 0.998 & 2.907 & $7.88 \mathrm{E}-05$ & 25.7 \\
$\mathbf{3}$ & 0.994 & 0.992 & 2.683 & $2.25 \mathrm{E}-04$ & 22.8 \\
$\mathbf{4}$ & 0.998 & 0.999 & 2.932 & $7.50 \mathrm{E}-05$ & 25.5 \\
$\mathbf{5}$ & 0.997 & 0.998 & 2.902 & $7.51 \mathrm{E}-05$ & 26.3 \\
$\mathbf{6}$ & 0.996 & 0.997 & 2.828 & $1.16 \mathrm{E}-04$ & 24.6 \\
\hline
\end{tabular}

Table 29: $\mathbf{P}_{50}$ Data for Severinghaus $\mathrm{SO}_{2}$ in Experiment 4

\begin{tabular}{rrrrrr}
\hline Subject & Linearized $\mathbf{R}^{2}$ & ${\text { Non-Linearized } \mathbf{R}^{\mathbf{2}}}^{\mathbf{n}}$ & $\mathbf{K}$ & $\mathbf{P}_{\mathbf{5 0}}$ \\
\hline $\mathbf{1}$ & 0.998 & 0.998 & 2.924 & $6.25 \mathrm{E}-05$ & 27.3 \\
$\mathbf{2}$ & 0.998 & 0.998 & 2.923 & $6.66 \mathrm{E}-05$ & 26.8 \\
$\mathbf{3}$ & 0.994 & 0.997 & 2.855 & $9.94 \mathrm{E}-05$ & 25.2 \\
$\mathbf{4}$ & 0.994 & 0.997 & 3.000 & $4.83 \mathrm{E}-05$ & 27.4 \\
$\mathbf{5}$ & 0.999 & 0.998 & 2.718 & $1.64 \mathrm{E}-04$ & 24.7 \\
$\mathbf{6}$ & 0.999 & 0.998 & 3.117 & $3.21 \mathrm{E}-05$ & 27.6 \\
$\mathbf{8}$ & 1.000 & 1.000 & 2.825 & $9.79 \mathrm{E}-05$ & 26.2 \\
$\mathbf{9}$ & 0.994 & 0.994 & 2.737 & $1.34 \mathrm{E}-04$ & 26.0 \\
\hline
\end{tabular}

12.1.3 Kelman $\mathrm{P}_{50}$ Data

Table 30: $\mathbf{P}_{50}$ Data for Kelman $\mathrm{SO}_{2}$ in Experiment 1

\begin{tabular}{rrrrrr}
\hline Subject & Linearized $\mathbf{R}^{\mathbf{2}}$ & Non-Linearized $\mathbf{R}^{\mathbf{2}}$ & $\mathbf{n}$ & $\mathbf{K}$ & $\mathbf{P}_{\mathbf{5 0}}$ \\
\hline $\mathbf{2 1}$ & 0.996 & 0.994 & 2.97 & $4.94 \mathrm{E}-05$ & 28.1 \\
$\mathbf{2 2}$ & 0.985 & 0.987 & 3.326 & $1.12 \mathrm{E}-05$ & 30.8 \\
$\mathbf{2 3}$ & 0.998 & 0.998 & 3.092 & $2.96 \mathrm{E}-05$ & 29.1 \\
$\mathbf{2 4}$ & 0.997 & 0.996 & 3.055 & $3.65 \mathrm{E}-05$ & 28.3 \\
$\mathbf{2 5}$ & 0.992 & 0.986 & 3.200 & $1.86 \mathrm{E}-05$ & 30.0 \\
$\mathbf{2 6}$ & 0.996 & 0.998 & 3.131 & $2.40 \mathrm{E}-05$ & 29.8 \\
$\mathbf{2 8}$ & 0.999 & 0.998 & 3.123 & $2.81 \mathrm{E}-05$ & 28.6 \\
$\mathbf{2 9}$ & 0.999 & 0.998 & 3.215 & $2.10 \mathrm{E}-05$ & 28.5 \\
$\mathbf{3 1}$ & 0.998 & 0.997 & 3.205 & $1.89 \mathrm{E}-05$ & 29.7 \\
$\mathbf{3 2}$ & 0.999 & 0.999 & 3.157 & $2.47 \mathrm{E}-05$ & 28.8 \\
$\mathbf{3 3}$ & 1.000 & 1.000 & 3.101 & $3.10 \mathrm{E}-05$ & 28.4 \\
$\mathbf{3 4}$ & 0.999 & 0.998 & 3.034 & $4.72 \mathrm{E}-05$ & 26.6 \\
\hline
\end{tabular}


Table 31: $\mathbf{P}_{50}$ Data for Kelman $\mathrm{SO}_{2}$ in Hypocapnia in Experiment 2

\begin{tabular}{rrrrrr}
\hline Subject & Linearized $\mathbf{R}^{\mathbf{2}}$ & Non-Linearized $\mathbf{R}^{\mathbf{2}}$ & $\mathbf{n}$ & $\mathbf{K}$ & $\mathbf{P}_{\mathbf{5 0}}$ \\
\hline $\mathbf{1}$ & 0.994 & 0.991 & 3.125 & $3.46 \mathrm{E}-05$ & 26.7 \\
$\mathbf{3}$ & 0.993 & 0.991 & 3.069 & $3.49 \mathrm{E}-05$ & 28.3 \\
$\mathbf{5}$ & 0.984 & 0.988 & 2.592 & $1.84 \mathrm{E}-04$ & 27.5 \\
$\mathbf{6}$ & 0.993 & 0.996 & 2.765 & $1.20 \mathrm{E}-04$ & 26.1 \\
$\mathbf{8}$ & 0.998 & 0.996 & 2.957 & $5.28 \mathrm{E}-05$ & 27.9 \\
$\mathbf{9}$ & 1.000 & 0.999 & 3.052 & $3.79 \mathrm{E}-05$ & 28.0 \\
$\mathbf{1 0}$ & 0.997 & 0.998 & 3.347 & $1.07 \mathrm{E}-05$ & 30.5 \\
$\mathbf{1 1}$ & 0.999 & 0.999 & 3.16 & $2.43 \mathrm{E}-05$ & 28.8 \\
$\mathbf{1 2}$ & 0.999 & 0.998 & 3.069 & $3.68 \mathrm{E}-05$ & 27.8 \\
$\mathbf{1 3}$ & 0.997 & 0.996 & 3.11 & $2.33 \mathrm{E}-05$ & 30.8 \\
$\mathbf{1 4}$ & 0.998 & 0.997 & 3.226 & $1.98 \mathrm{E}-05$ & 28.7 \\
$\mathbf{1 5}$ & 1.000 & 1.000 & 3.039 & $4.27 \mathrm{E}-05$ & 27.4 \\
$\mathbf{1 6}$ & 0.999 & 0.999 & 2.906 & $6.65 \mathrm{E}-05$ & 27.3 \\
$\mathbf{1 7}$ & 1.000 & 1.000 & 3.103 & $2.97 \mathrm{E}-05$ & 28.7 \\
$\mathbf{1 9}$ & 1.000 & 1.000 & 3.015 & $4.84 \mathrm{E}-05$ & 27.0 \\
$\mathbf{2 2}$ & 1.000 & 1.000 & 3.157 & $2.23 \mathrm{E}-05$ & 29.7 \\
\hline
\end{tabular}

Table 32: $\mathbf{P}_{50}$ Data for Kelman $\mathrm{SO}_{2}$ in Normocapnia in Experiment 2

\begin{tabular}{rrrrrr}
\hline Subject & Linearized $\mathbf{R}^{\mathbf{2}}$ & Non-Linearized $\mathbf{R}^{2}$ & $\mathbf{n}$ & $\mathbf{K}$ & $\mathbf{P}_{\mathbf{5 0}}$ \\
\hline $\mathbf{1}$ & 0.997 & 0.995 & 3.039 & $4.04 \mathrm{E}-05$ & 27.9 \\
$\mathbf{3}$ & 0.998 & 0.999 & 3.076 & $3.28 \mathrm{E}-05$ & 28.6 \\
$\mathbf{5}$ & 0.998 & 0.997 & 3.224 & $1.55 \mathrm{E}-05$ & 31 \\
$\mathbf{6}$ & 0.996 & 0.993 & 3.077 & $3.07 \mathrm{E}-05$ & 29.2 \\
$\mathbf{7}$ & 0.998 & 0.997 & 3.218 & $1.48 \mathrm{E}-05$ & 31.7 \\
$\mathbf{8}$ & 0.997 & 0.995 & 3.189 & $1.82 \mathrm{E}-05$ & 30.6 \\
$\mathbf{9}$ & 0.993 & 0.995 & 2.999 & $4.01 \mathrm{E}-05$ & 29.2 \\
$\mathbf{1 0}$ & 0.999 & 0.999 & 3.162 & $2.14 \mathrm{E}-05$ & 29.9 \\
$\mathbf{1 1}$ & 0.999 & 0.998 & 3.039 & $3.63 \mathrm{E}-05$ & 28.9 \\
$\mathbf{1 2}$ & 0.997 & 0.997 & 3.054 & $3.72 \mathrm{E}-05$ & 28.1 \\
$\mathbf{1 3}$ & 0.997 & 0.995 & 3.206 & $1.47 \mathrm{E}-05$ & 32.1 \\
$\mathbf{1 4}$ & 0.999 & 0.998 & 3.128 & $2.74 \mathrm{E}-05$ & 28.7 \\
$\mathbf{1 5}$ & 0.999 & 0.999 & 3.043 & $3.90 \mathrm{E}-05$ & 28.1 \\
$\mathbf{1 6}$ & 0.999 & 0.998 & 3.125 & $2.51 \mathrm{E}-05$ & 29.6 \\
$\mathbf{1 7}$ & 0.998 & 0.998 & 3.145 & $2.34 \mathrm{E}-05$ & 29.6 \\
$\mathbf{1 9}$ & 0.998 & 0.996 & 2.989 & $4.96 \mathrm{E}-05$ & 27.5 \\
$\mathbf{2 0}$ & 0.998 & 0.997 & 3.08 & $3.47 \mathrm{E}-05$ & 28 \\
$\mathbf{2 1}$ & 0.998 & 0.997 & 3.13 & $2.34 \mathrm{E}-05$ & 30.1 \\
$\mathbf{2 2}$ & 0.999 & 0.998 & 3.114 & $2.47 \mathrm{E}-05$ & 30.1 \\
\hline
\end{tabular}


Table 33: $\mathbf{P}_{50}$ Data for Kelman $\mathrm{SO}_{2}$ in Hypercapnia in Experiment 2

\begin{tabular}{rrrrrr}
\hline Subject & ${\text { Linearized } \mathbf{R}^{2}}^{\mathbf{2}}$ & ${\text { Non-Linearized } \mathbf{R}^{\mathbf{2}}}^{\mathbf{n}}$ & $\mathbf{n}$ & $\mathbf{P}_{\mathbf{5 0}}$ \\
\hline $\mathbf{1}$ & 0.992 & 0.995 & 3.252 & $1.46 \mathrm{E}-05$ & 30.6 \\
$\mathbf{3}$ & 0.999 & 0.997 & 3.044 & $2.97 \mathrm{E}-05$ & 30.7 \\
$\mathbf{6}$ & 0.993 & 0.992 & 3.14 & $2.12 \mathrm{E}-05$ & 30.8 \\
$\mathbf{9}$ & 0.999 & 1 & 3.054 & $2.90 \mathrm{E}-05$ & 30.6 \\
$\mathbf{1 0}$ & 0.998 & 0.998 & 3.277 & $1.16 \mathrm{E}-05$ & 32 \\
$\mathbf{1 1}$ & 0.999 & 1 & 3.13 & $2.26 \mathrm{E}-05$ & 30.5 \\
$\mathbf{1 2}$ & 0.999 & 0.998 & 3.06 & $3.16 \mathrm{E}-05$ & 29.5 \\
$\mathbf{1 3}$ & 0.999 & 0.999 & 3.32 & $8.29 \mathrm{E}-06$ & 33.9 \\
$\mathbf{1 4}$ & 0.999 & 0.999 & 3.209 & $1.76 \mathrm{E}-05$ & 30.3 \\
$\mathbf{1 5}$ & 1 & 1 & 3.148 & $2.37 \mathrm{E}-05$ & 29.4 \\
$\mathbf{1 6}$ & 1 & 1 & 3.206 & $1.60 \mathrm{E}-05$ & 31.3 \\
$\mathbf{1 9}$ & 0.999 & 0.998 & 3.108 & $2.78 \mathrm{E}-05$ & 29.2 \\
\hline
\end{tabular}

Table 34: $\mathbf{P}_{50}$ Data for Kelman $\mathrm{SO}_{2}$ in Experiment 3

\begin{tabular}{rrrrrr}
\hline Subject & Linearized R $^{2}$ & Non-Linearized $\mathbf{R}^{\mathbf{2}}$ & $\mathbf{n}$ & $\mathbf{K}$ & $\mathbf{P}_{\mathbf{5 0}}$ \\
\hline $\mathbf{1}$ & 0.997 & 0.996 & 2.724 & $1.86 \mathrm{E}-04$ & 23.4 \\
$\mathbf{2}$ & 0.997 & 0.998 & 2.907 & $7.88 \mathrm{E}-05$ & 25.7 \\
$\mathbf{3}$ & 0.994 & 0.992 & 2.683 & $2.25 \mathrm{E}-04$ & 22.8 \\
$\mathbf{4}$ & 0.998 & 0.999 & 2.932 & $7.50 \mathrm{E}-05$ & 25.5 \\
$\mathbf{5}$ & 0.997 & 0.998 & 2.902 & $7.51 \mathrm{E}-05$ & 26.3 \\
$\mathbf{6}$ & 0.996 & 0.997 & 2.828 & $1.16 \mathrm{E}-04$ & 24.6 \\
\hline
\end{tabular}

Table 35: $\mathbf{P}_{50}$ Data for Kelman $\mathrm{SO}_{2}$ in Experiment 4

\begin{tabular}{rrrrrr}
\hline Subject & Linearized R $^{2}$ & Non-Linearized $\mathbf{R}^{\mathbf{2}}$ & $\mathbf{n}$ & $\mathbf{K}$ & $\mathbf{P}_{\mathbf{5 0}}$ \\
\hline $\mathbf{1}$ & 0.999 & 0.999 & 2.945 & $5.97 \mathrm{E}-05$ & 27.1 \\
$\mathbf{2}$ & 0.999 & 0.999 & 3.086 & $3.79 \mathrm{E}-05$ & 27 \\
$\mathbf{3}$ & 0.987 & 0.993 & 2.891 & $9.44 \mathrm{E}-05$ & 24.6 \\
$\mathbf{4}$ & 0.991 & 0.995 & 3.116 & $3.35 \mathrm{E}-05$ & 27.3 \\
$\mathbf{5}$ & 0.993 & 0.994 & 2.742 & $1.59 \mathrm{E}-04$ & 24.3 \\
$\mathbf{6}$ & 0.998 & 0.998 & 3.299 & $1.64 \mathrm{E}-05$ & 28.2 \\
$\mathbf{8}$ & 0.999 & 1 & 3.03 & $4.71 \mathrm{E}-05$ & 26.8 \\
$\mathbf{9}$ & 0.998 & 0.998 & 2.919 & $7.03 \mathrm{E}-05$ & 26.4 \\
\hline
\end{tabular}




\subsection{Comparison of Hill Parameters $\left(\mathrm{P}_{50}, \mathrm{n}, \mathrm{K}\right)$ Across $\mathrm{SO}_{2}$ Types (Measured, Severinghaus \& Kelman) within each Experiment}

A one-way repeated-measures ANOVA test was done to compare the $\mathrm{P}_{50}, \mathrm{n}$ and $\mathrm{K}$ values from the measured and calculated data. Since the $\mathrm{SO}_{2}$ values were different in the case of Experiment 4, we expected to find a difference between these parameters across the data sets. The results for each measured variable are shown below:

\subsubsection{Experiment 1}

Table 36: Experiment $1 \mathrm{P}_{50}$ Values

\begin{tabular}{clrrr}
\hline Category & SO $_{\mathbf{2}}$ Type & Mean & Std Dev & SEM \\
\hline \multirow{4}{*}{$\mathbf{P}_{\mathbf{5 0}}$} & Measured & 29.767 & 2.042 & 0.589 \\
& Severinghaus & 28 & 1.233 & 0.356 \\
& Kelman & 28.892 & 1.092 & 0.315 \\
\hline
\end{tabular}

The analysis of variance revealed a significant difference in the P50s of the three groups, $F(2,22)=7.243, p=.004$. A Tukey post-hoc analysis revealed that the measured $\mathrm{P}_{50}$ was significantly higher than that of Severinghaus $(p=.003)$.

This is surprising, given that measured $\mathrm{SO}_{2}$ tended to be greater than the calculated $\mathrm{SO}_{2}$. While 28 falls on the upper range of "normal" P50s, 29.77 is right-shifted as compared to "normal". It is not clear why this translated to a right-shifted curve, with a higher average $\mathrm{P}_{50}$.

\section{Table 37: Experiment 1 n Values}

\begin{tabular}{clrrr}
\hline Category & SO $_{2}$ Type & Mean & Std Dev & SEM \\
\hline \multirow{3}{*}{$\mathbf{n}$} & Measured & 3.418 & 0.283 & 0.0818 \\
& Severinghaus & 2.964 & 0.0929 & 0.0268 \\
& Kelman & 3.134 & 0.0951 & 0.0275 \\
\hline
\end{tabular}

The analysis of variance revealed a significant difference in the $n$ values of the three groups, $F(2,22)=19.523, p<.001$. A Tukey post-hoc analysis revealed that the measured $\mathrm{n}$ was significantly higher than that of Severinghaus $(p<.001)$ and that of Kelman $(p=.002)$. The difference between the Severinghaus $\mathrm{n}$ values and the Kelman $\mathrm{n}$ values approached significance 
$(\mathrm{p}=.074) . \mathrm{n}$ is dependent upon the medium in which the $\mathrm{Hb}$ is found, so it seems likely that some metabolic factor is changing the way in which $\mathrm{Hb}$ is binding to $\mathrm{O}_{2}$ in vivo.

Table 38: Experiment $1 \mathrm{~K}$ Values

\begin{tabular}{clrrr}
\hline Category & $\mathbf{S O}_{2}$ Type & Median & $\mathbf{2 5 \%}$ & $\mathbf{7 5 \%}$ \\
\hline \multirow{3}{*}{ K } & Measured & $8.92 \mathrm{E}-06$ & $4.27 \mathrm{E}-06$ & $1.94 \mathrm{E}-05$ \\
& Severinghaus & $5.55 \mathrm{E}-05$ & 0.00004 & $6.49 \mathrm{E}-05$ \\
& Kelman & $2.64 \mathrm{E}-05$ & $1.99 \mathrm{E}-05$ & $3.38 \mathrm{E}-05$ \\
\hline
\end{tabular}

The $\mathrm{K}$ value data is not normally distributed $(p<.001)$, so a repeated measures ANOVA was performed on ranks instead. There was a significant difference between the median $\mathrm{K}$ values among the experimental groups, $X^{2}(2)=16.167, p<.001$. A Tukey test was used for a pairwise comparison of the ranks of the three groups. It revealed a significant difference between the Severinghaus and Measured values $(p<.05)$ and between the Severinghaus and Kelman values $(\mathrm{p}<.05)$.

\subsubsection{Experiment 2}

Table 39: Experiment $2 P_{50}$ Results for Hypocapnia $(n=16)$

\begin{tabular}{clrrr}
\hline Category & SO $_{\mathbf{2}}$ Type & Median & $\mathbf{2 5 \%}$ & $\mathbf{7 5 \%}$ \\
\hline \multirow{3}{*}{$\mathbf{P}_{\mathbf{5 0}}$} & Measured & 28.95 & 28 & 30.7 \\
& Severinghaus & 27.3 & 26.15 & 27.9 \\
& Kelman & 27.95 & 27.35 & 28.75 \\
\hline \multirow{4}{*}{$\mathbf{n}$} & Measured & 3.398 & 3.165 & 3.481 \\
& Severinghaus & 2.88 & 2.819 & 2.942 \\
& Kelman & 3.069 & 2.986 & 3.141 \\
\hline \multirow{3}{*}{$\mathbf{K}$} & Measured & $1.07 \mathrm{E}-05$ & $7.93 \mathrm{E}-06$ & $2.39 \mathrm{E}-05$ \\
& Severinghaus & $7.76 \mathrm{E}-05$ & $5.48 \mathrm{E}-05$ & $1.02 \mathrm{E}-04$ \\
& Kelman & $3.59 \mathrm{E}-05$ & $2.38 \mathrm{E}-05$ & $5.06 \mathrm{E}-05$ \\
\hline
\end{tabular}


Table 40: Experiment $2 P_{50}$ Results for Normocapnia $(n=19)$

\begin{tabular}{clrrr}
\hline Category & SO $_{\mathbf{2}}$ Type & Mean & Std Dev & SEM \\
\hline \multirow{2}{*}{$\mathbf{P}_{\mathbf{5 0}}$} & Measured & 30.816 & 1.765 & 0.405 \\
& Severinghaus & 28.747 & 1.428 & 0.328 \\
& Kelman & 29.416 & 1.303 & 0.299 \\
\hline Category & $\mathbf{S O}_{\mathbf{2}}$ Type & Median & $\mathbf{2 5 \%}$ & $\mathbf{7 5 \%}$ \\
\hline \multirow{4}{*}{$\mathbf{n}$} & Measured & 3.528 & 3.404 & 3.662 \\
& Severinghaus & 2.979 & 2.933 & 3.025 \\
& Kelman & 3.114 & 3.046 & 3.158 \\
\hline Category & SO $_{\mathbf{2}}$ Type & Mean & Std Dev & SEM \\
\hline \multirow{2}{*}{ K } & Measured & $8.04 \mathrm{E}-06$ & $7.81 \mathrm{E}-06$ & $1.79 \mathrm{E}-06$ \\
& Severinghaus & $4.81 \mathrm{E}-05$ & $1.81 \mathrm{E}-05$ & $4.14 \mathrm{E}-06$ \\
& Kelman & $2.89 \mathrm{E}-05$ & $1.00 \mathrm{E}-05$ & $2.30 \mathrm{E}-06$ \\
\hline
\end{tabular}

Table 41: Experiment $2 P_{50}$ Results for Hypercapnia ( $\left.n=12\right)$

\begin{tabular}{clrrr}
\hline Category & SO $_{2}$ Type & Mean & Std Dev & SEM \\
\hline \multirow{4}{*}{$\mathbf{P}_{\mathbf{5 0}}$} & Measured & 31.825 & 2.206 & 0.637 \\
& Severinghaus & 29.883 & 1.402 & 0.405 \\
& Kelman & 30.733 & 1.275 & 0.368 \\
\hline Category & SO $_{2}$ Type & Median & $\mathbf{2 5 \%}$ & $\mathbf{7 5 \%}$ \\
\hline \multirow{4}{*}{$\mathbf{n}$} & Measured & 3.555 & 3.236 & 3.755 \\
& Severinghaus & 2.967 & 2.954 & 3.037 \\
& Kelman & 3.144 & 3.084 & 3.231 \\
\hline Category & SO $_{2}$ Type & Mean & Std Dev & SEM \\
\hline \multirow{3}{*}{ K } & Measured & $1.02 \mathrm{E}-05$ & $1.08 \mathrm{E}-05$ & $3.12 \mathrm{E}-06$ \\
& Severinghaus & $3.94 \mathrm{E}-05$ & $1.25 \mathrm{E}-05$ & $3.60 \mathrm{E}-06$ \\
& Kelman & $2.11 \mathrm{E}-05$ & $7.60 \mathrm{E}-06$ & $2.19 \mathrm{E}-06$ \\
\hline
\end{tabular}

A two-way repeated measures ANOVA was done on each $\mathrm{P}_{50}$ parameter $\left(\mathrm{P}_{50}, \mathrm{n}\right.$ and $\left.\mathrm{K}\right)$ in order to determine the individual and combined effects of $\mathrm{PCO}_{2}$ and $\mathrm{SO}_{2}$ type.

\subsubsection{1 $P_{50}$}

There is a main effect of $\mathrm{PCO}_{2}$ on $\mathrm{P}_{50}(\mathrm{p}<0.001)$. A Tukey post-hoc analysis revealed that $\mathrm{P}_{50}$ in the hypercapnia condition was significantly higher than in the hypocapnia condition ( $\mathrm{q}=13.057$, $\mathrm{p}<.001)$ and the normocapnia condition ( $\mathrm{q}=7.671, \mathrm{p}<.001)$. There is also a main effect of $\mathrm{SO}_{2}$ type on $\mathrm{P}_{50}(\mathrm{p}=<0.001)$. A Tukey post-hoc analysis revealed that $\mathrm{P}_{50}$ was significantly higher when measured $\mathrm{SO}_{2}$ was used than when Severinghaus $(\mathrm{q}=6.392, \mathrm{p}<0.001)$ or Kelman was used 
$(q=4.012, p=0.025)$. There is no significant interaction between $\mathrm{PCO}_{2}$ and $\mathrm{SO}_{2}$ type on $\mathrm{P}_{50}(\mathrm{p}=$ 0.789).

\subsubsection{2 n}

The effect of $\mathrm{PCO}_{2}$ on $\mathrm{n}$ approached significance $(\mathrm{p}=.099)$, while there was a significant effect of $\mathrm{SO}_{2}$ type on the $\mathrm{n}$ value $(\mathrm{p}<.001)$. A Tukey post-hoc analysis revealed that measured $\mathrm{n}$ was significantly greater than those of Severinghaus $(q=10.974, p<0.001)$ and $\operatorname{Kelman}(q=7.833$, $\mathrm{p}<.001)$. There is no significant interaction between $\mathrm{PCO}_{2}$ and $\mathrm{SO}_{2}$ type on $\mathrm{n}(\mathrm{p}=.93)$.

\subsubsection{K}

There was a significant effect of $\mathrm{PCO}_{2}$ on $\mathrm{K}(\mathrm{p}=.005)$. A Tukey post-hoc test showed that the $\mathrm{K}$ value in hypocapnia was significantly higher than that in hypercapnia $(q=4.979, p=.005)$ and normocapnia ( $\mathrm{q}=3.737, \mathrm{p}=.038$ ). There was also a significant effect of $\mathrm{SO}_{2}$ type on $\mathrm{K}$. A Tukey post-hoc test revealed that Severinghaus K was significantly higher than measured $\mathrm{K}(\mathrm{q}=5.583$, $\mathrm{p}=.002)$ and Kelman $\mathrm{K}(\mathrm{q}=3.909, \mathrm{p}=0.029)$. There was no significant interaction between $\mathrm{PCO}_{2}$ and $\mathrm{SO}_{2}$ type on $\mathrm{K}(\mathrm{p}=0.604)$.

\subsubsection{Experiment 3}

\section{Table 42: Experiment $3 \mathbf{P}_{50}$ Values}

\begin{tabular}{clrrr}
\hline Category & SO $_{\mathbf{2}}$ Type & Mean & Std Dev & SEM \\
\hline \multirow{3}{*}{$\mathbf{P}_{\mathbf{5 0}}$} & Measured & 26.2 & 2.59 & 1.057 \\
& Severinghaus & 24.833 & 0.987 & 0.403 \\
& Kelman & 24.717 & 1.379 & 0.563 \\
\hline
\end{tabular}

The analysis of variance did not reveal a significant difference in the P50s of the three data sets, $F(2,10)=1.316, p=.311$. However, the power of the performed test $(0.086)$ was below the desired power (0.800). With more subjects, they results may have been significant. 
Table 43: Experiment 3 n Values

\begin{tabular}{clrrr}
\hline Category & SO $_{2}$ Type & Mean & Std Dev & SEM \\
\hline \multirow{3}{*}{$\mathbf{n}$} & Measured & 3.229 & 0.506 & 0.206 \\
& Severinghaus & 2.795 & 0.0709 & 0.029 \\
& Kelman & 2.829 & 0.104 & 0.0426 \\
\hline
\end{tabular}

The analysis of variance revealed a significant difference in the $n$ values of the three data sets, $F(2,10)=4.402, p=.043$. A Tukey post-hoc pairwise analysis did not detect any significant differences between any of the individual data sets. However, the difference between measured $\mathrm{n}$ and Severinghaus $\mathrm{n}$ approached significance $(\mathrm{p}=.056)$ and the difference between Measured $\mathrm{n}$ and Kelman $n$ approached significance as well (0.079). Because the power of the Tukey test (0.500) was below the desired power (0.800), these negative findings should be interpreted cautiously.

Table 44: Experiment $3 \mathrm{~K}$ Values

\begin{tabular}{clrrr}
\hline Category & SO2 Type & Median & $\mathbf{2 5 \%}$ & $\mathbf{7 5 \%}$ \\
\hline \multirow{3}{*}{ K } & Measured & $2.85 \mathrm{E}-05$ & $7.97 \mathrm{E}-06$ & $6.19 \mathrm{E}-05$ \\
& Severinghaus & $1.38 \mathrm{E}-04$ & $9.74 \mathrm{E}-05$ & $1.53 \mathrm{E}-04$ \\
& Kelman & $9.74 \mathrm{E}-05$ & $7.51 \mathrm{E}-05$ & $1.86 \mathrm{E}-04$ \\
\hline
\end{tabular}

The $\mathrm{K}$ value data is not normally distributed $(p=.002)$, so a repeated measures ANOVA was performed on ranks instead. There was no significant difference between the median $\mathrm{K}$ values among the experimental groups, $\mathrm{X}^{2}(2)=4.333, p=.142$.

\subsubsection{Experiment 4}

Table 45: Experiment $4 \mathbf{P}_{50}$ Values

\begin{tabular}{clrrr}
\hline Category & SO2 Type & Mean & Std Dev & SEM \\
\hline \multirow{4}{*}{$\mathbf{P}_{\mathbf{5 0}}$} & Measured & 23.163 & 2.662 & 0.941 \\
& Severinghaus & 26.4 & 1.065 & 0.377 \\
& Kelman & 26.463 & 1.346 & 0.476 \\
\hline
\end{tabular}


The analysis of variance revealed a significant difference in the P50s of the three data sets, $F(2,14)=7.026, p=.008$. A Tukey post-hoc pairwise comparison revealed that measured $\mathrm{P}_{50}$ was significantly lower than Severinghaus $\mathrm{P}_{50}(\mathrm{p}=.016)$ and Kelman $\mathrm{P}_{50}(\mathrm{p}=.014)$.

Table 46: Experiment $4 \mathrm{n}$ Values

\begin{tabular}{clrrr}
\hline Category & SO2 Type & Mean & Std Dev & SEM \\
\hline \multirow{4}{*}{$\mathbf{n}$} & Measured & 2.843 & 0.577 & 0.204 \\
& Severinghaus & 2.887 & 0.133 & 0.0471 \\
& Kelman & 3.004 & 0.169 & 0.0596 \\
\hline
\end{tabular}

The analysis of variance did not reveal a significant difference between the $\mathrm{n}$ values in the three data sets, $\mathrm{F}(2,14)=0.36, \mathrm{p}=.704$. However, because the power of the test (.049) is below the desired power (0.800), there may still be a difference between the n values of the 3 data sets.

\section{Table 47: Experiment $4 \mathrm{~K}$ Values}

\begin{tabular}{clrrr}
\hline Category & SO2 Type & Median & 25\% & 75\% \\
\hline \multirow{3}{*}{ K } & Measured & $1.38 \mathrm{E}-04$ & $8.77 \mathrm{E}-05$ & $4.80 \mathrm{E}-04$ \\
& Severinghaus & $8.22 \mathrm{E}-05$ & $5.54 \mathrm{E}-05$ & $1.17 \mathrm{E}-04$ \\
& Kelman & $5.34 \mathrm{E}-05$ & $3.57 \mathrm{E}-05$ & $8.23 \mathrm{E}-05$ \\
\hline
\end{tabular}

The $\mathrm{K}$ value data is not normally distributed $(p=<001)$, so a repeated measures ANOVA was performed on ranks instead. There was no significant difference between the median $\mathrm{K}$ values among the experimental groups, $\mathrm{X}^{2}(2)=7.0, p=.03$. A Tukey post-hoc pairwise comparison revealed that the $\mathrm{K}$ value for the measured data was significantly greater than that in the Kelman data set $(\mathrm{p}<.05)$.

\subsection{Comparison of Hill Parameters $\left(P_{50}, n, K\right)$ Across Normocapnia Conditions within each $\mathrm{SO}_{2}$ Type}

For each experimental group, the Hill parameters were determined in three different ways, using measured $\mathrm{SO}_{2}$, Severinghaus $\mathrm{SO}_{2}$ and Kelman $\mathrm{SO}_{2}$. The comparisons of the results for each parameter within each group were presented above. This section deals only with comparisons across groups, within each $\mathrm{SO}_{2}$ method. 1-way ANOVA tests were used to compare across groups with an alpha level of .05. We did not expect to find any differences between those in 
Experimental Group 1 and Experimental Group 2, since both groups comprised of lowlanders at sea-level. However, the method of testing varied slightly between these two groups, so differences reflecting the method are possible. The results are shown below.

\subsubsection{P50 Comparison}

\subsubsection{Measured $\mathrm{P}_{50}$}

Table 48: Measured $P_{50}$ Values for All Groups at Normocapnia

\begin{tabular}{lrrrr}
\hline Experiment & N & Mean & Std Dev & SEM \\
\hline $\mathbf{1}$ & 12 & 29.767 & 2.042 & 0.589 \\
$\mathbf{2}$ normocapnia & 19 & 30.816 & 1.765 & 0.405 \\
$\mathbf{3}$ & 6 & 26.2 & 2.59 & 1.057 \\
$\mathbf{4}$ & 8 & 23.163 & 2.662 & 0.941 \\
\hline
\end{tabular}

The analysis of variance showed that measured $\mathrm{P}_{50}$ differed significantly across experimental groups, $F(3,41)=28.108, p<0.001$. Post hoc analysis using the Tukey test indicated that $\mathrm{P}_{50} \mathrm{~S}$ in Experiment 1 were significantly higher than those in Experiment $3(p=.009)$ and those in Experiment $4(p<0.001)$. Similarly, P50s in Experiment 2 were significantly higher than those in Experiment $3(p<0.001)$ and those in Experiment $4(p<0.001)$. The $\mathrm{P}_{50}$ difference between Experiments 3 and 4 approached significance $(p=.054)$.

\subsubsection{Severinghaus $P_{50}$}

Table 49: Severinghaus $\mathbf{P}_{50}$ Values for All Groups at Normocapnia

\begin{tabular}{lrrrr}
\hline Experimental Group & N & Mean & Std Dev & SEM \\
\hline $\mathbf{1}$ & 12 & 28 & 1.233 & 0.356 \\
$\mathbf{2}$ normocapnia & 19 & 28.747 & 1.428 & 0.328 \\
$\mathbf{3}$ & 6 & 24.833 & 0.987 & 0.403 \\
$\mathbf{4}$ & 8 & 26.4 & 1.065 & 0.377 \\
\hline
\end{tabular}

The analysis of variance showed that Severinghaus $\mathrm{P}_{50}$ differed significantly across experimental groups, $F(3,41)=17.403, p<0.001$. Post hoc analysis using the Tukey test indicated that $\mathrm{P}_{50} \mathrm{~S}$ in Experiment 1 were significantly higher than those in Experiment $3(p<0.001)$ and those in Experiment 4 ( $p=0.042)$. Similarly, P50s in Experiment 2 were significantly higher than those in Experiment $3(p<0.001)$ and those in Experiment $4(p<0.001)$. 


\subsubsection{Kelman $\mathrm{P}_{50}$}

Table 50: Kelman $\mathbf{P}_{50}$ Values for All Groups at Normocapnia

\begin{tabular}{lrrrr}
\hline Experimental Group & N & Mean & Std Dev & SEM \\
\hline $\mathbf{1}$ normocapnia & 12 & 28.892 & 1.092 & 0.315 \\
$\mathbf{3}$ & 19 & 29.416 & 1.303 & 0.299 \\
$\mathbf{4}$ & 6 & 24.717 & 1.379 & 0.563 \\
\hline
\end{tabular}

The analysis of variance showed that Kelman $\mathrm{P}_{50}$ differed significantly across experimental groups, $F(3,41)=27.092, p<0.001$. Post hoc analysis using the Tukey test indicated that $\mathrm{P}_{50} \mathrm{~S}$ in Experiment 1 were significantly higher than those in Experiment $3(p<0.001)$ and those in Experiment $4(p<0.001)$. Similarly, P50s in Experiment 2 were significantly higher than those in Experiment $3(p<0.001)$ and those in Experiment $4(p<0.001)$. The $\mathrm{P}_{50}$ difference between Experiments 3 and 4 approached significance $(p=.067)$.

\subsection{2 n Value Comparison}

\subsubsection{Measured $n$ Values}

\section{Table 51: Measured n Values for All Groups at Normocapnia}

\begin{tabular}{lrrrr}
\hline Experimental Group & N & Mean & Std Dev & SEM \\
\hline $\mathbf{1}$ & 12 & 3.418 & 0.283 & 0.0818 \\
$\mathbf{2}$ normocapnia & 19 & 3.529 & 0.217 & 0.0498 \\
$\mathbf{3}$ & 6 & 3.229 & 0.506 & 0.206 \\
$\mathbf{4}$ & 8 & 2.843 & 0.577 & 0.204 \\
\hline
\end{tabular}

The analysis of variance showed that measured $\mathrm{n}$ differed significantly across experimental groups, $F(3,41)=7.146, p<0.001$. Post hoc analysis using the Tukey test indicated that $\mathrm{n}$ values in Experiment 1 were significantly higher than those in Experiment 4 ( $p=.006)$. Similarly, $n$ values in Experiment 2 were significantly higher than those in Experiment $4(p<0.001)$. 


\subsubsection{Severinghaus $n$ Values}

Table 52: Severinghaus n Values for All Groups at Normocapnia

\begin{tabular}{lrrrr}
\hline Experimental Group & N & Mean & Std Dev & SEM \\
\hline $\mathbf{1}$ & 12 & 2.964 & 0.0929 & 0.0268 \\
$\mathbf{2}$ normocapnia & 19 & 2.979 & 0.0761 & 0.0175 \\
$\mathbf{3}$ & 6 & 2.795 & 0.0709 & 0.029 \\
$\mathbf{4}$ & 8 & 2.887 & 0.133 & 0.0471 \\
\hline
\end{tabular}

The analysis of variance showed that measured $\mathrm{n}$ differed significantly across experimental groups, $F(3,41)=7.169, p<0.001$. Post hoc analysis using the Tukey test indicated that $\mathrm{n}$ values in Experiment 1 were significantly higher than those in Experiment 3 ( $p=.004$ ). Similarly, $\mathrm{n}$ values in Experiment 2 were significantly higher than those in Experiment $3(p<0.001)$. The difference between the $\mathrm{n}$ values in Experiments 2 and 4 approached significance $(p=.10)$.

\subsubsection{Kelman $n$ Values}

Table 53: Kelman n Values for All Groups at Normocapnia

\begin{tabular}{lrrrr}
\hline Experimental Group & N & Mean & Std Dev & SEM \\
\hline $\mathbf{1}$ & 12 & 3.134 & 0.0951 & 0.0275 \\
$\mathbf{2}$ normocapnia & 19 & 3.107 & 0.0718 & 0.0165 \\
$\mathbf{3}$ & 6 & 2.829 & 0.104 & 0.0426 \\
$\mathbf{4}$ & 8 & 3.004 & 0.169 & 0.0596 \\
\hline
\end{tabular}

The analysis of variance showed that measured $\mathrm{n}$ differed significantly across experimental groups, $F(3,41)=13.892, p<0.001$. Post hoc analysis using the Tukey test indicated that $\mathrm{n}$ values in Experiment 1 were significantly higher than those in Experiment $3(p<.001)$ and Experiment 4 $(p=.043)$. Similarly, $\mathrm{n}$ values in Experiment 2 were significantly higher than those in Experiment $3(p<0.001)$. The difference between the $\mathrm{n}$ values in Experiments 2 and 4 approached significance $(p=.101)$. The difference between the $\mathrm{n}$ values in Experiments 3 and 4 was also significant $(p=.018)$ 


\subsubsection{K Value Comparison}

\subsubsection{Measured K Values}

These data failed the normality test $(\mathrm{p}<.001)$ so a Kruskal-Wallis One Way ANOVA was performed on ranks.

Table 54: Measured K Values for All Groups at Normocapnia

\begin{tabular}{lrrrr}
\hline Experimental Group & $\mathbf{N}$ & Median & $\mathbf{2 5 \%}$ & $\mathbf{7 5 \%}$ \\
\hline $\mathbf{1}$ & 12 & $8.92 \mathrm{E}-06$ & $4.27 \mathrm{E}-06$ & $1.94 \mathrm{E}-05$ \\
$\mathbf{2}$ normocapnia & 19 & $5.08 \mathrm{E}-06$ & $3.32 \mathrm{E}-06$ & $1.16 \mathrm{E}-05$ \\
$\mathbf{3}$ & 6 & $2.85 \mathrm{E}-05$ & $7.97 \mathrm{E}-06$ & $6.19 \mathrm{E}-05$ \\
$\mathbf{4}$ & 8 & $1.38 \mathrm{E}-04$ & $8.77 \mathrm{E}-05$ & $4.80 \mathrm{E}-04$ \\
\hline
\end{tabular}

There was a statistically significant difference in the median values among the experimental groups $H(3)=13.205, p=.004$. Dunn's Method was used as a pair-wise multiple comparison procedure to determine which groups differed from one another. This revealed a significant difference between the $\mathrm{K}$ values in experiments 2 and $4(p<.05)$.

\subsubsection{Severinghaus K Values}

Table 55: Severinghaus K Values for All Groups at Normocapnia

\begin{tabular}{lrrrr}
\hline Experimental Group & N & Mean & Std Dev & SEM \\
\hline $\mathbf{1}$ & 12 & $5.54 \mathrm{E}-05$ & $2.37 \mathrm{E}-05$ & $6.84 \mathrm{E}-06$ \\
$\mathbf{2}$ normocapnia & 19 & $4.81 \mathrm{E}-05$ & $1.81 \mathrm{E}-05$ & $4.14 \mathrm{E}-06$ \\
$\mathbf{3}$ & 6 & $1.30 \mathrm{E}-04$ & $3.65 \mathrm{E}-05$ & $1.49 \mathrm{E}-05$ \\
$\mathbf{4}$ & 8 & $8.81 \mathrm{E}-05$ & $4.46 \mathrm{E}-05$ & $1.58 \mathrm{E}-05$ \\
\hline
\end{tabular}

The analysis of variance showed that Severinghaus K values differed significantly across experimental groups, $F(3,41)=14.981, p<0.001$. Post hoc analysis using the Tukey test indicated that $\mathrm{K}$ values in Experiment 1 were significantly lower than those in Experiment $3(p<.001)$. K values in Experiment 2 were significantly lower than those in Experiment $3(p<0.001)$ and higher than those in Experiment 4 ( $p=.009)$. The difference between the $\mathrm{K}$ values in Experiments 1 and 4 approached significance $(p=.069)$. The difference between the $\mathrm{K}$ values in Experiments 3 and 4 was also significant $(p=.042)$ 


\subsubsection{Kelman K Values}

This data failed the normality test $(\mathrm{p}<.001)$ so a Kruskal-Wallis One Way ANOVA was performed on ranks.

Table 56: Kelman K Values for All Groups at Normocapnia

\begin{tabular}{lrrrr}
\hline Experimental Group & $\mathbf{N}$ & Median & $\mathbf{2 5 \%}$ & $\mathbf{7 5 \%}$ \\
\hline $\mathbf{1}$ & 12 & $2.64 \mathrm{E}-05$ & $1.99 \mathrm{E}-05$ & $3.38 \mathrm{E}-05$ \\
$\mathbf{2}$ normocapnia & 19 & $2.74 \mathrm{E}-05$ & $2.19 \mathrm{E}-05$ & $3.70 \mathrm{E}-05$ \\
$\mathbf{3}$ & 6 & $9.74 \mathrm{E}-05$ & $7.51 \mathrm{E}-05$ & $1.86 \mathrm{E}-04$ \\
$\mathbf{4}$ & 8 & $5.34 \mathrm{E}-05$ & $3.57 \mathrm{E}-05$ & $8.23 \mathrm{E}-05$ \\
\hline
\end{tabular}

There was a statistically significant difference in the median values among the experimental groups $H(3)=19.889, p<.001$. Dunn's Method was used as a pair-wise multiple comparison procedure to determine which groups differed from one another. This revealed a significant difference between the $\mathrm{K}$ values in experiments 1 and $3(p<.05)$ and between experiments 2 and $3(p<.05)$. 